\title{
Otimização de pavimentos de edifícios com estruturas de concreto pré-moldado utilizando algoritmos genéticos
}

Augusto Teixeira de Albuquerque

Tese apresentada à Escola de Engenharia de São Carlos, da Universidade de São Paulo, como parte dos requisitos para a obtenção do título de Doutor em Engenharia de Estruturas.

Orientador: Mounir K. El Debs

Co-orientador: Antonio Macário C. de Melo

São Carlos 
AUTORIZO A REPRODUÇÃO E DIVULGAÇÃO TOTAL OU PARCIAL DESTE TRABALHO, POR QUALQUER MEIO CONVENCIONAL OU ELETRÔNICO, PARA FINS DE ESTUDO E PESQUISA, DESDE QUE CITADA A FONTE.

Ficha catalográfica preparada pela Seção de Tratamento da Informação do Serviço de Biblioteca - EESC/USP

Albuquerque, Augusto Teixeira de

Otimização de pavimentos de edifícios com estruturas de concreto pré-moldado utilizando algoritmos genéticos / Augusto Teixeira de Albuquerque ; orientador Mounir K. el Debs, co-orientador Antonio Macário C. de Melo. -- São Carlos, 2007 .

Tese (Doutorado-Programa de Pós-Graduação e Área de Concentração em Engenharia de Estruturas) -- Escola de Engenharia de São Carlos da Universidade de São Paulo, 2007 .

1. Pavimentos de concreto pré-moldado. 2. Otimização. 3. Algoritmos genéticos. I. Título. 
FOLHA DE JULGAMENTO

Candidato: Engenheiro AUGUSTO TEIXCIRA DE ALBUQUERQUE

Tese defendida e julgada em 20/12/2007 perante a Comissão Julgadora:

Prof. Titular MOUNIR KHALIL ML DEBS (Orientador)

A PROXNADO

(Escola de Engenharia de Sĩo Carlos/USP)

$\frac{\#}{\text { Prof. Dr. ANTONIO MACARIO CARTAXo de MTLO (Co-orientador) }}$ (Universidade Federal do Ceara/UFC)

Prof. Dr. ROBERTO CHUST CARVALHO

(Universidade Federal de São Carlos/UFSCar)

APNONADO

Prof: D*', SYLVIA REGINA MESQUTTA DE ALMEDA (Universidade Federal de Goiás/UFG)

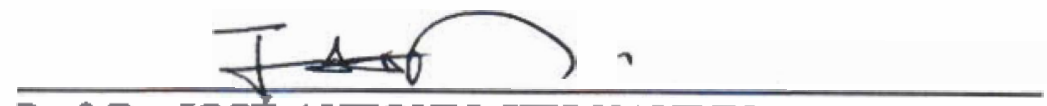

APROVADO

Prof. Dr. JOSE ANTONIO HERNANDES

(Instituto Tecnológico de Aeronáutica//TA)

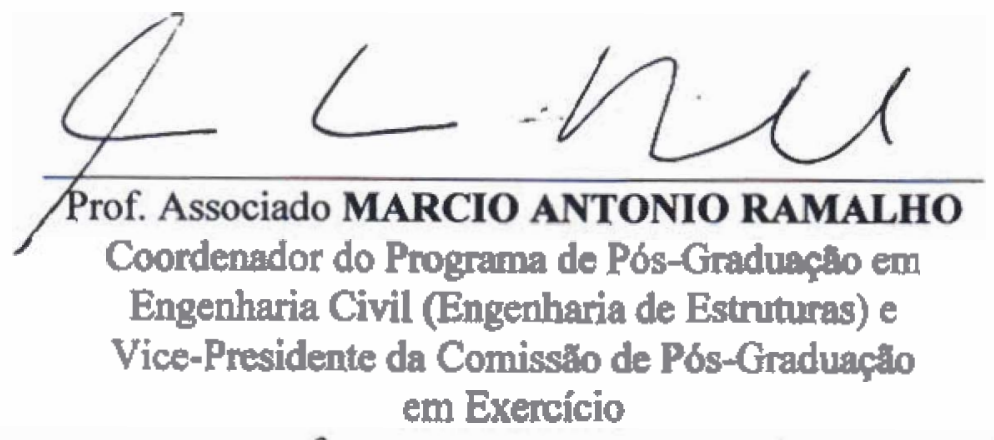

* Os Profs. Syluia Regina Merquita de Mlmeida. da defera através de videoconferéncia. 


\section{SUMÁRIO}

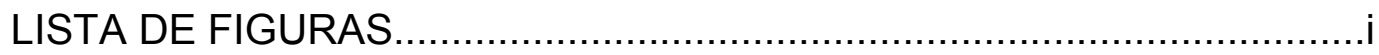

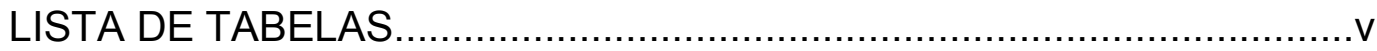

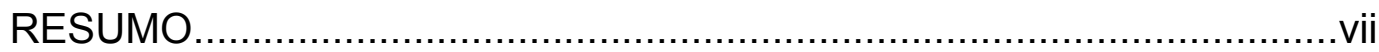

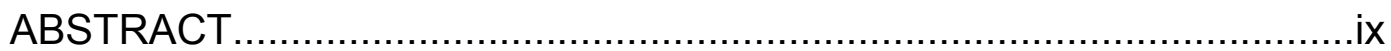

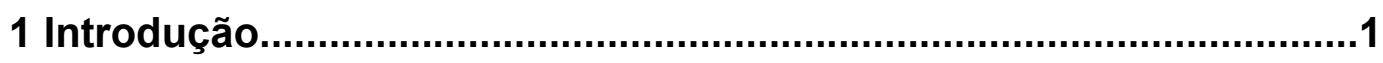

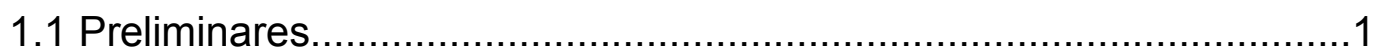

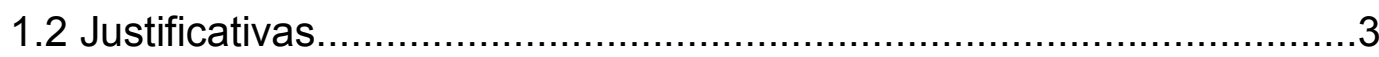

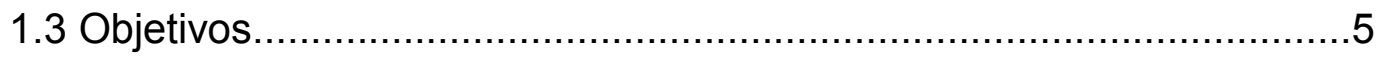

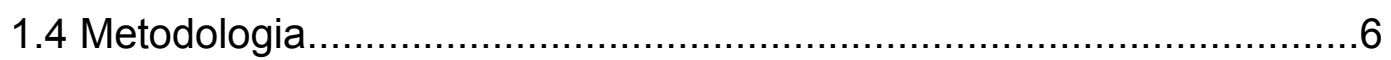

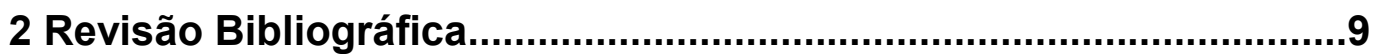

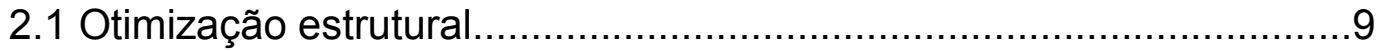

2.2 Otimização estrutural utilizando AG's...........................................11

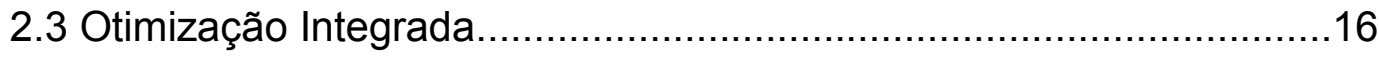

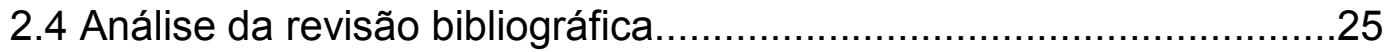

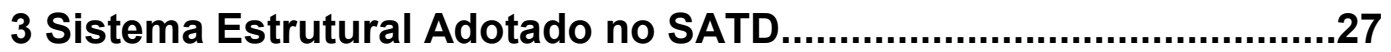

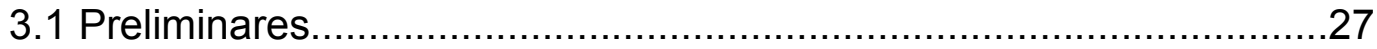

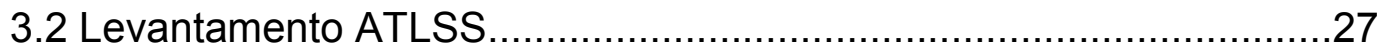

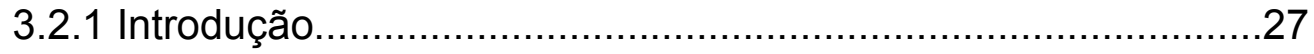

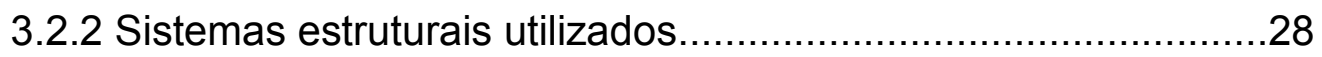

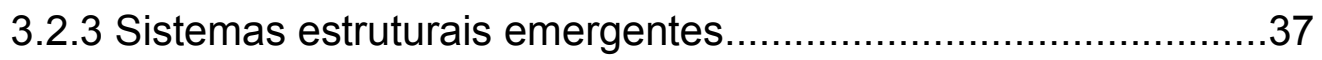

3.2.4 Conclusões relatório ATLSS ............................................... 41

3.3 Levantamento dos sistemas estruturais PM utilizados no Brasil........43

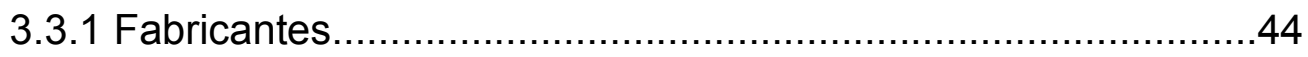

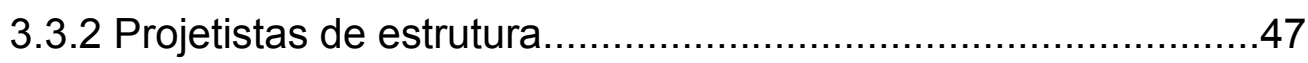

3.3.3 Conclusões do levantamento Brasil e do banco ABCIC.............49

3.4 Análise dos levantamentos (ATLSS e Brasil)....................................54

3.5 Definição do sistema estrutural a ser utilizado no SATD....................55

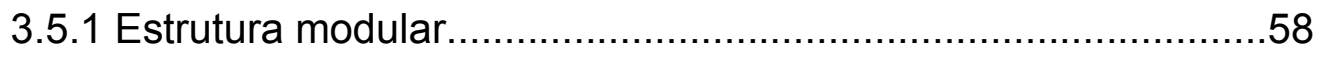

3.5.2 Características dos elementos estruturais...............................61

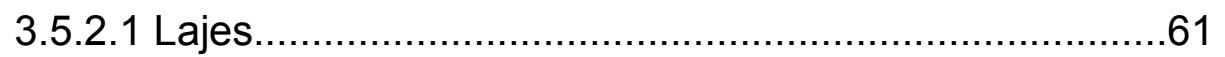


3.5.2.2.Vigas. 63

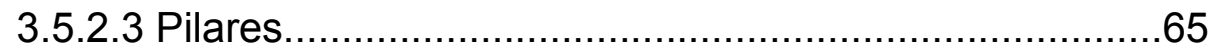

3.5.3 Resistências à compressão dos concretos..............................66

3.6 Hipótese de cálculo adotada...................................................6

4 Sistema de apoio à tomada de decisão (SATD)................................69

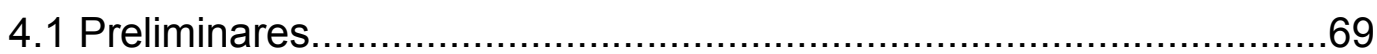

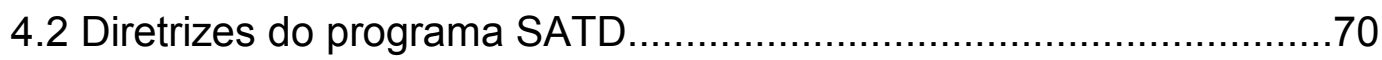

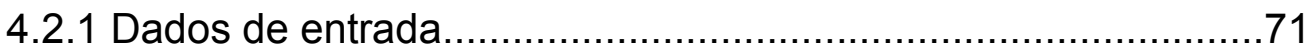

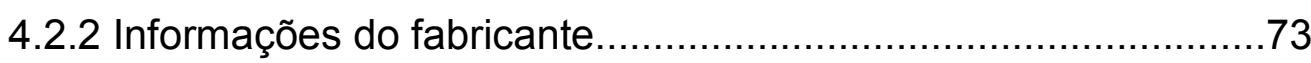

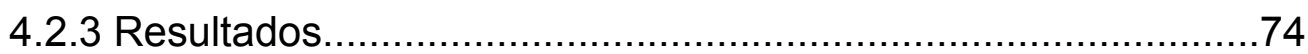

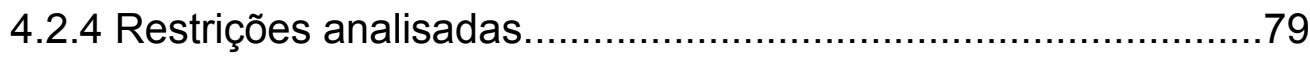

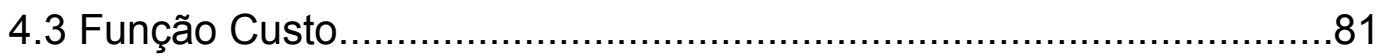

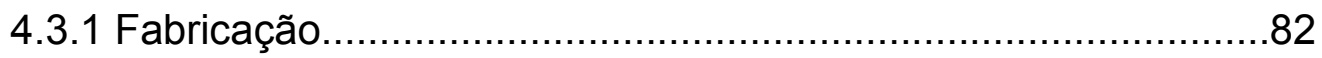

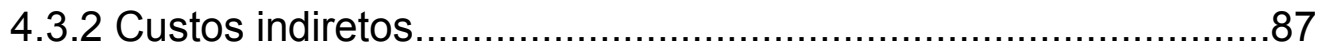

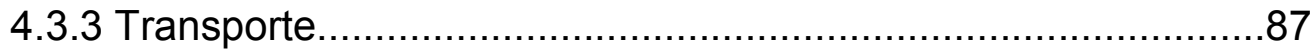

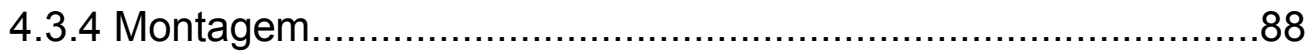

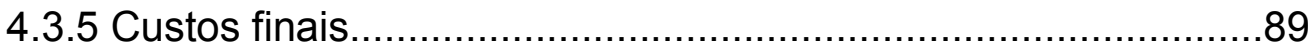

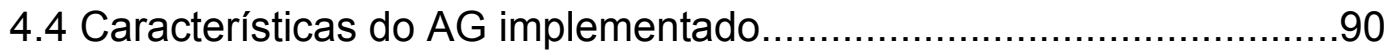

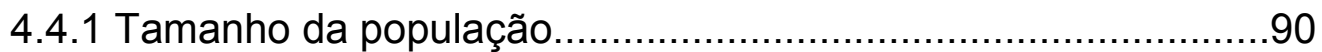

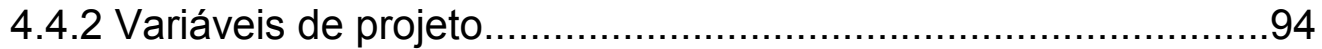

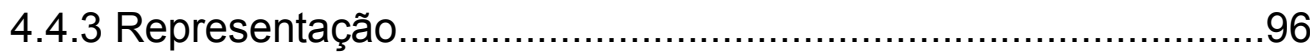

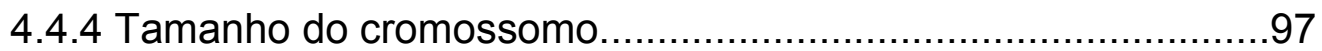

4.4.4.1 Distância mínima entre pilares.....................................98

4.4.4.2 Largura máxima das vigas........................................98

4.4.5 Função objetivo penalizada (aptidão)......................................99

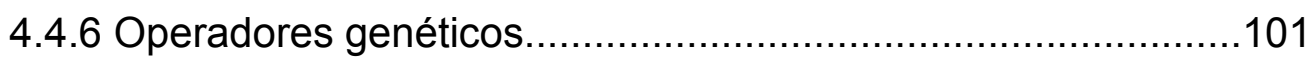

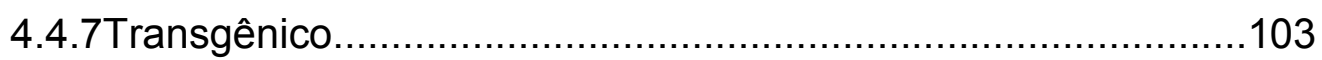

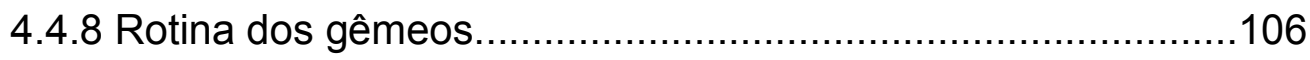

4.4.9 Comentários finais sobre o AG adotado...............................107

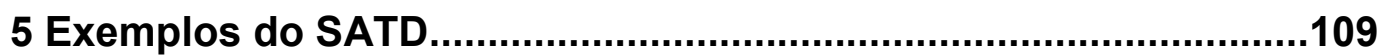

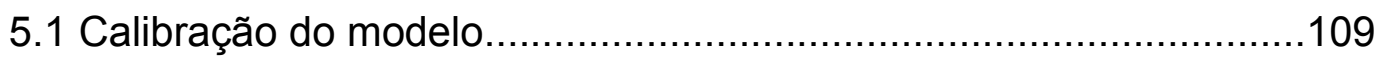

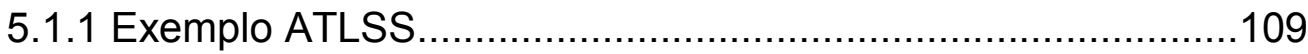

5.1.2 Hotel Holliday-Inn............................................................116 
5.1.3 Conclusões da calibração do modelo. 117

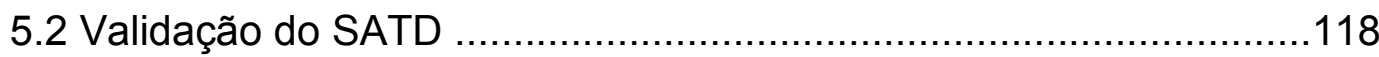

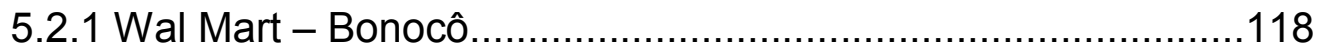

5.2.2 Edifício Comercial Carvalho................................................121

5.3 Exemplos de utilização do SATD................................................131

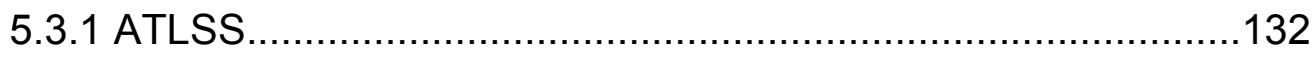

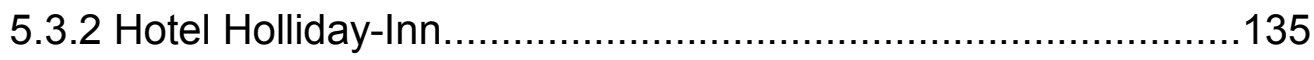

5.3.3 Estacionamento Super Mercado Nordestão...........................137

5.4 Considerações adicionais sobre o SATD.......................................151

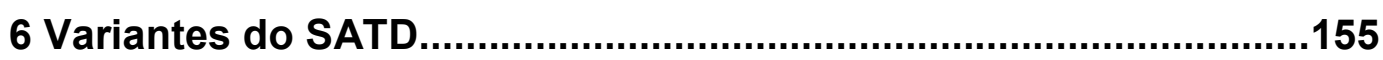

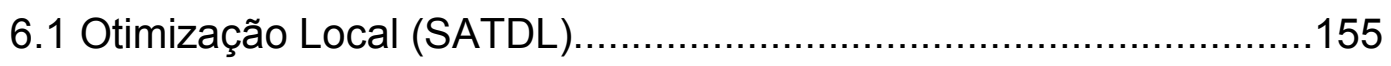

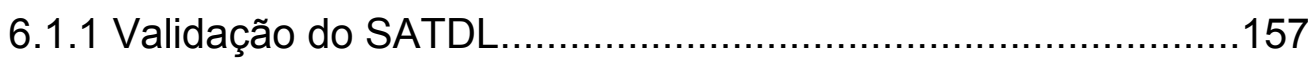

6.1.2 Exemplos de utilização do SATDL..........................................158

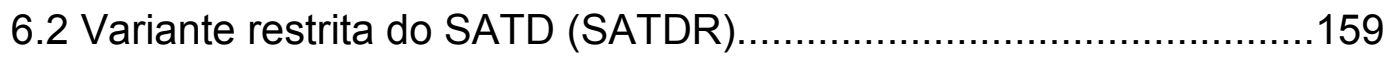

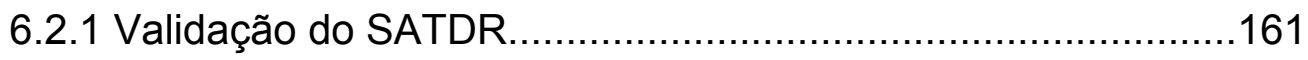

6.2.2 Exemplos de utilização do SATDR........................................165

6.3 Considerações adicionais sobre as variantes do SATD....................168

7 Considerações finais e conclusões.............................................171

Referência Bibliográfica.............................................................177

Anexo I - Midwest Office System (MOS)................................183

Apêndice A - Questionários........................................................201

Apêndice B - Otimização convencional viga "T" invertida...............205

Apêndice C - Rotina para dimensionamento viga " $T$ " invertida......213

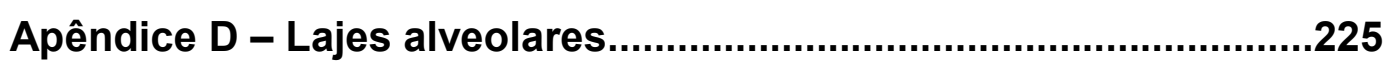

Apêndice E - Fundamentos dos Algoritmos Genéticos....................241 


\section{LISTA DE FIGURAS}

Figura 2-1 - Otimização da configuração estrutural de uma treliça

[RAJEEV \& KRISHNAMOORTHY (1997)].....

Figura 2-2 - Edifício utilizado como exemplo para a otimização

[SARMA \& ADELI (2005)]

Figura 2-3 - Alternativas de posições para pilares e paredes

[PULMMANN et al. (2003)].....

Figura 2-4 - Sistemas estruturais disponíveis

[RAFIQ et al. (2003)].

Figura 2-5 - Soluções apresentadas para um determinado problema

[RAFIQ et al. (2003)].

Figura 2-6 - Alternativas estruturais para um determinado problema

[GRIERSON et al. (2002)]. .24

Figura 3-1 - Conventional System [adaptação EL DEBS, M. K. (2000) ] ….................29

Figura 3-2 - Duotek System [PRIOR et al. (1993)].............................................. 30

Figura 3-3 - Dycore [adaptação EL DEBS, M. K. (2000)] .....................................30

Figura 3-4 - Dyna-frame System [PRIOR et al. (1993)]............................. 31

Figura 3-5 - PG Connection System [PRIOR et al. (1993)] ............................ 32

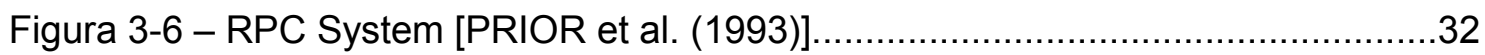

Figura 3-7 - IMS system [adaptação EL DEBS, M. K. (2000)] ...................................33

Figura 3-8 - PD2 Frame System [PRIOR et al. (1993)] .............................. 34

Figura 3-9 - Prestressed Joisty System [PRIOR et al. (1993)]..........................34

Figura 3-10 - Quickfloor System [PRIOR et al. (1993)] .............................. 35

Figura 3-11 - Triposite System [PRIOR et al. (1993)] .............................. 36

Figura 3-12 - Thomas System [PRIOR et al. (1993)] ............................. 37

Figura 3-13 - Contiframe System [PRIOR et al. (1993)] .......................... 38

Figura 3-14 - Contiframe System [PRIOR et al. (1993)] ............................ 39

Figura 3-15 - Spanlight System [PRIOR et al. (1993)]...........................................40

Figura 3-16 - University of Nebraska system .................................................... 41

Figura 3-17 - Distribuição das resistências do concreto pré-moldado.........................49

Figura 3-18 - Distribuição das resistências do concreto moldado in loco.....................50

Figura 3-19 - Pórticos posicionados na direção do maior lado do pavimento................50

Figura 3-20 - Pórticos posicionados na direção do menor lado do pavimento..............51

Figura 3-21 - Distribuição dos sistemas estruturais no banco de dados dos

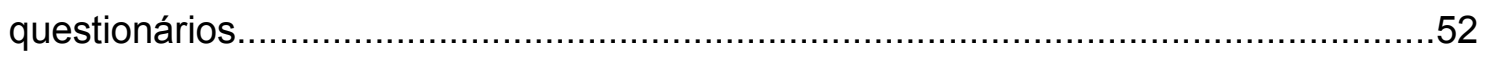

Figura 3-22 - Distribuição dos sistemas no banco de obras da ABCIC .......................52 


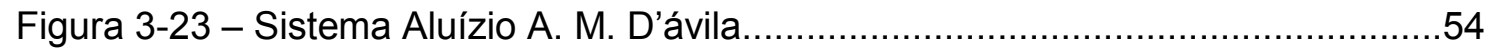

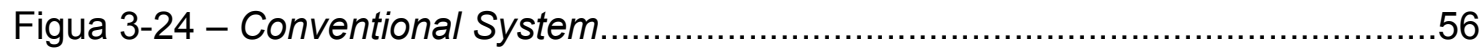

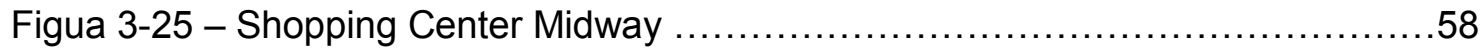

Figura 3-26 - Exemplo ATLSS report [PRIOR et al. (1993)]....................................59

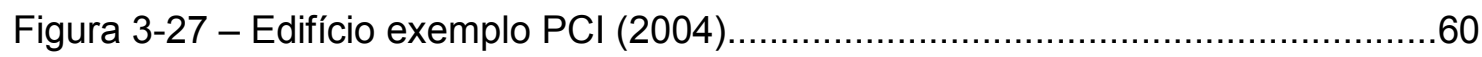

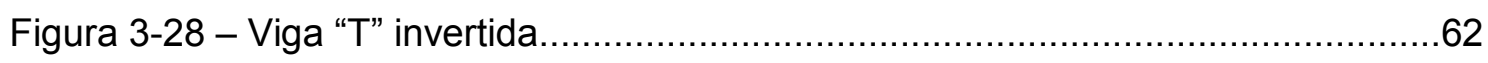

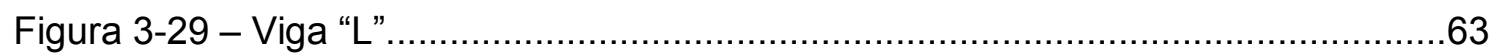

Figura 3-30 - Viga "T" invertida seção composta ....................................................64

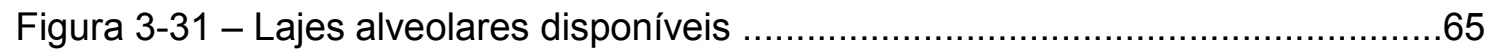

Figura 4-1 - Número de vãos e direções das vigas e das lajes ..................................72

Figura 4-2 - Direção assumida pelas lajes e vãos ................................................75

Figura 4-3 - Disposição dos cabos de protensão das vigas.....................................75

Figura 4-4 - Organograma da função Custo.........................................................78

Figura 4-4 - Consolo (medidas em "cm") ........................................................... 81

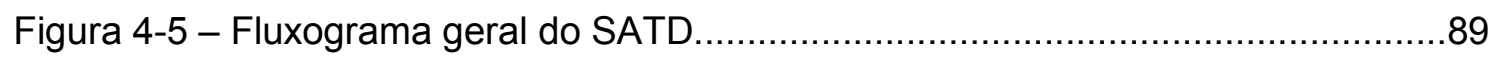

Figura 4-6 - Pseudo-código para a população inicial..............................................90

Figura 4-7 - Exemplo de cruzamento uniforme........................................................99

Figura 5-1 - Layout estrutural 1 ATLSS report [PRIOR, R. (1993)]...........................105

Figura 5-2 - Layout estrutural 2 ATLSS report [PRIOR, R. (1993)]...........................106

Figura 5-3 - Layout estrutural 3 ATLSS report [PRIOR, R. (1993)]............................107

Figura 5-4 - Aptidões em função número gerações e tamanho da população...........109

Figura 5-5 - Aptidões em função número gerações e tamanho da população com suas

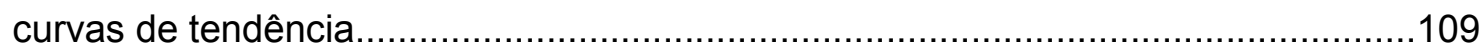

Figura 5-6 - Valores das aptidões em função do tamanho da população (valores

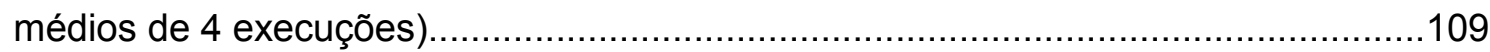

Figura 5-7 - Configuração estrutural Holliday Inn ...................................................110

Figura 5-8 - Região modulada do pavimento do Wal Mart - Bonocô .........................113

Figura 5-9 - Forma parcial da configuração estrutural da alternativa 2 ....................114

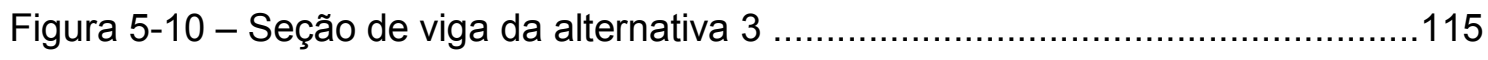

Figura 5-11 - Forma parcial do edifício Comercial Carvalho ...................................116

Figura 5-12 - Configuração estrutural, parcial, das alternativas 1 e $3 \ldots \ldots \ldots \ldots \ldots \ldots \ldots . . . . .117$

Figura 5-13 - Viga adotada pelo SATD (alternativa 3)........................................118

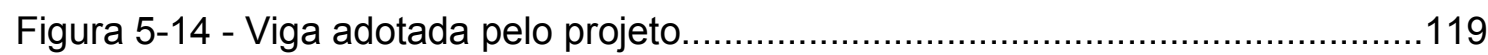

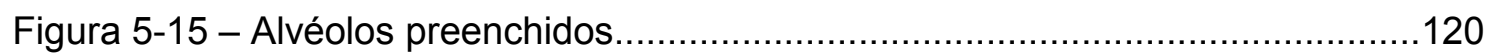

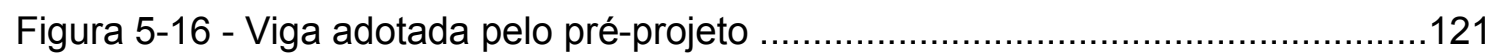

Figura 5-17 - Configuração estrutural da alternativa 5 .........................................124

Figura 5-18 - Arquitetura do estacionamento do supermercado Nordestão..............132 
Figura 5-19 - Config. estruturais da primeira série de processamentos. 134

Figura 5-20 - Config. estruturais da segunda série de processamentos 136

Figura 5-21 - Config. estruturais da terceira série de processamentos 138

Figura 5-22 - Config. para o caso em que o aço é 25\% mais caro. 140

Figura 5-23 - Config. para o caso em que o concreto é $25 \%$ mais caro. 141

Figura 5-24 - Custo estrutura acréscimos incrementais dos insumos. 142

Figura 5-25 - Custo estrutura acréscimos incrementais dos insumos. 143

Figura 5-26 - Fabricação para a alternativa 1 da tabela 5-16. .145

Figura 5-27 - Fabricação para a alternativa 3 da tabela 5-16. .145

Figura 6-1 - Alinhamentos pré-determinados do SATDR. .155

Figura 6-2 - Forma do pavimento tipo 156

Figura 6-3 - Seção de viga apresentada pelo SATDR. 157

Figura 6-4 - Seção de viga apresentada no projeto 158

Figura 6-5 - Seção de viga apresentada pelo SATDR para uma altura de pavimento máxima de $55 \mathrm{~cm}$. 159

Figura 6-6 - Planta de forma do pavimento de escritórios. 161

Figura 6-7 - Seção de viga apresentada pelo SATDR para uma altura de pavimento máxima de $65 \mathrm{~cm}$. 162

Figura 6-8 - Seção de viga apresentada pelo SATDR para uma altura máxima de pavimento de $60 \mathrm{~cm}$. 


\section{LISTA DE TABELAS}

Tabela 1-1 - Proposta de nomenclatura para classificação do tipo de otimização.

Tabela 2-1- Trabalhos na literatura na área de otimização em concreto armado [CASTILHO (2002)].

Tabela 2-2- Trabalhos na área de otimização em concreto pré-moldado [CASTILHO (2002)].

Tabela 2-3- Trabalhos na área de otimização estrutural utilizando métodos convencionais.

Tabela 2-4 - Trabalhos em AG.

Tabela 3-1 - Vãos médios $(\mathrm{m})$ dos elementos

Tabela 3-2 - Seções adotadas de pilar em função da carga vertical característica ....66

Tabela 3-3 - Consumo médio de aço no pilar em função de sua resistência... .66

Tabela 4-1 - Características das lajes vinculadas à variável VL................................75

Tabela 4.2 - Características das vigas vinculadas à variável VV.............................76

Tabela 4-3 - Número de elementos montados por dia..............................................85

Tabela 4-4 - Valor da função aptidão do melhor indivíduo para dez processamentos. .90

Tabela 4-5 - Comprimento máximo do cromossomo (quantidade máxima de bits).....94

Tabela 4-6 - Número de bits das variáveis $\mathrm{N}_{X}$ e $\mathrm{N}_{Y}$ .95

Tabela 4-7 - Número de bits da variável VV. .95

Tabela 4-8 - Valores da função aptidão para penalizações distintas. .98

Tabela 4-9 - Custo da estrutura dos melhores indivíduos para os processamentos do exemplo $1\left(\mathrm{R} \$ / \mathrm{m}^{2}\right)$...... 100

Tabela 4-10 - Custo da estrutura dos melhores indivíduos para os processamentos do exemplo $2\left(R \$ / m^{2}\right)$......

Tabela 4-11 - Custo da estrutura dos melhores indivíduos para os processamentos do exemplo $3\left(\mathrm{R} \$ / \mathrm{m}^{2}\right)$.

Tabela 4-12 - Custo da estrutura dos melhores indivíduos para os processamentos do exemplo $3\left(R \$ / m^{2}\right)$......

Tabela 4-13 - Operadores mais comumente utilizados, e ordenados em função de suas freqüências, valores do SATD em negrito [KICINGER et al. (2005)]..................103

Tabela 5-1 - Características dos operadores em 12 processamentos........................107

Tabela 5-2 - Aptidões dos melhores indivíduos dos 12 processamentos iniciais.......107

Tabela 5-3 - Aptidões médias dos melhores indivíduos em 5 processamentos..........109

Tabela 5-4 - Características dos operadores em 8 processamentos.........................111

Tabela 5-5 - Aptidões dos melhores indivíduos dos 8 processamentos.....................111 
Tabela 5-6 - Tabela comparativa entre o projeto e os resultados do SATD. 113

Tabela 5-7 - Participação das etapas nos resultados do SATD*.... 115

Tabela 5-8 - Resultados do SATD para o Comercial Carvalho.

Tabela 5-9 - Resultados do SATD com altura máxima aumentada (Comercial Carvalho)

Tabela 5-10 - Resultados do SATD para o Comercial Carvalho com o custo do transporte alterado.

Tabela 5-11 - Resultados Comercial Carvalho com vão mínimo 5,0 m.

Tabela 5-12 - Resultados Comercial Carvalho com vão mínimo 10,0 m e altura máxima do pavimento $66 \mathrm{~cm}$

Tabela 5-13 - Resultados do exemplo ATLSS $\left(\mathrm{d}_{\text {minimo }}=7,5 \mathrm{~m}\right)$ 126

Tabela 5-14 - Resultados do exemplo ATLSS ( $d_{\text {mínimo }}=5,0 \mathrm{~m}$ ). 128

Tabela 5-15 - Resultados do exemplo do hotel $\left(\mathrm{d}_{\text {minimo }}=7,5 \mathrm{~m}\right)$. 129

Tabela 5-16 - Resultados do exemplo do Nordestão $\left(d_{\text {mínimoX,Y }}=7,5 \mathrm{~m}\right)$ 132

Tabela 5-17 - Resultados Nordestão ( $d_{\text {mínimox }}=7,5 \mathrm{~m} \mathrm{e} \mathrm{d}_{\text {minimoY }}=10,0 \mathrm{~m}$ )..... 135

Tabela 5-18 - Resultados do exemplo do Nordestão para altura máxima de $60 \mathrm{~cm}$ $\left(\mathrm{d}_{\text {minimoX,Y }}=7,5 \mathrm{~m}\right)$ 137

Tabela 5-19 - Resultados com custo do aço 25\% maior. 139

Tabela 5-20 - Resultados com o custo do concreto $25 \%$ maior 140

Tabela 5-21 - Resultados com o custo do concreto e do aço $25 \%$ maior. 143

Tabela 5-22 - Composição relativa do item fabricação. 144

Tabela 5-23 - Custos relativos de estruturas em CML 146

Tabela 5-24 - Índice de espaço explorado. 148

Tabela 6-1 - Comprimento máximo do cromossomo. 150

Tabela 6-2 - Comparativo de validação do SATDL. 152

Tabela 6-3 - Variação da aptidão nos melhores indivíduos 152

Tabela 6-4 - Variação da aptidão de indivíduos com configurações diferentes da do melhor indivíduo 153

Tabela 6-5 - Comprimento máximo do cromossomo 154 


\section{RESUMO}

ALBUQUERQUE, A. T. (2007). Otimização de pavimentos de edifícios com estruturas de concreto pré-moldado utilizando algoritmos genéticos. Tese (doutorado). Escola de Engenharia de São Carlos, Universidade de São Paulo.

As estruturas de concreto pré-moldado tendem a ser mais moduladas e mais padronizados do que as estruturas de concreto moldadas no local, logo as técnicas de otimização podem produzir mais benefícios econômicos devido à produção em escala. Entre as técnicas de otimização utilizadas em engenharia estrutural, os algoritmos genéticos têm sido reconhecidos como uma forte tendência devido à sua facilidade de implementação e os excelentes resultados obtidos. Este trabalho trata da otimização integrada de pavimentos de edifícios com estruturas de concreto pré-moldado utilizando algoritmos genéticos e minimizando os custos. O principal objetivo é apresentar uma formulação para a otimização do pavimento, baseado em restrições arquitetônicas; restrições estruturais e restrições construtivas. A função-objetivo contemplou não só o consumo de materiais, mas também os aspectos relativos à fabricação, transporte e montagem. Atesta-se a consistência da representação do problema pelo modelo em função dos resultados que foram muito coerentes com a prática dos projetos. Os vários exemplos apresentados mostraram a robustez e a aplicabilidade do modelo e evidenciou-se a possibilidade de sua utilização em um sistema de apoio à tomada de decisão, que sirva como ferramenta de auxílio aos projetistas na concepção estrutural. Foi implementada a rotina dos transgênicos, que melhorou a convergência, e, a dos gêmeos, que aumentou a variabilidade da população.

Palavras-chave: pavimentos de concreto pré-moldado, otimização e algoritmos genéticos 


\begin{abstract}
ALBUQUERQUE, A. T. (2007). Floor optimization in precast concrete building using GA. Ph.D Thesis. Escola de Engenharia de São Carlos, Universidade de São Paulo.
\end{abstract}

The precast concrete structures are more modular and standardized than the cast in place concrete structures, therefore optimization techniques can improve economics gain because of series production. Among the optimization techniques in structural engineering design, genetic algorithms have been recognized as a trend. This work aims the floor precast concrete building optimization using GA's and minimizing the cost. The main goal of the work is to present a model to optimize the floor taking account of the structural, architectonics and constructive restrictions. The adopted model reached its purpose of the representing the more realist as possible the problem. The cost function considered not only the material consumption but the manufacture, transport and assembled stage. An integrated structural optimization is performed from the structural layout (columns position, directions and spans for beams and hollow cores) through the complete elements detailing (dimensions and reinforcement). The example results evidence the effectiveness of the formulation, they were very consistent with the design practice and they present the system application possibility like a decision support system that helps the engineer in the projects development. It was implemented a transgenic routine to improve the convergence and a twin routine to improve the variability of the population.

Key-words: Floors in precast concrete, optimization and genetic algorithm 


\section{INTRODUÇÃO}

\subsection{PRELIMINARES}

A indústria da construção civil, durante um longo período, se acomodou por acreditar tratar-se de uma atividade menos tecnológica. Hoje, busca recuperar 0 atraso tecnológico, procura mais eficiência nos processos construtivos e minimiza os desperdícios. Para isso muitos conceitos da indústria tradicional foram incorporados, desde as técnicas gerenciais até a automação das etapas de fabricação. Dentro deste contexto, as estruturas prémoldadas em concreto estrutural ganham espaço. Trata-se de um produto literalmente industrial, onde as peças produzidas em linhas de montagem são transportadas e montadas no local da obra. Com isso, ganha-se em controle de qualidade, em redução da mão-de-obra, em tempo de execução, com maior precisão administrativa, com menor índice de acidentes de trabalho, com menor influência das condições climáticas, com maior preservação do meio ambiente, com maior resistência aos incêndios e com maior durabilidade, já que se trata de um concreto de melhor qualidade.

Durante algum tempo, a utilização de estruturas pré-moldadas de concreto ficou restrita a galpões e lajes. Recentemente, têm surgido muitos edifícios executados em estruturas pré-moldadas (comerciais, hospitais, shopping centers, escolas e residenciais). Havia um preconceito que as estruturas de concreto pré-moldado limitavam muito a concepção dos projetos arquitetônicos dos edifícios e também havia impedimentos orçamentários, por não terem ainda preços competitivos. Estas restrições foram sendo equacionadas e hoje há uma plena aceitação por parte de todos os envolvidos na cadeia da construção (arquitetos, construtores, projetistas de estrutura, incorporadores e usuários) e a solução em pré-moldados passou a apresentar 
viabilidade econômica quando comparada a sistemas estruturais tradicionais (estruturas moldadas no local) em alguns casos.

Citam-se, como exemplos, de vantagens econômicas: os casos de empreendimentos que necessitam de velocidade de construção, para se obter o retorno financeiro, e os casos de obras que postergam o seu início em função do menor tempo de construção que o sistema exige, deixando o capital aplicado por um maior período no mercado financeiro. Segundo o Engenheiro Pierre Prelorentzo ${ }^{1}$, o complexo empresarial Millenium (São Paulo / SP) postergou o início da obra, em um ano, sem atrasar o prazo de entrega ao adotar a solução em estrutura de concreto pré-moldado.

Um substancial aumento no volume de obras com estruturas prémoldadas tem ocorrido, bem como uma diversificação das áreas de aplicação. Esse sistema, largamente utilizado na Europa e nos Estados Unidos, se firma em nosso país e há muito tempo várias universidades nacionais desenvolvem pesquisas na área.

Algumas destas pesquisas têm lidado com a aplicação de técnicas de otimização ao projeto de estruturas pré-moldadas, que é uma união bastante pertinente já que as estruturas pré-moldadas são mais moduladas e padronizadas e feitas em linha de produção. Este aspecto torna mais fácil a modelagem matemática do problema de otimização e produz economia em escala quando os resultados ótimos são alcançados.

Em um problema de otimização buscam-se valores para as variáveis de projeto que maximizem ou minimizem uma função-objetivo, que é sujeita a restrições.

Dentre as várias técnicas de otimização, os algoritmos genéticos vêm-se destacando como uma excelente ferramenta e por isso será utilizada neste trabalho. O primeiro trabalho desenvolvido, utilizando algoritmos genéticos no âmbito da Escola de Engenharia de São Carlos (EESC/USP), foi o doutorado de CASTILHO (2003) e o presente trabalho trata-se de uma continuação dessa linha de pesquisa.

Os algoritmos genéticos, que são apresentados no apêndice $\mathrm{E}$, tratamse de uma técnica heurística baseada na teoria da evolução natural, em que as

\footnotetext{
${ }^{1} 2^{\circ}$ Seminário Nacional de Pré-fabricados de Concreto
} 
variáveis de projeto vão sendo combinadas e alteradas por meio de operadores tais como seleção, cruzamento e mutação. A avaliação dos resultados se dá por uma função-aptidão que é a função-objetivo penalizada pelas restrições do problema.

\subsection{JUSTIFICATIVAS}

Define-se concepção estrutural como a escolha do sistema estrutural seguido da definição do posicionamento dos elementos estruturais: vigas, lajes e pilares. Denomina-se, neste trabalho como configuração estrutural, a etapa de definição do posicionamento e da quantidade dos elementos estruturais.

Assim como para as estruturas, em concreto, moldadas no local, as estruturas de concreto pré-moldado necessitam de uma boa concepção estrutural. Segundo CORRÊA (1991), sobre a concepção estrutural, "O problema tem como característica fundamental a complexidade, por causa do número de variáveis presentes e da multiplicidade de soluções possíveis". O projetista de estruturas, por mais experiente que seja, necessita sempre fazer estudos comparativos procurando, entre os sistemas estruturais e suas configurações, a alternativa estrutural que esteja entre as mais econômicas para a edificação que se está projetando. Esta atividade demanda tempo e, mesmo assim, nem sempre alcança o resultado ótimo, já que a solução ótima pode não figurar entre as alternativas testadas.

Conforme MILES (2001), o processo de projetar um edifício é complexo e exige habilidades em várias disciplinas, tais como arquitetura, estrutura, instalações e outras. Uma decisão bem fundamentada, em conhecimentos interdisciplinares, garante compatibilidade e promove soluções de projeto que efetivamente satisfazem custo, tempo e restrições de funcionalidade. Logo na fase da concepção estas decisões determinam a maior parte do custo final do edifício, de forma que é essencial concentrar esforços nesta etapa para garantir decisões acertadas.

Nas estruturas de concreto pré-moldado, aumentam-se as dificuldades de escolha por ter-se de considerar a influência da fabricação, do transporte e da montagem na composição dos custos. 
Sobre a configuração estrutural de edifícios com estrutura de concreto pré-moldado, ELLIOTT (1996) ressalta que, apesar de geralmente a melhor alternativa ser o posicionamento das vigas na direção paralela à maior direção do pavimento, nem sempre o obvio se confirma como a melhor alternativa, atestando assim a necessidade de uma análise de várias alternativas.

Motivado pela difícil etapa de concepção da estrutura, e baseado nos bons resultados de CASTILHO (2003) e de vários outros autores, com a utilização dos algoritmos genéticos, desenvolve-se aqui a otimização do pavimento de edifício com estrutura de concreto pré-moldado. O pavimento é otimizado desde sua configuração até o detalhamento dos elementos, ou seja, uma otimização integrada.

Justifica-se ainda a otimização do pavimento por ser, segundo PRIOR et al. (1993), o responsável pela maior parcela dos custos e do peso de uma estrutura de concreto e ainda tem importante impacto na altura das edificações e na acomodação das instalações.

Ainda, segundo PRIOR et al. (1993), as instalações merecem especial atenção na escolha dos sistemas estruturais já que nos Estados Unidos o custo da estrutura, de concreto pré-moldado, corresponde, em média, a 17\% do custo total da edificação, enquanto os custos da instalação são em torno de $38 \%$, em média. Por isso a importância de se otimizar o pavimento levando em consideração todos os aspectos da edificação. Segundo informações coletadas com fabricantes, no Brasil o custo direto da estrutura pré-moldada representa entre $20 \%$ e $25 \%$ do custo total da edificação.

Entende-se, neste contexto, o sistema estrutural como o tipo de laje e viga a serem adotadas e a configuração estrutural como a orientação, quantidade e vãos das peças. O sistema desenvolvido tem o sistema estrutural escolhido previamente e indica todas as informações referentes à laje e à viga, bem como sua geometria, suas armaduras protendidas, armaduras passivas e suas disposições (vãos e direções) e também a localização e a quantidade de pilares. Para isso, dados característicos da indústria deverão ser implementados para garantir a confiabilidade e a representatividade dos resultados.

Para uniformização da classificação do tipo de otimização, que se faz em estruturas, propõe-se a nomenclatura apresentada na tabela 1-1. 
Tabela 1-1 - Proposta de nomenclatura para classificação de otimização estrutural

\begin{tabular}{|c|c|c|}
\hline \multicolumn{2}{|c|}{ Otimização } & Objetivo \\
\hline \multirow[t]{2}{*}{ Estrutura } & Sistema estrutural & $\begin{array}{l}\text { Indica o tipo de sistema estrutural, por } \\
\text { exemplo: tipo de laje a ser adotado, } \\
\text { presença ou não de vigas e } \\
\text { necessidade ou não de protensão. }\end{array}$ \\
\hline & $\begin{array}{l}\text { Configuração } \\
\text { estrutural }\end{array}$ & $\begin{array}{l}\text { Indica a disposição, quantidade e os } \\
\text { vãos dos elementos, a partir de um } \\
\text { sistema estrutural definido. }\end{array}$ \\
\hline Elemento & & $\begin{array}{l}\text { Otimização de uma peça completa } \\
\text { (laje, viga ou pilar). }\end{array}$ \\
\hline Seção & & $\begin{array}{c}\text { Otimização de apenas uma seção de } \\
\text { um elemento. }\end{array}$ \\
\hline
\end{tabular}

\subsection{OBJETIVOS}

O principal objetivo deste trabalho é apresentar uma formulação para a otimização de pavimentos de edifícios com estruturas de concreto prémoldado, baseado em restrições arquitetônicas, em função da finalidade da obra (comercial, shopping center, escola, residencial etc); restrições estruturais; restrições de acomodação das instalações e restrições construtivas. Pretendese produzir um conjunto de soluções estruturais ótimas, minimizando o custo.

A partir de um pavimento retangular com dimensões $\left(\ell_{x}\right.$ e $\left.\ell_{y}\right)$ e carregamentos definidos, adotam-se como variáveis de projeto: (a) da configuração estrutural, o número de vãos em cada direção e a direção das vigas e lajes e (b) dos componentes, as dimensões, os detalhes das armaduras das peças e suas resistências à compressão.

Para isso se faz necessário uma forte interface com o usuário para que o sistema seja alimentado de forma que apresente resultados coerentes com a realidade. Logo, permite que o usuário indique regiões onde não se podem ter 
apoios, indique os vãos mínimos nas duas direções e a altura máxima do pavimento, e ainda permite ao usuário que crie um banco de dados com as seções de pilares, vigas e lajes disponíveis pelo fabricante.

Assim, o objetivo geral da pesquisa é desenvolver um programa para otimização estrutural do pavimento de edifícios com estruturas de concreto prémoldado, utilizando algoritmo genético e tendo o custo como função-objetivo. Este programa será denominado SATD (sistema de apoio à tomada de decisão).

São objetivos específicos deste projeto:

a) Implementar uma função-custo o mais completa e representativa possível;

b) Implementar uma rotina simulando o conceito dos transgênicos, fenômeno bastante pesquisado em engenharia genética, nos dias de hoje, e que produz excelentes resultados;

c) Implementar uma estratégia para melhorar o elitismo utilizando a verificação de irmãos gêmeos;

d) Em função da análise dos resultados, indicar algumas diretrizes para a elaboração de projetos estruturais de concreto pré-moldado;

e) Demonstrar a viabilidade da utilização de uma ferramenta como essa no dia-a-dia dos escritórios.

\subsection{METODOLOGIA}

Várias etapas caracterizam este trabalho, inicialmente é feita a revisão bibliográfica e é feito o levantamento sobre a utilização das estruturas de concreto pré-moldado no Brasil:

a) Pesquisa bibliográfica nos assuntos: algoritmos genéticos, inteligência artificial e dimensionamento dos elementos pré-moldados utilizados em edifícios;

b) Pesquisa junto aos arquitetos, projetistas de estruturas e fabricantes sobre quais os sistemas estruturais mais adequados para os diversos edifícios com estruturas de concreto pré-moldado, quais as limitações 
mais recorrentes, quais as dificuldades de compatibilização de projetos e quais as restrições em função do tipo de obra. Pretende-se transformar a prática profissional em alguma forma mensurável que possa ser incorporada no modelo numérico de otimização;

Na segunda etapa o modelo de otimização é criado e o sistema é desenvolvido:

c) Foi feita uma parceria junto a uma fábrica de pré-moldados para se fazer um levantamento sobre o funcionamento da indústria, as características da produção, do transporte e da montagem, bem como da composição de custos, tendo-se como idéia inicial procurar exaustivamente montar um modelo de função-custo o mais real e completa possível. A empresa escolhida foi a T\&A, que tem vasta experiência na fabricação de edifícios e atua em toda a região nordeste. Conforme MILES (2001), as informações e as sugestões do meio técnico são muito importantes, tanto na fase de concepção como na fase de avaliação de um trabalho como este;

d) Dividiu-se a otimização em duas etapas, inicialmente será otimizado o sistema estrutural completo, desde a configuração até o detalhamento dos elementos. Depois será feita uma otimização local em algumas variáveis, partindo-se de uma configuração estrutural já estabelecida pelo SATD;

e) O candidato passou um período do programa, maio a agosto de 2006, fazendo um estágio internacional na University of Nebraska at Omaha acompanhando o Professor Maher Tadros, reconhecidamente uma referência nas pesquisas em pré-moldados. Neste período foi pesquisado o funcionamento de algumas indústrias de estruturas prémoldadas americanas e, também, o candidato desenvolveu um novo sistema estrutural o Midwest Office System (Anexo 1), sob orientação dos Professores Maher Tadros e Amgad Girgis;

f) Fez-se a formulação do modelo, onde otimiza-se a configuração estrutural juntamente com a otimização dos elementos (vigas e lajes); 
g) Desenvolveu-se um programa em Fortran (SATD) para implementação do algoritmo de otimização, analisando diferentes possibilidades de características dos algoritmos genéticos;

h) Desenvolveu-se variantes específicas do SATD.

Por fim são feitas análises dos resultados encontrados com o sistema:

i) Usou-se um projeto real como bench-mark;

j) Aplicações, análise dos resultados e conclusões. 


\section{REVISÃO BIBLIOGRÁFICA}

Será apresentada neste capítulo uma revisão bibliográfica sobre otimização estrutural em geral e utilizando algoritmos genéticos. Será apresentado ainda o estado da arte da otimização estrutural integrada. A revisão foi feita basicamente no período de janeiro de 2004 a agosto de 2006.

\subsection{OTIMIZAÇÃO ESTRUTURAL}

Conforme CASTILHO (2003), existem inúmeros trabalhos no campo da otimização em engenharia estrutural e na sua maioria buscam a minimização dos custos das estruturas em geral, utilizando métodos de programação matemática. Os principais encontrados na literatura, são: Simplex, Penalidade e Lagrangiano aumentado. Alguns dos mais relevantes desses trabalhos em concreto estrutural são apresentados nas tabelas 2-1 e 2-2.

Apresentam-se ainda alguns trabalhos em otimização estrutural na tabela 2-3, que foram desenvolvidos recentemente, e também utilizaram-se métodos de programação matemática.

Os métodos de programação matemática apresentam algumas limitações tais como dificuldade de identificar soluções ótimas globais, pois são dependentes do ponto de partida, dificuldade de trabalhar com variáveis discretas e dificuldade de operar com funções não diferenciáveis. Devido a isso, muitas pesquisas com problemas com as características acima, têm-se voltado para métodos mais flexíveis e simples como os heurísticos. Dentre os métodos heurísticos, os algoritmos genéticos têm-se destacado pela sua eficiência e simplicidade. 
Tabela 2-1- Trabalhos na literatura na área de otimização em concreto armado Fonte - CASTILHO (2003)

\begin{tabular}{|c||c||c|}
\multicolumn{1}{c||}{} & \multicolumn{2}{c|}{ Características } \\
\hline $\begin{array}{c}\text { Trabalhos em } \\
\text { concreto armado }\end{array}$ & Função objetivo & Variáveis \\
\hline \hline $\begin{array}{c}\text { PRAKASH, AGARWALA } \\
\text { \& SINGER (1988) }\end{array}$ & $\begin{array}{c}\text { Minimizar o custo das vigas de } \\
\text { concreto armado }\end{array}$ & Dimensões das seções da viga \\
\hline \multirow{2}{*}{ CHAKRABARTY (1992) } & $\begin{array}{c}\text { Minimizar o custo das vigas } \\
\text { retangulares de concreto armado }\end{array}$ & $\begin{array}{c}\text { Dimensões das seções da viga e } \\
\text { armadura longitudinal }\end{array}$ \\
\hline SOARES (1997) & $\begin{array}{c}\text { Minimizar o vigamento de um } \\
\text { pavimento }\end{array}$ & Altura das vigas e da área de aço \\
\hline $\begin{array}{c}\text { SARMA \& ADELI (1998) e } \\
\text { KOUMOUSIS \& } \\
\text { ARSENIS (1998) }\end{array}$ & $\begin{array}{c}\text { Minimizar o custo dos materiais } \\
\text { para as estruturas de concreto } \\
\text { armado }\end{array}$ & $\begin{array}{c}\text { Dimensões das seções } \\
\text { transversais }\end{array}$ \\
\hline
\end{tabular}

Tabela 2-2- Trabalhos na área de otimização em concreto pré-moldado Fonte - CASTILHO (2003)

\begin{tabular}{|c|c|c|}
\hline & \multicolumn{2}{|c|}{ Características } \\
\hline $\begin{array}{l}\text { Trabalhos em } \\
\text { concreto } \\
\text { pré-moldado }\end{array}$ & Função objetivo & Variáveis \\
\hline $\begin{array}{c}\text { LOUNIS \& COHN (1993) } \\
\text { e } \\
\text { COHN \& LOUNIS (1994) }\end{array}$ & $\begin{array}{l}\text { Minimizar o custo de produção e } \\
\text { de montagem para lajes e vigas I } \\
\text { protendidas de ponte }\end{array}$ & $\begin{array}{c}\text { Comprimento e largura do sistema } \\
\text { de ponte, dimensões das vigas e } \\
\text { lajes }\end{array}$ \\
\hline $\begin{array}{c}\text { KOSKISTO \& } \\
\text { ELLINGWOOD (1998). }\end{array}$ & $\begin{array}{c}\text { Minimizar o custo de produção } \\
\text { para uma laje alveolar }\end{array}$ & $\begin{array}{c}\text { Área da armadura de protensão, } \\
\text { resistência do concreto e da altura } \\
\text { da laje }\end{array}$ \\
\hline $\begin{array}{l}\text { HASSANAIN \& LOOV } \\
\qquad(1999)\end{array}$ & $\begin{array}{l}\text { Minimizar o custo de produção, } \\
\text { transporte e montagem para vigas } \\
\text { protendidas de seção I de ponte }\end{array}$ & $\begin{array}{c}\text { Força de protensão, } \\
\text { excentricidades dos cabos, } \\
\text { armadura de flexão, } \mathrm{f}_{\mathrm{ck}} \mathrm{e} \\
\text { espessura do tablado }\end{array}$ \\
\hline
\end{tabular}


Tabela 2-3- Trabalhos na área de otimização estrutural utilizando métodos convencionais

\begin{tabular}{|c|c|}
\hline Trabalhos & Título \\
\hline \hline $\begin{array}{c}\text { SOEIRO et al. } \\
(1999)\end{array}$ & Design and optimization of prefabricated tee beams \\
\hline LIU \& LU (2003) & Multi-objective and multi-loading optimization of \\
& ultralightweight truss materials \\
\hline MELO \& & Optimum compression strength of HSC cantilever \\
MONTEIRO (2002) & columns by mathematical programming \\
\hline
\end{tabular}

\subsection{OTIMIZAÇÃO ESTRUTURAL UTILIZANDO ALGORÍTMOS GENÉTICOS}

SOARES (1999) citou que os algoritmos genéticos mostram um bom potencial, mas que na época de sua pesquisa bibliográfica, estavam apenas começando a ser aplicados em otimização estrutural. Nos dias de hoje, pouco tempo depois, já se observam muitos trabalhos em otimização estrutural, via algoritmos genéticos.

CASTILHO (2003) apresenta um trabalho sobre otimização, via algoritmos genéticos, de elementos pré-moldados (vigotas protendidas e painéis de lajes alveolares) considerando, para a composição dos custos, as etapas de produção, transporte e montagem. Esse trabalho (CASTILHO, (2003)) apresenta possíveis propostas de estudo para sua continuação, que foram implementadas:

a) Análise de diferentes funções-penalidades;

b) Análise do impacto nos resultados de duas estratégias para o tratamento de restrições - rejeição e reparação;

c) Uso de populações iniciais não randômicas;

d) Fazer um modelo de levantamento de custos que traduza melhor as situações reais dos fabricantes.

CASTILHO (2003) apresenta, em sua revisão bibliográfica, vários trabalhos em otimização estrutural utilizando algoritmos genéticos e, nos 
últimos seis anos, muitos trabalhos continuaram surgindo, ressaltando as vantagens e a eficácia do método (Tabela 2-4).

Tabela 2-4 - Trabalhos em otimização estrutural utilizando algoritmos genéticos

\begin{tabular}{|c|c|}
\hline Trabalhos em AG & Título: característica principal \\
\hline $\begin{array}{c}\text { RAJEEV \& } \\
\text { KRISHNAMOORTHY } \\
(1992)\end{array}$ & $\begin{array}{l}\text { Discrete optimization of structures using GA: O conceito de } \\
\text { otimização utilizando algoritmos genéticos é apresentado em } \\
\text { detalhe usando exemplo de otimização de barras em treliças. }\end{array}$ \\
\hline $\begin{array}{l}\text { BRADSHAW \& MILES } \\
\text { (1997) }\end{array}$ & $\begin{array}{l}\text { Using Standard fitnesses with GA: Uma nova abordagem } \\
\text { para a seleção e aptidão é apresentada. }\end{array}$ \\
\hline $\begin{array}{c}\text { RAJEEV \& } \\
\text { KRISHNAMOORTHY } \\
\text { (1997) }\end{array}$ & $\begin{array}{l}\text { GA based methodologies for design optimization of } \\
\text { trusses: Otimização integrada de uma treliça plana. }\end{array}$ \\
\hline $\begin{array}{c}\text { RAFIQ \& SOUTHCOMBE } \\
\text { (1998) }\end{array}$ & $\begin{array}{l}\text { GA in optimal design and detailing of reinforced concrete } \\
\text { biaxial columns supported by a declarative approach for } \\
\text { capacity checking: Apresenta uma nova abordagem para } \\
\text { otimização de pilares utilizando algoritmos genéticos, } \\
\text { contemplando a dimensão e o arranjo das barras. }\end{array}$ \\
\hline LEMONC & $\begin{array}{l}\text { Aplicação de algoritmos genéticos em otimização } \\
\text { estrutural: Mostra a potencialidade dos algoritmos genéticos } \\
\text { para analisar problemas variados, com diversos objetivos e as } \\
\text { facilidades de implementação. }\end{array}$ \\
\hline $\begin{array}{c}\text { MANOHARAM \& } \\
\text { SHANMUGANATHAN } \\
(1999)\end{array}$ & $\begin{array}{l}\text { A comparison of search mechanisms for structural } \\
\text { optimization: É apresentada uma comparação entre algoritmos } \\
\text { apropriados para otimização de problemas discretos. }\end{array}$ \\
\hline $\begin{array}{l}\text { GHABOUSSI \& RAICH } \\
(2000)\end{array}$ & $\begin{array}{l}\text { Evolving structural design solutions using an implicit } \\
\text { redundant genetic algorithm: Apresentam uma nova } \\
\text { abordagem para os algoritmos genéticos permitindo que os } \\
\quad \text { cromossomos tenham comprimentos aleatórios. }\end{array}$ \\
\hline SILVA (2001) & $\begin{array}{l}\text { Otimização de estruturas de concreto armado usando } \\
\text { algoritmos genéticos: Apresenta as diferenças básicas entre os } \\
\text { métodos clássicos e os algoritmos genéticos e apresenta os } \\
\text { principais parâmetros no funcionamento de um AG. }\end{array}$ \\
\hline
\end{tabular}


Tabela 2-4 - Trabalhos em otimização estrutural utilizando algoritmos genéticos (Continuação)

\begin{tabular}{|c|c|}
\hline Trabalhos em AG & Título: característica principal \\
\hline MILES et al. (2001) & $\begin{array}{l}\text { The conceptual design of commercial building using a GA: } \\
\text { Descreve um sistema de apoio à tomada de decisão de edifícios } \\
\text { comerciais em estrutura metálica. }\end{array}$ \\
\hline $\begin{array}{c}\text { NANAKORN \& } \\
\text { MEESOMKLIN (2001) }\end{array}$ & $\begin{array}{l}\text { An adaptive penalty function in GA for structural design } \\
\text { optimization: Uma penalização variável é apresentada. O } \\
\text { coeficiente de penalização vai se ajustando durante a evolução. }\end{array}$ \\
\hline KHAJEHPOUR (2001) & $\begin{array}{l}\text { Optimal conceptual design of high-rise office buildings: } \\
\text { Trata da otimização de projetos arquitetônicos. }\end{array}$ \\
\hline GRIERSON, et al. (2002) & $\begin{array}{l}\text { Method for conceptual design applied to office buildings: } \\
\text { Otimização da concepção de projetos de edifícios comerciais. }\end{array}$ \\
\hline LAGAROS et al. (2002) & $\begin{array}{l}\text { Structural optimization using evolutionary algoritms: } \\
\text { Investiga a eficiência de vários algoritmos evolucionários. }\end{array}$ \\
\hline ALI et al. (2003) & $\begin{array}{l}\text { Applicability and viability of a GA based finite element } \\
\text { analysis: Um AG, baseado num procedimento de análise com } \\
\text { elementos finitos, é utilizado para otimizar tamanho e formato } \\
\text { de treliças planas e espaciais. }\end{array}$ \\
\hline PULLMANN et al. (2003) & $\begin{array}{l}\text { Structural design of reinforced concrete tall building: } \\
\text { Otimização de edifícios altos em CA. }\end{array}$ \\
\hline RAFIQ et al. (2003) & $\begin{array}{c}\text { Conceptual building design - evolutionary approach: Faz } \\
\text { uma otimização do sistema estrutural, onde define a } \\
\text { arquitetura a partir da estrutura. }\end{array}$ \\
\hline HRSTA et al. (2003) & $\begin{array}{c}\text { A competitive comparison of different types of evolutionary } \\
\text { algorithms: Apresentam uma comparação entre várias técnicas } \\
\text { heurísticas, entre as quais algoritmos genéticos. }\end{array}$ \\
\hline CAMP et al. (2003) & $\begin{array}{c}\text { Flexural design of reinforced concrete frames using a GA: } \\
\text { O objetivo da otimização é minimizar os custos e materiais do } \\
\text { pórtico sujeito aos requerimentos do ACI. }\end{array}$ \\
\hline LEE (2003) & $\begin{array}{l}\text { Flexural design of reinforced concrete frames by GA: } \\
\text { Utiliza o AG, para efetuar uma otimização discreta de um } \\
\text { pórtico em concreto armado, sujeito a combinações de ações } \\
\text { verticais e laterais. }\end{array}$ \\
\hline LEPS \& SEJNOHA (2003) & $\begin{array}{c}\text { New approach to optimization of reinforced concrete } \\
\text { beams: Utiliza algoritmo híbrido com } \mathrm{AG} \text { e simulated anneling. }\end{array}$ \\
\hline
\end{tabular}


Tabela 2-4 - Trabalhos em otimização estrutural utilizando algoritmos genéticos (Continuação)

\begin{tabular}{|c|c|}
\hline Trabalhos em AG & Título: característica principal \\
\hline PARK et al. (2004) & $\begin{array}{c}\text { Integrated optimum design of viscoelastically damped } \\
\text { structural systems: otimiza a localização de amortecedores em } \\
\text { uma estrutura. }\end{array}$ \\
\hline ZHENG & $\begin{array}{l}\text { Applying a GA based multiobjective approach for time cost } \\
\text { optimization: Otimiza o tempo das atividades de construção. }\end{array}$ \\
\hline $\begin{array}{c}\text { KICINGER \& } \\
\text { ARCISZEWSKI (2004) }\end{array}$ & $\begin{array}{c}\text { Multiobjective evolutionary design of steel structures in tall } \\
\text { buildings: Otimização integrada de estrutura metálica para } \\
\text { edifícios altos. }\end{array}$ \\
\hline SAHAAB & $\begin{array}{l}\text { A hybrid GA for reinforced concrete flat slab building: } \\
\text { Detalha o AG modificado utilizado no trabalho anterior. }\end{array}$ \\
\hline SAHAAB & $\begin{array}{l}\text { Cost optimization of reinforced concrete flat slab buildings: } \\
\text { Otimização completa de uma laje lisa, considerando a } \\
\text { localização dos pilares e o detalhamento dos elementos. }\end{array}$ \\
\hline $\begin{array}{c}\text { GOVINDARAJ \& } \\
\text { RAMASAMY (2005) }\end{array}$ & $\begin{array}{c}\text { Optimum Detailed design of reinforced concrete } \\
\text { continuous beams using GA: Otimizam uma viga continua } \\
\text { em concreto armado utilizando AG. }\end{array}$ \\
\hline CASTRO \& LOPES (2005) & $\begin{array}{l}\text { Aplicação e AG na otimização do dimensionamento de } \\
\text { seções transversais de vigas de concreto armado: Aplica- } \\
\text { se um AG, com codificação binária, ao dimensionamento de } \\
\text { seções transversais de vigas em concreto armado, submetidas à } \\
\text { flexão simples. }\end{array}$ \\
\hline KICINGER et al. (2005) & $\begin{array}{c}\text { Evolutionary computation and structural design: A survey } \\
\text { of the state of the art: Levantamento completo dos algoritmos } \\
\text { evolucionários. }\end{array}$ \\
\hline CASTRO et al. (2006) & $\begin{array}{c}\text { The influence of penalty functions in structural optimization } \\
\text { using genetic algorithm: apresentam uma comparação entre } \\
\text { várias funções-penalidades. }\end{array}$ \\
\hline $\begin{array}{l}\text { FONSECA \& BARBOSA } \\
\qquad(2006)\end{array}$ & $\begin{array}{l}\text { A genetic algorithm with similarity-based fitness } \\
\text { approximation for structural optimization. }\end{array}$ \\
\hline
\end{tabular}

Esses trabalhos, em sua maioria, testaram a viabilidade, eficiência e perspectiva da utilização dos algoritmos genéticos em problemas de 
Engenharia Estrutural. Muitos exemplos, muitas comparações e muitos testes foram apresentados, bem como muitos casos de hibridação, onde o algoritmo genético era aliado a outras técnicas de otimização tais como simulated anelling, redes neurais, sistemas especialistas e técnicas tradicionais de programação matemática para melhorar os resultados. Pode-se citar ainda que muitas variações do método foram desenvolvidas e testadas para a funçãoaptidão, função-penalidade, representação do cromossomo etc.

$\mathrm{Na}$ área dos pré-moldados, além da otimização dos elementos, muitos trabalhos têm sido feitos para otimizar, via algoritmo genético, a linha de produção das fábricas, por exemplo: ZHENG et al. (2004), CHAN \& HU (2001), LEU \& HWANG (2001) e DAWOOD (1995 e 2002).

Pode-se dizer ainda, conforme a revisão bibliográfica, que os algoritmos genéticos são uma das ferramentas utilizadas como inteligência artificial (IA) assim como sistemas especialistas, redes neurais, lógica fuzzy etc. Cita-se o exemplo de BENJAORAN \& DAWOOD (2006), que desenvolveram um sistema inteligente, para planejar a produção de uma fábrica de pré-moldados utilizando em conjunto algoritmos genéticos e redes neurais.

Em KICINGER et al. (2005) é apresentado o estado da arte completo e atualizado dos algoritmos evolutivos aplicados à engenharia estrutural. Faz-se uma apresentação de todo o desenvolvimento teórico e um levantamento de todos os trabalhos desde os primeiros, nos anos setenta, até as últimas pesquisas, ainda em desenvolvimento. Nesse trabalho são referenciados 304 trabalhos no total. $p$

KICINGER (2005) et al. conclui que as pesquisas em algoritmos evolucionários continuam a crescer rapidamente e se desenvolvem em várias direções e, para embasar suas conclusões, cita a existência de sete jornais e sete conferencias internacionais que têm publicado pesquisas sobre o assunto.

Nos trabalhos pesquisados são citadas como vantagens do método: ser considerado uma técnica robusta de encontrar mínimo global; não precisar de cálculo de gradientes; não ser limitado por restrições do espaço como continuidade e derivadas; ser robusto e poder rapidamente explorar um complexo espaço multidimensional; ser de fácil implementação; ser comprovadamente confiável e estável; funcionar bem em problemas discretos e 
não diferenciáveis em que o valor da função objetivo muda drasticamente na faixa das variáveis de projeto.

Segundo GOLDBERG (1989), com relação à robustez, os algoritmos genéticos se diferenciam dos procedimentos tradicionais por:

a) Trabalhar com uma codificação das variáveis e, não, com valores propriamente ditos;

b) Fazer busca dentro de uma população de pontos;

c) Trabalhar com informação da função-objetivo e, não, de derivadas;

d) Usar regras de transição probabilística.

Segundo KINCINGER et al. (2005), são citadas como vantagens dos algoritmos genéticos:

a) Não é necessário nenhum conhecimento prévio do espaço de busca;

b) Habilidade para lidar com problemas de várias dimensões;

c) Apresenta-se robusto para várias classes de problemas;

d) Apresentam várias boas soluções;

e) Habilidade para encontrar regiões de ótimo global;

Ressalta-se, porém, que para os casos em que a análise estrutural seja muito demorada, o método não seria indicado, com as máquinas disponíveis hoje, devido ao seu custo computacional.

\subsection{OTIMIZAÇÃO INTEGRADA}

KICINGER et al. (2005), após o completo levantamento sobre algoritmos evolucionários aplicados à engenharia estrutural, concluem que uma das áreas de pesquisa mais promissoras, na computação evolucionária, é a otimização integrada da estrutura. A otimização integrada da estrutura, conforme comentado no item 1.2, deve considerar, ao mesmo tempo, a fase de criação da configuração estrutural e a fase de detalhamento dos elementos, ao contrário dos processos tradicionais que pouco, ou nada, consideram a interação entre essas fases. Cita-se, até, que a otimização integrada surgiu 
com a difusão dos algoritmos genéticos, já que os métodos clássicos de otimização têm dificuldade para tratar problemas com variáveis de natureza distinta.

Vários trabalhos foram encontrados na literatura abordando diretamente o tema otimização integrada ou fazendo comentários sobre sua necessidade e importância. Apresentam-se as descrições dos mais relevantes.

RAJEEV \& KRISHNAMOORTHY (1992) desenvolveram inicialmente um trabalho sobre otimização das seções das barras de uma treliça, utilizando algoritmos genéticos. Posteriormente, fizeram uma otimização mais ampla considerando a configuração e os elementos da treliça (figura 2-1), variando o número de nós, o número de elementos e as seções das barras (RAJEEV \& KRISHNAMOORTHY, 1997).

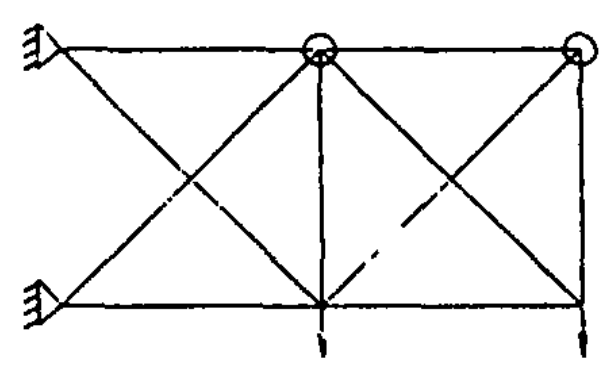

(a)

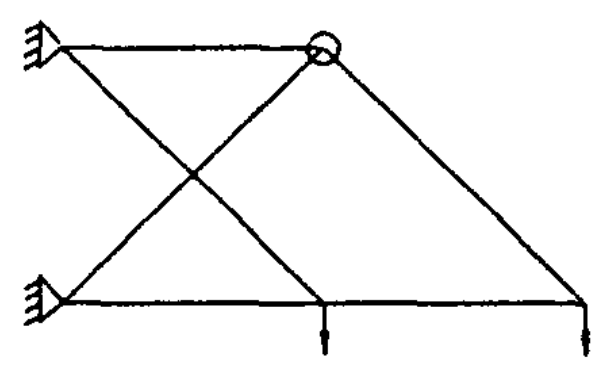

(c)

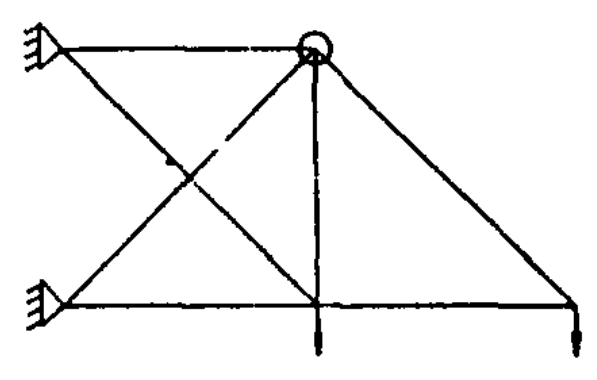

(b)

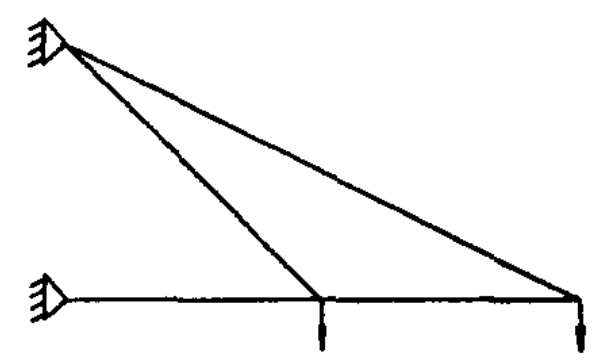

(d)

Figura 2-1 - Otimização da configuração estrutural de uma treliça Fonte - RAJEEV \& KRISHNAMOORTHY (1997)

Segundo LOUNIS \& COHN (1993), a otimização pode ser processada em três níveis: otimização dos elementos (nível 1), otimização das configurações estruturais (nível 2) e otimização do sistema estrutural como um 
todo (nível 3). Eles realizaram uma pesquisa buscando a solução ótima nestes três níveis para uma ponte com elementos pré-moldados de concreto protendido, onde, a partir do comprimento, da largura e de algumas especificações de uma ponte, o sistema buscava qual a configuração estrutural ótima e quais as seções e armaduras ótimas para um dado sistema estrutural. Por fim, concluíram que a otimização realizada nos três níveis se mostra mais eficiente que a otimização realizada simplesmente em seus elementos isolados.

Observa-se que LOUNIS \& COHN (1993) tiveram a preocupação de se fazer uma otimização integrada, mas segmentaram-na em etapas quando, na realidade, o processo deveria ser único já que as fases de projeto são interligadas e dependentes. O dimensionamento dos elementos é feito em função dos seus vãos, que, por sua vez, foram definidos na etapa de configuração estrutural. Por isso a mesma rotina de otimização deve contemplar desde a configuração até o detalhamento.

COHN \& DINOVITZER ${ }^{2}$ apud SAHAAB et al. (2005a) concluem que a otimização seria muito mais atrativa se os exemplos fossem desenvolvidos para estruturas reais submetidas às condições de carregamento e aos estados limites, e não simplesmente de elementos isolados.

SARMA e ADELI (1998), ao fazerem uma revisão sobre trabalhos em otimização de estruturas em concreto, citam que muitos trabalhos têm sido feitos sobre otimização de elementos estruturais, mas, que, na época, registraram apenas dois trabalhos que consideravam a estrutura completa. Comentam, então, a importância de os trabalhos utilizarem um modelo que melhor representasse a realidade, que otimizem uma estrutura real com vários elementos onde a otimização pudesse apresentar ganhos consideráveis. Comentam, ainda, que o custo da estrutura, muitas vezes, é tratado de maneira simplificada e, que seria significante a consideração de uma função-custo mais representativa, incluindo mão-de-obra, transporte, montagem e fabricação. Anos depois, os mesmos autores (SARMA \& ADELI, 2005) apresentaram uma otimização de todos os elementos de edifícios em estrutura metálica, mas a partir de uma configuração estrutural já definida (figura 2-2).

\footnotetext{
${ }^{2}$ COHN, M. Z. \& DINOVITZER, A. S. (1994). Application of structural optimization. Journal of Structural Engineering, ASCE, 124 (5):570-8.
} 


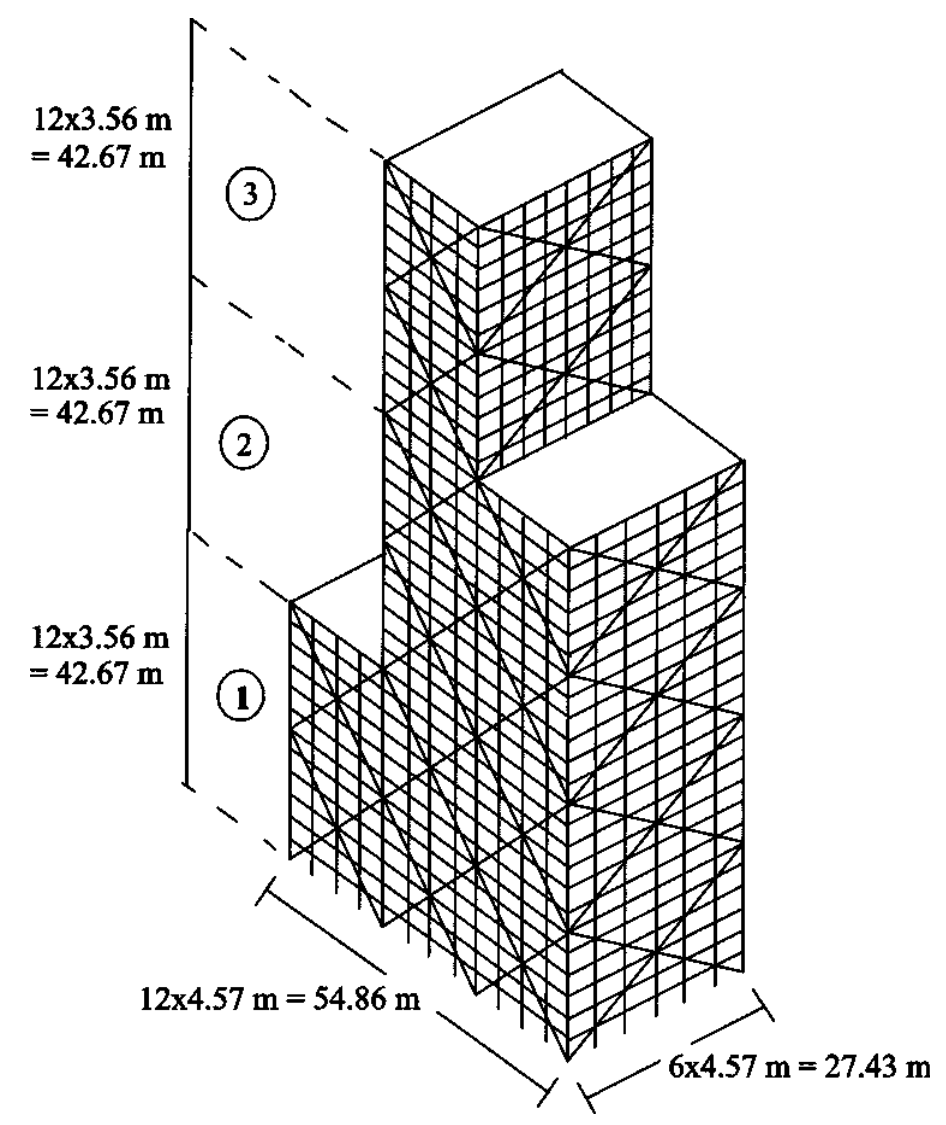

Figura 2-2 - Edifício utilizado como exemplo para a otimização Fonte - SARMA \& ADELI (2005)

SAHAAB et al. (2005b) também comentam a carência de trabalhos de otimização que contemplem a estrutura globalmente e, não, apenas, a otimização de seus elementos. Baseados nesta premissa, desenvolveram um trabalho de otimização de um pavimento de laje lisa em concreto armado. Neste trabalho, variam o layout dos pilares e otimizam com algoritmo genético a laje do pavimento, porém não fica claro como são geradas as alternativas de layout da estrutura. A otimização é dividida em três níveis, inicialmente, otimiza-se a localização dos pilares; depois as dimensões; e, por fim, otimizamse as armaduras dos elementos. Após a otimização via algoritmo genético, o resultado é refinado por meio da técnica de Hooke \& Jeeves, de programação matemática. Salientam a importância do custo do pavimento no custo total da estrutura, e apresentam os valores percentuais de cata etapa no custo total.

MILES et al. (2001) apresentam uma formulação para a otimização via AG, da configuração estrutural de um edifício em aço, levando em 
consideração aspectos de arquitetura e de instalações. Justificam o trabalho, citando que $80 \%$ dos custos de construção ficam definidos ao final da fase de projetos e, que, a pressão pela velocidade de projetos impede a análise de várias alternativas antes da escolha da estrutura. O sistema desenvolvido foi avaliado por vários projetistas, e foi considerado como uma ferramenta viável para utilização em projetos por $68 \%$ deles.

O trabalho de MILES et al. (2001) não se aprofunda na otimização dos elementos, optando por fazer uma escolha simplificada, a partir de tabelas de pré-dimensionamento. Faz também uma simplificação na função-custo, adotando um custo unitário por sistemas estruturais, desprezando aspectos construtivos, por exemplo.

PULLMANN et al. (2003) apresentam uma formulação para a otimização da configuração de edifícios altos em concreto armado. Comentam a importância de uma otimização integral, considerando ao mesmo tempo a configuração e o detalhamento, e comentam que a fase de concepção estrutural (fase inicial dos projetos), muitas vezes, é definida pela sensibilidade e experiência do engenheiro. Acontece que esta etapa tem muitas variáveis, e algumas alternativas teriam de ser analisadas para se chegar ao projeto mais econômico, de forma que uma ferramenta, que auxiliasse na otimização do projeto integral, seria de bastante utilidade. Lembram ainda que as decisões tomadas na fase da concepção estrutural são muito mais importantes em termos de execução e de custos, da estrutura, do que a otimização dos elementos isoladamente.

O trabalho descrito, no parágrafo anterior, requer que o usuário indique os alinhamentos onde poderiam ser inseridos os pilares e as vigas (figura 2-3), de forma que o programa não fique totalmente livre. Esse aspecto é necessário, devido ao sistema estrutural adotado ser em concreto armado, moldado no local, que geralmente permite uma arquitetura mais complexa.

RAFIQ et al. (2003) apresentam uma formulação para a otimização apenas do sistema estrutural. A partir de uma área necessária de edificação propõe várias alternativas estruturais: estrutura metálica, pré-moldada, em concreto protendido etc (figura 2-4). Essas alternativas são baseadas em um vasto banco de dados que contém informações sobre a capacidade resistente de cada sistema. Na realidade, seria uma ferramenta onde se define 
inicialmente a estrutura e então a arquitetura está determinada, já que a área e a quantidade dos pavimentos também são variáveis (figura 2-5).

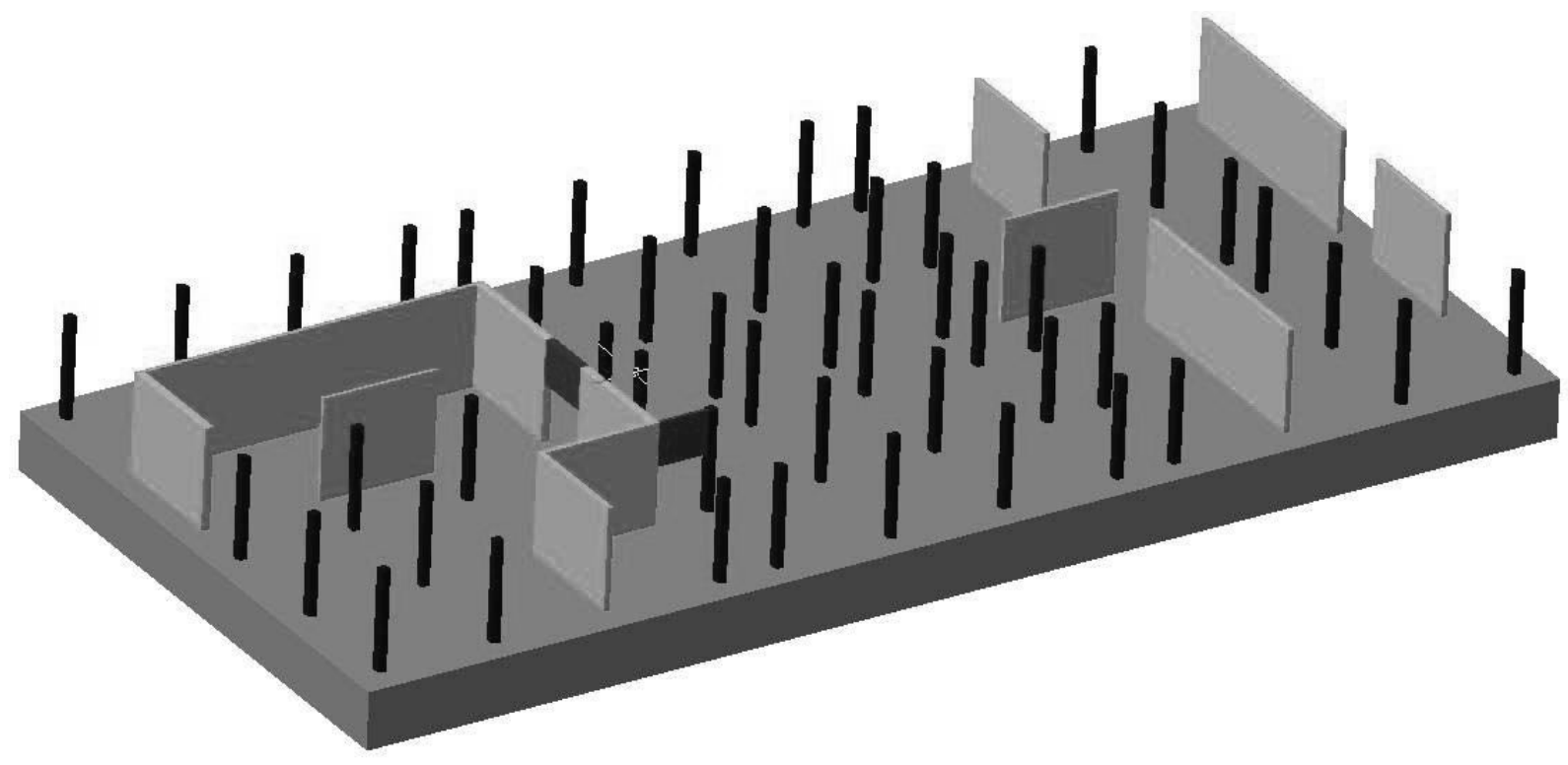

Figura 2-3 - Alternativas de posições para pilares e paredes Fonte - PULMMANN et al. (2003)

O trabalho descrito acima é de difícil aplicabilidade já que o procedimento natural seria desenvolver um projeto estrutural, a partir de um projeto arquitetônico definido. Fazer uma otimização da arquitetura é muito complexo, devido ao algoritmo precisar tomar decisões em cima de uma programação arquitetônica em função do tipo de edificação. O algoritmo precisaria idealizar todos os ambientes, bem como suas divisões internas, e circulações para poder definir as dimensões horizontais e verticais do pavimento.

Salienta-se também que fazer a escolha do sistema estrutural implica comparações entre indivíduos com características totalmente diferentes, de forma que a comparação fica superficial, e não considera todas as particularidades de cada sistema estrutural. 


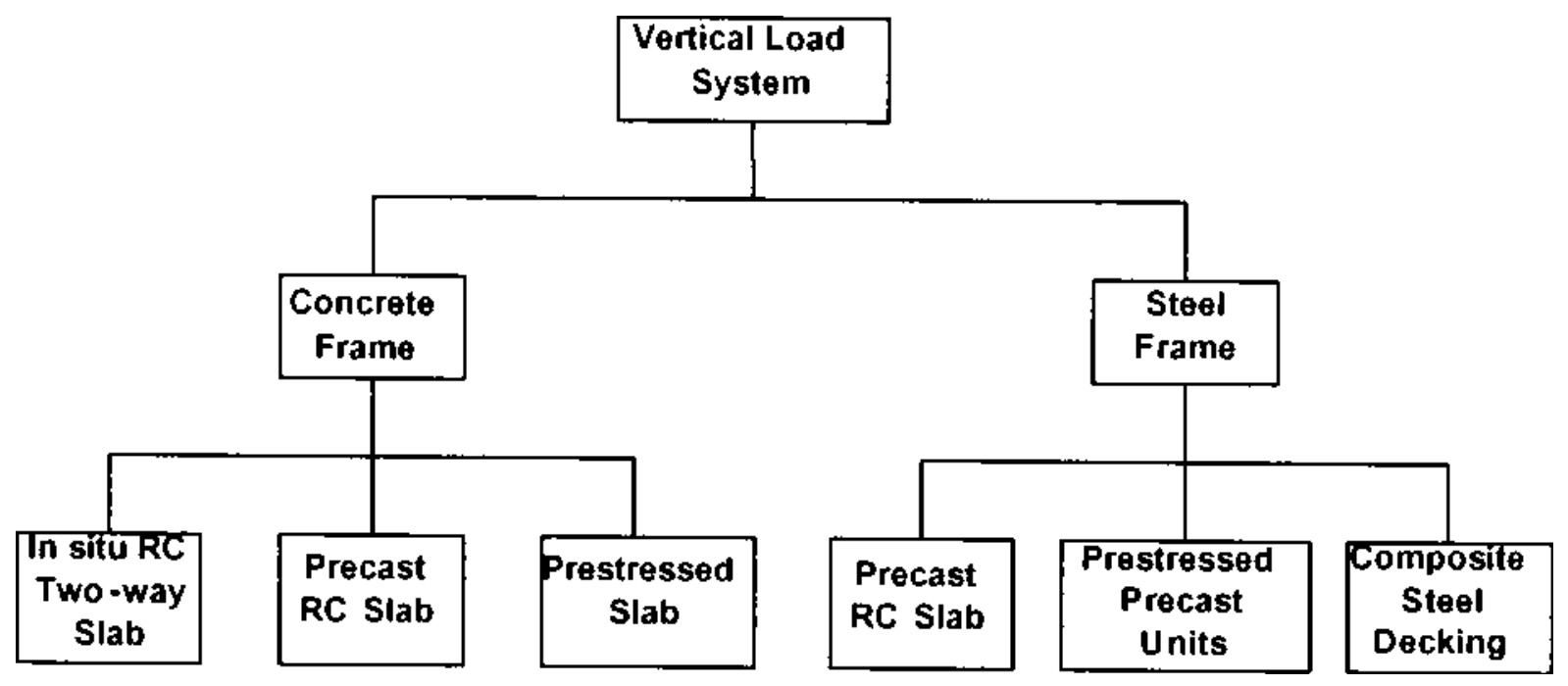

Figura 2-4 - Sistemas estruturais disponíveis

Fonte - RAFIQ et al. (2003)

GRIERSON et al. (2002) fazem uma otimização da concepção de projetos de edifícios comerciais e apresentam como resultados o sistema estrutural, o tipo de revestimento, tipo de esquadrias, tamanho e número de pavimentos. Esse trabalho tem a mesma filosofia do apresentado em RAFIQ et al. (2003), onde há também uma definição da arquitetura a partir da escolha do sistema estrutural (figura 2-6). Salienta-se que esse trabalho tem como objetivo minimizar o custo de construção e de manutenção e maximizar a taxa de retorno do investimento.

GRIERSON et al. (2002), assim como RAFIQ et al. (2003), fazem uma otimização integrada superficial por considerarem a otimização desde a concepção arquitetônica até a escolha do sistema estrutural. Acredita-se que uma maneira mais factível seria, diante de um projeto arquitetônico, utilizar algoritmos que fizessem a otimização a partir da configuração estrutural até o detalhamento dos elementos. Esse algoritmo poderia ser personalizado para cada sistema estrutural separadamente para considerar todos os aspectos pertencentes aos sistemas. Dessa forma o edifício seria otimizado, para cada sistema separadamente, e depois os melhores resultados poderiam ser comparados. 
(a)

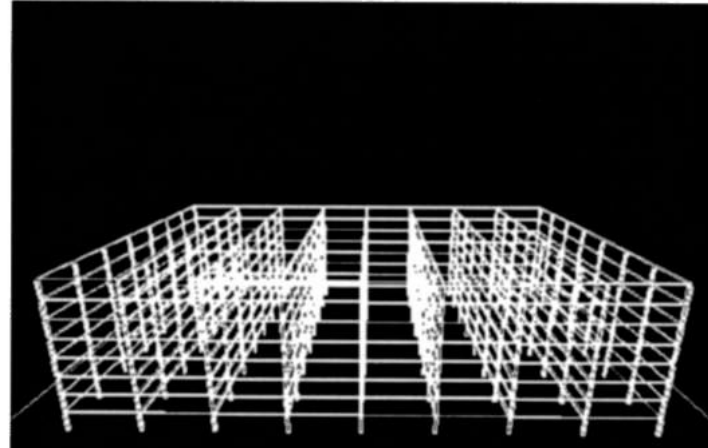

\begin{tabular}{|l|l|}
\hline 20 & (3D \\
\hline
\end{tabular}

in out

Rotate Orbit

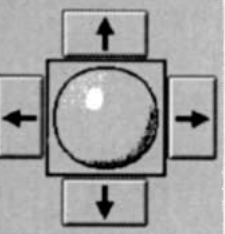

Render Nou

Show Hide

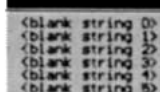

bin : :

(b)

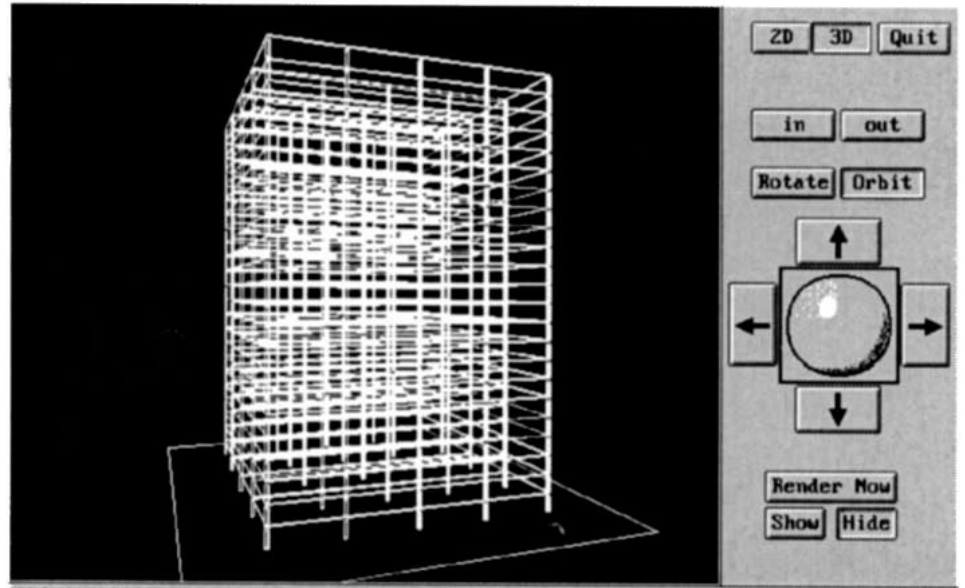

solen

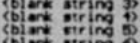

ciser :

(c)

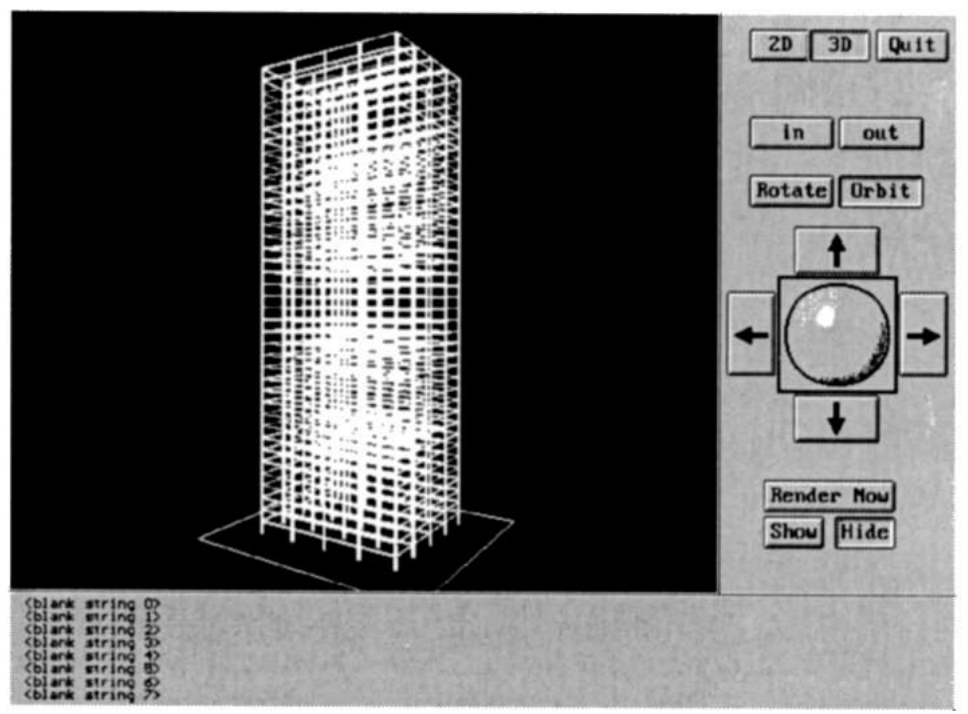

Figura 2-5 - Soluções apresentadas para um determinado problema Fonte - RAFIQ et al. (2003) 
Structure: Concrete Frame

Floor: Waffle Slab

Stories: 19

Footprint: $45 \mathrm{~m} \mathrm{x} 44 \mathrm{~m}$

Bay Area: $9 \mathrm{~m} \times 11 \mathrm{~m}$

Core: $17.68 \mathrm{~m} \times 22.40 \mathrm{~m}$

Floor Area: $30095 \mathrm{~m}^{2}$

Window Ratio: $25 \%$

Window: Standard glass

Cladding: Metal siding panel

Elevators: 11

Stairs: 2

HVAC:

$18707 \mathrm{MW} \mathrm{hr} / \mathrm{yr}$

Lights:

Fluorescent

(A)

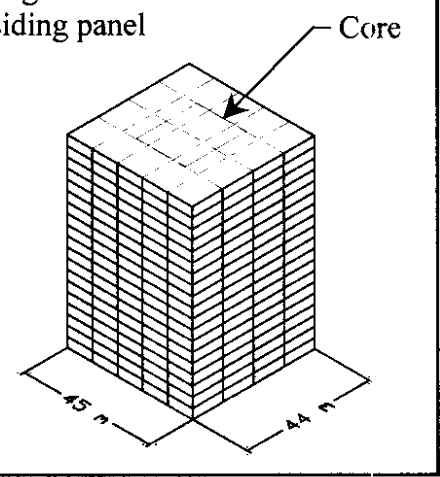

Structure: Steel Frame \& Bracing

Floor: Composite Beam with Deck \& Slab

Stories: 30

Footprint: $33 \mathrm{~m} \mathrm{x} 38 \mathrm{~m}$

Bay Area: $11 \mathrm{~m} \times 9.5 \mathrm{~m}$

Core: $12.96 \mathrm{~m} \mathrm{x} 19.35 \mathrm{~m}$

Floor Area: $30097 \mathrm{~m}^{2}$

Window Ratio: $50 \%$

Window: Insulated glass

Cladding: Pre-cast concrete

Elevators: 11

Stairs: 2

HVAC: $21243 \mathrm{MW}$ hr/yr

Lights:

Fluorescent

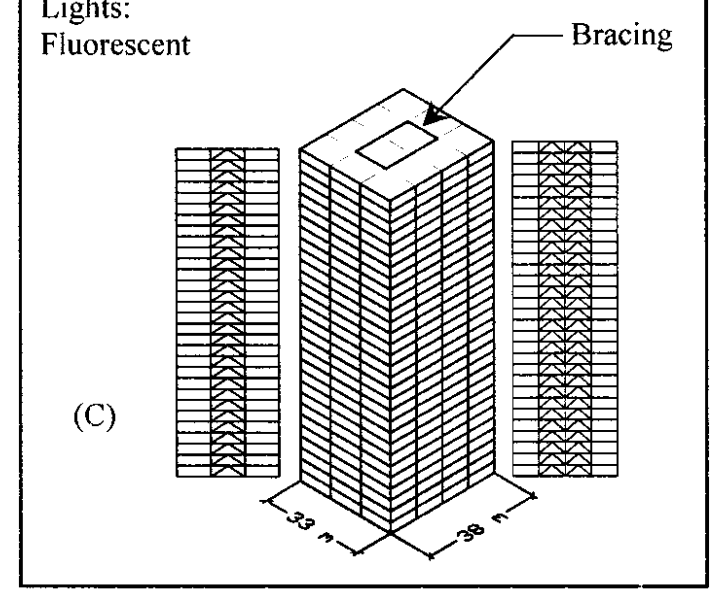

$$
\begin{aligned}
& \mathrm{CC}=\$ 40.4 \mathrm{M} \\
& \mathrm{OC}=\$ 8.1 \mathrm{M} \\
& \mathrm{IR}=\$ 15 \mathrm{M}
\end{aligned}
$$

(C)
Structure: Steel Frame

Floor: Composite Beam with Deck \& Slab

Stories: 23

Footprint: $36 \mathrm{~m} \mathrm{x} 46 \mathrm{~m}$

Bay Area: $12 \mathrm{~m} \mathrm{x} 11.5 \mathrm{~m}$

Core: $14.14 \mathrm{~m} \times 23.42 \mathrm{~m}$

Floor Area: $3047: \mathrm{m}^{2}$

Window Ratio: $50 \%$

Window: Insulated glass

Cladding: Metal siding panel

Elevators: 11

Stairs: 2

HVAC:

$22126 \mathrm{MW}$ hr/yr

Lights:

Fluorescent

(B)

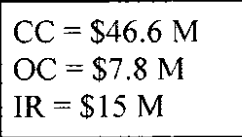

$\mathrm{IR}=\$ 15 \mathrm{M}$

(B)

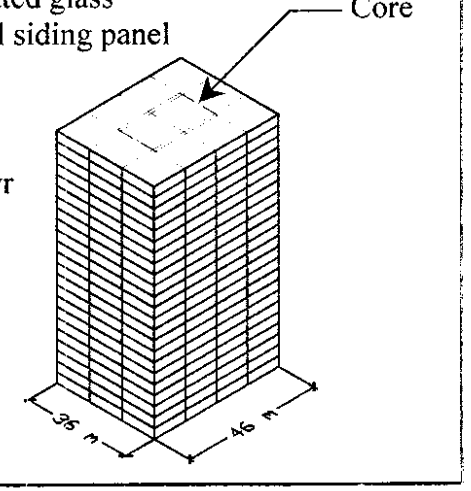

Structure: Concrete Frame \& Shear Wall

Floor: Flat Plate

Stories: 46

Footprint: $26 \mathrm{~m} \times 31.5 \mathrm{~m}$

Bay Area: $6.5 \mathrm{~m} \times 10.5 \mathrm{~m}$

Core: $13.24 \mathrm{~m} \mathrm{x} 12.3 .7 \mathrm{~m}$

Floor Area: $30139 \mathrm{~m}^{2}$

Window Ratio: $45 \%$

Window: Insulated glass

Cladding: Pre-cast concrete

Elevators: 11

Stairs: 2

HVAC:

$21721 \mathrm{MW} \mathrm{hr} / \mathrm{yr}$

Lights:

Fluorescent

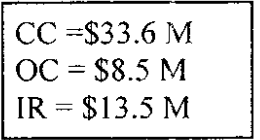

(D)

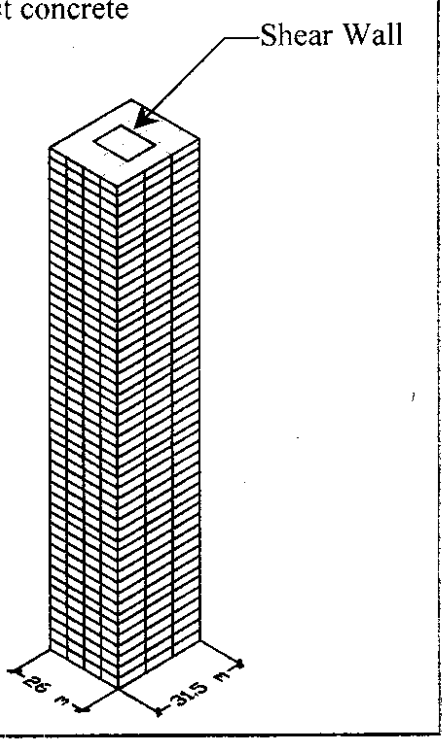

Figura 2-6 - Alternativas estruturais para um determinado problema

Fonte - GRIERSON et al. (2002) 
KICINGER \& ARCISZEWSKI (2004) apresentam uma otimização evolucionária integrada para estruturas metálicas de edifícios altos. Porém mantêm a posição dos pilares fixa, logo sobre a configuração estrutural a maior busca está nos elementos de contraventamento, já que a posição das vigas fica muito vinculada aos pilares.

\subsection{ANÁLISE DA REVISÃO BIBLIOGRÁFICA}

Percebe-se, pelos trabalhos pesquisados, a grande potencialidade dos algoritmos genéticos como ferramenta de otimização em engenharia estrutural e também como ferramenta para criação de sistemas inteligentes.

Observa-se, porém, a inexistência de trabalhos de pesquisa em otimização estrutural integrada especificamente para edifícios com estrutura de concreto pré-moldado, que sirvam de suporte ao projetista de estruturas no desenvolvimento específico do projeto estrutural, considerando todas as particularidades inerentes ao sistema estrutural tais como resistência, fabricação e montagem.

De acordo com o que foi exposto e comentado, o trabalho desenvolvido nesta tese busca, a partir de uma arquitetura definida, uma otimização integrada em estruturas pré-moldadas desde a configuração estrutural até o completo detalhamento dos elementos (vigas e lajes). A configuração estrutural, o detalhamento das vigas e das lajes, a fabricação, o transporte e a montagem são consideradas dentro de uma mesma rotina, já que são etapas muito dependentes.

A opção por pesquisar uma estrutura pré-moldada deve-se ao fato de se tratar de uma atividade efetivamente industrial, mais padronizada e produzida em série. O próprio projeto arquitetônico, quando já é concebido para uma estrutura pré-moldada, também apresenta uma forma mais repetitiva. Pretende-se, com a ajuda do fabricante, a consideração mais representativa possível e abrangente dos custos de produção, de transporte e de montagem. 


\section{SISTEMA ESTRUTURAL ADOTADO NO SATD}

\subsection{PRELIMINARES}

A preocupação com o sistema estrutural se justifica devido ao fato de representar a maior parte dos custos e do peso de um edifício com estrutura de concreto pré-moldado. Salienta-se que o item "custo da estrutura" compreende o custo do sistema estrutural em si e, também, os efeitos causados nas demais etapas da obra, como nas instalações e nos revestimentos. Por exemplo, de acordo com a altura da edificação, que é influenciada pelo tipo de sistema estrutural adotado, serão quantificados os gastos com os revestimentos externos e internos, com as divisórias e instalações.

Diante disso, observa-se que uma maior eficiência pode ser alcançada pelos edifícios de múltiplos pavimentos com estrutura de concreto pré-moldado, se melhorias forem incorporadas aos sistemas estruturais.

Serão apresentados a seguir os levantamentos realizados por PRIOR et al. (1993), nos Estados Unidos, e, por ALBUQUERQUE \& EL DEBS (2005), no Brasil, para identificarem os sistemas estruturais mais utilizados em concreto pré-moldado. Com base nesses levantamentos, foi escolhido o sistema estrutural a ser utilizado no SATD.

\subsection{LEVANTAMENTO ATLSS (PRIOR et al., 1993)}

\subsubsection{Introdução}

Com o objetivo de desenvolver um novo sistema estrutural de concreto pré-moldado, para edifícios de múltiplos pavimentos, e, também, de criar uma 
metodologia para comparar e avaliar os diferentes sistemas estruturais, de concreto pré-moldado, existentes, a Lehigh University através do projeto Advanced Technology for Large Structural Systems (ATLSS) realizou uma pesquisa, nos Estados Unidos, que foi apresentada por meio do relatório No. 93-07 (PRIOR et al., 1993).

Para a realização dessa pesquisa foi necessário um levantamento dos sistemas estruturais existentes e para isso foi estabelecida uma forte interação com a indústria de pré-moldados. Inicialmente, foram consultadas duas fontes: publicações e fabricantes de estruturas pré-moldadas. As publicações revelaram poucos detalhes dos sistemas, e as pesquisas com os fabricantes foram as mais ricas em informações. As seguintes informações foram solicitadas aos fabricantes:

$\checkmark$ Quando o sistema foi inicialmente desenvolvido;

$\checkmark$ Para qual tipo de edificação o sistema foi planejado;

$\checkmark$ Descrição dos componentes estruturais e detalhes das ligações;

$\checkmark$ Seqüência de construção;

$\checkmark$ Como os sistemas de serviço são incorporados.

Após o levantamento dos sistemas, partiu-se para o desenvolvimento de critérios que permitissem a avaliação dos sistemas, e nessa fase foi solicitada a cooperação dos projetistas de estrutura, dos fabricantes e dos projetistas de instalação.

Foram identificados 19 sistemas estruturais que são compatíveis com edifícios comerciais, que eram o foco principal da pesquisa, originais de vários países: Estados Unidos, Inglaterra, Canadá, Suécia, Japão, Itália e Austrália. Fez-se uma distinção entre sistemas estruturais utilizados e emergentes, ou seja, que estão em fase de desenvolvimento ou de registro de patente.

\subsubsection{Sistemas Estruturais Utilizados}

Serão apresentadas abaixo, sucintamente, as descrições de alguns dos sistemas estruturais existentes e catalogados. 


\section{a) Sistema convencional americano (U.S. Conventional System)}

O sistema convencional americano é composto por vigas " $\mathrm{T}$ " invertidas e vigas "L" na periferia, pilares de múltiplos pavimentos e lajes alveolares ou painéis " $\pi$ " (Figura 3-1). O sistema pode usar ou, não, concreto moldado no local, doravante denominado CML, apenas como capa das lajes. Em geral, as vigas são simplesmente apoiadas de forma que as ligações resistem cisalhamento, mas não momento fletor. Nos Estados Unidos, segundo o Professor Maher Tadros $^{3}$, em muitos casos não se utiliza mais a capa de concreto.
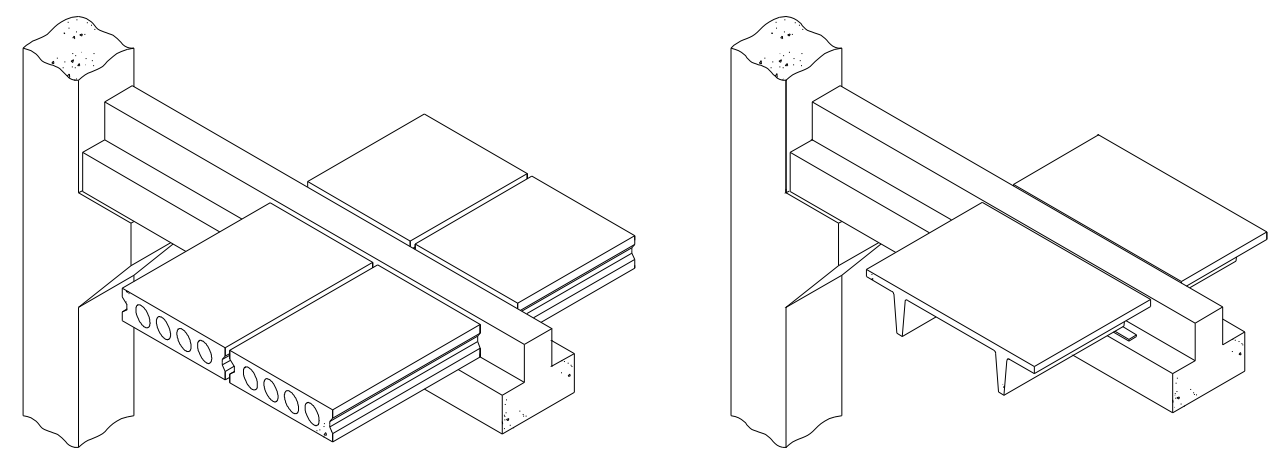

Figura 3-1 - Conventional System

Fonte - adaptação EL DEBS, M. K. (2000)

\section{b) Sistema da Associação dos fabricantes de pré-moldados de Ontário e}

\section{Associação do cimento Portland (Duotek System, llinois - USA)}

O Duotek system é um sistema modular que acomoda as instalações. É composto por vigas, lajes e pilares pré-moldados que são conectados utilizando CML. A altura do pavimento é constante de 1,22 $\mathrm{m}$, do topo do capa para o fundo de viga, e as vigas possuem aberturas a cada 1,52 m para acomodar as instalações (figura 3-2). Este sistema foi desenvolvido em 1960 e gera boa economia quando utilizado em situações que exigem grandes vãos.

\footnotetext{
${ }^{3}$ Conversa particular na Universidade do Nebraska (maio de 2006)
} 


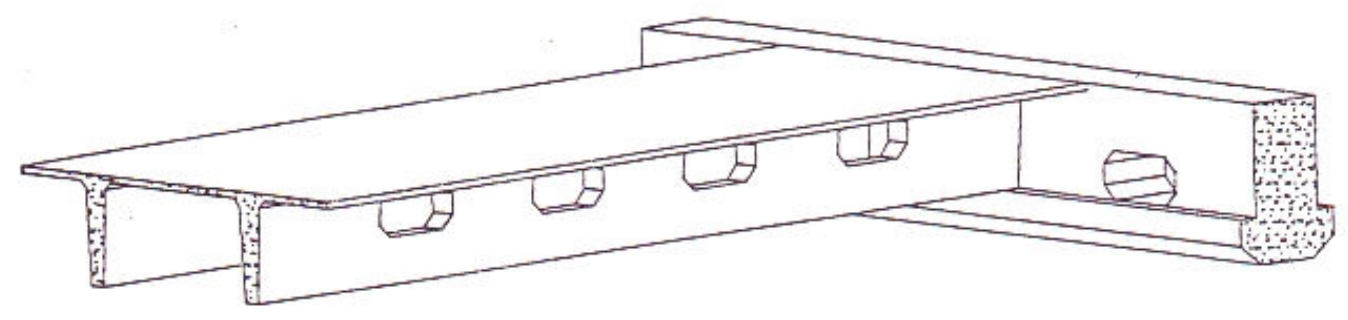

Figura 3-2 - Duotek System

Fonte - PRIOR et al. (1993)

\section{c) Sistema desenvolvido pelo fabricante Finfrock (Dycore System, Florida} - USA)

O Dycore system é composto por vigas chatas que utilizam escoramento, lajes do tipo Dycore de alta resistência e pilares de vários andares (figura 3-3). As vigas e lajes servem de pré-forma para o CML, e, juntos, formam seções compostas e ligações. Este sistema tem sido utilizado para: escolas, centros de saúde e garagens.

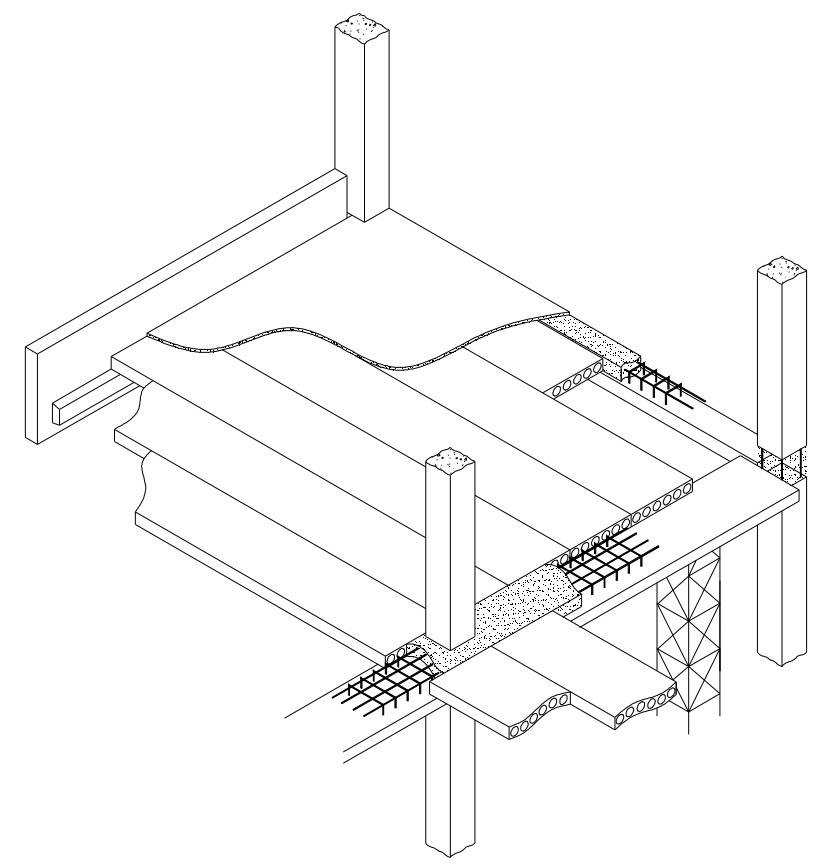

Figura 3-3 - Dycore

Fonte - adaptação EL DEBS, M. K. (2000) 


\section{d) Sistema desenvolvido pelo fabricante Flexicore (Dyna-frame System, Ohio - USA)}

As particularidades deste sistema são os encaixes entre vigas, entre pilares e entre vigas e pilares (figura 3-4). O sistema utiliza pilares simples (apenas um pé-direito), vigas retangulares com seção parcial e lajes alveolares. As seções são completadas posteriormente com a capa. Este sistema é tipicamente utilizado em edifícios residenciais, comerciais, escolas e garagens.

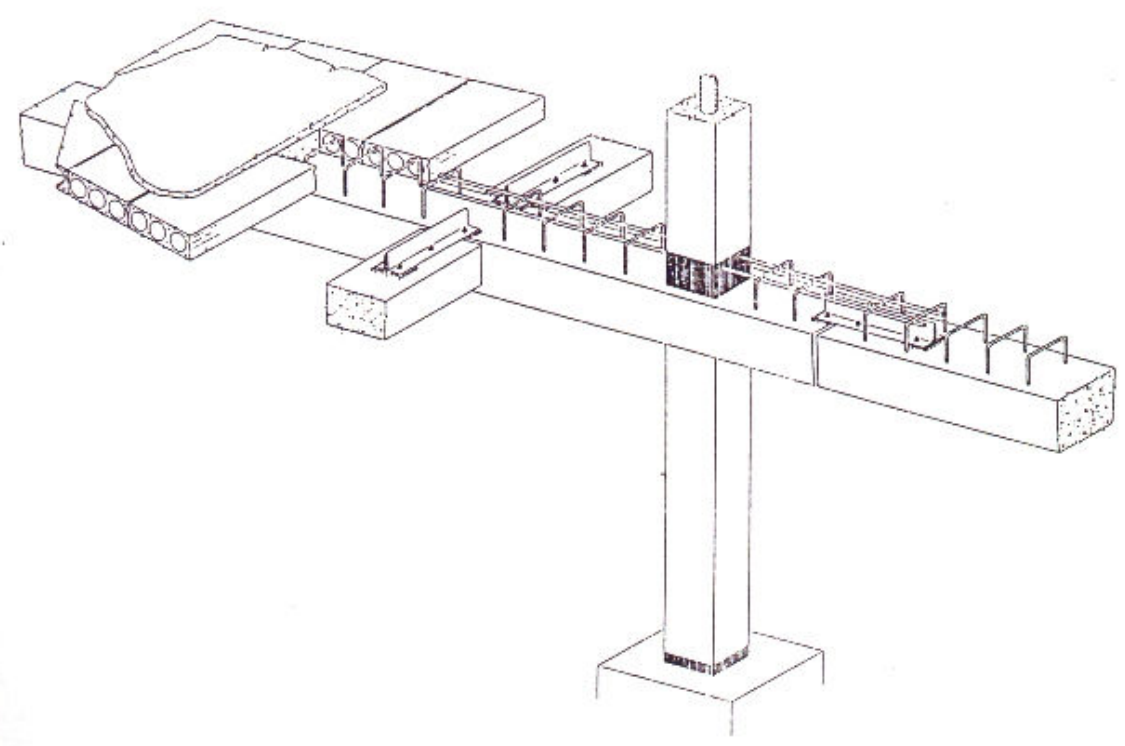

Figura 3-4 - Dyna-frame System

Fonte - PRIOR et al. (1993)

\section{e) Sistemas utilizando lajes treliçadas (Filigree Method of Construction)}

Esses sistemas utilizam pré-laje treliçada e são bastante difundidos nos Estados Unidos e Japão.

- PG Connection System (Obayashi Corporation Technical Research Institute - Tokyo/Japan): utiliza componentes de vigas (figura 3-5) em cruz sobre os pilares em CML e utiliza solda ou encaixe mecânico para ligação entre vigas. 


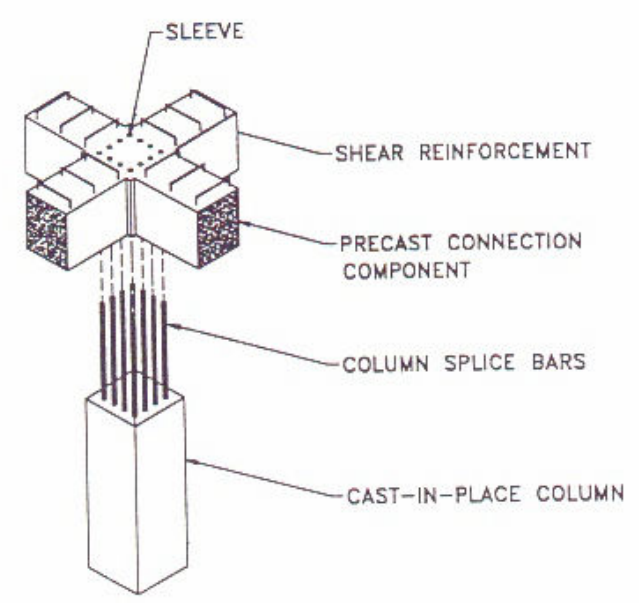

Figura 3-5 - PG Connection System

Fonte - PRIOR et al. (1993)

○ RPC-K System (Kabuki Construction - Toshima/Japan): as vigas prémoldadas são em formato de "U" (figura 3-6), e servem de forma para o CML, que é utilizado em todas as ligações do pavimento. Os pilares são em CML e este sistema permite um conjunto monolítico.

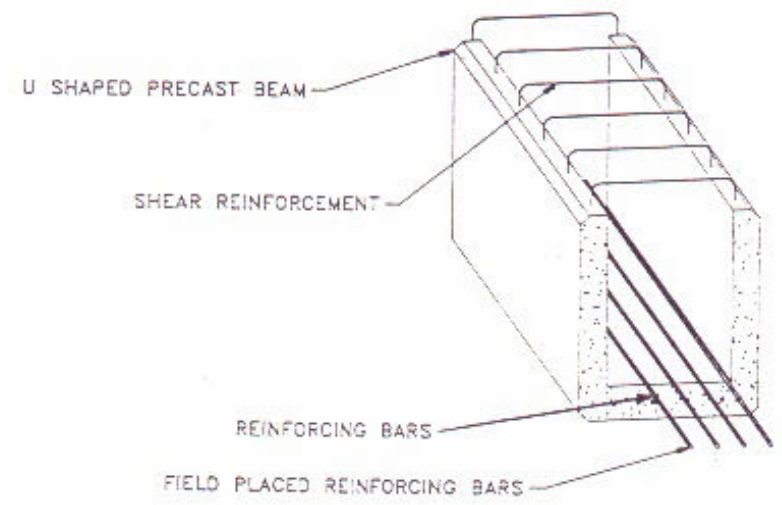

Figura 3-6 - RPC System

Fonte - PRIOR et al. (1993)

f) Sistema da Companhia estadual de prédios (IMS System, Baranya County - Hungary)

A filosofia, por trás do IMS system, é prover um sistema pré-moldado aberto que se ajuste a edifícios residenciais e comerciais, permitindo 
flexibilidade ao projeto. O IMS é composto de uma laje pré-moldada modular, quadrada ou retangular, protendida (figura 3-7). Os módulos de lajes transferem as cargas verticais diretamente aos pilares mediante o atrito gerado pela pós-tensão que é aplicada entre os módulos, passando pelos pilares. Eles são montados temporariamente em suportes metálicos, enquanto a pós-tensão não é concluída. Esse sistema foi bastante utilizado em Cuba, Hungria, e lugoslávia para construção de escolas, hospitais, edifícios comerciais e residenciais e hotéis.

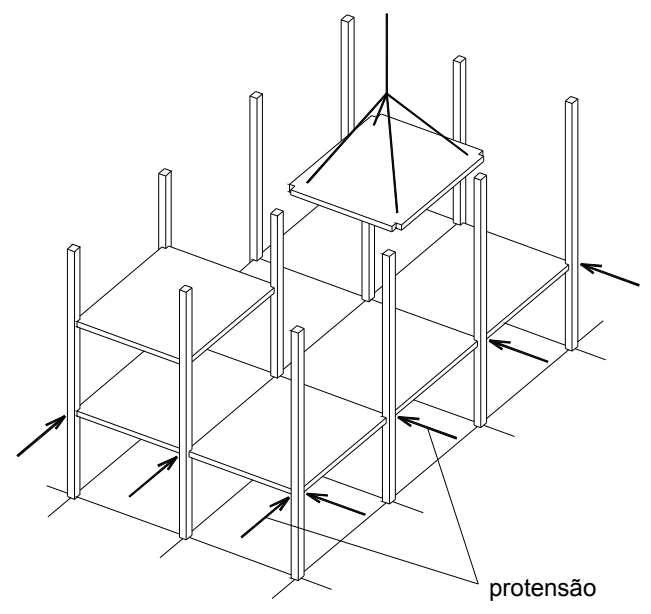

$\underline{\text { esquema de montagem }}$

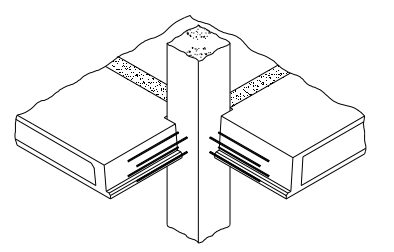

esquema de ligação junto ao pilar

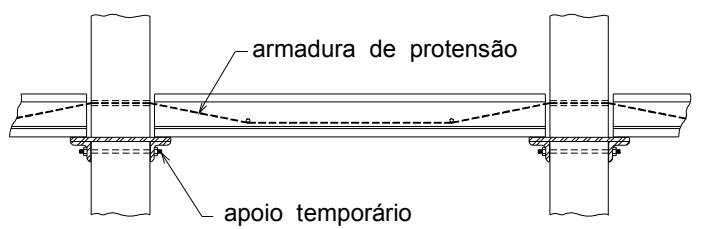

$\underline{\text { corte vertical }}$

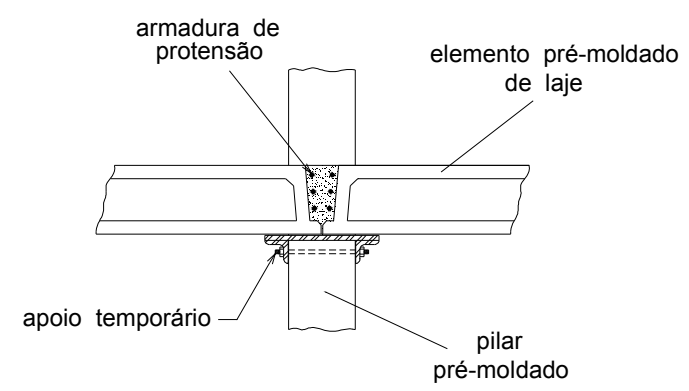

detalhe da ligação pilar-laje

Figura 3-7 - IMS system

Fonte - adaptação EL DEBS, M. K. (2000)

g) Sistema desenvolvido pelo fabricante Bison (PD2 Frame System, Buckinghamshire - Great Britain)

A filosofia desse sistema é utilizar um número bastante limitado de peças e permitir a passagem das instalações através das vigas primárias (figura 3-8). O sistema tem sido usado na Inglaterra em escolas, hospitais, shoppings e edifícios residenciais. É composto por vigas "T", invertidas, que 
são ligadas aos pilares por soldas entre chapas metálicas embutidas nos elementos.

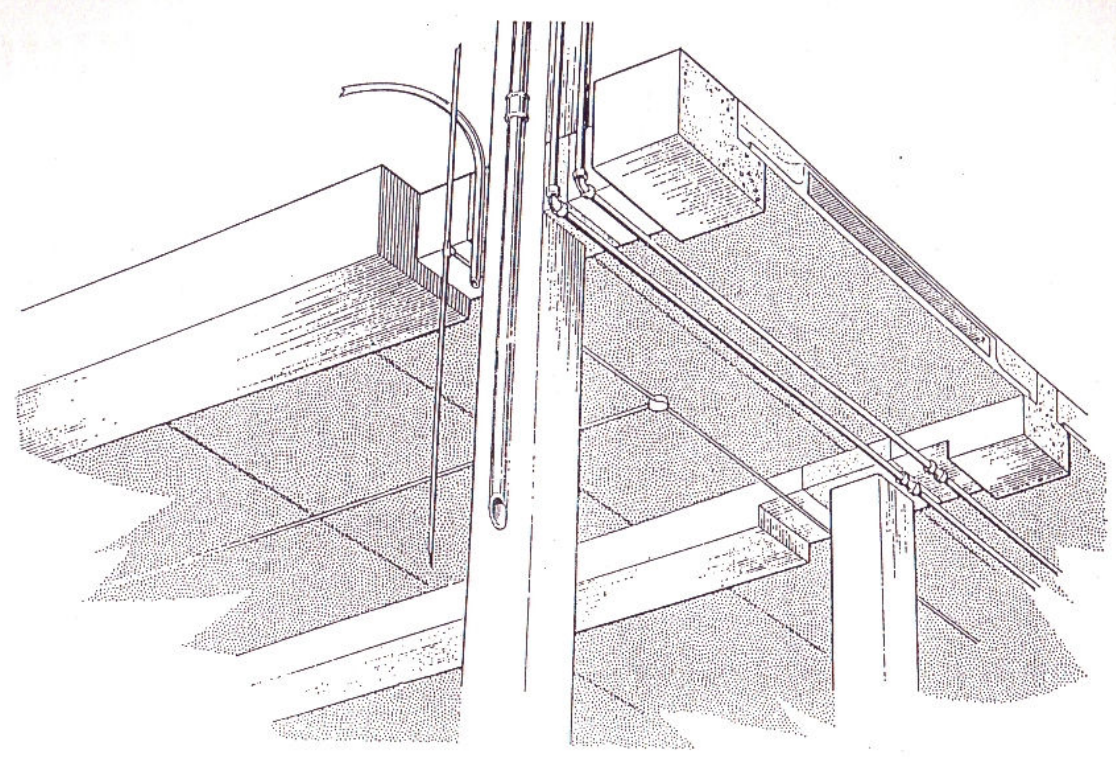

Figura 3-8 - PD2 Frame System

Fonte - PRIOR et al. (1993)

\section{h) Sistema desenvolvido pelo fabricante Prestressed (Prestressed Joist}

\section{System, Miami - USA)}

Este sistema incorpora viga pré-moldada, nervuras protendidas e CML para produzir um pavimento com seção composta (figura 3-9). Indica-se o sistema para alcançar grandes vãos com pouco peso, por isso é bastante utilizado em edifícios comerciais, hospitais, garagens e lojas de departamento.

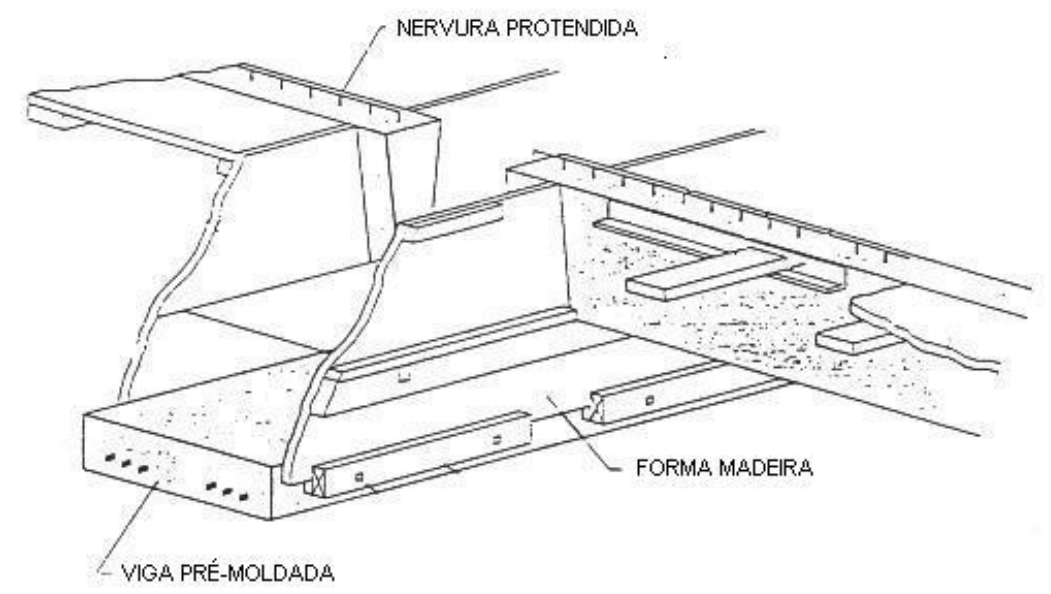

Figura 3-9 - Prestressed Joisty System

Fonte - PRIOR et al. (1993) 


\section{i) Sistema desenvolvido pela Quick Floor America (Quickfloor System,}

\section{Brooklin Park - USA)}

O sistema é composto de vigas chatas e lajes alveolares, estas vigas têm formato semelhante ao da laje alveolar e diferem pela ausência de concretagem da mesa superior (figura 3-10). Dessa forma, é possível se utilizar a pós-tensão para as vigas, já que a maior parte da seção da viga é executada com CML. Foi criado na Austrália e tem sido utilizado para garagens, shoppings e edifícios residenciais. Tem como vantagem a utilização dos mesmos equipamentos para a produção das lajes e vigas.

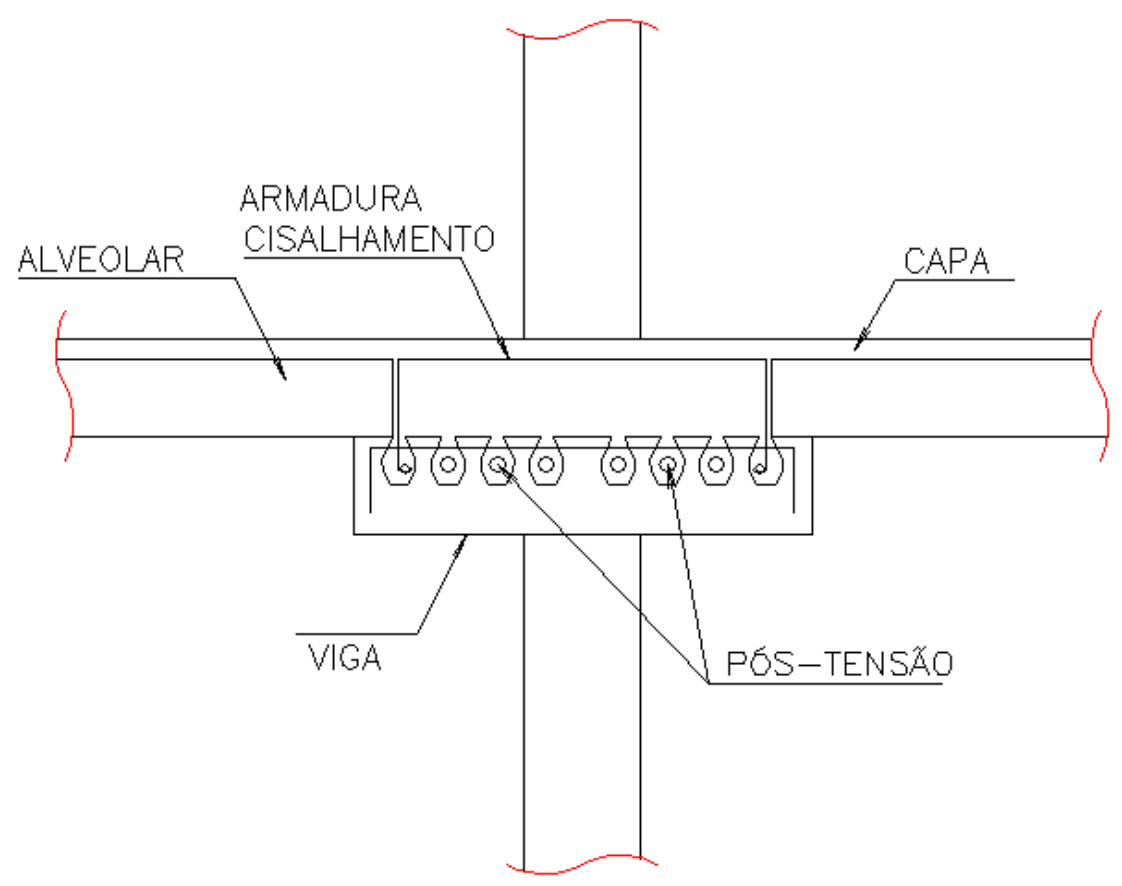

Figura 3-10 - Quickfloor System

Fonte - PRIOR et al. (1993)

i) Sistema desenvolvido pela Associação de cimento Portland (Triposite System, Illinois - USA)

Nesse sistema as unidades de laje são similares a painéis " $\pi$ " invertidos que são fechados com uma mesa de concreto (figura 3-11), o que possibilita sejam as instalações posicionadas dentro do pavimento. 


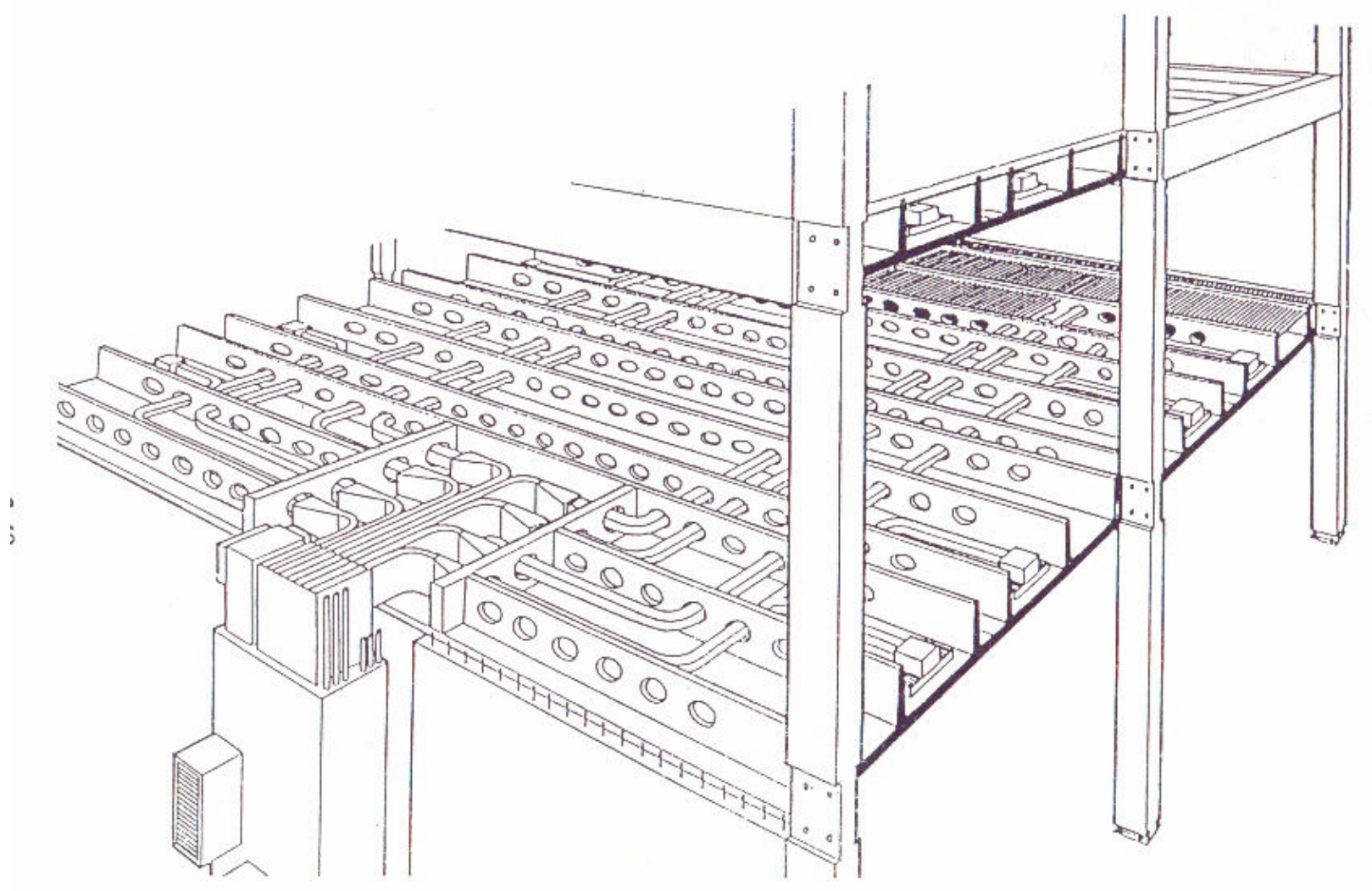

Figura 3-11 - Triposite System

Fonte - PRIOR et al. (1993)

\section{I) Sistema desenvolvido pelo fabricante Thomas Concrete (Thomas}

\section{System, Oklahoma - USA)}

O sistema é composto de vigas "U", que possuem bases para apoiar as lajes " $\pi$ " (figura 3-12). As vigas e as lajes servem de forma para o concreto moldado no local, formando seções compostas. Este sistema tem sido utilizado para edifícios comerciais. 


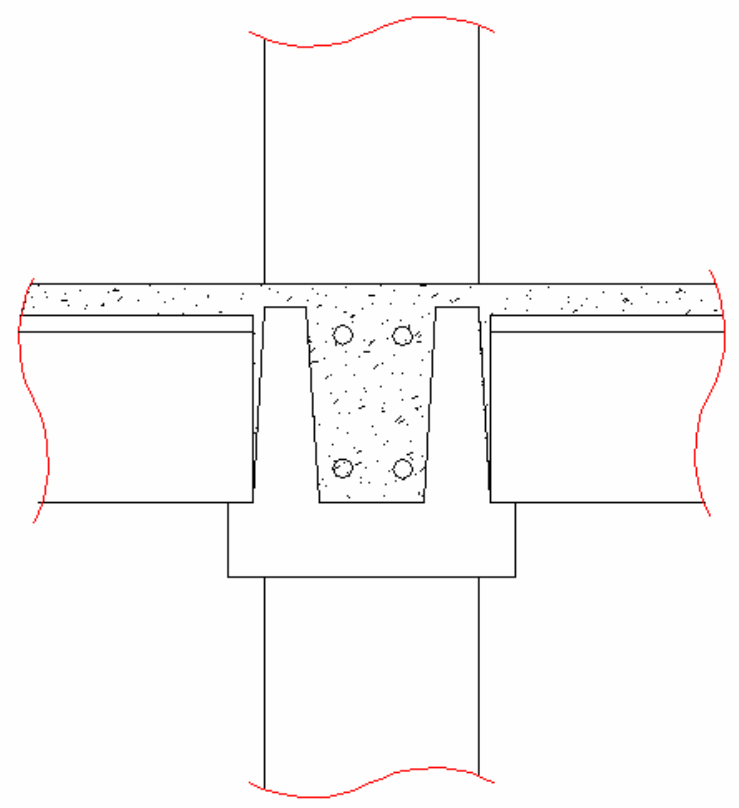

Figura 3-12 - Thomas System

Fonte - PRIOR et al. (1993)

\subsubsection{Sistemas Estruturais Emergentes}

Serão apresentados abaixo alguns dos sistemas emergentes catalogados.

a) Sistema desenvolvido pelo fabricante Contiframe Structures (Contiframe System, Warwickshire - Great Britain)

O conceito do sistema é eliminar ligações em zonas de altas solicitaçes, para torná-las mais fáceis (figuras 3-13). O sistema é analisado como uma estrutura de CML, ou seja, monolítica. Apresentam-se na figura 3-14 os detalhes das ligações. 


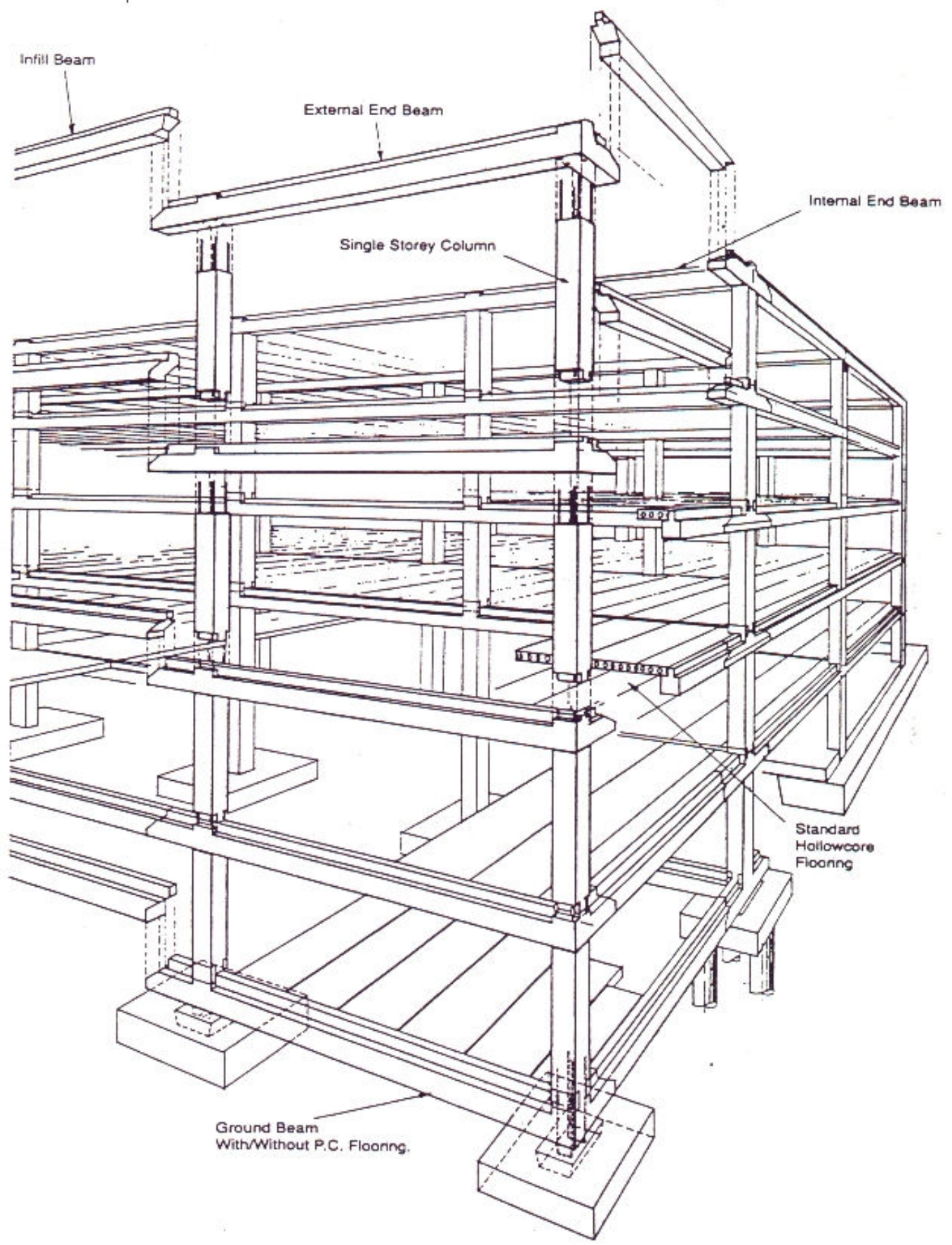

Figura 3-13 - Contiframe System

Fonte - PRIOR et al. (1993) 


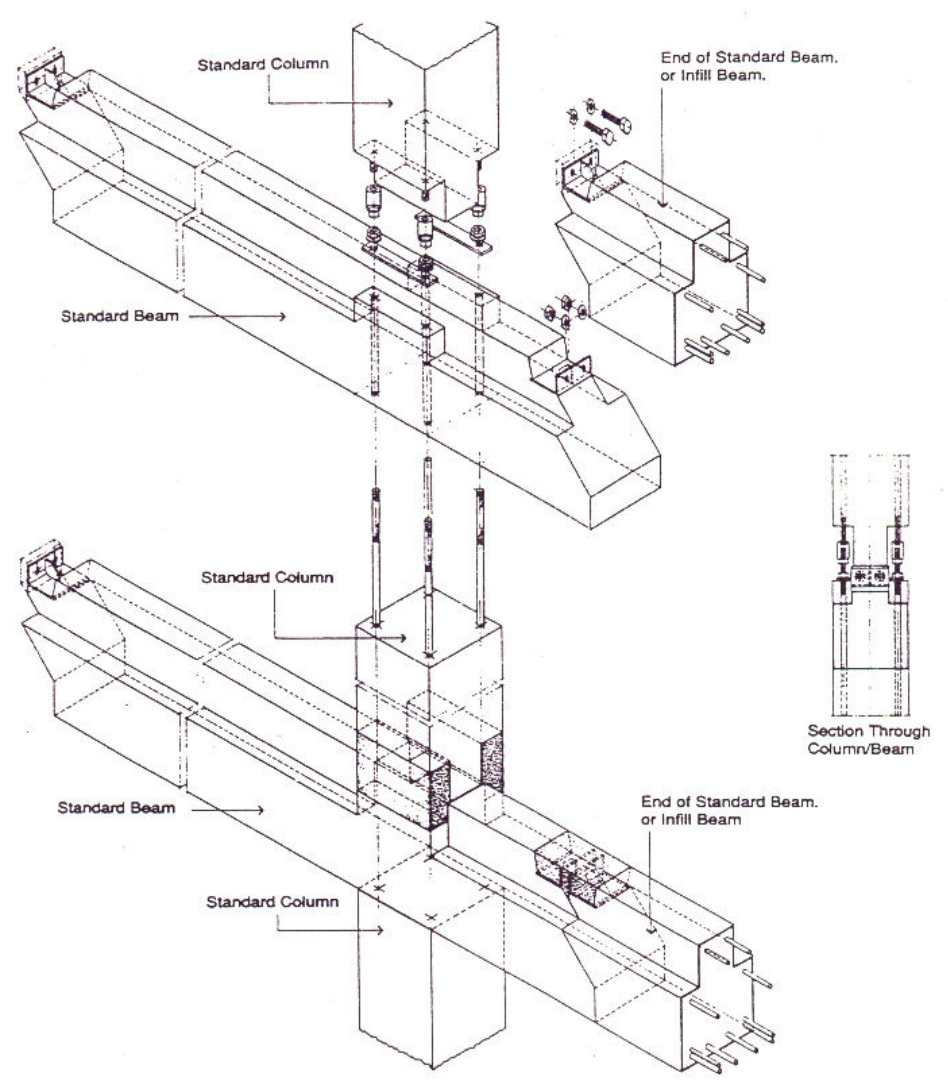

Figura 3-14 - Contiframe System

Fonte - PRIOR et al. (1993)

b) Sistema desenvolvido por Dow Mac Projects (Spanlight System, Stamford - Great Britain)

O sistema está em desenvolvimento na Polytechnic of Central London, e consiste em pilares pré-moldados, viga suporte protendida com pré-tração e lajes alveolares (figura 3-15). A viga suporte, com o mesmo formato de uma laje " $\pi$ " invertida, serve de forma para o concreto moldado no local, e, após a concretagem, é protendida, aumentando sua capacidade portante e promovendo a continuidade do pórtico. Têm-se como características do sistema: relação vão / altura do pavimento entre 18 e 20, eliminação de escoramento e uso da pós-tensão. 


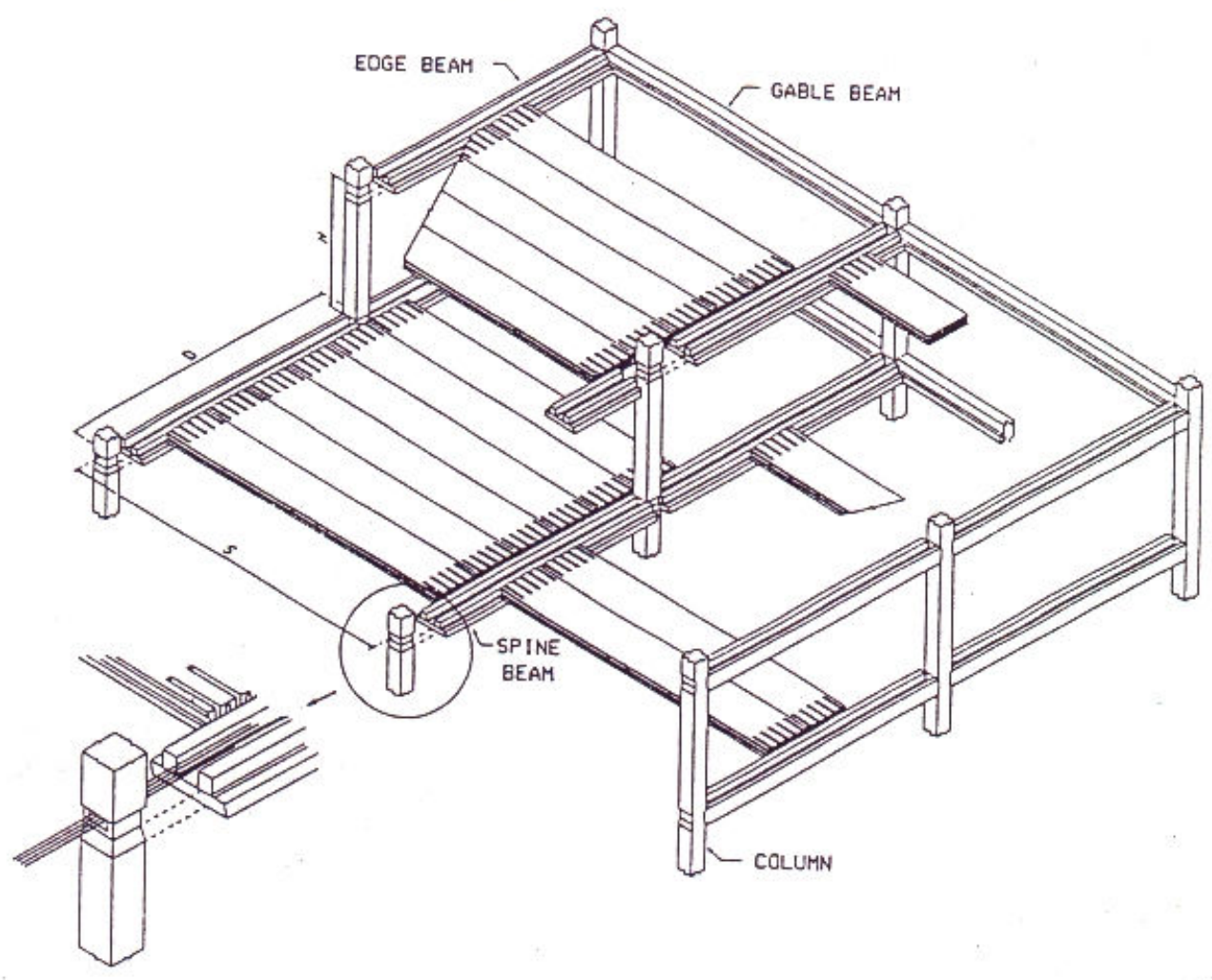

Figura 3-15 - Spanlight System

Fonte - PRIOR et al. (1993)

\section{c) Sistema da Universidade do Nebraska (University of Nebraska System,}

\section{Omaha - USA)}

Trata-se de um sistema unidirecional com vigas de seção parcial. A viga de seção " $\Pi$ " invertido de pequena altura é protendida, de maneira que combinada com o CML, forma a seção final (figura 3-16). O sistema elimina a necessidade de escoramento, e requer pequena quantidade de formas. Foi desenvolvido em 1991 no centro de pesquisa de infra-estrutura na Universidade do Nebraska. Para sua execução, é necessário que se executem todas as ligações da viga e que a ligação seja concretada antes da montagem das lajes. Essa particularidade é apontada como empecilho, por muitos fabricantes, para a produtividade da montagem do sistema. 

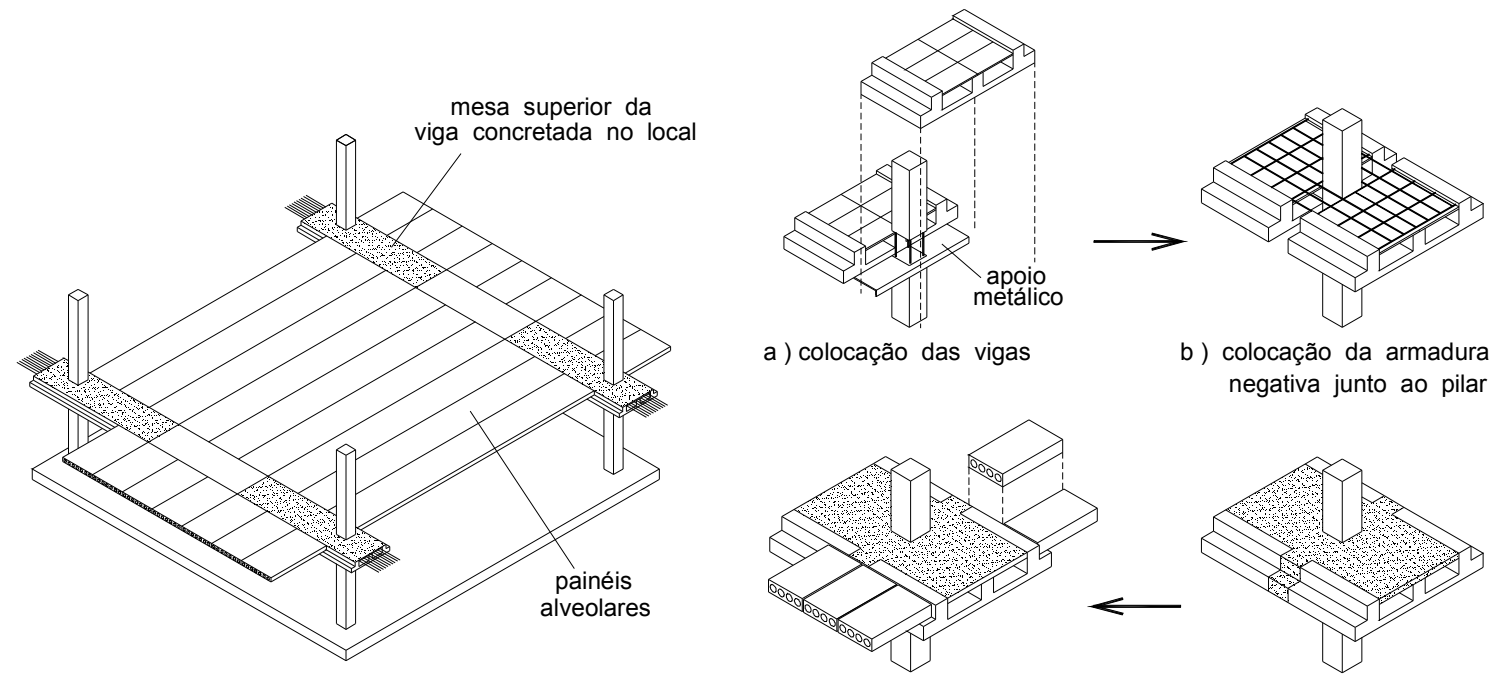

a ) colocação das vigas

b ) colocação da armadura negativa junto ao pilar

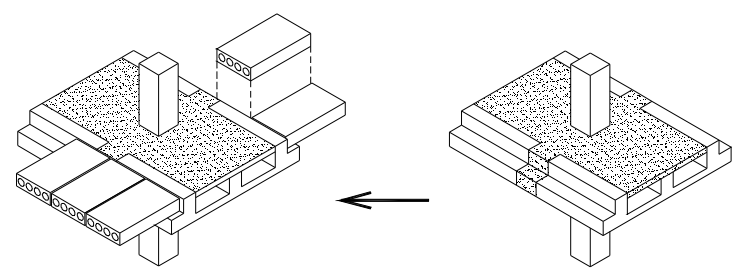

d) colocação dos painéis alveolares

c) concretagem da mesa superior junto ao pilar

Figura 3-16 - University of Nebraska system

Fonte - adaptação EL DEBS, M. K. (2000)

\subsubsection{Conclusões do Relatório ATLSS}

Segundo o relatório, as conclusões obtidas com a pesquisa foram:

a. Com relação à estrutura, observa-se que são decisivos os fatores de fabricação e montagem. Quanto à fabricação, os entrevistados comentam que os projetos, com grande número de formas diferentes, apresentam custos mais elevados. Citam, ainda, os entrevistados, que sistemas com grandes elementos proporcionam facilidade de fabricação, porém dificultam o transporte. Sobre as atividades realizadas no local, comentam que são mais eficientes os sistemas que não requerem escoramento, e, requerem menos mão-de-obra com formas e CML;

b. Relativo aos sistemas de serviços, a avaliação conclui que o mais eficiente seria a acomodação das instalações por baixo do pavimento, independentemente. Os exemplos, com as instalações acomodadas dentro da estrutura, necessitam de uma maior coordenação das atividades e dos projetos, e dificultam a 
manutenção, além de, algumas vezes, prejudicarem a velocidade de construção do sistema;

c. Nos projetos arquitetônicos, conclui-se que cada sistema estrutural tem particularidades que influem na altura do pavimento, no tamanho dos vãos e na maneira como acomoda as regiões de escada e elevadores dentro do pavimento. Respeitando essas características, a estrutura modulada seria a mais eficiente para a fabricação, para o transporte e para a montagem. O projeto arquitetônico deve ainda contemplar a racionalização do processo na sua concepção, e um exemplo seria a utilização dos prémoldados de fachada acoplados na estrutura.

Para concluir, o relatório indica oportunidades para melhorias dos sistemas existentes e para o desenvolvimento de novos:

a. Reduzir o número de peças, para que tenham produção em larga escala, ou seja, incentivar a modulação para que se aproveitem ao máximo as vantagens da pré-fabricação;

b. Analisar as dimensões das peças, em função dos equipamentos disponíveis de transporte e montagem;

c. Reduzir a quantidade de serviços na obra, e facilitar as ligações para garantir a velocidade da obra;

d. Aumentar a resistência dos elementos e da sua rigidez para melhorar o desempenho da estrutura em relação às solicitações e deformações;

e. Permitir uma fácil acomodação dos serviços na estrutura, de forma que não dificulte a continuação da montagem e permita uma adequada manutenção; 
f. Para os projetos arquitetônicos recomenda-se uma maior utilização da modulação para que se aproveitem, ao máximo, as vantagens do sistema pré-moldado.

Conforme comentado no capítulo 1 , o candidato desenvolveu, na University of Nebraska, um novo sistema estrutural que busca contemplar todas essas oportunidades indicadas para melhorias nos sistemas estruturais, além de eliminar alguns inconvenientes detectados no University of Nebraska System (figura 3-16). Esse sistema chama-se Midwest Office System e é apresentado, por completo, no Anexo 1.

\subsection{LEVANTAMENTO DOS SISTEMAS ESTRUTURAIS PRÉ-MOLDADOS UTILIZADOS NO BRASIL}

Com intuito de se colherem informações sobre a utilização dos prémoldados em edifícios de múltiplos pavimentos no Brasil desenvolveu-se uma pesquisa, com metodologia similar à aplicada no Estados Unidos (PRIOR et al., 1993). Foram distribuídos questionários (apêndice A) para projetistas de estruturas, fabricantes e arquitetos, a fim de se enumerarem os sistemas estruturais disponíveis e as características técnicas e econômicas de cada um deles.

Esses questionários foram divulgados pela comunidade $\mathrm{TQS}^{4}$ e pela Associação Brasileira da Construção Industrializada de Concreto $(A B C I C)$. Os questionários foram também enviados por correio eletrônico para muitos arquitetos, fabricantes e projetistas de estruturas. Vale salientar que muitos contatos telefônicos também foram estabelecidos com os profissionais que receberam os questionários.

Juntamente com os questionários, 11 projetistas de estruturas e fabricantes enviaram vários projetos estruturais que foram organizados em um banco de dados com 30 obras e, além desse banco de dados, foram tabulados dados extraídos do banco de obras da $A B C I C$, disponível no site da $A B C I C^{5}$.

\footnotetext{
${ }^{4}$ Fórum eletrônico sobre engenharia estrutural

${ }^{5}$ www.abcic.com.br (outubro de 2004)
} 
A partir dos resultados desta pesquisa, apresenta-se uma avaliação das soluções estruturais, para edifícios pré-moldados de múltiplos pavimentos, que têm sido adotadas no Brasil. Serão apresentadas, em separado, considerações feitas pelos fabricantes e projetistas de estrutura. Infelizmente não se obteve nenhum questionário respondido por arquitetos. Em seguida, serão apresentados alguns dados extraídos do banco de obras da $\mathrm{ABCIC}$ e do banco de obras, montado a partir dos questionários recebidos.

\subsubsection{Fabricantes}

Considerações feitas por vários fabricantes de estruturas pré-moldadas de todas as regiões do país.

a) $70 \%$, em média, das obras pré-moldadas executadas não foram originalmente concebidas para a utilização do sistema, mas, sim, adaptadas de uma concepção arquitetônica apropriada para uma estrutura em concreto moldado no local;

b) Os maiores empecilhos para o desenvolvimento e / ou a expansão do setor no ramo dos edifícios de múltiplos pavimentos são:

i. Pouco conhecimento do sistema, das suas possibilidades e dos seus benefícios, por parte dos integrantes da cadeia produtiva da construção civil, principalmente dos arquitetos ${ }^{6}$;

ii. Estrutura inadequada de financiamento das construções residenciais, já que a rentabilidade da operação de financiamento do imóvel é mais atraente para o incorporador do que a redução de prazos, proporcionada pela pré-fabricação;

iii. Dificuldade de planejamento das obras pré-moldadas, que exigem um desembolso mais rápido no custo da estrutura;

\footnotetext{
${ }^{6}$ Com o aquecimento da economia registrado no final de 2007 e o conseqüente aumento na quantidade de obras, percebe-se uma maior difusão do sistema, fato que não ocorria à época em que foi realizado o levantamento.
} 
iv. Os projetos não terem sido concebidos visando à utilização dos pré-moldados, desde o projeto arquitetônico até os projetos complementares como modulação de alvenarias ou divisórias e de instalação;

v. Baixo custo da mão-de-obra para estruturas moldadas no local;

vi. Inércia do mercado que não quer sair de soluções convencionais.

c) A tendência dos pré-moldados para os edifícios de múltiplos pavimentos é:

i. Utilização conjunta de componentes pré-moldados, e moldados no local, caracterizando assim uma solução mista que atenda a uma grande quantidade de obras. Pode-se optar por uma maior ou menor pré-fabricação, dependendo das características da obra, tais como condições do canteiro, prazo e disponibilidade de recursos;

ii. Admite-se uma maior pré-fabricação, ou mesmo completa, para edifícios baixos e, para edifícios altos, uma menor pré-fabricação;

iii. Utilização de elementos pré-moldados no canteiro;

iv. Utilização em edifícios comerciais, principalmente edifícios de até seis pavimentos;

v. Crescimento da utilização de elementos pré-moldados de fachadas.

d) Um projeto arquitetônico, para que o sistema pré-moldado atinja sua maior eficiência, deve procurar:

i. Por meio da modulação, proporcionar um bom índice de repetição das peças, reduzindo o custo de fabricação;

ii. Explorar, ao máximo, a capacidade das peças, devido à facilidade de utilização da protensão nas pistas;

iii. Já posicionar os pilares no projeto, não tentar esconder os pilares nas alvenarias. Os pilares pré-moldados são geralmente mais 
robustos que os moldados no local, devido às verificações das situações transitórias;

iv. Considerar que as distâncias entre os pisos são maiores, uma vez que, muitas vezes, as lajes são apoiadas sobre as vigas aumentando a altura total do pavimento;

v. Ampliar o conceito da construção industrializada para outros elementos além da estrutura, tais como fachadas, divisórias, equipamentos de instalação etc. Para que os ganhos com a velocidade de execução sejam obtidos em todas as etapas;

vi. Ter formato ortogonal, e concentrar instalações e passagens para diminuir a quantidade de shafts.

e) Para melhorar a relação entre projeto, indústria e obra deve-se:

i. Aumentar o conhecimento dos projetistas sobre o sistema e aumentar a divulgação dos resultados do sistema entre projetistas e construtores;

ii. Tornar a indústria flexível para acompanhar as mudanças do mercado;

iii. Melhorar a coordenação dos projetos.

f) A compatibilização dos projetos, na maioria das vezes, é feita por profissional contratado pelo cliente ou pelo próprio arquiteto;

g) A maioria dos fabricantes utiliza algum software para otimizar a alocação dos equipamentos e funcionários, do transporte e da montagem das peças;

h) A maioria dos fabricantes acredita que todos os tipos de edifícios (comerciais, shoppings, escolas, hospitais, hotéis e residenciais) se adaptam ao sistema pré-moldado, mas alguns ressaltam que os residenciais não são tão comuns, e os supermercados, as faculdades e shoppings têm maior facilidade. 


\subsubsection{Projetistas de Estruturas}

Considerações feitas por vários projetistas de estruturas pré-moldadas de todas as regiões do país.

a) A tendência dos pré-moldados para os edifícios de múltiplos pavimentos é:

i. Se tornar mais atrativo pelo fato de proporcionar uma obra com mais durabilidade, aspecto bastante valorizado atualmente;

ii. Maior utilização de fachadas pré-moldadas de concreto;

iii. Ser bastante competitiva nas obras que tiverem recursos financeiros e precisarem diminuir prazos de execução, tais como shoppings, estacionamentos, hotéis, hospitais e escolas. As obras residenciais, que são na sua maioria auto financiadas não terão grande avanço.

b) Sobre a capa de concreto, praticamente todos os que responderam, utilizavam uma capa de $5 \mathrm{~cm}$ para formar a seção composta e garantir o efeito do diafragma, além de muitas vezes facilitarem as execuções das ligações entre os elementos;

c) Sobre a seqüência de desenvolvimento do projeto estrutural para estruturas pré-moldadas:

i. Inicialmente, coletam-se informações do fornecedor, pois é importante conhecer as possibilidades e restrições do fabricante. A interação do projetista, fabricante e montador é fundamental para o processo;

ii. Definição do sistema estrutural e das vinculações que serão utilizadas (continuidades e ligações posteriores);

iii. Segue seqüência de um projeto estrutural convencional com a diferença que os elementos são verificados em várias etapas: transporte, montagem e estrutura pronta. Deve-se lembrar que o 
projeto, além do detalhamento, deve fornecer as diretrizes de montagem.

d) Sobre a acomodação das instalações, têm-se muitas opções de instalações embutidas: nichos ou eletrodutos já concretados nas vigas, furos nas vigas para dutos de ar, dutos pluviais verticais em pilares, eletrodutos montados na laje, antes da execução da capa, com caixas de passagem e pontos-de-luz aplicados na pré-laje na usina ou no recorte na obra e nos recortes, via úmida, nas lajes alveolares. Mas a maioria dos projetistas considera que a tendência são as instalações horizontais independentes, pelo forro, para não atrasar a obra, e proporcionar uma maior agilidade ao sistema;

e) As restrições impostas pelos projetos arquitetônicos são muitas devido ao fato de não serem, conforme atestado pelos fabricantes, em sua maioria, projetados para o sistema pré-moldado;

f) O projeto estrutural, para ser mais racional, deve procurar sempre a padronização das seções dos elementos, e este aspecto é sempre cobrado por parte dos fabricantes. Não se pode pensar apenas em consumo. Deve-se pensar como em uma linha de montagem, logo tem de haver repetição. Deve-se partir da premissa de que a racionalização dos custos é a diretriz de projeto;

g) Sobre as condições ideais para o desenvolvimento de um projeto racional:

i. O proprietário da obra deve estabelecer as prioridades de projeto, e nomear um coordenador que tenha bastante conhecimento sobre pré-moldagem;

ii. Mais tempo e melhor remuneração dos projetos, já que demanda mais tempo de trabalho. Assim como na indústria, deve-se gastar mais tempo planejando e, menos, executando. O tempo, que se aumenta na fase de projeto, recupera-se na de construção. 


\subsubsection{Conclusões do levantamento no Brasil e do banco de obras $A B C I C$}

A partir do cadastro de várias obras pré-moldadas, enviadas gentilmente por fabricantes e projetistas, e do banco de obras da ABCIC, algumas informações serão apresentadas, sobre a utilização dos pré-moldados no Brasil. Essas obras são compostas de vários tipos de edificações de múltiplos pavimentos, tais como shoppings, edifícios comerciais, edifícios residenciais, escolas, faculdades, igrejas, estacionamentos etc.

\section{a) Resistência à compressão característica do concreto}

Sobre a resistência à compressão característica do concreto, a do prémoldado varia de 30 a $50 \mathrm{MPa}$ (figura 3-17) e a do moldado no local, de 20 a $30 \mathrm{MPa}$ (figura 3-18).

\section{b) Pórticos}

Todas as obras cadastradas foram concebidas com pórticos unidirecionais, onde as vigas eram dispostas numa direção e as lajes dispostas perpendicularmente, apoiadas nas vigas. A partir do banco de dados, obtevese que $54,5 \%$ dos pórticos foram orientados na mesma direção do lado de maior dimensão do pavimento (figura 3-19) e 45,5\% na direção do lado de menor dimensão do pavimento (figura 3-20).
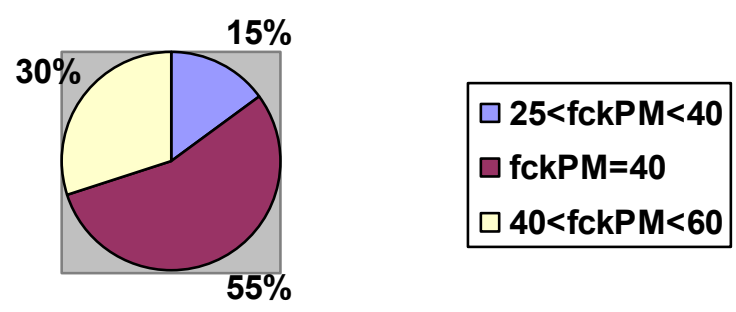

Figura 3-17 - Distribuição das resistências à compressão do concreto pré-moldado (MPa) 


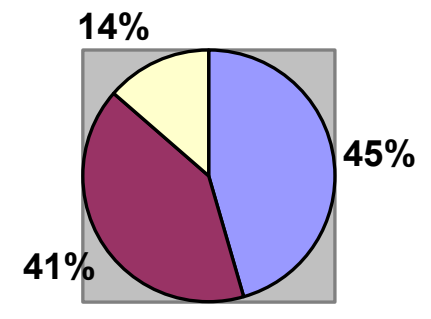

$\square$ fckCML $=25$

$\square \mathrm{fckCML}=30$

$\square$ fckCML=35

Figura 3-18 - Distribuição das resistências à compressão do concreto moldado no local (MPa)

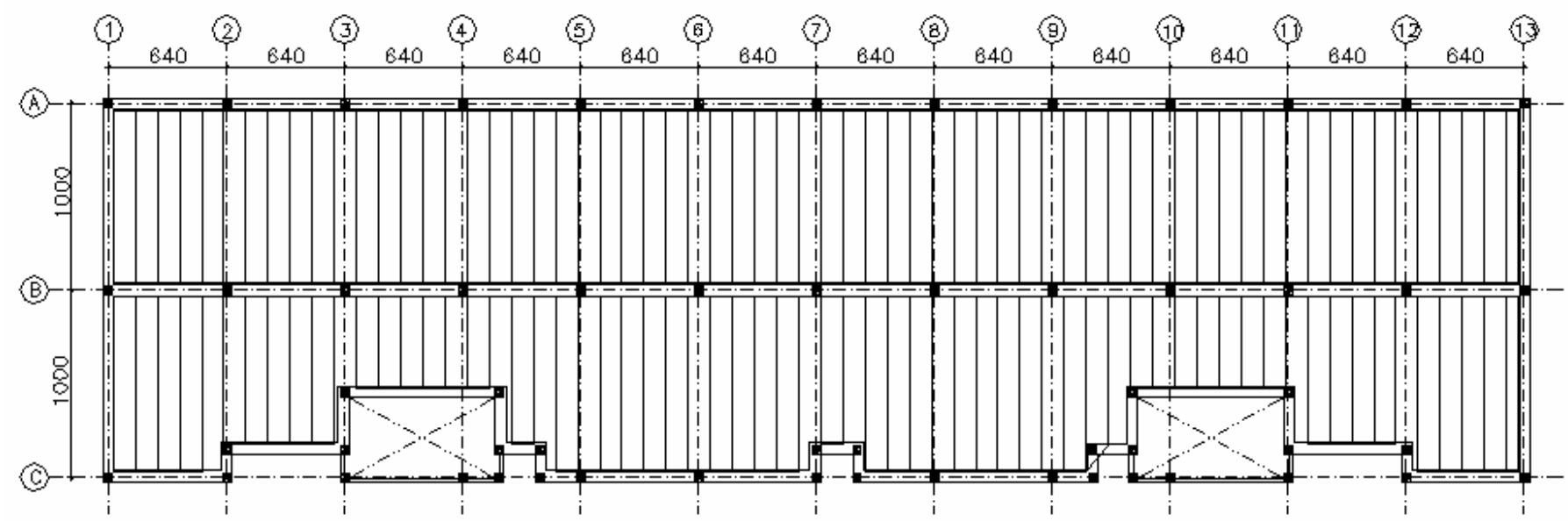

Figura 3-19 - Exemplo de pórticos posicionados na direção do maior lado do pavimento (unidades em $\mathrm{cm}$ ) 


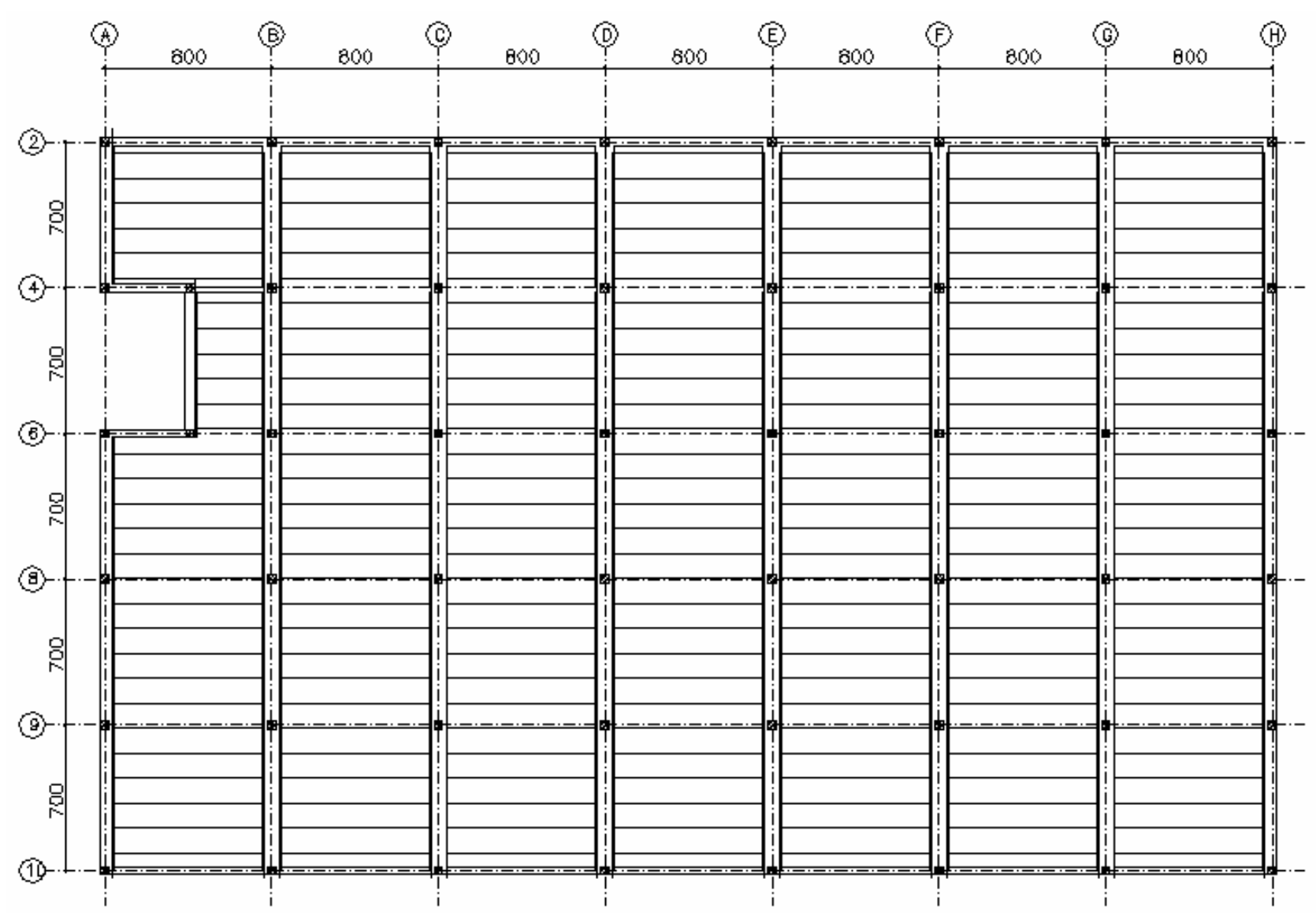

Figura 3-20 - Exemplo de pórticos posicionados na direção do menor lado do pavimento (unidades em $\mathrm{cm}$ )

\section{c) Sistema Estrutural}

Sobre o sistema estrutural, observou-se que as lajes mais utilizadas são as lajes alveolares e as lajes " $\Pi$ " e estão sempre apoiadas em vigas de seção: "T" invertida, "L", "I" e retangular (figura 3-21). Pode-se afirmar que o sistema estrutural mais utilizado no Brasil é composto por lajes alveolares apoiadas em vigas "T" invertidas, no interior do pavimento, e em vigas "L" na periferia. Esta conclusão também pode ser confirmada pelo banco de obras da $\mathrm{ABCIC}$ que indica a presença do sistema lajes alveolares, apoiadas em vigas "T" invertidas e vigas "L" em 51,6\% da obras (figura 3-22). Quase a totalidade das obras cadastradas se encaixariam na classificação Conventional System definida em 3.2.2. 
d) Vão médio dos elementos

Sobre o vão médio dos elementos, embora estes dados não sejam conclusivos, pois cada tipo de obra tem suas particularidades e restrições arquitetônicas, de maneira que a escolha dos vãos não se baseia exclusivamente na capacidade e eficiência das peças. Serão apresentados apenas os resultados dos elementos que aparecem com mais freqüência (tabela 3-1).
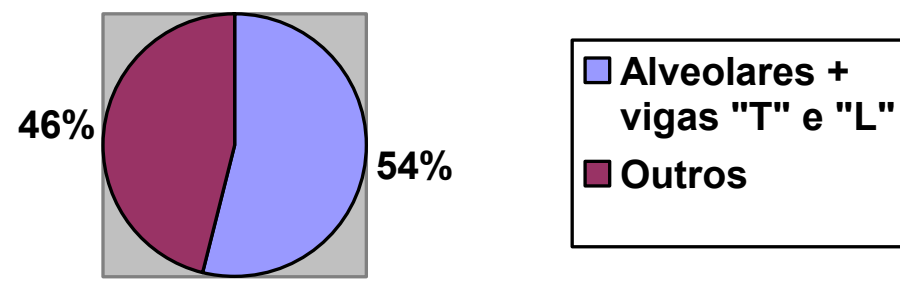

Figura 3-21 - Distribuição dos sistemas estruturais no banco de dados dos questionários
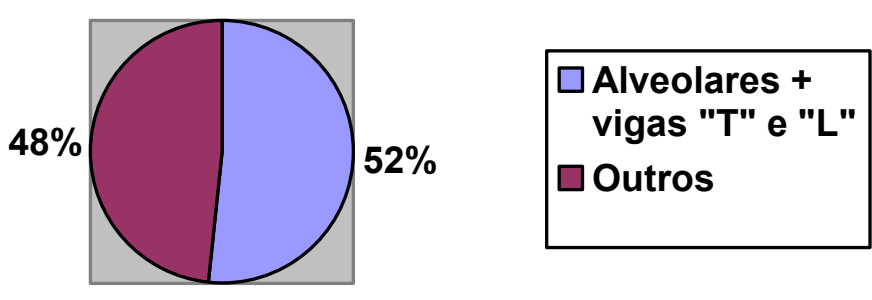

Figura 3-22 - Distribuição dos sistemas estruturais no banco de obras da ABCIC 
Tabela 3-1 - Vãos médios ( $m$ ) dos elementos

\begin{tabular}{|c|c|}
\hline Elemento & Vão médio $(\mathrm{m})$ \\
\hline Viga "T" invertida & 8,9 \\
\hline Laje Alveolar & 7,7 \\
\hline
\end{tabular}

\section{e) Sistema estrutural patenteado no Brasil}

Constatou-se, entre todas as informações colhidas, o registro de apenas um sistema estrutural patenteado, idealizado por Aluízio A. M. D’avila Projetos Estruturais, registrado no CONFEA sob o no. 826. O sistema é composto de lajes, vigas e pilares pré-moldados com solidarização posterior. O sistema permite que as lajes sejam montadas sobre as vigas, ambas na condição de peças isostáticas, em que posteriormente são introduzidas as armações negativas na parte superior das vigas e lajes e feita a concretagem complementar. Com isso o sistema se assemelha a um sistema moldado no local devido ao seu maior grau de engastamento (figura 3-23).

\section{f) Ligações}

A partir do banco de obras da ABCIC e do banco de obras da pesquisa, também se conclui que a grande maioria das edificações adota um modelo hiperestático, com as solidarizações posteriores para as vigas. Essas solidarizações permitem que as vigas sejam contínuas para todo o carregamento aplicado após a capa, tais como pavimentação, revestimento, divisórias e carga acidental. A ligação é realizada, em geral, por soldas entre a viga e o consolo do pilar na zona inferior e armaduras posicionadas na capa, sobre a viga, passando por luvas deixadas dentro do pilar e por suas laterais. 
DETALHE DAS VIGAS PRE MOLDADAS

(esc. 1:25)

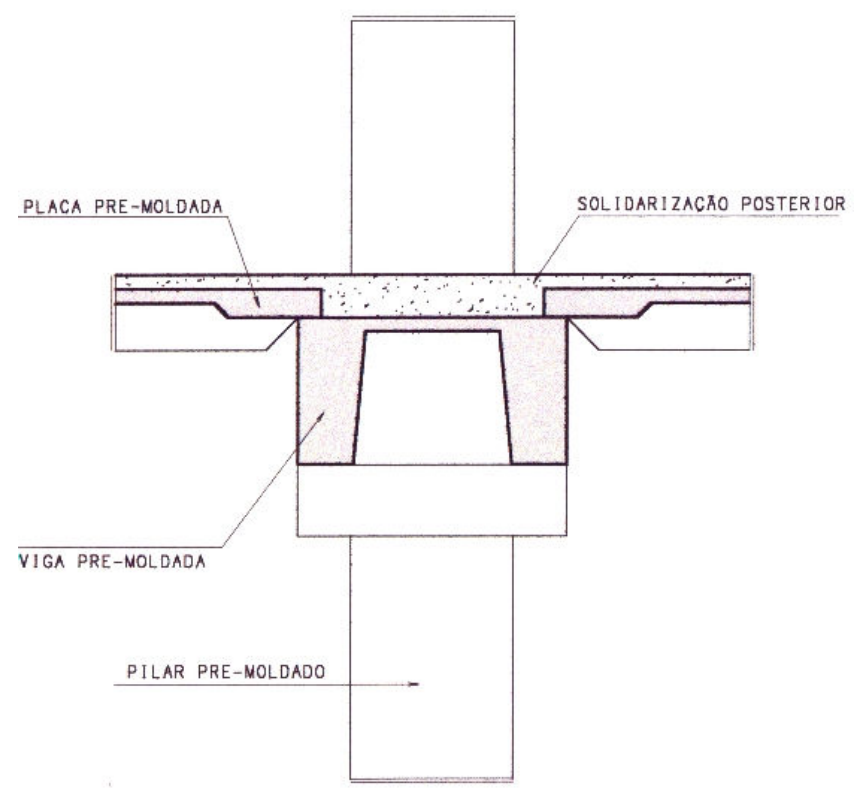

CORTE DA PLACA PRE MOLDADA

(esc. 1:25)

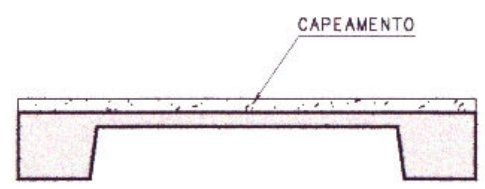

Figura 3-23 - Sistema Aluízio A. M. D’ávila

\subsection{ANÁLISE DOS LEVANTAMENTOS (ATLSS E BRASIL)}

Observam-se muitas semelhanças entre as expectativas e dificuldades dos envolvidos no setor nos Estados Unidos e no Brasil. A diferença marcante é quanto à tentativa de se desenvolver um formato de sistema estrutural, que proporcione um melhor desempenho ao pré-moldado. Percebe-se isto claramente pela diferença entre as quantidades de sistemas estruturais desenvolvidos e em desenvolvimento relatados em PRIOR et al. (1993) e os sistemas utilizados no Brasil.

Salienta-se, também, a maior integração entre universidade e empresa nos Estados Unidos, fato que não é ainda tão comum em nosso país. O trabalho em questão encontrou grande dificuldade para recebimento dos dados e não conseguiu receber nenhum questionário de firma de arquitetura. No entanto, no período em que foi realizado um estágio na University of Nebraska at Omaha observou-se uma forte integração entre a universidade e a indústria, tanto para o financiamento de pesquisas como para a definição das linhas de pesquisa, além do próprio desenvolvimento. 
Baseado na informação dos fabricantes de que, em média, $70 \%$ das obras pré-moldadas, que foram viabilizadas no Brasil, não foram originalmente planejadas para esta solução, conclui-se que a utilização dos pré-moldados em edifícios de múltiplos pavimentos é bastante promissora, principalmente se houver uma maior divulgação entre os arquitetos.

\subsection{DEFINIÇÃO DO SISTEMA ESTRUTURAL A SER UTILIZADO NO SATD}

Baseado no levantamento realizado, adotou-se como alternativa estrutural, a ser utilizada no sistema de apoio à tomada de decisão (SATD), uma estrutura composta por lajes alveolares apoiadas sobre vigas "T" invertidas. Este sistema, conforme os dados apresentados, nos dois bancos de dados, é prioritariamente o mais utilizado no Brasil. Este sistema corresponde, na classificação apresentada em PRIOR et al. (1993), ao Conventional System (figura 3-24).

Será adotada uma capa de concreto moldada no local $(5 \mathrm{~cm})$ em todo o pavimento. A capa de concreto, conforme os questionários dos projetistas de estruturas, é utilizada praticamente em todas as obras, além de melhorar o desempenho das peças (lajes e vigas) para a flexão como seções compostas, facilita as ligações e implementa o efeito do diafragma no pavimento ( $\mathrm{PCl}$, 2004). Segundo o Engenheiro José Zamarion Ferreira Diniz" ${ }^{7}$ "para o assentamento do piso e a regularização do pavimento já se faz necessária uma camada de contra-piso. Então por que não usá-la estruturalmente?"

Ainda conforme o levantamento sobre os sistemas utilizados no Brasil, os fabricantes esperam que as obras sejam planejadas, ou seja, que a arquitetura já contemple o uso do pré-moldado. Logo, a modulação é fundamental. Diante disso o SATD, partindo de uma arquitetura definida de um pavimento retangular, faz uma busca por uma estrutura modulada que obtenha o melhor desempenho em termos de economia, obedecendo a todas as restrições arquitetônicas, de fabricação, de transporte, de montagem e técnicas. Segundo PRIOR et al. (1993), a quantidade de peças diferentes e a complexidade das formas têm grande impacto sobre a composição dos custos.

\footnotetext{
${ }^{7}$ Contato pessoal em seu escritório no ano de 2004.
} 


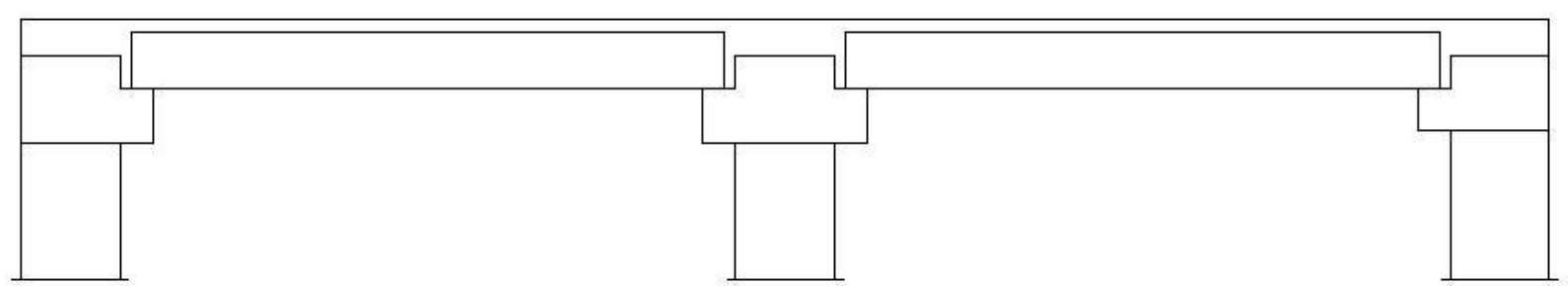

(a) Lajes alveolares apoiadas sobre vigas "T" invertidas

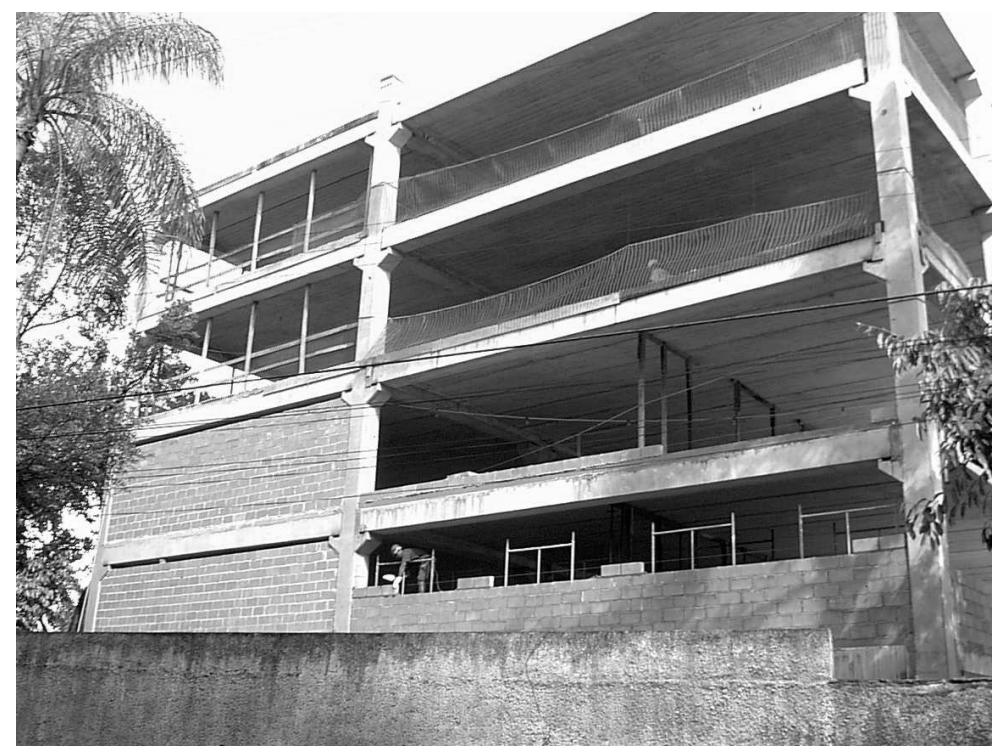

(b) Ed. Bureau Jurídico (Recife/PE)

Figua 3-24 - Exemplo de Conventional System

Pretende-se que o SATD, além de fornecer subsídios ao projetista de estruturas para que ele faça a opção pela melhor estrutura, sirva como importante ferramenta para o arquiteto idealizar os seus espaços, a partir de uma estrutura pré-moldada racional, já que antecipa uma modulação "ótima". Desta forma, o projeto de arquitetura já contemplaria as particularidades da estrutura, que seria um importante passo na compatibilidade dos projetos.

Sobre a localização da escada e dos elevadores, admite-se que, a partir do pavimento modulado, respeitando-se os vãos mínimos exigidos pela arquitetura, pode ajustar-se o posicionamento dos vazios da escada e dos elevadores, a partir da inserção de algumas vigas extras para definição do contorno. Ressalta-se, ainda, que de acordo com KHAJEPOUR (2001), a área 
referente à região de escada e aos elevadores corresponde, em média, a apenas $20 \%$ do pavimento total.

Todas essas diretrizes, que fazem parte de um projeto otimizado e racionalizado, podem ser observados no projeto do Shopping Center Midway (figura 3-25), gentilmente cedido pelos autores ${ }^{8}$.

O projeto arquitetônico do Shopping Midway, segundo o arquiteto Pedro Siqueira (ARAÚJO, 2003), na sua concepção já levou em consideração que a obra seria executada com estrutura de concreto pré-moldado. Em função disto primou pela racionalidade e simplicidade, o que permitiu um projeto limpo e funcional. Assim facilitou a construção do empreendimento com base em uma modulação adequada e que atendia às necessidades arquitetônicas dos vãos comerciais. Ressalta ainda o arquiteto que várias reuniões foram feitas, na fase de projetos, com todos os envolvidos para que se atingisse a compatibilidade com eficiência e economia necessárias.

Sobre a acomodação dos sistemas de serviços (instalações), admitiu-se que seriam independentes do pavimento, conforme tendência observada nos levantamentos realizados pelos questionários.

A adoção de um único sistema estrutural (lajes alveolares apoiadas em vigas "T") deve-se às informações dos fabricantes que indicaram este sistema como sendo o preferencial para os edifícios residenciais, comerciais e hotéis. Caso a finalidade do empreendimento fosse um edifício-garagem ou shopping center, por exemplo, bastaria trocar as lajes alveolares por lajes $\pi$, ou seja, uma otimização independente para cada sistema estrutural. A mudança de sistema estrutural é relativamente simples para o programa (SATD), bastando que se altere as rotinas de cálculo dos elementos e se crie um banco de dados com as características dos novos elementos.

\footnotetext{
${ }^{8}$ Zamarion \& Consultores Associados.
} 


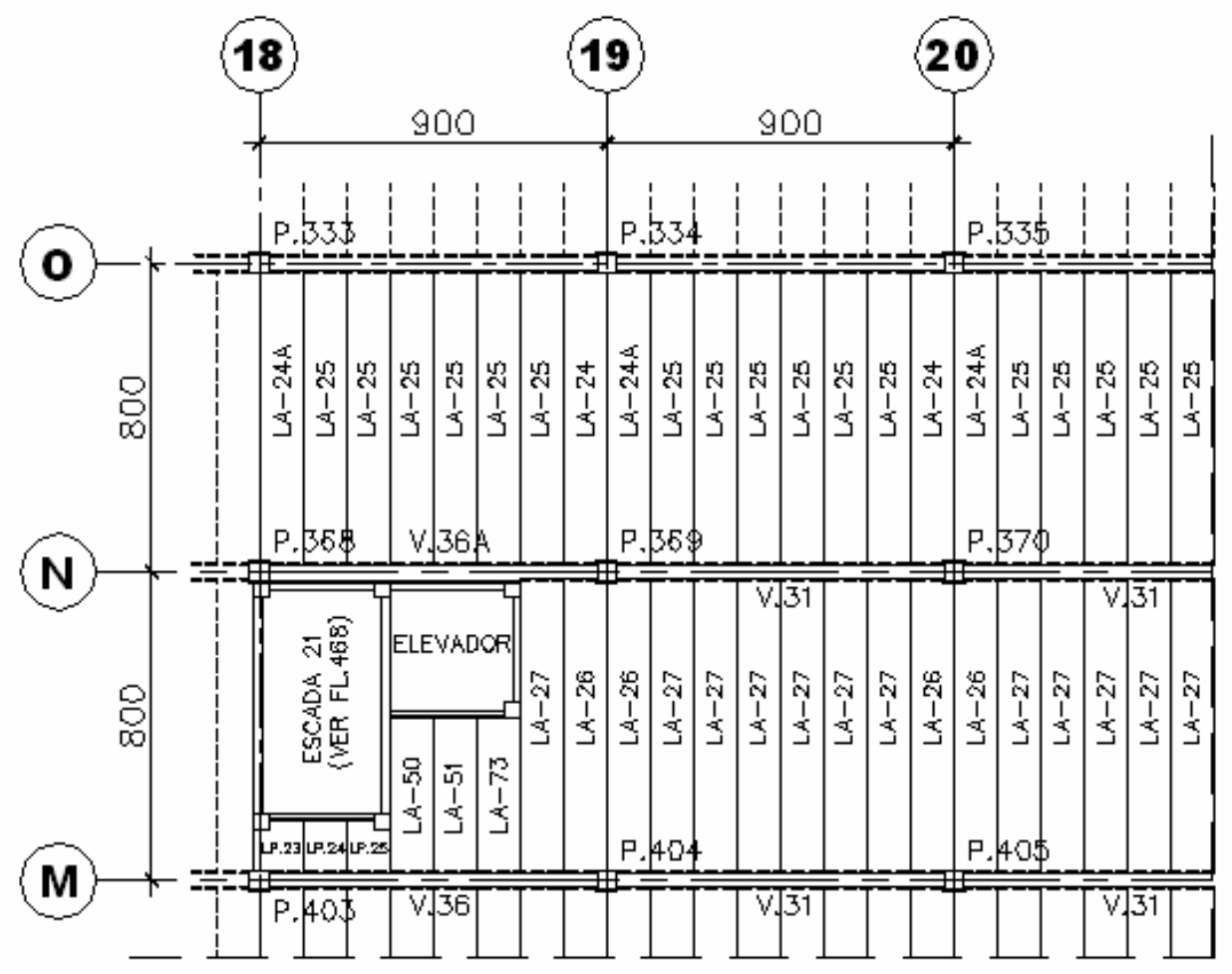

Figura 3-25 - Shopping Center Midway (unidades em "cm")

Conforme ALBUQUERQUE (1998) a inclusão das fundações para estudos comparativos, em termos de custos, não altera as diferenças percentuais entre os custos totais das alternativas estruturais analisadas. Por isso, desprezaram-se os elementos de fundações, além do que em vários casos as fundações não são produzidas pela fábrica de pré-moldados, inclusive.

\subsubsection{Estrutura Modulada}

Com o intuito de atestar a representatividade de se adotar uma estrutura modulada, apresentam-se vários exemplos de sua aplicação, de forma que se constata ser uma prática corrente nos projetos.

Em PRIOR et al. (1993), para se fazerem comparações entre as estruturas catalogadas, utilizou-se uma estrutura modulada (figura 3-26). Os exemplos apresentados no $\mathrm{PCl}$ (design handbook, 2004) também são de estruturas moduladas (figura 3-27). A maioria dos projetos, que é fabricada 
pela Concrete Industries (Lincoln, NE, US), é modulada. Muitos dos projetos, a que se teve acesso pelo levantamento feito no Brasil, também apresentam estruturas moduladas.

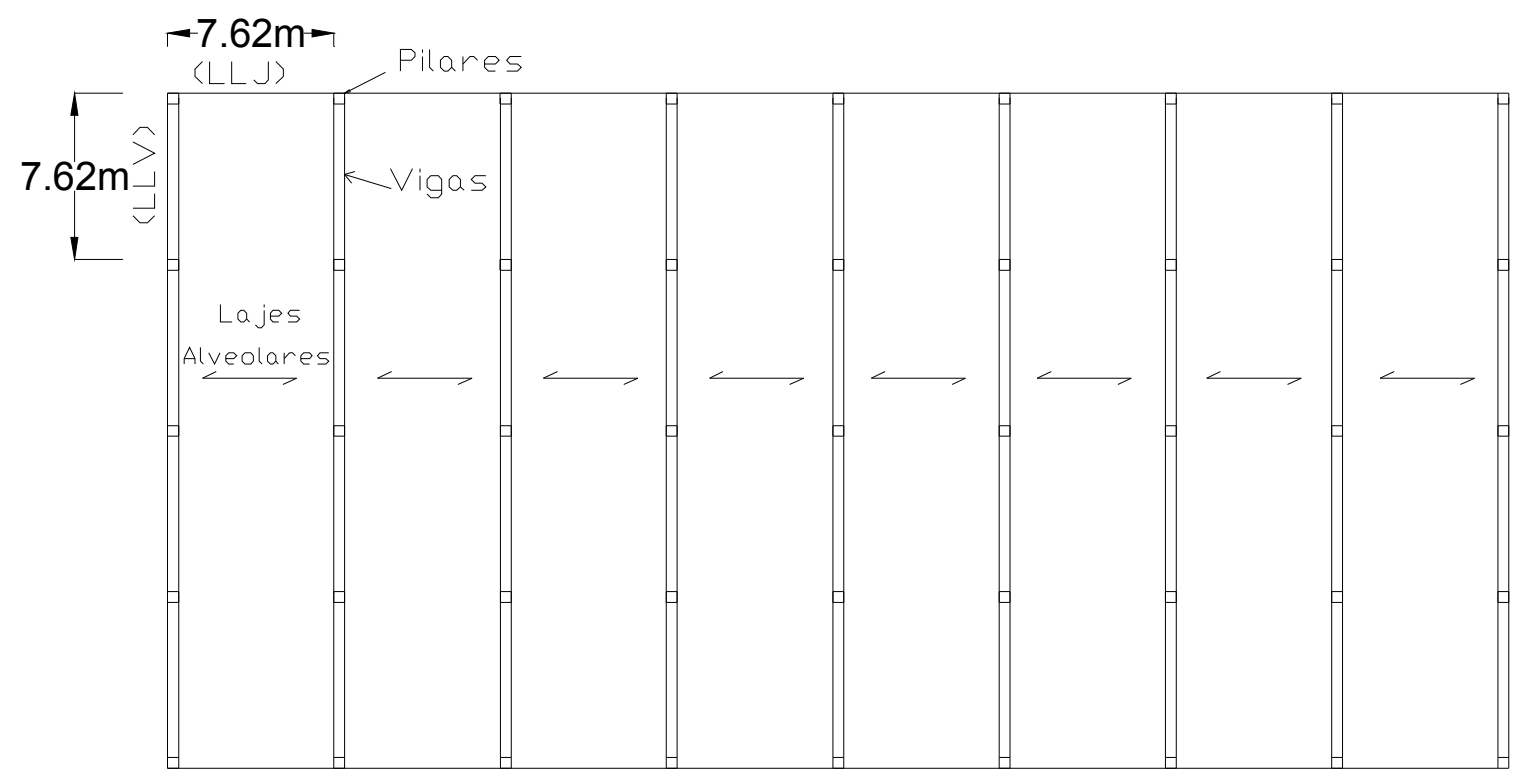

Figura 3-26 - Exemplo ATLSS report

Fonte: PRIOR et al. (1993)

Cita-se, ainda, que a hipótese da estrutura modulada foi assumida em vários trabalhos que otimizam a configuração estrutural. Entre esses trabalhos, estão GRIERSON et al. (2002), RAFIQ et al. (2003) e PULLMANN et al. (2003). Segundo BRANKOVIC et al. (2001), edifícios modulados em estruturas prémoldadas são bastante comuns principalmente para algumas obras específicas como hotéis e prédios residenciais de universidades. Existem também vários projetos que, embora não sejam completamente modulados, apresentam uma área bastante representativa que o é. 


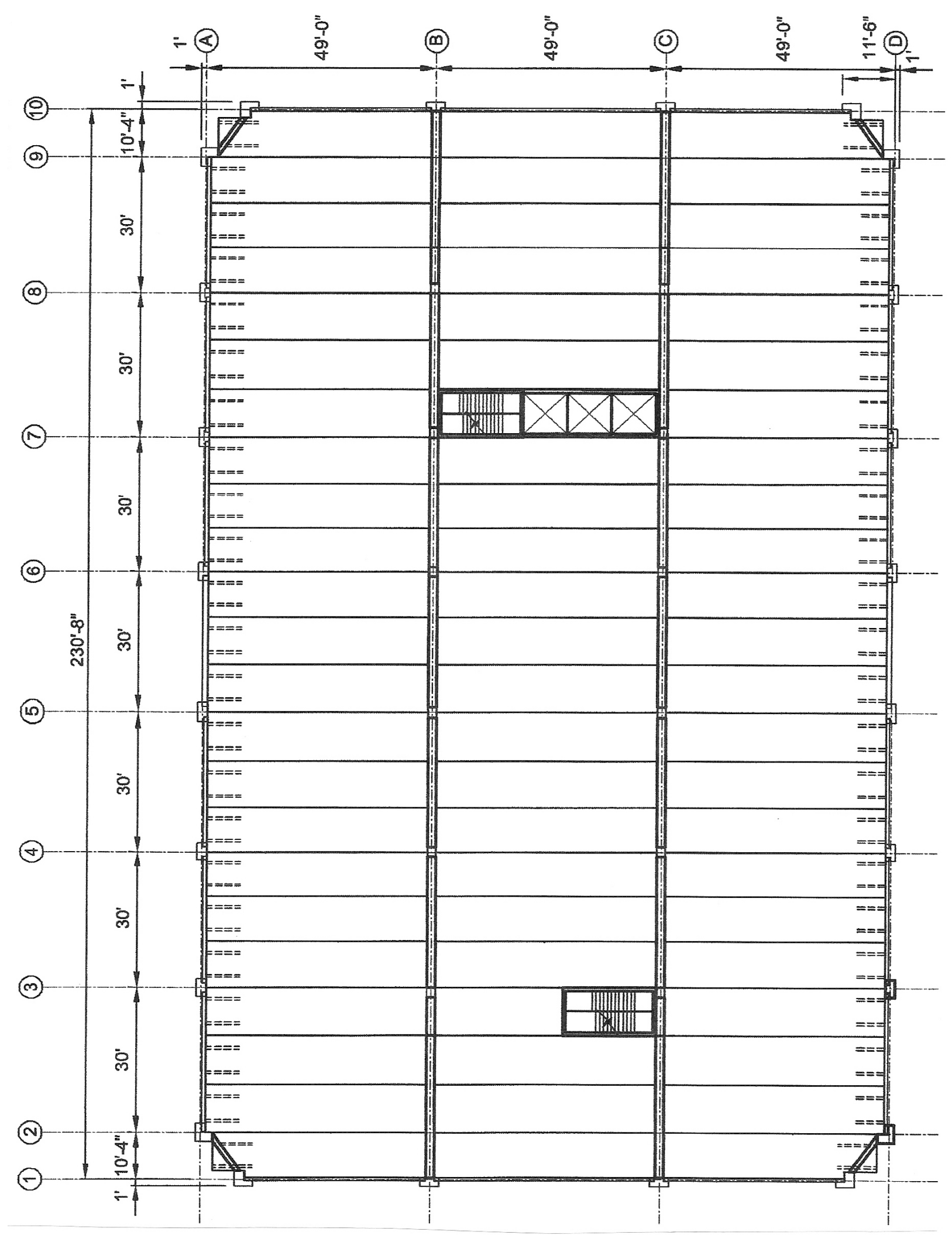

Figura 3-27 - Edifício exemplo PCl (2004) (medidas em "foot") Fonte: $\mathrm{PCl}(2004)$ 


\subsubsection{Características dos elementos estruturais}

A geometria das lajes e das vigas não pode assumir valores aleatórios, já que cada fabricante possui seus moldes. Assim, os tipos das lajes alveolares e as dimensões das vigas são variáveis discretas. Diante disso, o SATD deve ser alimentado pelo fabricante com suas famílias de vigas e lajes, de forma que a busca seja feita entre opções disponíveis. Neste trabalho foram adotadas as peças disponíveis do fabricante T\&A, mas a adaptação para quaisquer outras indústrias é perfeitamente viável, já que seria apenas uma mudança no banco de dados. As vigas e lajes são calculadas durante o ciclo do AG.

\subsubsection{Lajes}

Os formatos disponíveis das lajes alveolares são apresentados na figura 3-28 e para cada tipo de laje foram adotadas alternativas de protensão, considerando quantidade e bitola de cordoalhas, em função dos padrões da indústria. Esses padrões são estabelecidos em função dos pentes metálicos que servem de guias para os fios na pista.

Essas combinações, entre tipo de laje e armadura de protensão adotadas, produziram 32 opções de lajes (ver tabela 4-1).

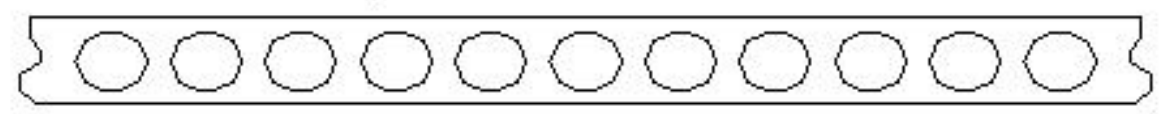

(a) Laje $\mathrm{h}=9$

LAJE DE $13 \mathrm{~cm}$

CONSUMO: $0,0880 \mathrm{~m} 3 / \mathrm{m}$

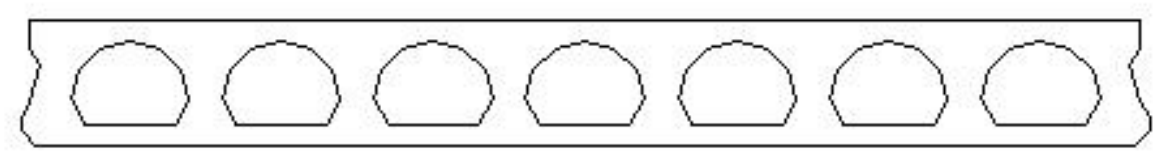

(b) Laje $\mathrm{h}=13$ 
LAJE DE $17 \mathrm{~cm}$

CONSUMO: $0,1083 \mathrm{~m} 3 / \mathrm{m}$

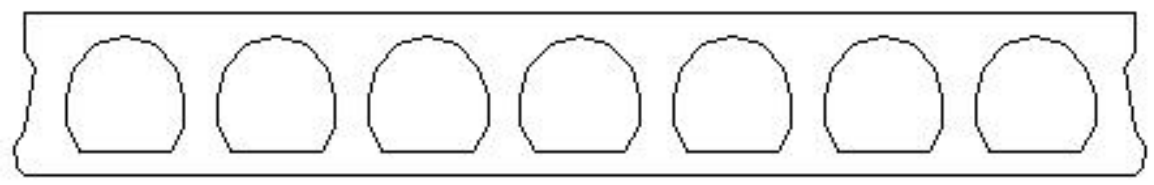

(c) Laje $\mathrm{h}=17$

LAJE DE $20 \mathrm{~cm}$

CONSLNW: $0,1194 \mathrm{m3} / \mathrm{m}$

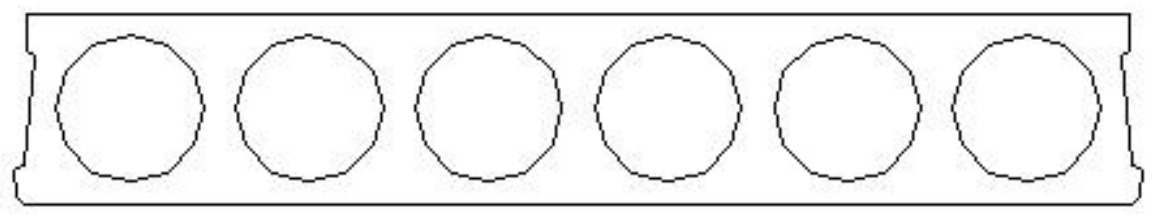

(d) Laje $\mathrm{h}=20$

LAJE DE $21 \mathrm{~cm}$

CONSUMO: $0,1279 \mathrm{m3} / \mathrm{m}$

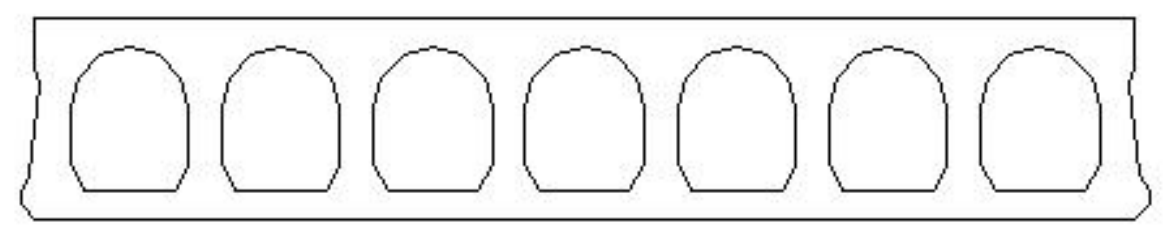

(e) Laje $\mathrm{h}=21$

LAJE DE $26 \mathrm{~cm}$

CONSUMO: $0,1728 \mathrm{~m} 3 / \mathrm{m}$

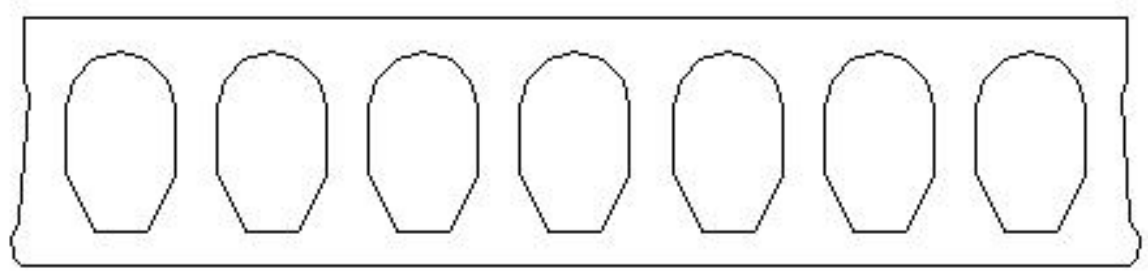

(f) Laje $h=26$

Figura 3-28 - Lajes alveolares disponíveis 


\subsubsection{Vigas}

As vigas "T" invertidas (figura 3-29) são definidas a partir de sua largura e altura, adicionando-se à largura da viga os dentes necessários ao apoio das lajes (15 cm para cada lado, valor adotado em função da experiência do fabricante). As vigas podem ser produzidas com larguras $\left(b_{w}\right)$ entre $40 \mathrm{~cm}$ e 90 $\mathrm{cm}$, variando em $10 \mathrm{~cm}$, e alturas $\left(h_{\mathrm{v}}\right)$ entre $20 \mathrm{~cm}$ e $40 \mathrm{~cm}$, variando em $5 \mathrm{~cm}$. Combinando-se largura e altura obtêm-se 32 opções de geometria de vigas (tabela 4-2). Salienta-se que para as vigas de borda a geometria seria a mesma da viga "T" sem um dos dentes para apoio das lajes (figura 3-30).

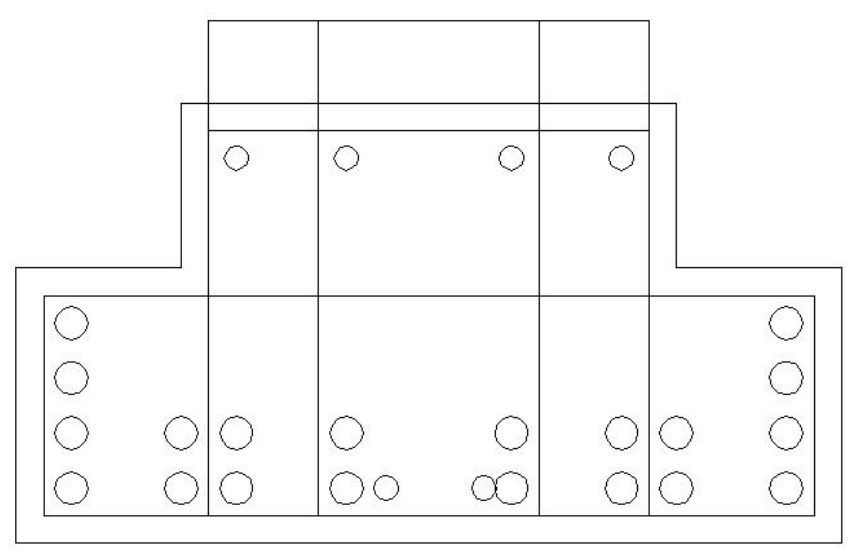

(a) Corte esquemático

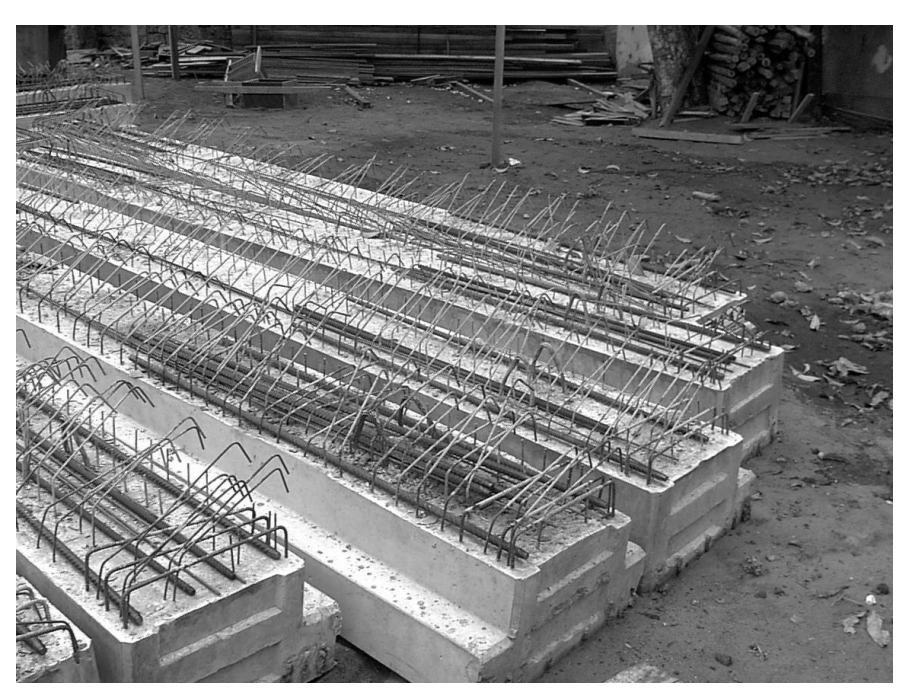

(b) Viga armazenada na T\&A (Fortaleza/CE)

Figura 3-29 - Viga "T" invertida 


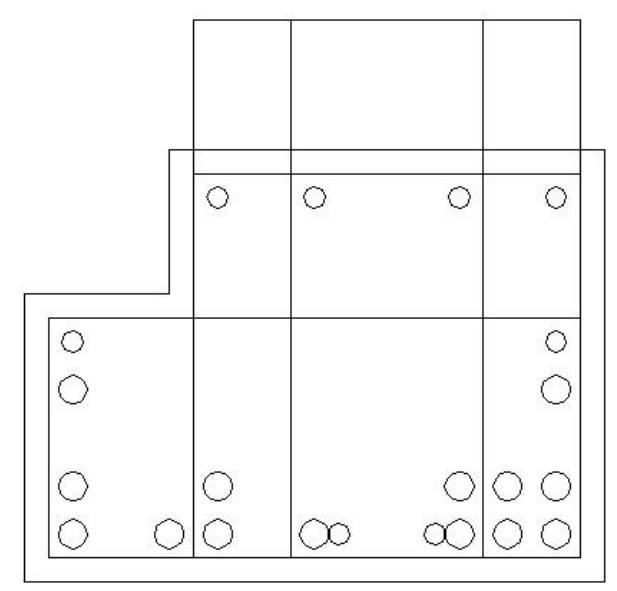

(a) Corte esquemático

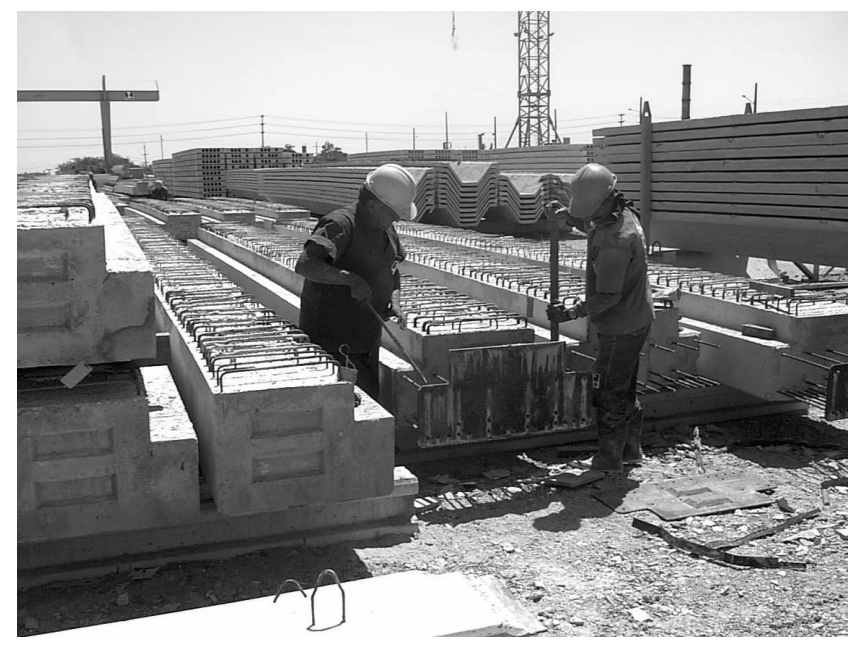

(b) Viga armazenada na T\&A (Fortaleza/CE)

Figura 3-30 - Viga "L"

Observa-se que a altura da base da viga $\left(h_{\mathrm{v}}\right)$ é ainda acrescida da altura da laje alveolar e mais a capa de concreto $(5 \mathrm{~cm})$ e a altura total da viga prémoldada é composta da altura da viga $\left(h_{v}\right)$ mais a altura da laje, subtraída de 5 $\mathrm{cm}$, de forma que a seção moldada no local sobre a viga tem $10 \mathrm{~cm}$ de altura (figura 3-31). Essa região de $10 \mathrm{~cm}$ de concreto moldado no local visa à colocação de armaduras passivas longitudinais e, também, a facilitar a ligação entre a capa e a seção pré-moldada, bem como à ligação com os pilares. 

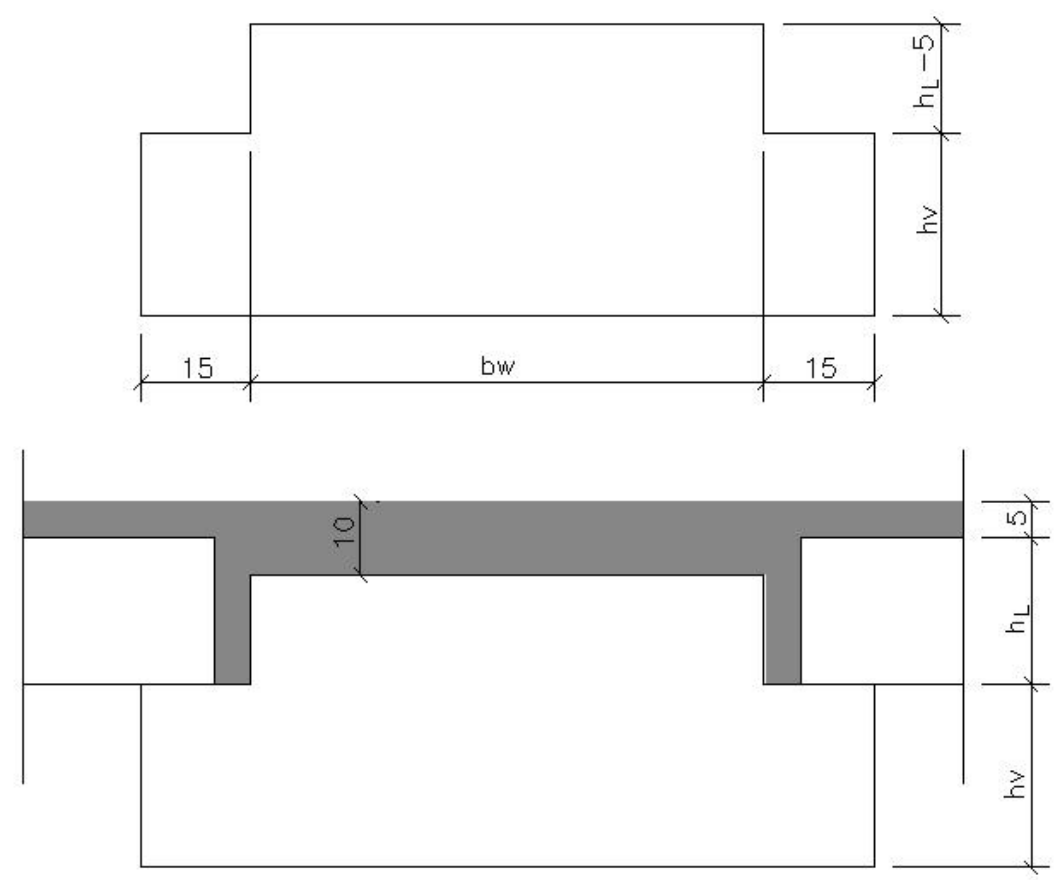

Figura 3-31 - Viga "T" invertida seção composta (unidades em "cm")

Adotou-se na parte superior das vigas quatro cordoalhas protendidas (figura 4-3) para diminuir os esforços de tração na fase construtiva. Salienta-se, ainda, que, para o fabricante, o custo da cordoalha em uma pista de protensão é mais viável do que o custo de armaduras passivas, devido à ausência de trabalhos manuais, tais como corte e amarração.

Segundo informações coletadas com a fábrica T\&A, a escolha da viga "T" invertida foi apropriada, pois em seus estudos comparativos essa seção é a que traz a melhor relação custo / benefício para vãos de até 10,0 m.

\subsubsection{Pilares}

Segundo as informações de vários fabricantes consultados, as seções de pilares não variam muito entre os projetos de edifícios pré-moldados. A partir disso, assumiu-se, como simplificação, a utilização da tabela 3-2 em função da capacidade de carga da seção do pilar. A tabela foi construída considerando-se uma resistência de $40 \mathrm{MPa}$ para o concreto com uma taxa de aço de 3,0 \% e uma distância de piso a piso de 4,0 m.

A partir de um levantamento realizado em vários projetos estruturais com concreto de resistência $40 \mathrm{MPa}$, observou-se que o consumo médio de aço nos 
pilares é de $100 \mathrm{~kg} / \mathrm{m}^{3}$ a $200 \mathrm{~kg} / \mathrm{m}^{3}$, dependendo da altura do edifício. Logo se adotou a tabela 3-3 para contemplar a diferença de consumo de aço no pilar para resistências diferentes, a partir da faixa citada.

Tabela 3-2 - Seções adotadas de pilar em função da carga vertical característica $\left(\mathrm{N}_{\mathrm{k}}\right)$

\begin{tabular}{|c|c|}
\hline Seção do Pilar (cm) & $\mathrm{N}_{\mathrm{k}}(\mathrm{kN})$ \\
\hline $40 \times 40$ & 3800 \\
\hline $50 \times 50$ & 6000 \\
\hline $60 \times 60$ & 8000 \\
\hline
\end{tabular}

Tabela 3-3 - Consumo médio de aço no pilar em função de sua resistência

\begin{tabular}{|c|c|}
\hline $\mathrm{f}_{\mathrm{ck}}$ & $\mathrm{kg} / \mathrm{m}^{3}$ \\
\hline 35 & 150 \\
\hline $\mathbf{4 0}$ & $\mathbf{1 2 0}$ \\
\hline 45 & 90 \\
\hline 50 & 60 \\
\hline
\end{tabular}

\subsubsection{Resistência à compressão do Concreto}

Em função dos resultados encontrados no levantamento brasileiro, as resistências do concreto podem assumir (em MPa) os valores: 20, 25, 30 e 35 para o concreto moldado no local utilizado na capa $\left(f_{c k m l}\right)$ e os valores: 35,40 , 45 e 50 para o concreto pré-moldado ( $\left.f_{c k p m}\right)$. Essas resistências ( $f_{c k p m}$ e $\left.f_{c k m l}\right)$ são variáveis de projeto e o custo, por volume $\left(\mathrm{R} \$ / \mathrm{m}^{3}\right)$ de cada uma dessas resistências, deve ser informado pelo usuário, de acordo com os valores praticados em sua região.

\subsection{HIPÓTESE DE CÁLCULO ADOTADA}

Adotou-se como hipótese simplificadora, de cálculo, que as lajes são apoiadas simplesmente sobre as vigas, de forma que são dimensionadas, somente, para um momento positivo de $M_{\text {positivo }}=\frac{q \cdot \ell^{2}}{8}$. 
Para o cálculo das vigas utiliza-se a viga central, que recebe lajes pelos dois lados, e considera-se, para efeito de cálculo, que a mesma está bi-apoiada para o carregamento aplicado antes da solidarização da capa $M_{\text {Positivo }}=\frac{q_{\text {Peso_proprio }} \cdot \ell^{2}}{8}$ e considera uma continuidade para todo carregamento aplicado após a capa. Para uma consideração simplificada da continuidade utilizou-se a indicação 8.3 do ACl-318 (1995) que recomenda $M_{\text {Positivo }}=\frac{q_{\text {apos_capa }} \cdot \ell^{2}}{16}$ e $M_{\text {Negativo }}=\frac{q_{\text {após_capa }} \ell^{2}}{10}$. Para combater o momento positivo da viga utiliza-se a armadura protendida e a passiva, para o momento negativo apenas a armadura passiva. 


\section{SISTEMA DE APOIO À TOMADA DE DECISÃO (SATD)}

\subsection{PRELIMINARES}

O SATD é um sistema de apoio à tomada de decisão, na busca da configuração estrutural ótima de edifícios de múltiplos pavimentos com planta retangular com estrutura de concreto pré-moldado, utilizando-se a técnica dos algoritmos genéticos. O sistema fornece ao usuário quase todos os resultados necessários ao desenvolvimento de um projeto, desde a configuração estrutural até o detalhamento dos elementos.

De acordo com ALTSHULLER ${ }^{9}$ apud KICINGER et al. (2005), a criatividade, em problemas de engenharia, é governada por paradigmas, e esses podem ser utilizados para se produzirem inovações. O SATD se enquadra no paradigma da "modificação", onde o conceito do projeto é produzido a partir de combinações e ou modificações de um conhecido espaço de busca, descrito no capítulo anterior, por meio de um processo de geração aleatória.

No processo tradicional, o projetista estrutural inicialmente adota algumas alternativas de concepção estrutural, que são os estudos preliminares, para fazer a escolha, entre as, que atendam a todos os critérios, da que apresente menor custo. Os critérios analisados são técnicos, construtivos e arquitetônicos. Sabe-se da dificuldade, por mais experiente que seja 0 projetista, de comparar os custos totais das estruturas entre as alternativas existentes, além do tempo demandado para fazer a análise de várias alternativas. Salienta-se ainda que essa análise deve ser realizada, não só por quem está projetando a estrutura, mas também por quem irá fabricar e executar a estrutura, ou seja, o fabricante e o montador.

\footnotetext{
${ }^{9}$ ALTSHULLER, G. (1999). The innovation algorithm: TRIZ. Technical Innovation Center, Moscow.
} 
Diante disso, enfatiza-se a importância de uma ferramenta que sirva de suporte ao projetista e, ao mesmo tempo, já tenha embutido as informações necessárias da indústria para aferir os custos, e fazer as comparações. Com isso, o projetista garante que suas comparações estariam levando em consideração custos baseados em dados mais representativos.

Adotou-se, então, como princípio fundamental do sistema, a otimização integrada do projeto estrutural do pavimento considerando a fabricação e a montagem, ao contrário do tratamento convencional dado aos problemas de otimização em engenharia estrutural, onde as etapas de concepção, detalhamento e construção são analisadas separadamente. A otimização integrada leva em consideração a relação existente entre as etapas, bem como a influência de cada uma delas na composição do custo da obra.

\subsection{DIRETRIZES DO PROGRAMA SATD}

As vigas e lajes são verificadas para todas as fases transitórias (armazenamento, transporte e montagem), estados limites de serviço e estados limites últimos. Para os estados limites de serviço, e últimos, são consideradas as seções compostas em função da capa existente de concreto moldado no local e verificadas segundo a NBR-6118 (2003).

Normalmente quem rege o dimensionamento das vigas é a verificação do limite de deformação e a verificação da capacidade resistente aos momentos fletores. De forma que a armadura de cisalhamento, em geral, contribui muito pouco para uma variação na composição dos custos (apêndice B), sendo muitas vezes adotada uma armadura mínima, inclusive. Estes resultados também foram encontrados por ABENDROTH \& SALMON ${ }^{10}$ apud SARMA \& ADELI (1998) e BALLING \& YAO (1997), que desconsideraram a armadura de cisalhamento em suas rotinas de otimização de vigas.

Diante disso, não se considerou para a otimização das vigas a verificação das armaduras de cisalhamento, porém foi computada uma armadura mínima de cisalhamento na composição dos custos. A consideração da armadura mínima, para as vigas, é necessária porque o SATD trata de uma

\footnotetext{
${ }^{10}$ ABENDROTH \& SALMON. (1986). "Sensitivity study of optimum RC restrained end T-sections". J. Struct. Engr., ACSE, 112(08), 1928-1943.
} 
otimização global, envolvendo, ao mesmo tempo, lajes, vigas e pilares, onde todos são computados em conjunto e por isso têm de estar quantificados por completo.

Pode-se desprezar a verificação da estabilidade global, sem prejudicar a otimização do pavimento, admitindo-se que os esforços laterais serão absorvidos por pilares paredes e núcleos, localizados nas caixas de escada e elevadores.

Ressalta-se que o PCI (2004) também comenta que a rigidez das estruturas pré-moldadas é facilmente implementada pelas paredes estruturais, nas regiões de escada, elevadores e em alguns possíveis locais do perímetro da edificação. No perímetro da edificação têm-se normalmente as vigas de borda, que podem formar pórticos bastante rígidos, devido à sua maior dimensão geralmente por razões arquitetônicas.

Lembra-se também que, nas estruturas de concreto pré-moldado, há o surgimento do efeito de pórticos ao se executarem algumas ligações rígidas ou semi-rígidas entre vigas através dos pilares, além do fato de que, segundo o levantamento, há uma tendência das estruturas totalmente pré-moldadas serem relativamente baixas.

Pode-se citar, ainda, como exemplo de trabalhos que desprezaram os efeitos das ações laterais na otimização do edifício PARK \& GRIERSON ${ }^{11}$ apud SACKS et al. (2000).

Em função do exposto, não foi implementada no SATD a verificação da estabilidade global, nem a otimização dos pórticos.

\subsubsection{Dados de Entrada}

Na entrada de dados define-se o pavimento a ser otimizado, a geometria e os carregamentos, além de definir as restrições arquitetônicas que influem nos resultados. O usuário deverá informar ao sistema os seguintes dados de entrada:

a) As dimensões do pavimento na direção $X\left(\ell_{x}\right)$ e na direção $Y\left(\ell_{y}\right)$;

\footnotetext{
${ }^{11}$ PARK \& GRIERSON (1999). "Pareto-optimal conceptual design of the structural layout of buildings using a multicriteria genetic algorithm". Comput.-Aided Infrastructure Eng. 14, 163-170.
} 
b) As distâncias mínimas aceitáveis entre os eixos de pilares na direção $X$ e na direção $Y$, ou seja, os vãos livres mínimos exigidos em função do tipo de obra e da arquitetura $\left(d_{\min x}\right.$ e $\left.d_{\text {miny }}\right)$;

c) Número total de pavimentos do edifício, que influencia na escolha dos pilares;

d) A altura máxima que o pavimento pode ter, que seria a altura da base da viga "T" invertida, juntamente com a altura da laje alveolar e a capa de concreto (adotada uma espessura de $5 \mathrm{~cm}$ em todos os casos). Essa medida é estabelecida em função das instalações e da altura livre que se necessita para a obra;

e) Largura máxima da alma da viga ( $\left.b_{w m a x}\right)$ : máxima largura que a alma da viga pode assumir;

f) Sobrecarga: carga acidental atuando no pavimento;

g) Carga permanente adicional: carga de pavimentação e revestimento atuando no pavimento. Observa-se que o peso próprio dos elementos é calculado automaticamente;

h) Paredes sobre laje: carga distribuída de paredes atuando nas lajes;

i) Número de indivíduos da população: número total de indivíduos que comporá cada geração;

j) Número de indivíduos para o elitismo: quantidade de melhores indivíduos que passará para a próxima geração sem nenhuma alteração;

k) Número total de gerações; 
I) Taxa de cruzamento: porcentagem de indivíduos da população que será selecionada para o cruzamento;

m) Taxa de mutação: probabilidade de ocorrência de mutação em todos os indivíduos da geração intermediária, exceto os originários do elitismo.

São adotadas como unidade de comprimento o metro [m] e como unidade de carregamento o kilo-Newton por metro quadrado [kN/m²].

\subsubsection{Informações do fabricante}

As informações do fabricante são os dados que alimentam o sistema de acordo com as particularidades de cada fabricante, tais como:

a) Preço do metro cúbico do concreto em função da sua resistência $\left(\mathrm{R} \$ / \mathrm{m}^{3}\right)$

b) Preços do aço de protensão e do aço para armadura passiva ( $R \$ / \mathrm{kg})$;

c) Preço de utilização de pista de protensão para vigas e lajes;

d) Consideração da amortização dos custos fixos da indústria na composição das peças e dos custos com as despesas operacionais;

e) Valores particulares para a formação da função-custo relativos à fabricação, montagem e transporte;

f) Tipos de produtos disponíveis, ou seja, a geometria das lajes e vigas disponíveis.

Esta fase de alimentação do sistema exige uma forte interação com a indústria, para que a função-objetivo seja efetivamente representativa do que acontece na prática. Lembra-se que é, de acordo com a função-objetivo que o sistema conduz à evolução para as melhores soluções. Cita-se, como exemplo da particularidade da composição da função-custo, o caso de algumas peças que consomem menos concreto, mas que, por serem menos utilizadas, têm seu custo mais elevado. 


\subsubsection{Resultados}

O sistema fornece como resultados várias alternativas de projetos estruturais, como por exemplo a figura 4-1, apresentadas em ordem crescente em função do custo, para cada processamento. Estas alternativas de projeto indicam a configuração estrutural, bem como o dimensionamento das vigas e lajes. A configuração estrutural é composta pelo posicionamento dos elementos estruturais, tais como lajes, vigas e pilares, e pela definição dos vãos das vigas e das lajes. O dimensionamento compreende a geometria e as armaduras das lajes e vigas. O item armaduras é composto pela quantidade e o diâmetro dos cabos de protensão e das barras de armadura.
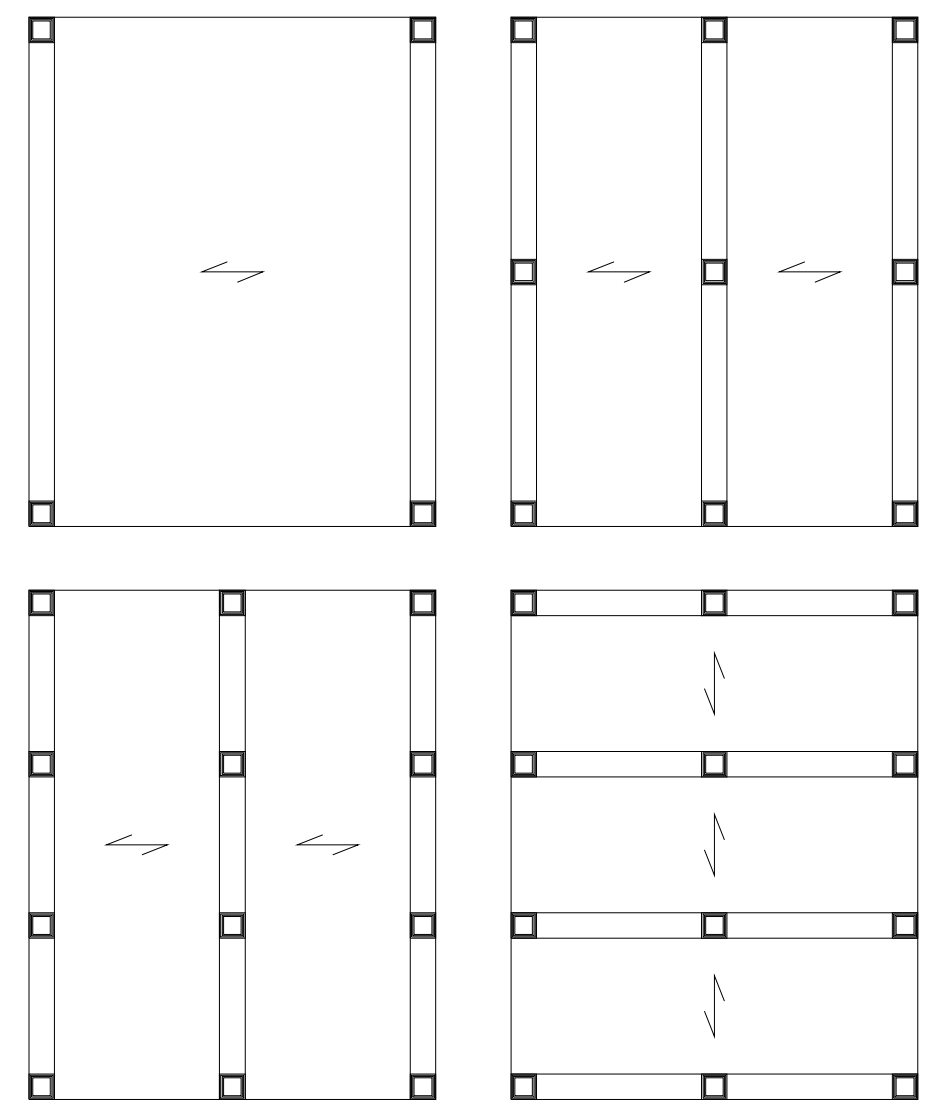

Figura 4-1 - Exemplos de número de vãos e direções das vigas e das lajes (Configuração estrutural)

Essas alternativas são chamadas de indivíduos, e alguns esclarecimentos são apresentados abaixo: 
a) Direção das lajes (DL) : As lajes podem ser disponibilizadas na direção $X(D L=0)$ ou na direção $Y(D L=1)$. Em função da direção das lajes, define-se a direção das vigas (figura 4-2);

b) $f_{c k m l}$ e $f_{c k p m}$ : Resistências à compressão características dos concretos utilizados, moldados no local (capa) e pré-moldados;

c) $h_{\text {laje }}$ : Altura da laje alveolar;

d) $\ell_{\text {laje }}$ : Vão da laje na direção determinada por DL (figura 4-2);

e) $h_{v}$ : Altura da base da viga, isto é, a altura do dente que recebe a laje alveolar;

f) $b_{w}$ : Largura da alma da viga, exceto os dentes, $15 \mathrm{~cm}$ para cada lado sendo $30 \mathrm{~cm}$ no total;

g) $\ell_{\text {viga }}$ : Vão da viga na direção determinada por DL (figura 4-2);

h) $n_{A}$ e $n_{B}$ : Número de cabos de protensão em duas camadas nas vigas, sendo $\mathrm{n}_{\mathrm{A}}$ o número de cabos na primeira camada e $\mathrm{n}_{\mathrm{B}} \mathrm{O}$ número na segunda camada. Adotou-se que o centro de gravidade dos cabos da primeira camada estaria a uma distância de $5 \mathrm{~cm}$ do fundo da viga e que o centro de gravidade da segunda camada estaria a uma distância de $10 \mathrm{~cm}$. Adotou-se, ainda, que a distância mínima entre cabos da mesma camada seria de $5 \mathrm{~cm}$ (figura 4-3). Implementou-se uma rotina que verifica se a quantidade de cabos, adotada por camada, pode ser alojada de acordo com a largura total da viga, e, caso não o seja adota-se a quantidade máxima permitida;

i) NPT : Número de barras de armadura passiva, também nas vigas; 
j) VL : Tipo de laje, deve-se consultar a tabela que vincula ao valor de $\mathrm{VL}$, a altura da laje ( $\left.\mathrm{h}_{\text {laje }}(\mathrm{VL})\right)$ e a configuração da protensão que é definida por: quantidade de cabos $(\mathrm{N})$, diâmetro dos cabos adotados (cordoalha), força de protensão $\left(P_{a}(V L)\right)$, área total de protensão $\left(A_{p l}\right.$ $(V L))$ e o limite máximo da linha neutra $\left(x_{\text {máx }}(V L)\right)$. São disponibilizadas 32 combinações (Tabela 4-1), entre 6 tipos de lajes alveolares e configurações de protensão;

$\sigma_{P i} \leq\left\{\begin{array}{l}0,77 \cdot f_{p t k} \\ 0,85 \cdot f_{p y k}\end{array}=1453 M P a \rightarrow C P 190-R B\right.$

Onde:

$P_{a}(V L)=A_{p l}(V L) \cdot \sigma_{P i} \cdot 0,97$

○ Coeficiente de perda inicial de protensão: 0,97;

○ Tensão inicial de protensão: $\sigma_{\mathrm{Pi}}$

k) VV: Tipo de viga, deve-se consultar a tabela que vincula, ao valor de $V V$, a altura da viga $\left(h_{v}(V V)\right)$, a largura da alma da viga $\left(b_{w}(V V)\right)$ e a quantidade máxima de cabos de protensão nessa viga, por camada $\left(\mathrm{n}_{\max }(\mathrm{VV})\right)$. A quantidade máxima de cabos considera uma distância de $5 \mathrm{~cm}$ entre os eixos dos cabos. São disponibilizadas 32 combinações (Tabela 4-2) entre altura e base;

Com estes valores tem-se a configuração estrutural e o dimensionamento do pavimento. As listas com as possibilidades de vigas e lajes podem ser ampliadas ou reduzidas, de acordo com a necessidade do usuário e a disponibilidade do fabricante. 


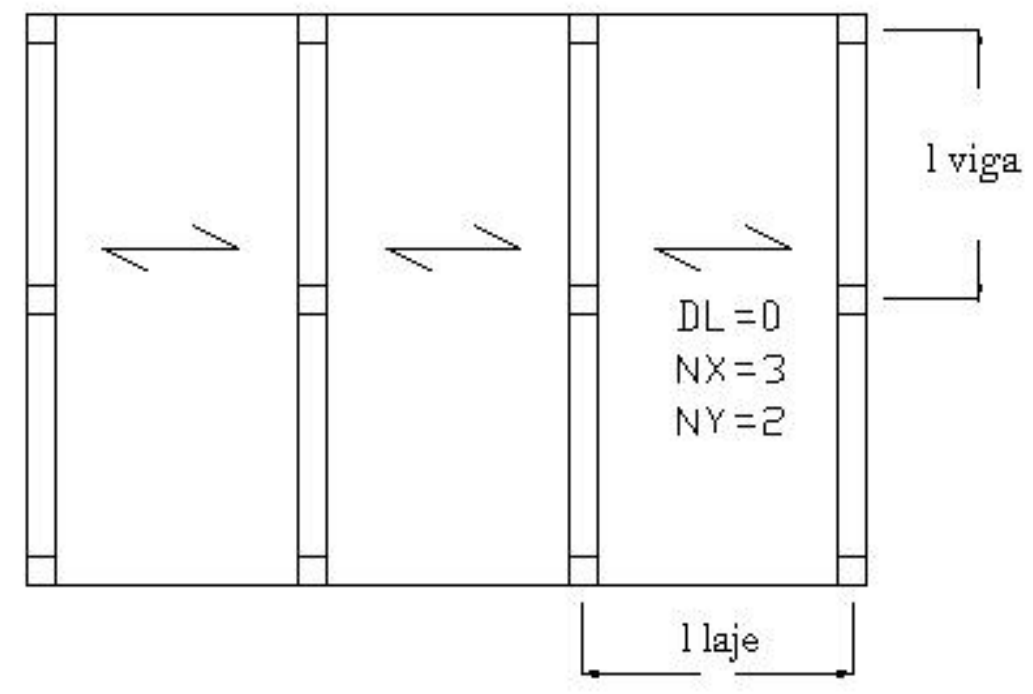

Figura 4-2 - Direção assumida pelas lajes e vãos (neste exemplo com 3 divisões na direção $X$ e 2 divisões na direção $Y$ )

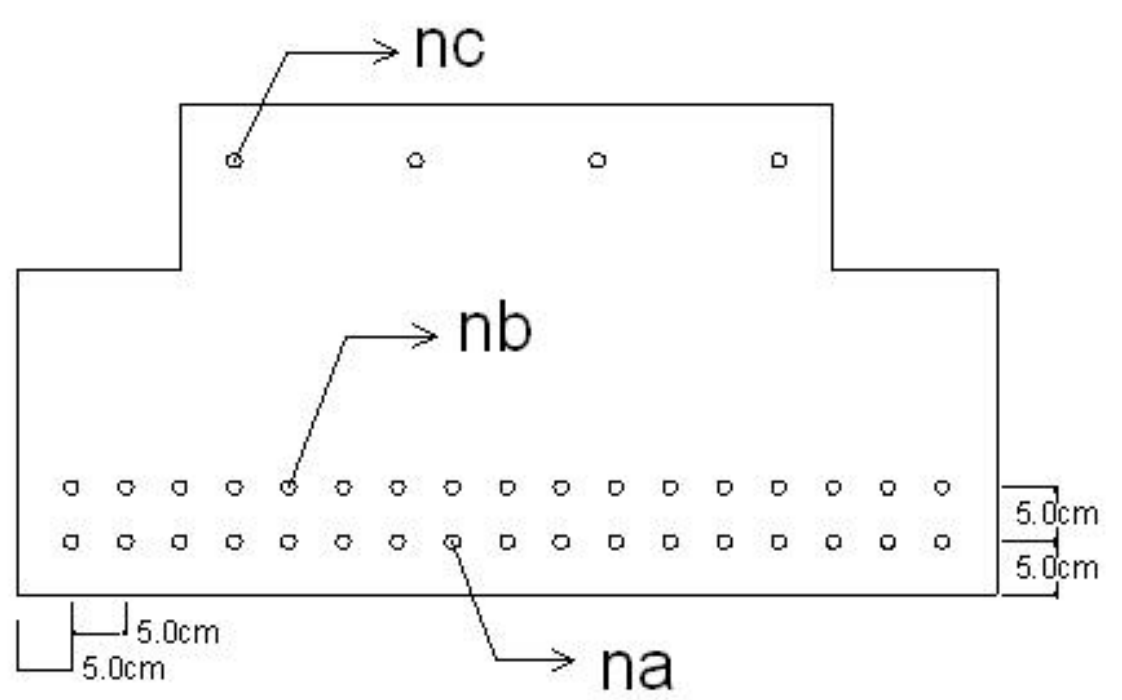

Figura 4-3 - Disposição dos cabos de protensão das vigas 
Tabela 4-1 - Características das lajes vinculadas à variável VL

\begin{tabular}{|c|c|c|c|c|c|c|}
\hline $\mathrm{VL}$ & $\mathrm{N}$ & $\begin{array}{c}\text { Cordoalha } \\
{\left[\mathrm{mm}^{2}\right]}\end{array}$ & $\mathrm{P}_{\mathrm{a}}(\mathrm{VL})[\mathrm{MN}]$ & $\begin{array}{c}\mathrm{h}_{\mathrm{L}}(\mathrm{VL}) \\
{[\mathrm{cm}]}\end{array}$ & $\begin{array}{l}x_{\text {máx }} \\
(\mathrm{VL}) \\
{[\mathrm{cm}]}\end{array}$ & $A_{p l}(V L)\left[m^{2}\right]$ \\
\hline 1 & 6 & 21,8 & 0,184351 & 9 & 6,5 & 0,000131 \\
\hline 2 & 8 & 21,8 & 0,245801 & 9 & 6,5 & 0,000174 \\
\hline 3 & 10 & 21,8 & 0,307251 & 9 & 6,5 & 0,000218 \\
\hline 4 & 12 & 21,8 & 0,368702 & 9 & 6,5 & 0,000262 \\
\hline 5 & 8 & 21,8 & 0,245801 & 13 & 7 & 0,000174 \\
\hline 6 & 8 & 30,3 & 0,341641 & 13 & 7 & 0,000242 \\
\hline 7 & 8 & 38,3 & 0,431843 & 13 & 7 & 0,000306 \\
\hline 8 & 8 & 46,5 & 0,524301 & 13 & 7 & 0,000372 \\
\hline 9 & 8 & 55,5 & 0,625778 & 13 & 7 & 0,000444 \\
\hline 10 & 8 & 21,8 & 0,245801 & 17 & 7,5 & 0,000174 \\
\hline 11 & 8 & 30,3 & 0,341641 & 17 & 7,5 & 0,000242 \\
\hline 12 & 8 & 38,3 & 0,431843 & 17 & 7,5 & 0,000306 \\
\hline 13 & 8 & 46,5 & 0,524301 & 17 & 7,5 & 0,000372 \\
\hline 14 & 8 & 55,5 & 0,625778 & 17 & 7,5 & 0,000444 \\
\hline 15 & 8 & 66,5 & 0,749806 & 17 & 7,5 & 0,000532 \\
\hline 16 & 8 & 38,3 & 0,431843 & 20 & 7,25 & 0,000306 \\
\hline 17 & 8 & 46,5 & 0,524301 & 20 & 7,25 & 0,000372 \\
\hline 18 & 8 & 55,5 & 0,625778 & 20 & 7,25 & 0,000444 \\
\hline 19 & 8 & 66,5 & 0,749806 & 20 & 7,25 & 0,000532 \\
\hline 20 & 8 & 101,4 & 1,143313 & 20 & 7,25 & 0,000811 \\
\hline 21 & 10 & 101,4 & 1,429142 & 20 & 7,25 & 0,001014 \\
\hline 22 & 8 & 38,3 & 0,431843 & 21 & 8 & 0,000306 \\
\hline 23 & 8 & 46,5 & 0,524301 & 21 & 8 & 0,000372 \\
\hline 24 & 8 & 55,5 & 0,625778 & 21 & 8 & 0,000444 \\
\hline 25 & 8 & 66,5 & 0,749806 & 21 & 8 & 0,000532 \\
\hline 26 & 8 & 101,4 & 1,143313 & 21 & 8 & 0,000811 \\
\hline 27 & 10 & 101,4 & 1,429142 & 21 & 8 & 0,001014 \\
\hline 28 & 8 & 38,3 & 0,431843 & 26 & 8,5 & 0,000306 \\
\hline 29 & 8 & 46,5 & 0,524301 & 26 & 8,5 & 0,000372 \\
\hline 30 & 8 & 55,5 & 0,625778 & 26 & 8,5 & 0,000444 \\
\hline 31 & 8 & 66,5 & 0,749806 & 26 & 8,5 & 0,000532 \\
\hline 32 & 8 & 101,4 & 1,143313 & 26 & 8,5 & 0,000811 \\
\hline
\end{tabular}


Tabela 4.2 - Características das vigas vinculadas à variável $\mathbf{V V}$

\begin{tabular}{cccc}
$\mathrm{VV}$ & $\begin{array}{c}\mathrm{h}_{\mathrm{v}}(\mathrm{VV}) \\
{[\mathrm{cm}]}\end{array}$ & $\begin{array}{c}\mathrm{b}_{\mathrm{w}}(\mathrm{VV}) \\
{[\mathrm{cm}]}\end{array}$ & $\begin{array}{c}\mathrm{n}_{\max }(\mathrm{VV}) \\
{[\mathrm{cm}]}\end{array}$ \\
\hline 1 & 20 & 40 & 13 \\
2 & 25 & 40 & 13 \\
3 & 30 & 40 & 13 \\
4 & 35 & 40 & 13 \\
5 & 40 & 40 & 13 \\
\hline 6 & 20 & 50 & 15 \\
7 & 25 & 50 & 15 \\
8 & 30 & 50 & 15 \\
9 & 35 & 50 & 15 \\
10 & 40 & 50 & 15 \\
\hline 11 & 20 & 60 & 17 \\
12 & 25 & 60 & 17 \\
13 & 30 & 60 & 17 \\
14 & 35 & 60 & 17 \\
15 & 40 & 60 & 17 \\
\hline 16 & 20 & 70 & 19 \\
17 & 25 & 70 & 19 \\
18 & 30 & 70 & 19 \\
19 & 35 & 70 & 19 \\
20 & 40 & 70 & 19 \\
\hline 21 & 20 & 80 & 21 \\
22 & 25 & 80 & 21 \\
23 & 30 & 80 & 21 \\
24 & 35 & 80 & 21 \\
25 & 40 & 80 & 21 \\
\hline 26 & 20 & 90 & 23 \\
27 & 25 & 90 & 23 \\
28 & 30 & 90 & 23 \\
29 & 35 & 90 & 23 \\
30 & 40 & 90 & 23 \\
& & &
\end{tabular}

\subsubsection{Restrições Analisadas}

São verificadas 20 restrições para as vigas e 17 restrições para as lajes, essas restrições estão detalhadas nos apêndices C e D e são referentes a:

a) Verificações das tensões normais nas fases transitórias (desmoldagem, transporte e montagem) que devem respeitar os limites da NBR-6118 (2003) de compressão e tração; 


$$
\begin{aligned}
& \left|\sigma_{\text {inf erior }}\right| \leq 0,7 \cdot\left(0,7 \cdot f_{c k P M}\right) \rightarrow \text { limite_compressão } \\
& \sigma_{\text {superior }} \leq f_{\text {ctk inf erior }} \rightarrow \text { limite_tração }
\end{aligned}
$$

b) Verificações dos estados limites de serviço, considerando protensão limitada, de descompressão e formação de fissuras, para combinações freqüentes e quasepermanentes respectivamente;

$\sigma_{\text {descompressão }} \leq 0$

$\sigma_{\text {formação_fissura }} \leq 1,5 \cdot f_{\text {ctk inf erior }}$

c) Verificação do momento resistente em relação ao momento de cálculo (ELU);

$M_{\text {resistente }} \leq M_{d}$

d) Verificação para que o $\beta_{x}$ esteja entre os limites do domínio 3, onde o $\beta_{x}=\frac{x}{d}$, que é a relação entre a distância da linha neutra e a face superior e a altura útil da peça;

$0 \leq \beta_{x} \leq 0,6$

e) Verificações dos vãos dos elementos que devem ser maiores do que os mínimos estabelecidos pelo usuário;

$\ell_{\text {viga }} \geq \ell_{\text {minimo }}$

$\ell_{\text {laje }} \geq \ell_{\text {minimo }}$

f) Verificações das flechas totais finais;

$f+c f \leq \frac{\ell}{250}$

g) No caso das lajes há uma verificação para que a linha neutra fique acima dos alvéolos, para que seja considerada uma seção retangular;

$x_{\text {laje }} \leq x_{\text {máximo }}$

h) Verificação para que a relação vão da laje e altura total da laje (laje + capa) seja menor que 45 , relação apresentada pelo ACI (2005);

$\frac{\ell_{\text {laje }}}{h_{\text {laje }}+0,5} \leq 45$ 
i) Para as vigas há verificações a fim de que a quantidade de cabos, por camada, seja menor ou igual à capacidade máxima em função da largura da viga. Verifica, ainda, se a quantidade de cabos, na primeira camada, é maior que a quantidade deles, na segunda;

$$
n_{a, b} \leq n_{\text {máximo }}
$$

j) Verificação de que a altura total do pavimento e a largura da viga sejam menores do que os limites informados pelo usuário;

$$
\begin{aligned}
& h_{\text {total }} \leq \text { altura_máxima } \\
& b_{w} \leq l \text { arg ura_máxima }
\end{aligned}
$$

\subsection{FUNÇÃO-CUSTO}

O fabricante de pré-moldados entrega a estrutura montada no local, logo o SATD procura contemplar todos os custos efetivos, desde a fabricação até a montagem da estrutura pré-moldada. Esses custos se dividem em fabricação (insumos, mão-de-obra, custos indiretos, armazenamento, transporte interno), transporte externo, montagem, impostos e lucro (figura 4-4).

Segundo PRIOR et al. (1993), um sistema eficiente deve procurar otimizar a capacidade do meio de transporte e a utilização do equipamento de montagem. Além disso, devem-se considerar as diferenças entre as atividades, já que trabalhos distintos têm custos diferenciados. Cita-se, como exemplo, a fabricação da laje alveolar e da viga que utilizam procedimentos e equipamentos distintos.

Conforme o PCl (2004), um layout econômico deve contemplar a modulação das vigas em relação ao comprimento das pistas, para que se tenha um máximo de aproveitamento na produção, bem como uma análise dos equipamentos de transporte e montagem, de forma que todas as etapas sejam racionalizadas. 


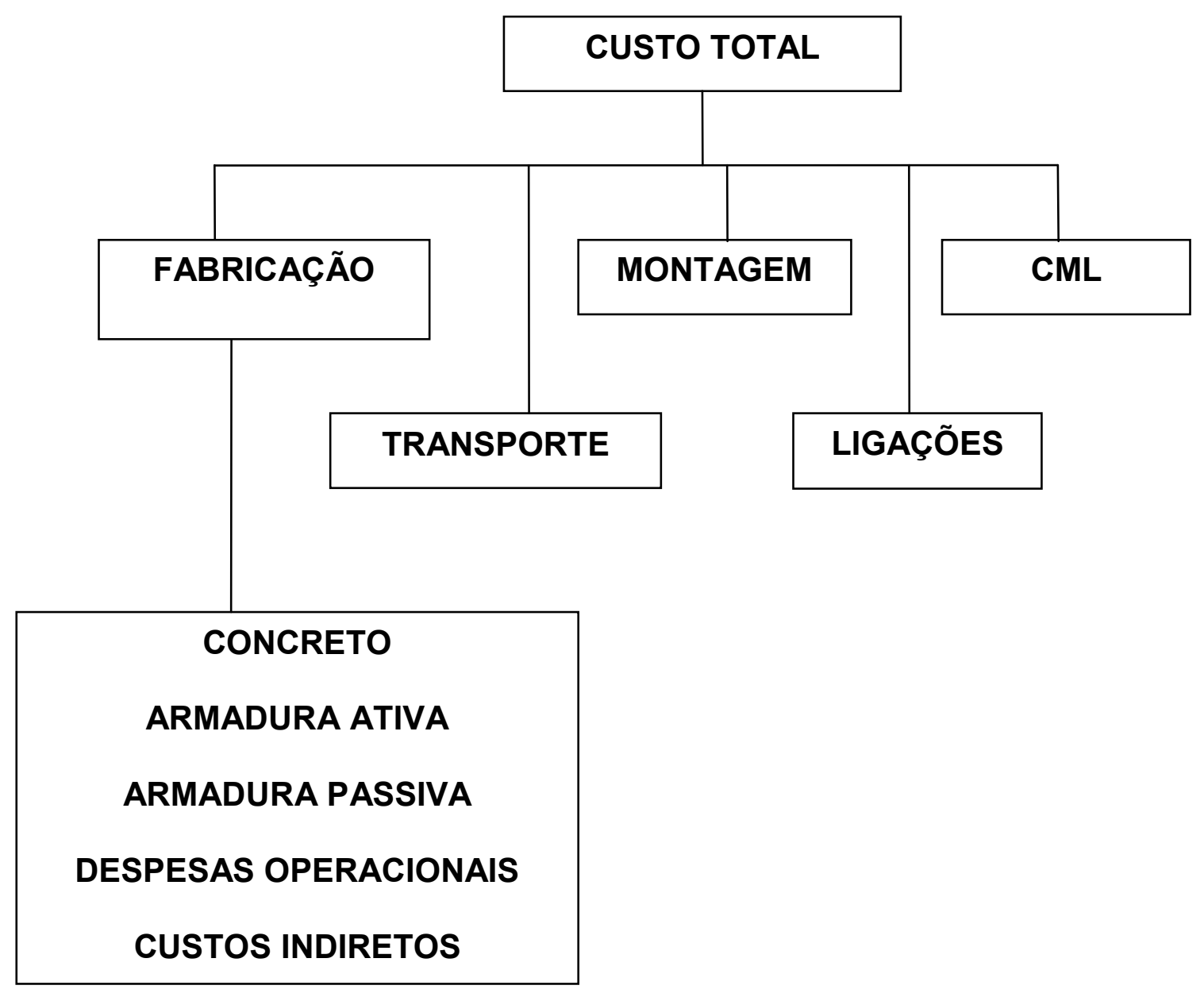

Figura 4-4 - Organograma da função Custo

Observa-se que as considerações feitas nos dois parágrafos anteriores estão contempladas no SATD. Ressalta-se que alguns valores numéricos dos custos não serão apresentados para resguardar a composição de custo do fabricante T\&A.

\subsubsection{Fabricação}

O custo de fabricação é composto pelo consumo de materiais e pelos custos com despesas operacionais. 


\section{Despesas Operacionais}

As despesas operacionais são compostas pela mão-de-obra da fabricação, utilização da pista de protensão, cura, armazenamento e transporte interno na fábrica das peças. Essas despesas operacionais são diferenciadas em função do elemento que está sendo produzido.

A fabricação das lajes alveolares, por ser um processo mais mecanizado e praticamente sem mão-de-obra, tem um custo de fabricação mais baixo e mais fácil de ser aferido. Por isso, adotaram-se custos unitários, por unidade de área de laje fabricada, para representar os custos operacionais desse elemento. Salienta-se, ainda, que mesmo no item custo com despesas operacionais de fabricação de lajes alveolares existem diferenciações em função do tipo de laje.

Por exemplo, a laje de espessura $h_{L}=32 \mathrm{~cm}$ requer que a moldadora se desloque com menor velocidade que resulta em uma produtividade mais baixa. Logo, o custo unitário com suas despesas operacionais é mais elevado.

Já a fabricação das vigas e pilares é um processo menos mecanizado que exige mais mão-de-obra. Esta mão-de-obra é necessária para o corte, dobra e o posicionamento da armadura passiva, para o ajuste das formas metálicas, concretagem, o adensamento, posicionamento dos cabos de protensão e colocação de insertos metálicos. Portanto, mais difícil de ser mensurado e, em função disso, o fabricante forneceu dados históricos que consideram todas as despesas operacionais, para a fabricação de vigas e pilares, embutidas no custo unitário do volume de concreto.

Por isso, os custos adotados por volume de concreto das vigas e dos pilares são diferentes dos custos unitários adotados para as lajes. Considerouse que o custo do concreto, para vigas e pilares, é $50 \%$ mais caro que o do concreto para as lajes.

Para o concreto moldado no local, adotou-se que as despesas operacionais seriam de $30 \%$ do valor do concreto, para considerar a mão-deobra de aplicação e a execução de formas localizadas.

As despesas operacionais ficaram definidas por: 
$D e s p ._{-} O p .=D e s p ._{-} O p ._{-} L a j e+D e s p .{ }_{-} O p ._{-} V i g a+D e s p ._{-} O p ._{-}$Pilar + Desp._Op._Cml

Desp._Op._Viga $=0,5 \cdot($ Custo_Concreto_Consumido_nas_vigas)

Desp._Op._Pilar $=0,5 \cdot($ Custo_CConcreto_CConsumido_nos_pilares $)$

Desp._Op._Cml $=0,3 \cdot($ Custo_Concreto_moldado_no_local $)$

- Despesa Operacional da Laje $\left(R \$ / \mathrm{m}^{2}\right)$ : valor adotado em função do tipo de laje a ser fabricada, sendo 24 ou $36 \mathrm{R} \$ / \mathrm{m}^{2}$;

- Despesa Operacional da Viga e Pilar (R\$): valor estimado em $50 \%$ do custo do concreto necessário para confecção das vigas e pilares;

- Despesa Operacional Concreto moldado no local (R\$): valor estimado em $30 \%$ do custo do concreto moldado no local.

\section{$\underline{\text { Consumo de materiais }}$}

Os insumos são compostos pelo concreto, aço de protensão, aço para armadura passiva, pela placa de policloropreno (conhecido comercialmente como neoprene) e solda que compõem as vigas, lajes e pilares.

De acordo com o que foi exposto, no custo unitário do concreto para vigas e pilares já foram embutidos os gastos com as despesas operacionais para a fabricação das vigas e dos pilares.

Para a consideração do consumo dos pilares, adotou-se uma distância de piso a piso de $3,50 \mathrm{~m}$, que é um pé-direito muito comum para as obras em pré-moldados. Foram considerados, ainda, para o levantamento de materiais e composição dos custos dos pilares os consolos (figura 4-5) e as placas de elastômero. Para a consideração da armadura dos pilares utilizou-se a tabela 3-3 com as taxas de aço. 


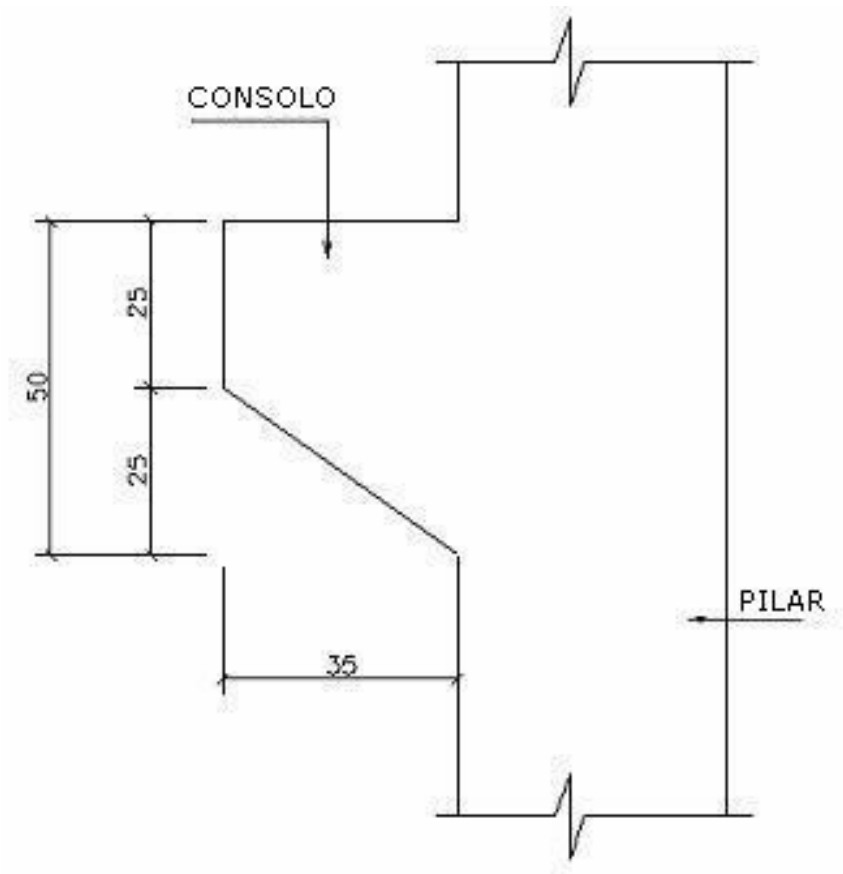

Figura 4-5 - Consolo (medidas em “cm")

Para o levantamento do consumo do aço de protensão, para vigas e lajes, levou-se em consideração a perda em função da modulação dos tamanhos dos elementos e do das pistas, já que os cabos são tracionados por todo o comprimento da pista. Segue, abaixo, a rotina para o cálculo das perdas das pistas para a confecção das lajes. Procedimento similar foi aplicado também para a confecção das vigas.

$$
\begin{aligned}
& N L P=\text { parte_int eira }\left(\frac{L P L}{\ell_{\text {laje }}}\right) \\
& Q P L=\text { parte_int eira }\left(\frac{Q L}{N L P}\right) \\
& P T A L=\left[(Q P L \cdot L P L)-\left(Q L \cdot \ell_{\text {laje }}\right)\right] \cdot A_{p l}(V L) \cdot c
\end{aligned}
$$

Onde:

- NLP : Número de elementos de laje por pista;

- LPL : Comprimento da pista de laje $(\mathrm{m})$; 
- QPL : Quantidade de pistas para confeccionar as lajes, em caso de fracionário arredondar para o próximo superior;

- PTAL : Perda total de aço de protensão para as lajes $(\mathrm{kg})$;

- QL : Quantidade de elementos de laje;

- $\quad \ell_{\text {laje }}$ : Vão da laje $(m)$;

○ c : Consumo de aço $\left(\mathrm{kg} / \mathrm{m}^{3}\right)$.

Ainda sobre o aço de protensão considerou-se uma diferença de custo entre o aço utilizado na laje e na viga, visto que na viga há uma maior variação na quantidade e no posicionamento dos cabos, de forma que torna a atividade mais demorada e, conseqüentemente, mais cara. Por isso, o custo do aço de protensão $(\mathrm{R} \$ / \mathrm{kg})$ para viga foi considerado $8,5 \%$ mais caro que o aço para a laje (informação fornecida pela T\&A).

Para a consideração da armadura passiva das vigas, computaram-se as barras passivas dimensionadas pelo SATD, à flexão, os porta-estribos, os estribos e a armadura de ligação entre vãos adjacentes, para os momentos negativos.

O custo unitário $\left(\mathrm{R} \$ / \mathrm{m}^{3}\right)$ do concreto, em função de sua resistência característica, foi estimado baseado nos dados do fabricante e de uma usina de concreto. De maneira geral, o custo do $\mathrm{m}^{3}$ do concreto aumenta $8 \%$ quando se aumenta a sua resistência em $5 \mathrm{MPa}$, para a faixa considerada de $20 \mathrm{MPa}$ a $50 \mathrm{MPa}$.

Sobre o concreto moldado no local, computou-se a capa em todo o pavimento, exceto na região dos pilares, e, o complemento das vigas que também é feito com concreto moldado no local.

Assim tem-se que:

Concreto $=$ Conc._Lajes + Conc._Vigas + Conc._Pilares + Cml

Aço_Protensão $=($ Aço_Prot._Vigas $) \cdot 1,085+$ Aço_Prot._Lajes

Armadura_Passiva $=$ Arm._Viga + Arm._Pilares

Arm._Viga $=$ Arm._Flexão + Estribos + Porta_Estribos + Ligação_Negativa

Insumos $=$ Concreto + Aço_Protensão + Arm._Passiva + Neoprene 


\subsubsection{Custos Indiretos}

Os custos indiretos são compostos pelos custos fixos da indústria, e, pela manutenção e depreciação dos equipamentos de produção. Os custos fixos englobam despesas com salários, contabilidade, energia, telefone, marketing, material de escritório, manutenção do escritório, aluguel e combustível.

Para a consideração dos custos indiretos, a indústria fez um levantamento médio-histórico anual dos seus custos indiretos e do seu volume de fabricação. Diante disso, calculou-se um fator, a partir do resultado da divisão entre os custos indiretos médios e o custo de fabricação médio. Esse fator permite que se estimem os custos indiretos devidos à fabricação de uma determinada estrutura, bastando que o multiplique pelo custo de fabricação. Tem-se então que:

$$
\begin{aligned}
& \text { Fator }_{\text {Custos_Indiretos }}=\frac{\text { Custos_Indiretos_Médios }}{\text { Custo_Fabricação_ }{ }_{-} \text {Médio }} \\
& \text { Custo_Fab.+Custos_Indiretos }=(\text { Insumos }+ \text { Despesas_Operacionais }) \cdot\left(F_{\text {Custos_Indiretos }_{-}}+1\right)
\end{aligned}
$$

Os custos indiretos são calculados vinculados diretamente aos custos de fabricação, por serem decorrentes da atividade industrial, que é a fabricação de elementos pré-moldados. Já os gastos com transporte e montagem não sofrem incidência dos indiretos, por serem independentes.

Adotou-se para esse fator Fator $_{\text {Custos__ndiretos }}=0,33$, em função das informações coletadas com a indústria.

\subsubsection{Transporte}

Para a composição do custo de transporte, adotaram-se duas alternativas de utilização: carreta comercial ou carreta extensiva. Esta tem um custo por viagem mais elevado, $60 \%$ mais caro, e é necessária quando o elemento tem um comprimento superior a $12,5 \mathrm{~m}$. Considerou-se, de acordo 
com as informações do fabricante, que as duas carretas têm uma capacidade de transportar $250 \mathrm{kN}$ por viagem, ou seja, o equivalente a $10 \mathrm{~m}^{3}$ de concreto.

Diante disso, adotou-se uma rotina para identificar o custo por viagem do transporte dos elementos, em função dos comprimentos das lajes, vigas e dos pilares, uma vez que inicialmente se precisaria classificar se eles seriam transportados pela carreta comercial ou extensiva. Posteriormente calcula-se o número de viagens necessárias em função do volume e da quantidade das peças, e, por fim, multiplica-se pelo custo das viagens. Então o custo de transporte é:

Custo_Transporte Elementos $_{-}=\operatorname{int}$ eiro $\left(\frac{\text { Volume }_{\text {Elementos }}}{10}\right) \cdot$ Custo_viagem $\rightarrow(R \$)$

- Elementos: vigas, lajes e pilares em separado;

- Número de viagens: no caso de um número fracionário adota-se o inteiro superior;

- Custo viagem: carreta comercial ou extensiva, de acordo com o comprimento dos elementos.

Os custos por viagem para carreta comercial e extensiva estão parametrizados, considerando que as viagens se fazem na mesma cidade da fábrica.

\subsubsection{Montagem}

A composição de custos do item montagem é dividida em custo do aluguel do guindaste e custo da mão-de-obra. Adotou-se um guindaste com um custo de aluguel de $\mathrm{R} \$ 1.100,00$ por dia e cuja produtividade é apresentada na tabela 4-3. Para a consideração da mão-de-obra considerou-se $R \$ 400,00$ por dia. 
Tabela 4-3 - Número de elementos montados por dia.

\begin{tabular}{|l|c|}
\hline Elemento & $\begin{array}{c}\text { Número } \\
\text { elementos }\end{array}$ \\
\hline Pilar & 8 \\
\hline Viga & 16 \\
\hline Laje & 24 \\
\hline
\end{tabular}

Logo, em função do número de peças montadas, por dia, para cada elemento, calcula-se a quantidade de dias necessária para a montagem da estrutura, e multiplica-se pelo valor do aluguel mais o custo da mão-de-obra diária para montagem. Para definição da quantidade de dias necessária computa-se a quantidade de dias para os pilares e, posteriormente, computase a quantidade de dias para vigas e lajes em conjunto.

Custo_Montagem $=\left\{\right.$ Inteiro $\left(\frac{\text { Qde.Vigas }}{16}+\frac{\text { Qde.Lajes }}{24}\right)+$ Inteiro $\left.\left(\frac{\text { Qde.Pilares }}{8}\right)\right\} \cdot$ Custo_dia

Para o cálculo do número de dias considerou-se sempre o inteiro superior, ou o próprio valor para o caso de número inteiro.

\subsubsection{Custos Finais}

Os custos finais devem levar em consideração, além da fabricação, custos indiretos, transporte e montagem, os custos relativos aos impostos e o lucro. Para isso o fabricante utiliza um fator que incide globalmente sobre todos os custos. Embora existam algumas diferenças entre as alíquotas de impostos, o fator é uniforme para que exista, propositalmente, uma margem no preço final que permita alguma acomodação para eventuais falhas na estimativa dos custos indiretos.

Custo_Final $=\left\lfloor(\right.$ Fabricação $) \cdot\left(F_{\text {Custos_Indiretos }_{-}}+1\right)+$ Transporte + Montagem $\rfloor \cdot$ Fator $_{\operatorname{Im} \text { postos }+ \text { Lucro }}$ 
A cooperação do fabricante T\&A foi fundamental para a composição da função custo apresentada e todos os dados tiveram como base o ano de 2007.

\subsection{CARACTERÍSTICAS DO ALGORITMO GENÉTICO IMPLEMENTADO}

Os fundamentos dos algoritmos genéticos são apresentados resumidamente no apêndice $\mathrm{E}$. Para informações completas recomenda-se GOLDBERG (1983) e CASTILHO (2003).

Em CASTILHO (2003), foram feitos vários testes variando-se os operadores: seleção, cruzamento, mutação e restauro da população. Em todos os exemplos apresentados, foi utilizada uma alternativa denominada MGA1, baseando-se na seleção tipo RANK e implementada por CASTILHO (2003). Este algoritmo genético apresentou sempre excelentes resultados e por isso a maioria de seus operadores também foi implementada neste trabalho. Segue um resumo do funcionamento do MGA1, conforme o fluxograma apresentado na figura 4-6.

Partindo de uma população inicial, gerada aleatoriamente, faz-se a ordenação tipo RANK. A partir dessa ordenação, já se estabelecem quais os indivíduos que passam pelo elitismo, de acordo com os dados de entrada, e a quantidade de indivíduos que participarão do cruzamento, que é calculada multiplicando-se $p$, que é a probabilidade de cruzamento, pelo tamanho da população. Para completar a população, após o cruzamento, novos indivíduos são gerados randomicamente, e esta fase é chamada de restauro da população.

Por exemplo, para uma população de 100 indivíduos, cujo elitismo seja 1 e a probabilidade de cruzamento seja 0,8, o primeiro do RANK passa por elitismo , os próximos 80 vão para o cruzamento , gerando 80 descendentes, e os dezenove indivíduos restantes são descartados e novos dezenove indivíduos são gerados aleatoriamente.

\subsubsection{Tamanho da População}

Existem algumas indicações na literatura sobre o tamanho da população inicial (KHAN (2002), GOLDBERG (1989) e CARROLL (1999)), mas observou- 
se que estas indicações forneciam populações iniciais muito pequenas e que os resultados não estavam satisfatórios. Diante disso, adotaram-se tamanhos de populações bem superiores nos exemplos testados, conforme LEMONGE (1999) que também usou populações bem superiores às preconizadas pelas equações abaixo.

KHAN (2002): $\ell<N_{P O P}<2 \cdot \ell \rightarrow 34<N_{p o p}<68$

GOLDBERG (1989): $N_{P O P}=1,65.2^{0,21 . l} \rightarrow N_{P O P}=233$

GOLDBERG $^{12}$ apud CARROLL ( 1999): $N_{P O P}=\frac{\ell}{\text { Cromossomo_Médio }} \cdot 2^{\text {Crom._Médio }}$ $\rightarrow N_{P O P}=94$

e: representa o tamanho do cromossomo;

O

Cromossomo médio: $\frac{\ell}{\text { quantidade_de_variáveis }}$

Observa-se que, além do tamanho do cromossomo, os indicativos de tamanho da população deveriam considerar a quantidade e intensidade das restrições verificadas. Como esta informação é muito particular de cada problema, acredita-se que o mais razoável seria calibrar cada modelo em função do problema analisado. Determina-se assim o tamanho da população, a quantidade de gerações e os parâmetros do algoritmo genético (elitismo, probabilidade de cruzamento e mutação).

O tamanho da população influencia diretamente a sua diversidade. Adotou-se como estratégia a geração de uma população inicial bem maior, que é avaliada e ordenada. Dessa forma selecionam-se os melhores indivíduos para entrarem no ciclo evolucionário com uma população previamente selecionada, conforme o pseudo-código apresentado na Figura 4-7.

${ }^{12}$ GOLDBERG, D. E. et al. (1992). "Genetic Algorithms, Noise, and Sizing of Populations” In: Complex System, Vol.6, Complex System Pub., Inc., 1992, pp. 333-362 


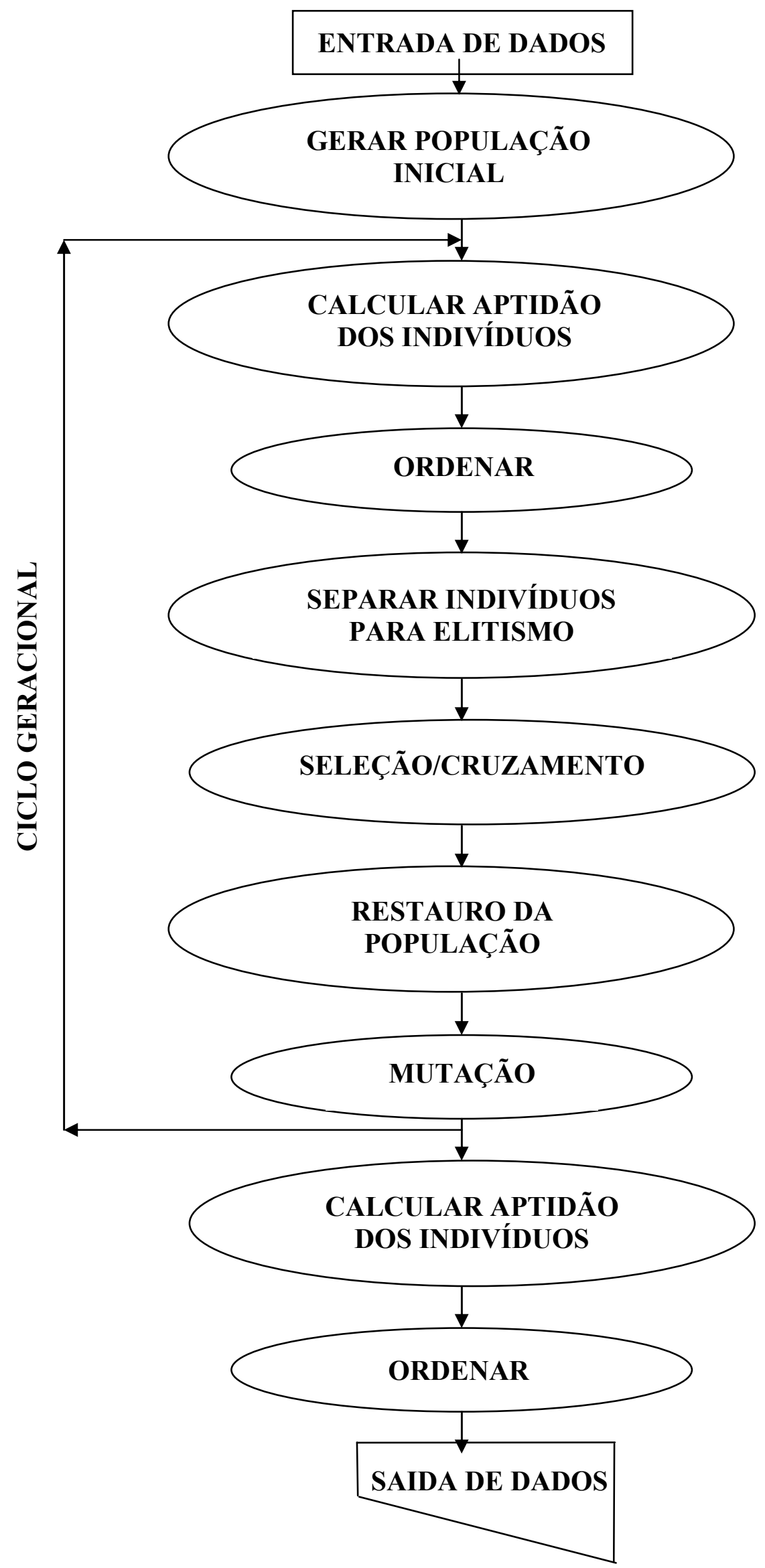

Figura 4-6 - Fluxograma geral do SATD 
Seja NUMIND o número de indivíduos especificado pelo usuário

Gerar uma população aleatoriamente com 10*NUMIND indivíduos

Calcular a função aptidão dos indivíduos

Ordenar os indivíduos

Selecionar os primeiros NUMIND individuos para iniciar o ciclo geracional

Fim

Figura 4-7 - Pseudo-código para a população inicial

Para avaliar esta estratégia fizeram-se vários exemplos, considerando uma população inicial dez vezes maior que o tamanho da população adotada pelo usuário (Numind). Os resultados encontram-se na Tabela 4-4.

Tabela 4-4 - Valor da função aptidão do melhor indivíduo para dez processamentos

\begin{tabular}{ccc}
\hline $\begin{array}{c}\text { População } \\
\text { Inicial }\end{array}$ & Numind & 10Numind \\
\hline & & \\
Apt(1) & 23950,00 & 24330,00 \\
Apt(2) & 24600,00 & 25390,00 \\
Apt(3) & 24960,00 & 24430,00 \\
Apt(4) & 24900,00 & 23740,00 \\
Apt(5) & 24020,00 & 24180,00 \\
Apt(6) & 25170,00 & 24540,00 \\
Apt(7) & 24390,00 & 24310,00 \\
Apt(8) & 24820,00 & 24900,00 \\
Apt(9) & 25040,00 & 25080,00 \\
Apt(10) & 24590,00 & 24570,00 \\
& & \\
\hline Média & 24644,00 & 24547,00 \\
Desvio & 417,70 & 474,09 \\
\hline
\end{tabular}

A partir desses resultados, optou-se por adotar uma população inicial dez vezes maior do que a população do ciclo geracional, que segundo a tabela 4-4 apresentou uma menor média nos processamentos. Este fato ratifica os resultados apresentados em KICINGER \& ARCISZEWSKI (2004), nos quais são melhores os indivíduos quando o processo inicia com uma população inicial de melhor qualidade. 


\subsubsection{Variáveis de Projeto}

As variáveis de projeto são parâmetros que definem o problema, quando se caminha no espaço de busca. Os valores, alimentados aleatoriamente pelo sistema, permitem que seja calculada a função-aptidão de cada indivíduo. Algumas variáveis auxiliares são necessárias para que o AG possa lidar com as listas. As variáveis de projeto são:

a) DL: Direção da laje;

b) $\mathrm{N}_{\mathrm{X}}$ e $\mathrm{N}_{Y}$ : Números de vãos em que serão divididas as dimensões do pavimento (figura 4-2). A partir desta informação e da direção da laje, pode-se calcular os vãos das lajes $\left(\ell_{\text {laje }}\right)$ e das vigas $\left(\ell_{\text {viga }}\right)$, que são variáveis dependentes;

$$
\begin{aligned}
& \ell_{\text {laje }}=\left(\frac{\ell_{X}}{N_{X}}\right) \cdot(1-D L)+\left(\frac{\ell_{Y}}{N_{Y}}\right) \cdot D L \\
& \ell_{\text {viga }}=\left(\frac{\ell_{X}}{N_{X}}\right) \cdot(D L)+\left(\frac{\ell_{Y}}{N_{Y}}\right) \cdot(1-D L)
\end{aligned}
$$

c) PM e CML: Variáveis auxiliares que vão determinar os valores das resistências do concreto moldado no local e do concreto prémoldado em função das listas;

d) ANPT e ABP: Variáveis auxiliares que vão determinar, em função das listas, a quantidade e a bitola da armadura passiva das vigas;

e) ANA e ANB: Variáveis auxiliares que vão determinar, em função das listas, a quantidade de cordoalhas de protensão nas vigas;

f) VL: Tipo de laje, definindo geometria e protensão;

g) V: Tipo de viga, definindo geometria. 
Cada fabricante já possui as formas para as vigas, definindo suas possíveis variações de geometria, possui as máquinas para a confecção das lajes e as características da pista que definem as características da protensão. A partir disto tem-se que:

a) As vigas e lajes foram apresentadas nas tabelas 4-1 e 4-2;

b) A quantidade de barras de armaduras passivas NPT(i) pode assumir os valores: 0, 2, 4 e 6. Essas barras são posicionadas, na zona inferior da viga, para ajudar a resistir aos esforços de momentos fletores positivos;

c) A área das bitolas de armaduras passivas BP(i) pode assumir os valores correspondentes às áreas das barras de $6,0 \mathrm{~mm}, 8,0 \mathrm{~mm}, 10,0 \mathrm{~mm}$ e 12,5 mm. Essas bitolas são utilizadas com a quantidade do item anterior;

d) A quantidade de cordoalhas na primeira camada da viga $\mathrm{n}_{\mathrm{A}}(\mathrm{i})$ pode ser: $3,5,6,7,8,10,13,14,15,16,17,18,19$, 20, 21 e 23;

e) A quantidade de cordoalhas na segunda camada da viga $\mathrm{n}_{\mathrm{B}}(\mathrm{i})$ pode ser: $0,2,4,6,8,10,12$ e 14 ;

f) $O$ número de divisões de vãos nas direções $X$ e $Y\left(N_{X}\right.$ e $N_{Y}$ ) podem ser de 1 a 16 . Considerando que a dimensão máxima do pavimento seja de $80 \mathrm{~m}$, tem-se que 16 divisões proporcionariam um vão de 5,0 m, no mínimo, que é razoável;

Por isto foram necessárias variáveis auxiliares inteiras para se fazer a locação das variáveis de projeto com seus valores em uma lista. As listas possibilitam a decodificação do genótipo no fenótipo. Como exemplo tem-se que: 
$N P T(A N P T)_{A N P T=0}^{A N P T=3}=$ Lista

Tem-se abaixo a lista com os possíveis valores de quantidade de barras de armaduras passivas.

$\operatorname{NPT}(0)=0$

$\operatorname{NPT}(1)=2$

$\operatorname{NPT}(2)=4$

$\operatorname{NPT}(3)=6$

A variável auxiliar ANPT varia de 0 a 3 (binário de 2 bits), baseada no comprimento do binário dado por:

$2^{\ell}=n b$

- $\quad \ell$ : quantidade de bits ou tamanho do cromossomo;

- $\mathrm{nb}$ : quantidade de opções na lista.

Se a variável ANPT fosse representada por 10, a sua decodificação, na base 10, seria calculada por $A N P T=1 \cdot 2^{1}+0 \cdot 2^{0}=2$, que apontaria para a terceira posição na lista, ou seja, 4 barras de armadura passiva.

\subsubsection{Representação}

Um aspecto importante da representação é dar a possibilidade de surgirem todas as soluções possíveis no domínio. Segundo MICHALEWICZ (1994), uma representação binária não seria eficiente para problemas com configuração em torno 100 variáveis de projeto e com domínio variando entre [500:500], que não é o caso do problema em questão.

Por se tratar, em sua maioria, de variáveis que as regiões viáveis pertencem à indústria, ou seja, que têm suas possíveis geometrias e dimensões estabelecidas, são variáveis discretas e, por isso, adotou-se que todas as variáveis também seriam discretas. Desta forma uniformizou-se a 
representação das variáveis. Em se tratando de variáveis discretas adotou-se a representação binária que seria a mais indicada para a formação das listas.

\subsubsection{Tamanho do Cromossomo}

O comprimento do cromossomo é variável em função dos dados de entrada, ou seja, se estipula o espaço de busca, baseado nas restrições arquitetônicas e com isso se fixa o tamanho do cromossomo. Isso não quer dizer que se tenha adotado tamanho de cromossomo variável, pois que, uma vez definido o tamanho do cromossomo, ele permanece constante até o fim do processamento.

Esta variação do cromossomo se dá por meio da redução do espaço de busca, ou seja, redução da lista. A quantidade máxima de bits que um indivíduo pode ter é 34 (Tabela 4-5), mas, em função de cada estrutura, pode diminuir até uma quantidade de 29 bits. Esta variação, no tamanho do cromossomo, se dá em função da distância mínima entre pilares e da largura máxima da viga.

Tabela 4-5 - Comprimento máximo do cromossomo (quantidade máxima de bits)

\begin{tabular}{|c|c|}
\hline Variável de projeto & $\begin{array}{c}\text { Tamanho do } \\
\text { cromossomo (bits) }\end{array}$ \\
\hline $\mathrm{Nx}$ & 4 \\
\hline $\mathrm{Ny}$ & 4 \\
\hline $\mathrm{DL}$ & 1 \\
\hline $\mathrm{pm}$ & 2 \\
\hline $\mathrm{cml}$ & 2 \\
\hline $\mathrm{VL}$ & 5 \\
\hline $\mathrm{VV}$ & 5 \\
\hline $\mathrm{n}_{\mathrm{A}}$ & 4 \\
\hline $\mathrm{n}_{\mathrm{B}}$ & 3 \\
\hline $\mathrm{npt}$ & 2 \\
\hline $\mathrm{bp}$ & 2 \\
\hline Comprimento Total & 34 \\
\hline
\end{tabular}


4.4.4.1 Distância mínima entre pilares

Calcula-se a quantidade máxima de vãos que se pode ter em cada direção, utilizando-se os ajustes $A_{J X}$ e $A_{J Y}$, e, em função deste valor, diminui-se o tamanho da lista, já que os vãos poderiam ser divididos em até 16 partes $\left(\mathrm{N}_{\mathrm{X}}\right.$ e $N_{Y}$ ). Desta forma evita-se que o sistema percorra um espaço que se sabe previamente infactível.

$$
\begin{gathered}
A_{J X}=\frac{\ell_{X}}{d_{\min X}} \\
A_{J Y}=\frac{\ell_{Y}}{d_{\min Y}}
\end{gathered}
$$

Os ajustes identificam a quantidade máxima de vãos que se podem dividir os lados do pavimento. Assim, tem-se a tabela 4-6 em função dos ajustes.

Tabela 4-6 - Número de bits das variáveis $\mathrm{N}_{X}$ e $\mathrm{N}_{Y}$

\begin{tabular}{|c|c|c|}
\hline$A_{J X}$ ou $A_{J Y}$ & $\begin{array}{c}\text { Número de bits da variável } \\
\left(N_{X} \text { ou } N_{Y}\right)\end{array}$ & $\begin{array}{c}\text { Número de divisões que o } \\
\text { vão pode assumir }\end{array}$ \\
\hline $4<A_{J X Y}<9$ & 3 & 8 \\
\hline$\geq 9$ & 4 & 4 \\
\hline$\leq 4$ & 2 & 46 \\
\hline
\end{tabular}

\subsubsection{Largura máxima da viga}

Em função da informação da largura máxima que a viga pode ter, fornecida nos dados de entrada, diminuem-se as opções da lista de vigas. 
Tabela 4-7 - Número de bits da variável VV

\begin{tabular}{|c|c|c|}
\hline$b_{\text {wmáx }}$ & $\begin{array}{c}\text { Número de bits da variável } \\
\mathrm{VV}\end{array}$ & $\begin{array}{c}\text { Número de vigas } \\
\text { disponíveis }\end{array}$ \\
\hline$>0.6$ & 5 & 32 \\
\hline$\leq 0.6$ & 4 & 16 \\
\hline
\end{tabular}

\subsubsection{Função-Objetivo Penalizada (Aptidão)}

Adotou-se a mesma estratégia de penalidade utilizada em RAJEEV \& KRISHNAMOORTHY (1992) e GOVINDARAJ \& RAMASAMY (2005), que é interessante por levar em consideração a intensidade dela.

Seja gj uma restrição genérica dada por:

$$
\begin{gathered}
g_{j}=\frac{\sigma_{\text {Calculado }}}{\sigma_{\text {Admissivel }}}-1 \leq 0 \\
\mathrm{E} \text { "C" dado por: } \\
C=\sum_{j=1}^{m} c_{j} \\
c_{j}=\left\{\begin{array}{l}
g_{j}-s e_{-} g_{j}>0 \\
0 \_s e_{-} g_{j} \leq 0
\end{array}\right\}
\end{gathered}
$$

Tem-se então que a função aptidão é:

$\phi=f(x) \cdot(1+K C)$

Onde $\sigma_{\text {calculado }}$ e $\sigma_{\text {admissivel }}$ são os valores calculados e admissíveis de uma determinada grandeza.

○ m= quantidade de restrições; 
- $\Phi=$ função-objetivo penalizada (função-aptidão);

- $\mathrm{K}=$ intensidade da penalização;

○ $g=$ restrições de desigualdade.

Sobre o valor da intensidade da penalização k, fez-se uma variação referente ainda à distância mínima entre pilares. Observa-se, no item 4.4.4.1, que a representação binária não permite, em geral, o corte na lista, exatamente no valor que divide a região viável da inviável. Por isso, ainda aparece a possibilidade de valores infactíveis relativos aos vãos mínimos. Então, com o intuito de aumentar a penalidade desses valores, adotou-se uma penalização extra para eles, multiplicando-se o valor do número de vãos ( $N_{X}$ ou $N_{Y}$ ) por 100 vezes quando fossem maiores que os valores dos ajustes $\left(A_{J X}\right.$ e $\left.A_{J Y}\right)$.

Adotou-se ainda uma estratégia de reparo em relação à variável de projeto largura máxima da viga (item 4.4.4.2), que, também, pelo mesmo motivo que foi apresentado no parágrafo anterior, pode ainda apresentar regiões de indivíduos infactíveis. Nesse caso, fez-se uma transformação na lista, quando a variável de viga (VV) assumia um valor infactível automaticamente aplicava-se uma subtração na variável (VV), de forma que voltasse para a região de indivíduos factíveis. Essa rotina é chamada de redução do domínio da base.

Essas duas estratégias adotadas, comentadas nos dois parágrafos anteriores, são na realidade estratégias de rejeição. A rejeição, em muitos casos, não é bem aceita por ser interessante para o otimizador caminhar por regiões infactíveis, mas que às vezes estão próximas do ótimo global. No caso em questão, não houve preocupação com este aspecto por se tratar de restrições geométricas do problema, ou seja, se era uma imposição da arquitetura não se terem vãos menores que um determinado valor ou, larguras de viga maiores que um determinado limite, seria uma perda de tempo computacional fazerem-se buscas por essas regiões.

A função penalidade funciona no algoritmo genético da mesma forma que o meio ambiente funciona na evolução das espécies, ou seja, faz pressão sobre a população para extrair os melhores indivíduos. Contudo, é importante que se mantenha a diversidade da população. Portanto a pressão do meio ambiente deve ser calibrada para evitar convergência prematura, devido a uma 
pressão muito forte, ou a obtenção de ótimos locais, devido a uma pressão muito fraca.

Para se fazer essa calibração processou-se três exemplos com três constantes de penalizações diferentes (Tabela 4-8), em função das soluções observou-se que os melhores resultados foram alcançados com a constante $k=20$. Porém, como se tem a idéia de fazer uma busca com uma grande população e com um grande número de gerações, adotou-se uma penalização intermediária $(k=15)$. A idéia é utilizar populações maiores com uma penalização um pouco mais branda a fim de permitir uma varredura maior no espaço de busca.

Tabela 4-8 - Valores da função aptidão para penalizações distintas

\begin{tabular}{lccc}
\hline & $\mathrm{K}=10$ & $\mathrm{~K}=20$ & $\mathrm{~K}=30$ \\
\hline & & & \\
Ex. 1 & 16590,00 & 16570,00 & 17070,00 \\
Ex. 2 & 7722,00 & 7643,00 & 7788,00 \\
Ex. 3 & 41300,00 & 41300,00 & 41300,00
\end{tabular}

Para o cálculo da função-aptidão, de cada individuo da população, verificam-se inicialmente as restrições e calculam-se as penalidades e então se calcula a função-aptidão $(\Phi)$, que é a função-objetivo multiplicada pela penalidade.

\subsubsection{Operadores genéticos}

\section{Seleção}

Os indivíduos selecionam-se para o elitismo, cruzamento, e para serem descartados em função de uma seleção tipo RANK. Na seleção tipo RANK os indivíduos têm sua função-aptidão calculada, e, em função desse valor, colocados em uma ordem crescente. Por se tratar de um problema de minimização, o primeiro indivíduo, que é o que tem a menor aptidão, é o melhor indivíduo. 
Em função do RANK, são retirados os indivíduos que vão seguir intactos para a próxima geração, e, escolhidos os que vão para o cruzamento. Essas quantidades são definidas nos dados de entrada do SATD por meio do elitismo, da taxa de cruzamento e do tamanho da população. O restante é descartado, e geram-se novos indivíduos, aleatoriamente, para restaurar a população.

\section{Cruzamento}

Adotou-se o cruzamento uniforme (figura 4-8) que foi testado em vários trabalhos (SAHAAB (2005) e CASTILHO (2003), por exemplo) e se mostrou bastante eficiente. Esse tipo de cruzamento consiste em se adotar uma máscara, de mesmo tamanho do cromossomo, e, em função dos valores de cada bit da máscara, padroniza-se a formação dos filhos. Adotou-se que, para o bit da máscara igual a "1", o bit do primeiro filho seria o mesmo do pai e o bit do segundo filho o mesmo da mãe. Para o bit da máscara igual a "0" se faz o contrário.

\begin{tabular}{|c|c|c|c|c|c|c|c|c|c|c|c|c|}
\hline Máscara & 1 & 0 & 1 & 0 & 1 & 0 & 0 & 0 & 1 & & & 1 \\
\hline Pai & 1 & 1 & 0 & 0 & 0 & 1 & 0 & 1 & 1 & 1 & & 1 \\
\hline Mãe & 0 & 1 & 1 & 0 & 1 & 0 & 0 & 0 & & 0 & & 1 \\
\hline Filho 1 & 1 & 1 & 0 & 0 & 0 & 0 & 0 & 0 & & & & 1 \\
\hline ho 2 & 0 & 1 & 1 & 0 & 1 & 1 & 0 & 1 & 1 & 1 & & 1 \\
\hline
\end{tabular}

Figura 4-8 - Exemplo de cruzamento uniforme

Para cada nova geração é criada aleatoriamente uma nova máscara, que é válida para todos os cruzamentos dentro dessa geração.

\section{Mutação}

Exceto os indivíduos que passaram pelo elitismo, todos os outros podem sofrer mutação. Adotou-se, na maioria dos exemplos, uma mutação de 1\%, valor utilizado em vários dos trabalhos da literatura. Esse valor foi verificado, 
também, mediante vários exemplos no SATD, como sendo uma boa recomendação.

Adotou-se no SATD que, para cada gene, seria gerado aleatoriamente um número real entre 0 e 100 , e, sempre que esse número fosse menor ou igual a taxa de mutação, o valor do gene seria trocado.

\subsubsection{Transgênicos}

Trata-se de uma modificação artificial imposta ao genótipo para melhorar alguma manifestação da característica do indivíduo (fenótipo). Segundo o biólogo Cláudio Picanço ${ }^{13}$, pesquisador do INPI, produz-se um transgênico quando se insere um gene de interesse e, por isso, é uma modificação pontual. Diferente da genética clássica, em que as características aparecem em função da aleatoriedade do cruzamento entre indivíduos com características diferentes.

No caso, foi adotado para o número de cabos de protensão na viga, a fim de evitar que apareçam mais cabos na segunda camada do que na primeira, que é, previamente sabido, uma situação antieconômica. O algoritmo sempre que decodifica uma situação dessa, automaticamente troca o valor de $\mathrm{n}_{\mathrm{B}}$ por $\mathrm{n}_{\mathrm{A}}$ e vice-versa, atribuindo o maior valor sempre a $\mathrm{n}_{\mathrm{A}}$.

Essa rotina é importante porque diminui a busca por alternativas que se sabe, previamente, não serem eficientes, e concentra a procura dentro de uma situação desejável. Para verificar a eficácia, foram feitos processamentos para dois exemplos, comparando os resultados sem a rotina dos transgênicos, implementada e com a rotina implementada.

Utilizou-se, como primeiro exemplo (tabela 4-9), um pavimento de $30 \mathrm{~m}$ por $15 \mathrm{~m}$, com uma restrição de vão mínimo de 7,0 m, com altura máxima de $60 \mathrm{~cm}$ e largura máxima da viga de $80 \mathrm{~cm}$. Para o segundo exemplo (tabela 410), repetiu-se o primeiro exemplo, alterando a restrição de vão mínimo para $5,0 \mathrm{~m}$.

\footnotetext{
${ }^{13}$ Correspondência eletrônica em maio de 2006
} 
Tabela 4-9 - Custo da estrutura dos melhores indivíduos para os processamentos do exemplo $1\left(\mathrm{R} \$ / \mathrm{m}^{2}\right)$

\begin{tabular}{|c|c|c|}
\hline Processamento & $\begin{array}{c}\text { SATD } \\
\text { sem Transgênico }\end{array}$ & $\begin{array}{c}\text { SATD } \\
\text { com Transgênico }\end{array}$ \\
\hline$(1)$ & 206,5 & 207,7 \\
\hline$(2)$ & 208,9 & 204,7 \\
\hline$(3)$ & 211,0 & 207,2 \\
\hline$(4)$ & 209,5 & 209,8 \\
\hline$(5)$ & 205,5 & 207,9 \\
\hline$(6)$ & 205,5 & 207,2 \\
\hline$(7)$ & 206,8 & 207,2 \\
\hline$(8)$ & 208,1 & 204,1 \\
\hline$(9)$ & 211,4 & 207,2 \\
\hline$(10)$ & 208,5 & 206,8 \\
\hline Média & 208,17 & 206,98 \\
\hline
\end{tabular}

Tabela 4-10 - Custo da estrutura dos melhores indivíduos para os processamentos do exemplo $2\left(\mathrm{R} \$ / \mathrm{m}^{2}\right)$

\begin{tabular}{|c|c|c|}
\hline Processamento & $\begin{array}{c}\text { SATD } \\
\text { sem Transgênico }\end{array}$ & $\begin{array}{c}\text { SATD } \\
\text { com Transgênico }\end{array}$ \\
\hline$(1)$ & 203,3 & 206,6 \\
\hline$(2)$ & 205,5 & 203,3 \\
\hline$(3)$ & 205,4 & 201,1 \\
\hline$(4)$ & 204,9 & 207,5 \\
\hline$(5)$ & 207,6 & 205,5 \\
\hline$(6)$ & 208,6 & 203,7 \\
\hline$(7)$ & 205,4 & 205,4 \\
\hline$(8)$ & 202,6 & 205,5 \\
\hline$(9)$ & 208,8 & 202,8 \\
\hline$(10)$ & 202,9 & 204,9 \\
\hline Média & 205,5 & 204,63 \\
\hline
\end{tabular}

Observou-se, no primeiro exemplo, uma redução média no custo da estrutura de $0,57 \%$ e, no segundo, uma redução média de $0,42 \%$. Além da 
redução do custo, observa-se que, na grande maioria dos processamentos com a rotina dos transgênicos, a convergência se deu antes em relação aos processamentos sem a rotina dos transgênicos. Com a implementação da rotina dos transgênicos a convergência passou a se dá, em média, na geração 1065 enquanto antes da implementação a convergência se dava, em média, na geração 1682.

Ressalta-se ainda que o SATD está parametrizado de forma que existem 16 opções de quantidades de cabos, na primeira camada, e, apenas 8 opções para a segunda camada (item 4.4.2), de forma que naturalmente já existem mais opções com mais quantidade na primeira camada. Então para testar o desempenho da rotina alterou-se esta parametrização para que se tivessem as mesmas 16 possibilidades na segunda camada e os resultados são apresentados na tabela 4-11. Observou-se que a redução média nos custos da estrutura passou a ser de $0,61 \%$.

Tabela 4-11 - Custo da estrutura dos melhores indivíduos para os processamentos do exemplo $3\left(\mathrm{R} \$ / \mathrm{m}^{2}\right)$

\begin{tabular}{|c|c|c|}
\hline Processamento & $\begin{array}{c}\text { SATD } \\
\text { sem Transgênico }\end{array}$ & $\begin{array}{c}\text { SATD } \\
\text { com Transgênico }\end{array}$ \\
\hline$(1)$ & 209,3 & 207,7 \\
\hline$(2)$ & 207,7 & 209,1 \\
\hline$(3)$ & 209,8 & 206,1 \\
\hline$(4)$ & 210,7 & 206,1 \\
\hline$(5)$ & 206,4 & 208,9 \\
\hline$(6)$ & 208,1 & 207,8 \\
\hline$(7)$ & 211,7 & 206,9 \\
\hline$(8)$ & 207,2 & 207,2 \\
\hline$(9)$ & 209,4 & 203,3 \\
\hline$(10)$ & 203,3 & 207,7 \\
\hline Média & 208,36 & 207,08 \\
\hline
\end{tabular}

Caso a rotina do transgênico não fosse implementada, a verificação de casos em que a segunda camada possui mais cabos do que a primeira seria feita através de uma penalização, que tornaria o SATD menos ágil. 


\subsubsection{Rotina dos Gêmeos}

Observou-se que, em alguns processamentos, os indivíduos da elite eram iguais, e então se inseriu uma rotina que verifica se os integrantes da elite são gêmeos (iguais). Caso a verificação seja positiva, um gêmeo é colocado para o cruzamento, e o primeiro indivíduo, que faria parte do cruzamento, entra no lugar deixado pelo gêmeo. A partir dessa implementação, foram refeitos exemplos em que apareciam gêmeos e obteve-se como resultado a inserção de novos indivíduos, sem se perder o melhor resultado que já havia sido encontrado. A partir do exemplo 1 fizeram-se novos processamentos, sem a rotina dos gêmeos (tabela 4-12), e chegou-se a uma redução média na melhor aptidão de $0,3 \%$, inclusive. De forma que houve uma melhoria na diversidade da população, além da melhoria na aptidão do melhor indivíduo.

Tabela 4-12 - Custo da estrutura dos melhores indivíduos para os processamentos do exemplo $3\left(\mathrm{R} \$ / \mathrm{m}^{2}\right)$

\begin{tabular}{|c|c|c|}
\hline Processamento & $\begin{array}{c}\text { SATD } \\
\text { sem Gêmeos }\end{array}$ & $\begin{array}{c}\text { SATD } \\
\text { com Gêmeos }\end{array}$ \\
\hline$(1)$ & 209,0 & 207,7 \\
\hline$(2)$ & 206,1 & 204,7 \\
\hline$(3)$ & 208,7 & 207,2 \\
\hline$(4)$ & 209,5 & 209,8 \\
\hline$(5)$ & 207,2 & 207,9 \\
\hline$(6)$ & 203,8 & 207,2 \\
\hline$(7)$ & 207,7 & 207,2 \\
\hline$(8)$ & 209,0 & 204,1 \\
\hline$(9)$ & 207,3 & 207,2 \\
\hline$(10)$ & 207,2 & 206,8 \\
\hline Média & 207,55 & 206,98 \\
\hline
\end{tabular}

Importante salientar que, na rotina dos gêmeos, se fez uma avaliação diretamente nas variáveis de projeto, comparando-se bit por bit, para verificar se eram todas iguais. Isso porque, se a comparação fosse no valor da aptidão, 
poder-se-ia desprezar indivíduos que tinham mesma aptidão, mas não eram exatamente iguais.

Salienta-se, ainda, que nos casos de pavimentos de planta quadrada os dois melhores indivíduos geralmente são iguais, apenas alternando a direção da laje e da viga, resultado que demonstra uma consistência do SATD.

\subsubsection{Comentários Finais Sobre O Algoritmo Genético Implementado}

Observando o resumo dos operadores genéticos utilizados nos trabalhos de otimização em engenharia estrutural, apresentado em KICINGER et al. (2005), verifica-se que os operadores implementados no presente trabalho são freqüentemente utilizados (Tabela 4-13, em negrito).

Tabela 4-13 - Operadores mais comumente utilizados, e ordenados em função de suas freqüências, valores do SATD em negrito

Fonte - KICINGER et al. (2005)

\begin{tabular}{|l|l|l|l|l|l|}
\hline Operador & 1 & 2 & 3 & 4 & 5 \\
\hline Representação & Binária & Real & Gráfica & $\begin{array}{l}\text { Computer } \\
\text { code }\end{array}$ & Outra \\
\hline $\begin{array}{l}\text { Tamanho } \\
\text { cromossomo }\end{array}$ & Fixo & Variável & - & - & - \\
\hline $\begin{array}{l}\text { População } \\
\text { inicial }\end{array}$ & Aleatória & $\begin{array}{l}\text { Previamente } \\
\text { conhecidas }\end{array}$ & $\begin{array}{l}\text { Definida } \\
\text { usuário }\end{array}$ & - & - \\
\hline $\begin{array}{l}\text { Tamanho } \\
\text { população }\end{array}$ & 1 & Fixa & Variável & - & - \\
\hline Seleção & Truncagem & Rank & Roleta & Torneio & Uniforme \\
\hline Mutação & 0 & Fixa & Adaptável & Aleatória & \\
\hline $\begin{array}{l}\text { Tipo } \\
\text { cruzamento }\end{array}$ & $N-p o i n t$ & Permuta & Uniforme & Subtree & $\begin{array}{l}\text { Definida } \\
\text { usuário }\end{array}$ \\
\hline $\begin{array}{l}\text { Taxa } \\
\text { cruzamento }\end{array}$ & 0 & Fixa & Adaptável & Aleatória & - \\
\hline
\end{tabular}




\section{EXEMPLOS do SATD}

Inicialmente foram feitos vários processamentos, baseados em dois exemplos, com o intuito de calibrar o SATD e verificar sua consistência. O primeiro exemplo foi o mesmo pavimento utilizado por PRIOR et al. (1993) para fazer testes comparativos entre os sistemas catalogados e o segundo foi o pavimento de um hotel em Omaha, NE, USA. Nesses processamentos, para calibração do SATD, utilizou-se uma função-custo simplificada.

Posteriormente, foram utilizados 2 projetos como bench-mark para validar os resultados do SATD, já com a função-custo completa implementada.

Por fim, executaram-se 3 exemplos para se analisar o comportamento do SATD. Dentre eles repetiram-se os dois exemplos que foram utilizados para a calibração.

\subsection{CALIBRAÇÃO DO SATD}

Conforme comentado no capítulo 4, cada modelo deve ser exaustivamente testado para estimar o tamanho da população, o número de gerações e os parâmetros do algoritmo genético. Diante disso fizeram-se os processamentos a seguir. $O$ procedimento de utilizar uma função-custo simplificada na fase de calibração é muito usual, e foi adotado na maioria dos trabalhos encontrados na literatura para diminuir o tempo dos processamentos. No caso utilizou-se uma função que considerava apenas o consumo de materiais.

\subsubsection{EXEMPLO APRESENTADO NO RELATÓRIO DA UNIVERSIDADE DE LEHIGH (ATLSS REPORT - PRIOR, 1993)}

O relatório final da pesquisa, realizada por PRIOR et al. (1993), apresenta uma série de comparações entre projetos de vários sistemas 
estruturais utilizando 3 configurações básicas de layout estrutural para um pavimento de 30,48 $\mathrm{m}$ x 60,96 $\mathrm{m}$ (figuras 5-1 a 5-3). Observa-se que as lajes e as vigas têm um vão mínimo de 7,62 m. Logo, se admite que havia uma restrição arquitetônica de que a distância mínima entre pilares seria de 7,62 m. Baseado neste exemplo, fez-se uma série de processamentos no SATD, tendo como dados de entrada as dimensões do pavimento $(30,48 \mathrm{~m} \times 60,96 \mathrm{~m})$ e a restrição de distância mínima entre pilares nas duas direções de 7,62 m.

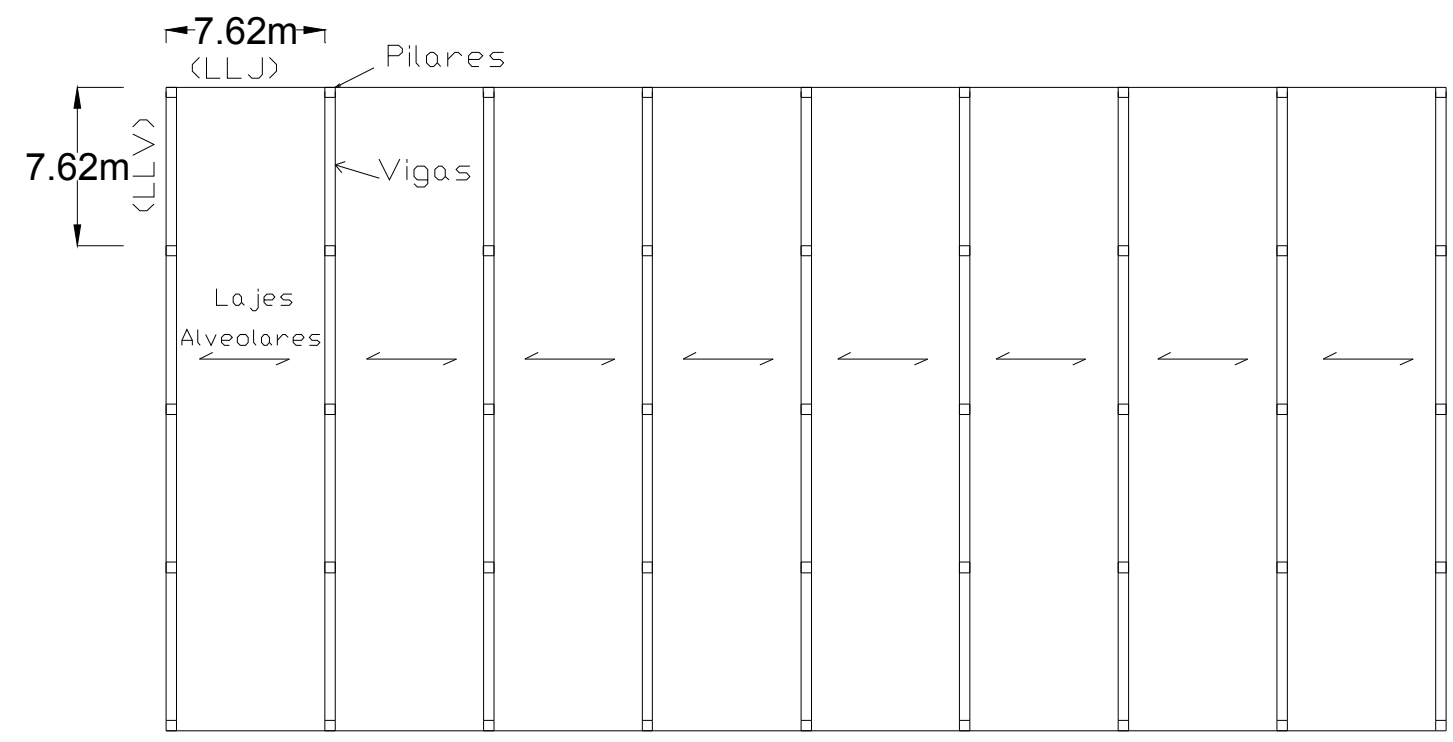

Figura 5-1 - Layout estrutural 1 ATLSS report

Fonte - PRIOR, R. (1993)

Em todos os processamentos, obteve-se, como melhor alternativa, a configuração da figura 5-1 que foi a primeira opção adotada pelo ATLSS report. Esse fato demonstra a consistência do sistema, por repetir em todos os processamentos, a mesma solução estrutural, além de demonstrar eficiência visto que se trata de uma alternativa sabidamente eficiente.

Foram feitos inicialmente 12 processamentos, de acordo com as características apresentadas na tabela 5-1, variando-se os valores dos operadores do algoritmo genético. Foram feitas variações no tamanho da 
população, na quantidade de gerações, na taxa de mutação e de cruzamento. Estas variações foram realizadas simultaneamente, e em separado, além de alguns processamentos que tiveram seus operadores mantidos fixos, como os de número 6 a 10. A aptidão do melhor indivíduo, de cada um desses processamentos, é apresentada na tabela 5-2.

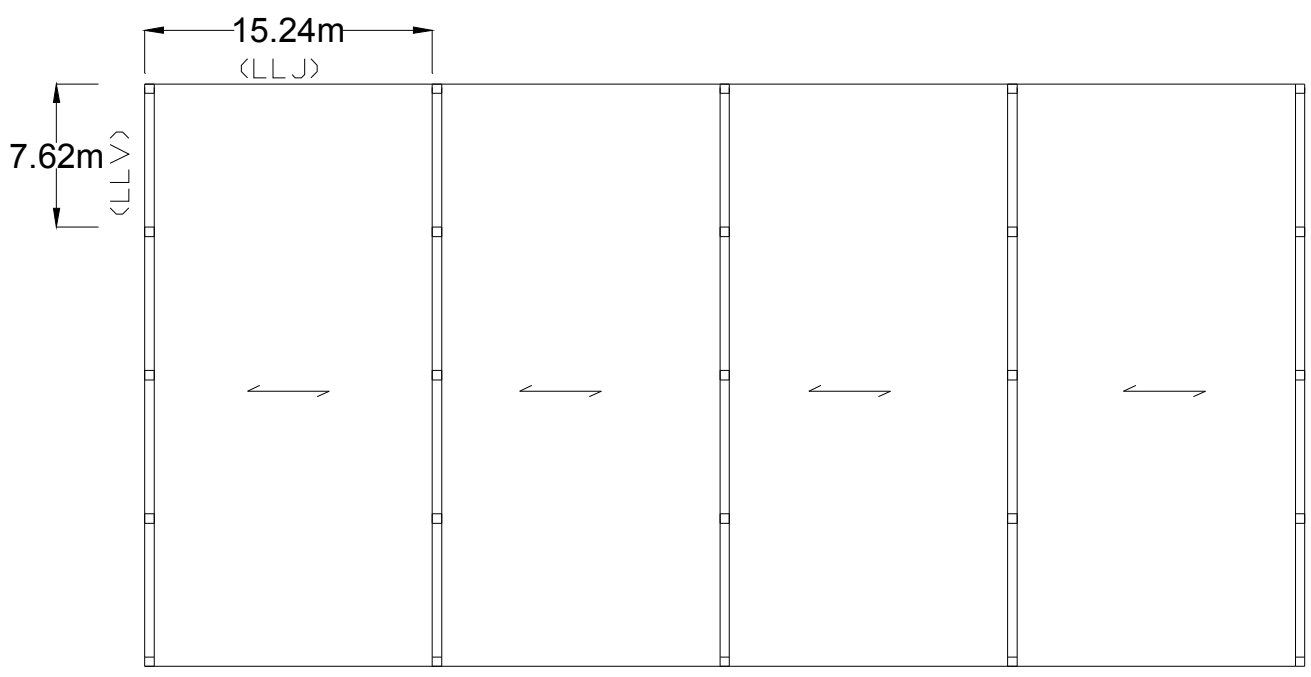

Figura 5-2 - Layout estrutural 2 ATLSS report Fonte - PRIOR, R. (1993) 


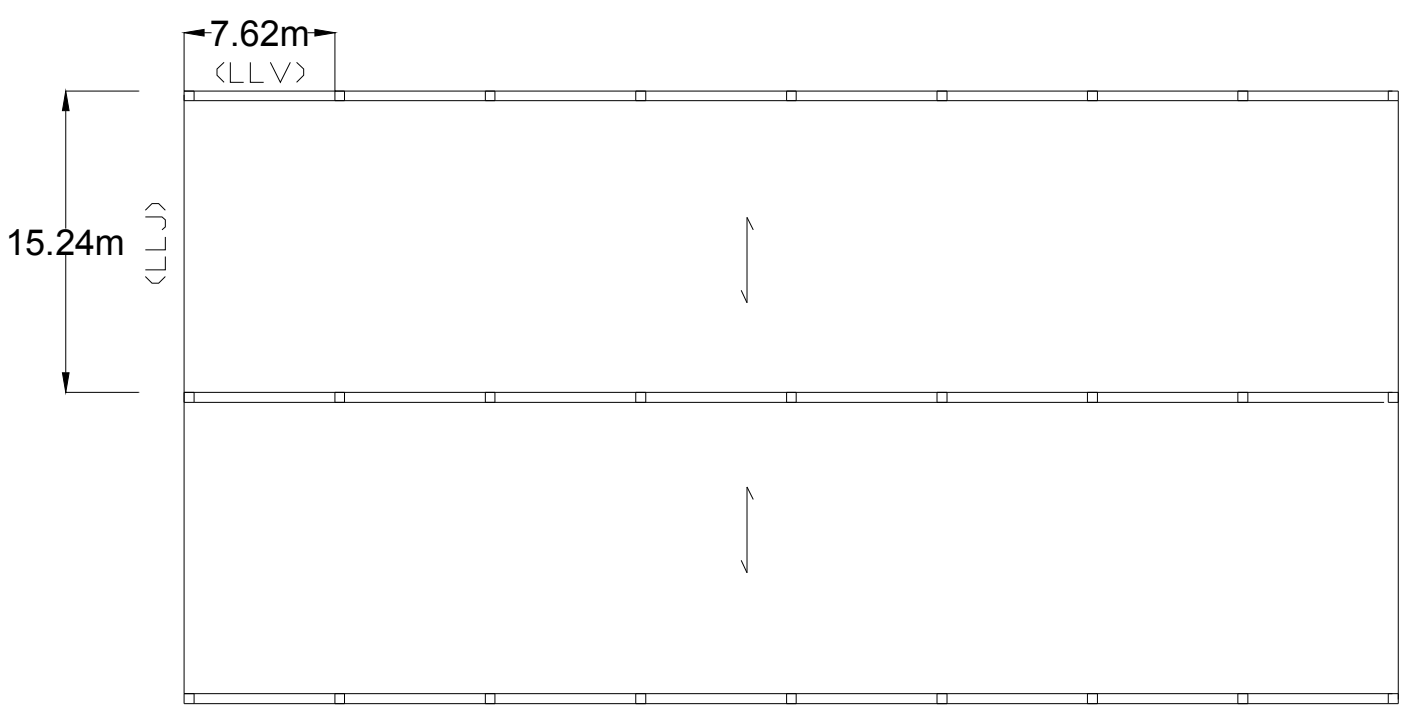

Figura 5-3 - Layout estrutural 3 ATLSS report

Fonte - PRIOR, R. (1993)

Tabela 5-1 - Características dos operadores em 12 processamentos

\begin{tabular}{|c|c|c|c|c|c|}
\hline Processamento & População & Gerações & $\begin{array}{c}\text { Cruzamento } \\
(\%)\end{array}$ & $\begin{array}{c}\text { Mutação } \\
(\%)\end{array}$ & Elitismo \\
\hline 1 & 700 & 3000 & 80 & 0,1 & 3 \\
\hline 2 & 700 & 6000 & 80 & 0,1 & 3 \\
\hline 3 & 1400 & 3000 & 80 & 0,1 & 3 \\
\hline 4 & 700 & 3000 & 80 & 1,0 & 3 \\
\hline 5 & 700 & 3000 & 60 & 1,0 & 3 \\
\hline $6(=5)$ & 700 & 3000 & 60 & 1,0 & 3 \\
\hline $7(=1)$ & 700 & 3000 & 80 & 0,1 & 3 \\
\hline $8(=1)$ & 700 & 3000 & 80 & 0,1 & 3 \\
\hline $9(=1)$ & 700 & 3000 & 80 & 0,1 & 3 \\
\hline $10(=1)$ & 700 & 3000 & 80 & 0,1 & 3 \\
\hline 11 & 1000 & 10000 & 80 & 1,0 & 3 \\
\hline 12 & 700 & 3000 & 80 & 2,0 & 3 \\
\hline
\end{tabular}


Tabela 5-2 - Aptidões dos melhores indivíduos dos 12 processamentos iniciais

\begin{tabular}{ccc}
\hline Processamento & $\begin{array}{c}\text { Aptidão } \\
\left(\mathrm{R} \$ / 10^{5}\right)\end{array}$ & $\Delta(\%)$ \\
\hline ATLSS1 & 1,459 & 0,90 \\
ATLSS2 & 1,47 & 1,66 \\
ATLSS3 & 1,465 & 1,31 \\
ATLSS4 & 1,471 & 1,73 \\
ATLSS5 & 1,45 & 0,28 \\
ATLSS6 & 1,469 & 1,59 \\
ATLSS7 & 1,459 & 0,90 \\
ATLSS8 & 1,465 & 1,31 \\
ATLSS9 & 1,449 & 0,21 \\
ATLSS10 & 1,471 & 1,73 \\
ATLSS11 & 1,446 & 0,00 \\
ATLSS12 & 1,45 & 0,28 \\
& & \\
\hline Menor Aptidão & 1,446 & \\
Maior $\Delta(\%)$ & & 1,73 \\
\hline
\end{tabular}

$\Delta=\left(\frac{\text { Aptidao }}{\text { Aptidao_min }_{\text {min }}}-1\right) \cdot 100$

A maior variação do valor da aptidão do melhor indivíduo, encontrada, nos 12 processamentos, foi de apenas $1,73 \%$ atestando assim a uniformidade do algoritmo.

Posteriormente, fizeram-se 20 processamentos variando-se apenas 0 número de gerações e o tamanho da população, separadamente (figura 5-4). Observa-se que, para a situação de 3000 gerações, a curva apresenta um resultado mais coerente, já que a aptidão apresenta uma tendência de diminuição com o acréscimo do tamanho da população. Para facilitar a visualização dessa observação, foram acrescentadas à figura 5-4 suas linhas de tendência (figura 5-5). Diante disso, serão adotados, como parâmetros, para os próximos processamentos, 3000 gerações e uma população de 700 indivíduos. 


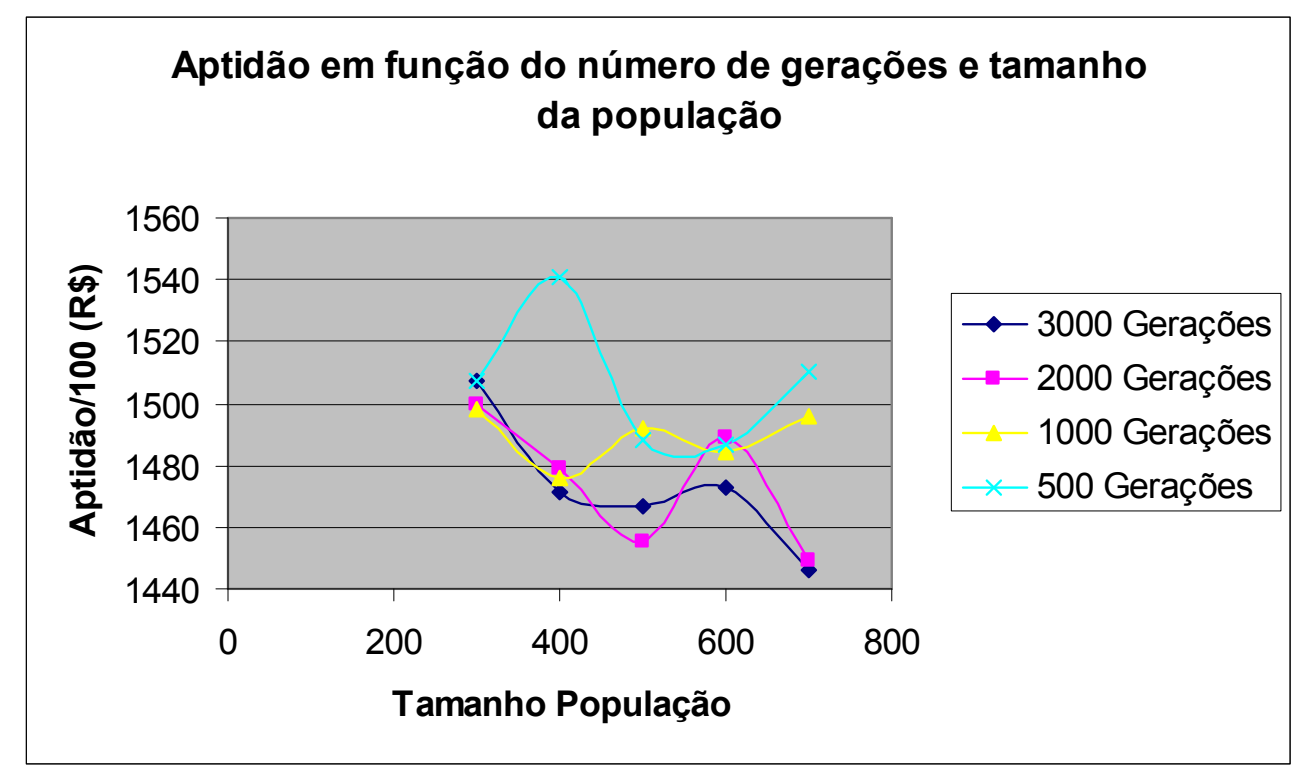

Figura 5-4 - Aptidões em função do número de gerações e tamanho da população

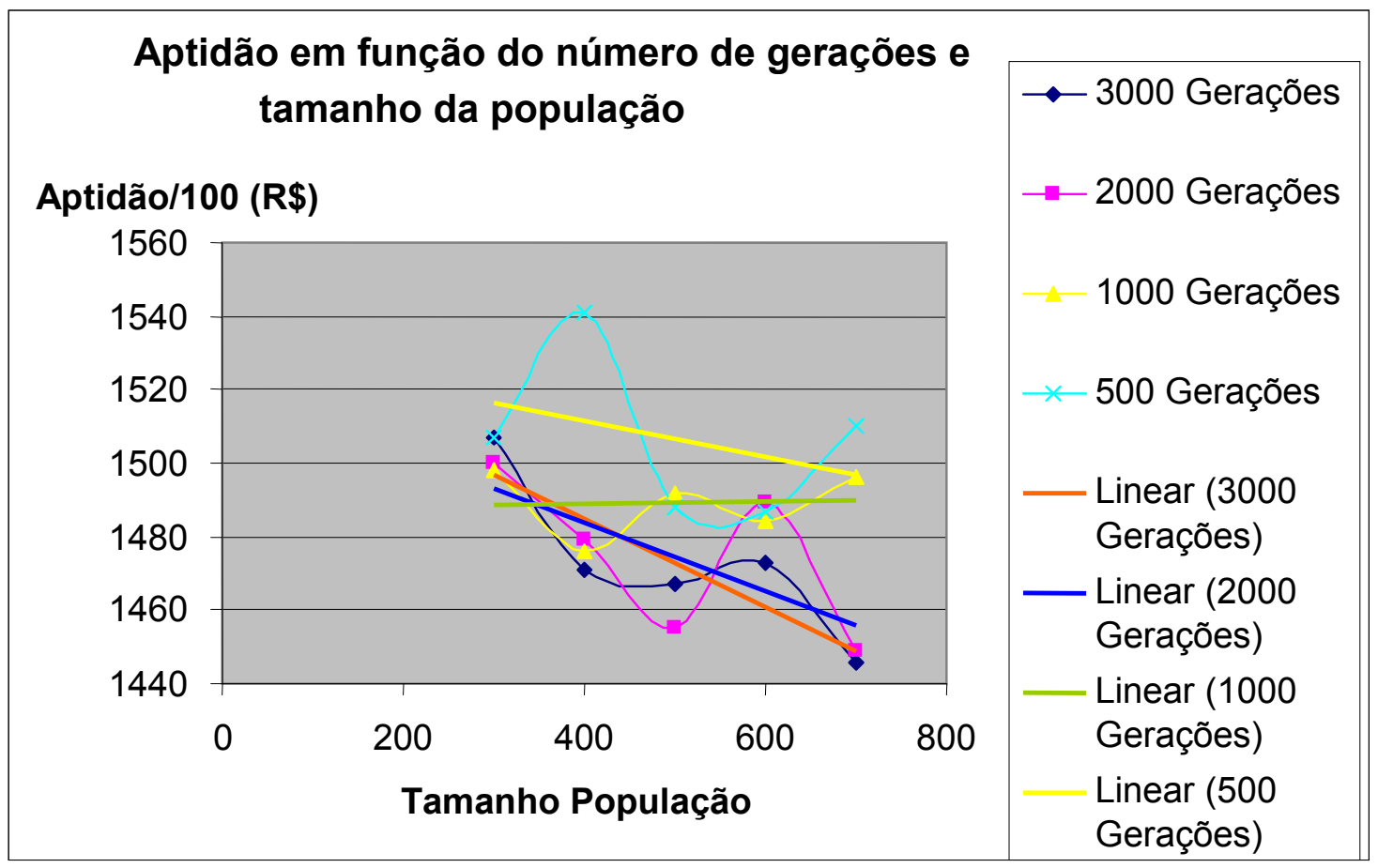

Figura 5-5 - Aptidões em função do número de gerações e tamanho da população com suas curvas de tendência

Com o intuito de confirmar esses resultados, repetiu-se o exemplo de 3000 gerações 4 vezes para cada tamanho de população (16 processamentos) e construiu-se o gráfico da média dos 4 processamentos (figura 5-6). Observa- 
se que o comportamento da curva continua coerente apresentando uma descendência.

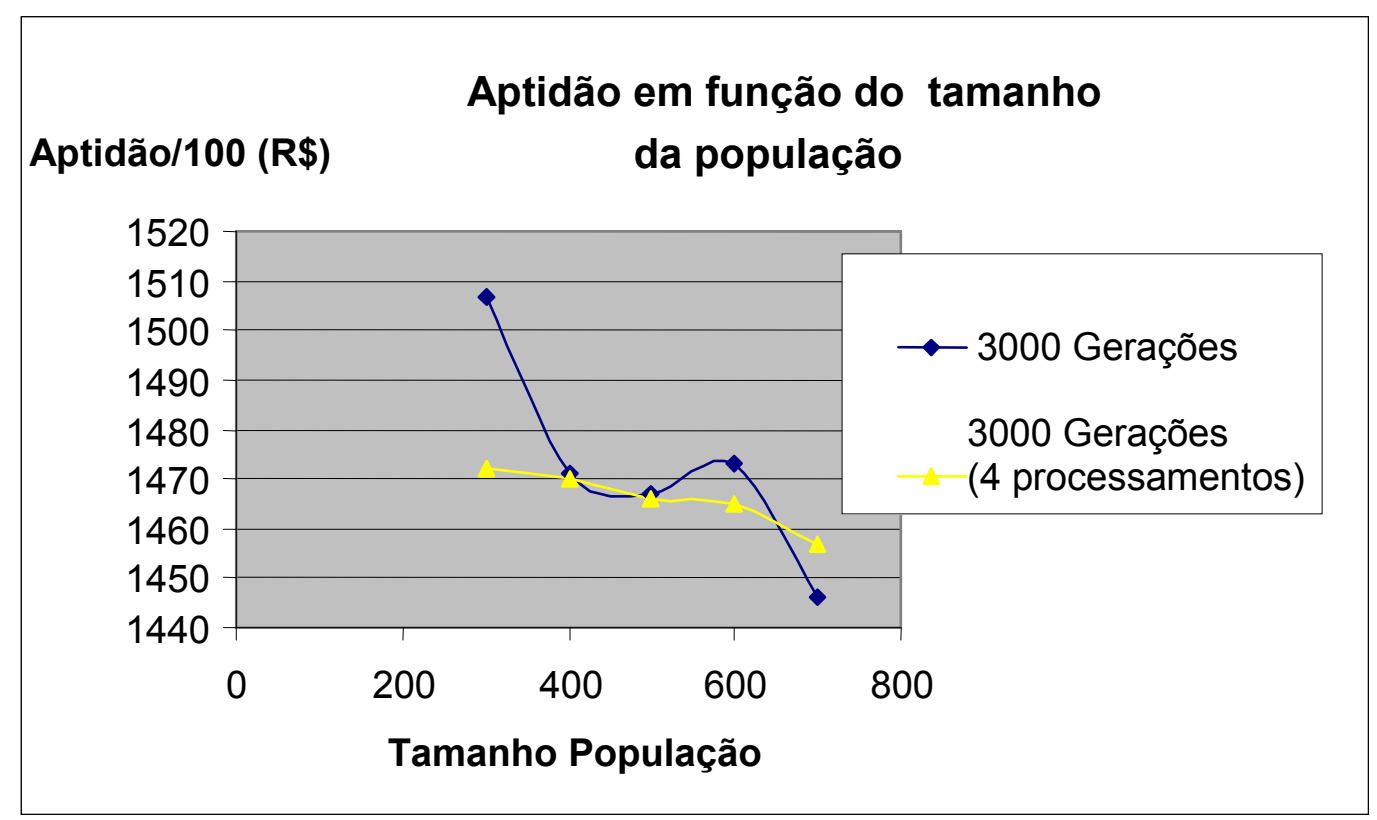

Figura 5-6 - Valores das aptidões em função do tamanho da população (valores médios de 4 execuções)

Fizeram-se, por fim, 25 testes variando o tamanho da população e o número de gerações que são apresentadas na tabela 5-3. Observa-se que uma população de 700 indivíduos e com 3000 gerações apresentou o melhor resultado.

Tabela 5-3 - Aptidões médias dos melhores indivíduos em 5 processamentos

\begin{tabular}{|c|c|}
\hline Características do teste & $\begin{array}{l}\text { Aptidão média de } 5 \\
\text { processamentos }\left(\mathrm{R} \$ 10^{5}\right)\end{array}$ \\
\hline $\begin{array}{l}\text { População=1000 } \\
\text { Gerações=1500 }\end{array}$ & 1,46 \\
\hline $\begin{array}{l}\text { População=1500 } \\
\text { Gerações }=1000\end{array}$ & 1,46 \\
\hline $\begin{array}{c}\text { População=1000 } \\
\text { Gerações }=1000\end{array}$ & 1,47 \\
\hline $\begin{array}{l}\text { População=700 } \\
\text { Gerações=2000 }\end{array}$ & 1,46 \\
\hline $\begin{array}{l}\text { Populações=700 } \\
\text { Gerações }=3000\end{array}$ & 1,45 \\
\hline
\end{tabular}




\subsubsection{HOTEL HOLLIDAY INN (OMAHA / NE)}

Foi utilizado, como segundo exemplo, o projeto do Hotel Holliday-Inn na cidade de Omaha, Nebraska, USA, que tinha 3 vãos na direção das vigas de aproximadamente $7,75 \mathrm{~m}$ e 8 vãos na direção das lajes de aproximadamente 9,20 m (figura 5-7). Foi fornecida ao sistema a informação de que o pavimento tinha como dimensões $74 \mathrm{~m}$ por $24 \mathrm{~m}$ e, que eram restrição da arquitetura distâncias mínimas de 8,5 m e 7,5 m, respectivamente, nas direções $X$ e $Y$, entre pilares. A melhor alternativa, apontada pelo SATD, para a configuração estrutural, coincide exatamente com a solução apresentada no projeto estrutural. Foram feitos 8 processamentos para se observar novamente a variação entre os melhores resultados, e mais uma vez constatou-se a uniformidade das respostas do algoritmo genético. As características adotadas do algoritmo genético e os valores das aptidões do melhor indivíduo encontram-se nas tabelas 5-4 e 5-5, respectivamente.

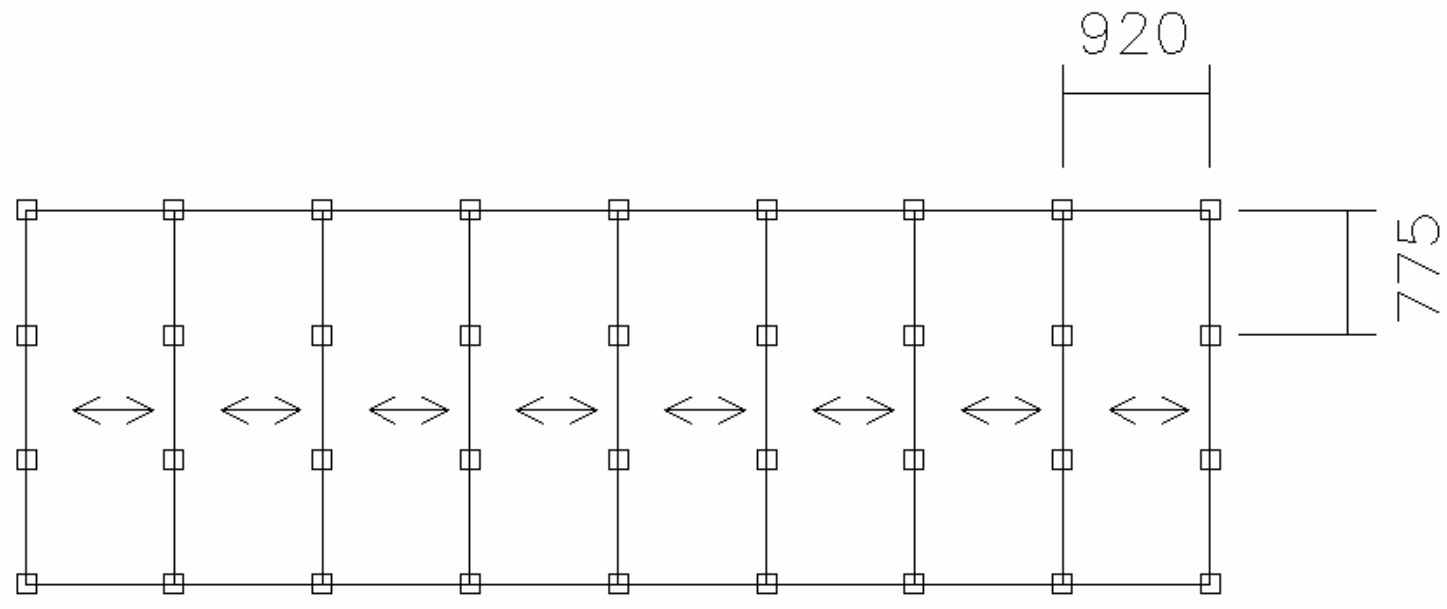

Figura 5-7 - Configuração estrutural Holliday Inn (medidas em "cm") 
Tabela 5-4 - Características dos operadores em 8 processamentos

\begin{tabular}{|c|c|c|c|c|c|}
\hline Processamento & População & Gerações & $\begin{array}{c}\text { Cruzamento } \\
(\%)\end{array}$ & $\begin{array}{c}\text { Mutação } \\
(\%)\end{array}$ & Elitismo \\
\hline 1 & 700 & 3000 & 80 & 1 & 2 \\
\hline 2 & 700 & 6000 & 80 & 1 & 5 \\
\hline 3 & $\mathbf{7 0 0}$ & $\mathbf{3 0 0 0}$ & $\mathbf{8 0}$ & $\mathbf{1}$ & $\mathbf{5}$ \\
\hline 4 & 1000 & 5000 & 80 & 1 & 5 \\
\hline 5 & 700 & 3000 & 80 & 1 & 4 \\
\hline 6 & 700 & 3000 & 80 & 1 & 4 \\
\hline 7 & 700 & 3000 & 80 & 1 & 4 \\
\hline 8 & 700 & 3000 & 80 & 1 & 4 \\
\hline
\end{tabular}

Tabela 5-5 - Aptidões dos melhores indivíduos dos 8 processamentos

\begin{tabular}{ccc}
\hline Processamento & $\begin{array}{c}\text { Aptidão } \\
\left(\mathrm{R} \$ / 10^{5}\right)\end{array}$ & $\Delta(\%)$ \\
\hline Hotel1 & 1,516 & 1,13 \\
Hotel2 & 1,509 & 0,67 \\
Hotel3 & 1,499 & 0,00 \\
Hotel4 & 1,499 & 0,00 \\
Hotel5 & 1,515 & 1,07 \\
Hotel6 & 1,524 & 1,67 \\
Hotel7 & 1,529 & 2,00 \\
Hotel8 & 1,514 & 1,00 \\
& & \\
\hline Menor Aptidão & 1,499 & \\
Maior $\Delta(\%)$ & & 2,00 \\
\hline
\end{tabular}

Observa-se que o aumento do tamanho da população e do número de gerações (processamentos 2 e 4), que elevam o custo computacional, não produziram melhoria nos resultados, já que se obteve o melhor resultado também no processamento 3 com um custo computacional menor.

\subsubsection{Conclusões da calibração do modelo}

Determinou-se, após a execução de vários testes, que seria adotada, nos exemplos finais uma população de 700 indivíduos com 3000 gerações. Constata-se que, em muitos processamentos, a convergência ocorre antes da 
milésima geração, mas, em alguns, a convergência se dá até a geração 2500, e por isso a adoção de 3000 gerações apresenta maior estabilidade nos resultados. Entende-se como convergência uma mudança não significativa na melhor aptidão entre as gerações consecutivas.

Estabeleceu-se, ainda, que seria adotada uma probabilidade de cruzamento de $80 \%$, uma taxa de mutação de $1 \%$ e um elitismo de 3 indivíduos.

\subsection{VALIDAÇÃO DO SATD}

Para validação do SATD, utilizaram-se 2 projetos, já executados como bench-mark, elaborados pela HEPTA Engenharia Estrutural e foram ou serão fabricados e montados pela T\&A.

\subsubsection{Wal Mart - Bonocô}

O edifício Wal Mart - Bonocô é um supermercado com 3 pavimentos que será montado em Salvador/BA. Uma parcela significativa do pavimento é modulada ( $\ell_{x}=46,5 \mathrm{~m}$ e $\ell_{y}=48,0 \mathrm{~m}$ ), conforme a figura $5-8$, e existia, na região modulada, uma restrição arquitetônica para que os vãos livres de pilares fossem de 7,0 m. Forneceu-se ao SATD essa restrição de vão mínimo, a altura máxima que o pavimento poderia assumir, de $60 \mathrm{~cm}$, e o carregamento de 8 $\mathrm{kN} / \mathrm{m}^{2}$. No carregamento, estão incluídos pavimentação, revestimento, divisórias e carga acidental.

Observa-se que o SATD indicou várias soluções (Tabela 5-6) e, que duas delas (SATD 1 e SATD 4) são bastante próximas da estrutura concebida pelo projeto original. As informações de armadura não foram apresentadas em função desse projeto está em fase preliminar, sem detalhamento.

Observa-se também que existem outras alternativas, com praticamente o mesmo custo, como a solução em que as lajes e vigas mudam de direção assumindo nova configuração (SATD 2, figura 5-9) e a solução em que a viga tem seção transversal com forma achatada e o pavimento fica com menor altura (SATD 3, figura 5-10). Dessa forma, o projetista tem alternativas com o mesmo desempenho para fazer a escolha. 


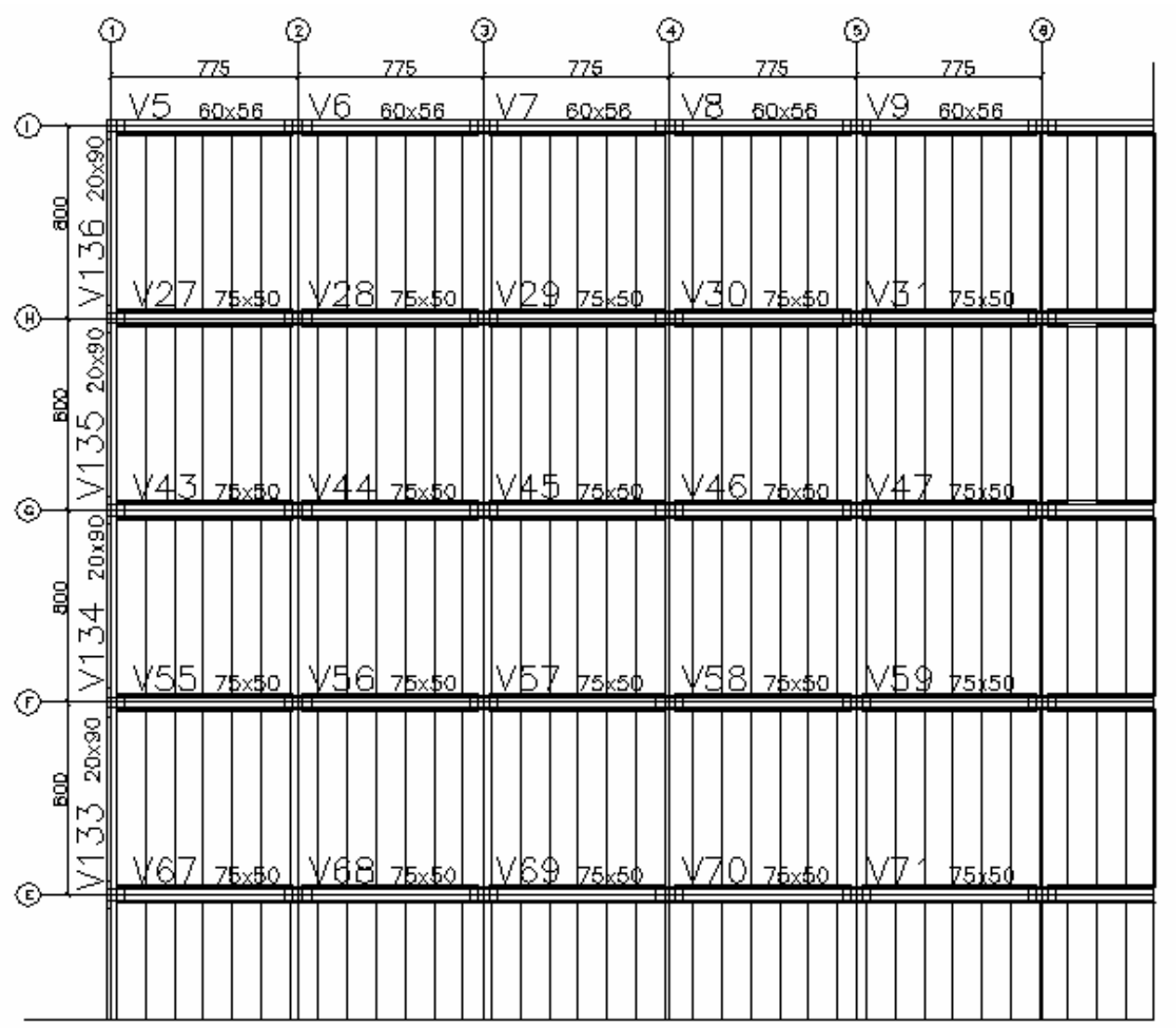

Figura 5-8 - Região modulada do pavimento do Wal Mart - Bonocô (medidas em "cm")

Tabela 5-6 - Tabela comparativa entre o projeto e os resultados do SATD

\begin{tabular}{|c|c|c|c|c|c|}
\hline Dados & Projeto & SATD 1 & SATD 2 & SATD 3 & SATD 4 \\
\hline $\begin{array}{c}\text { Configuração } \\
\left(\mathrm{N}_{\mathrm{X}} / \mathrm{N}_{\mathrm{Y}} / \mathrm{DL}\right)\end{array}$ & $6 / 6 / 1$ & $6 / 6 / 1$ & $6 / 6 / 0$ & $6 / 6 / 1$ & $6 / 6 / 1$ \\
\hline $\mathrm{f}_{\mathrm{ckml}}$ & 25 & 25 & 20 & 20 & 30 \\
\hline $\mathrm{f}_{\mathrm{ckPM}}$ & 40 & 40 & 40 & 40 & 40 \\
\hline $\mathrm{h}_{\mathrm{L}}$ & 20 & 21 & 20 & 20 & 20 \\
\hline $\mathrm{h}_{\mathrm{V}}$ & 30 & 30 & 30 & 25 & 25 \\
\hline $\mathrm{b}_{\mathrm{w}}$ & 60 & 50 & 60 & 70 & 60 \\
\hline$\ell_{\text {viga }}$ & 7,75 & 7,75 & 8,0 & 7,75 & 7,75 \\
\hline$\ell_{\text {laje }}$ & 8,0 & 8,0 & 7,75 & 8,0 & 8,0 \\
\hline Custo $\left(\mathrm{R} \$ / \mathrm{m}^{2}\right)^{*}$ & - & 215,6 & 216,3 & 216,2 & 212,5 \\
\hline
\end{tabular}

* Custo da estrutura pré-moldada montada, exceto o custo do concreto moldado no local 

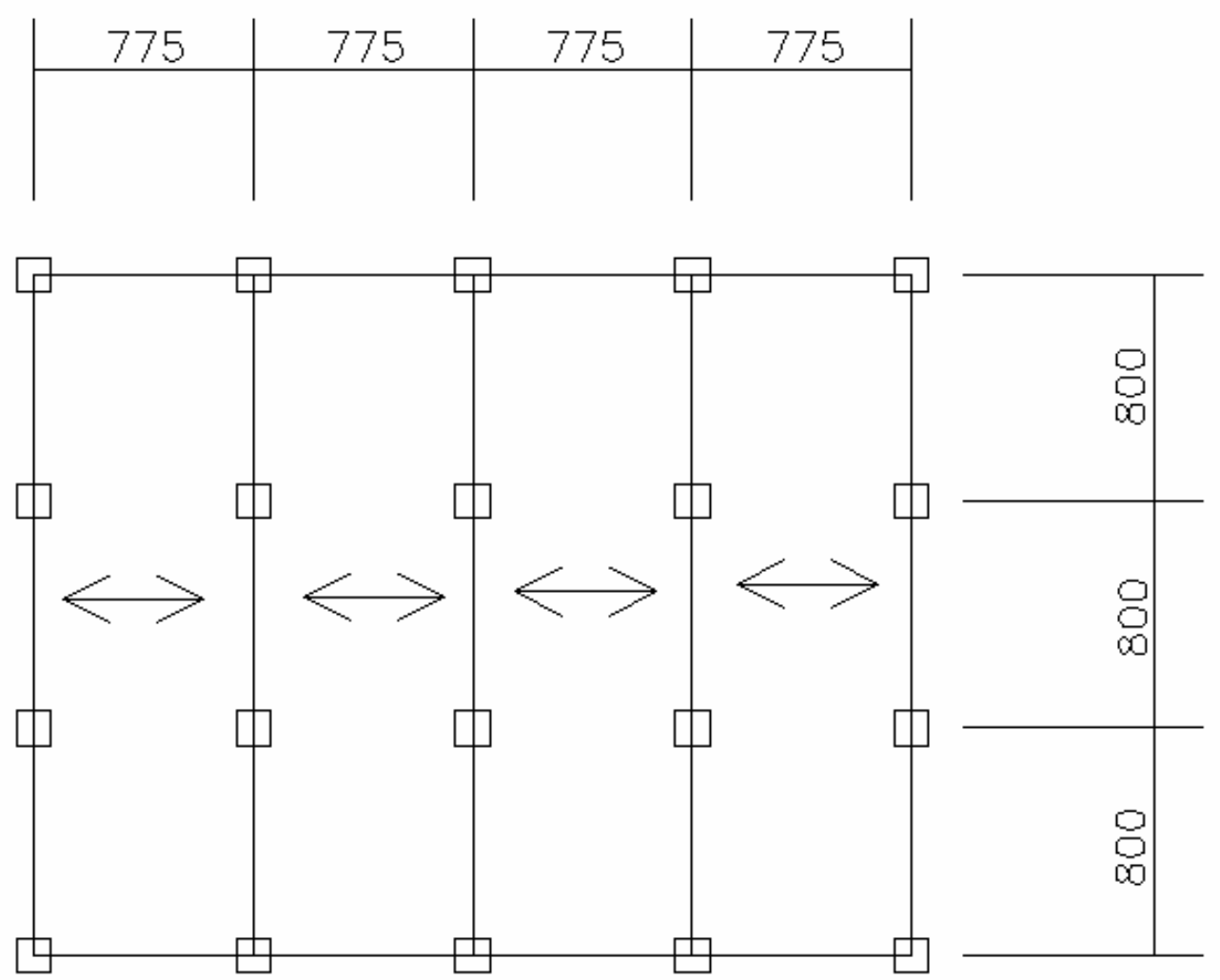

Figura 5-9 - Configuração estrutural da alternativa 2 (medidas em "cm")

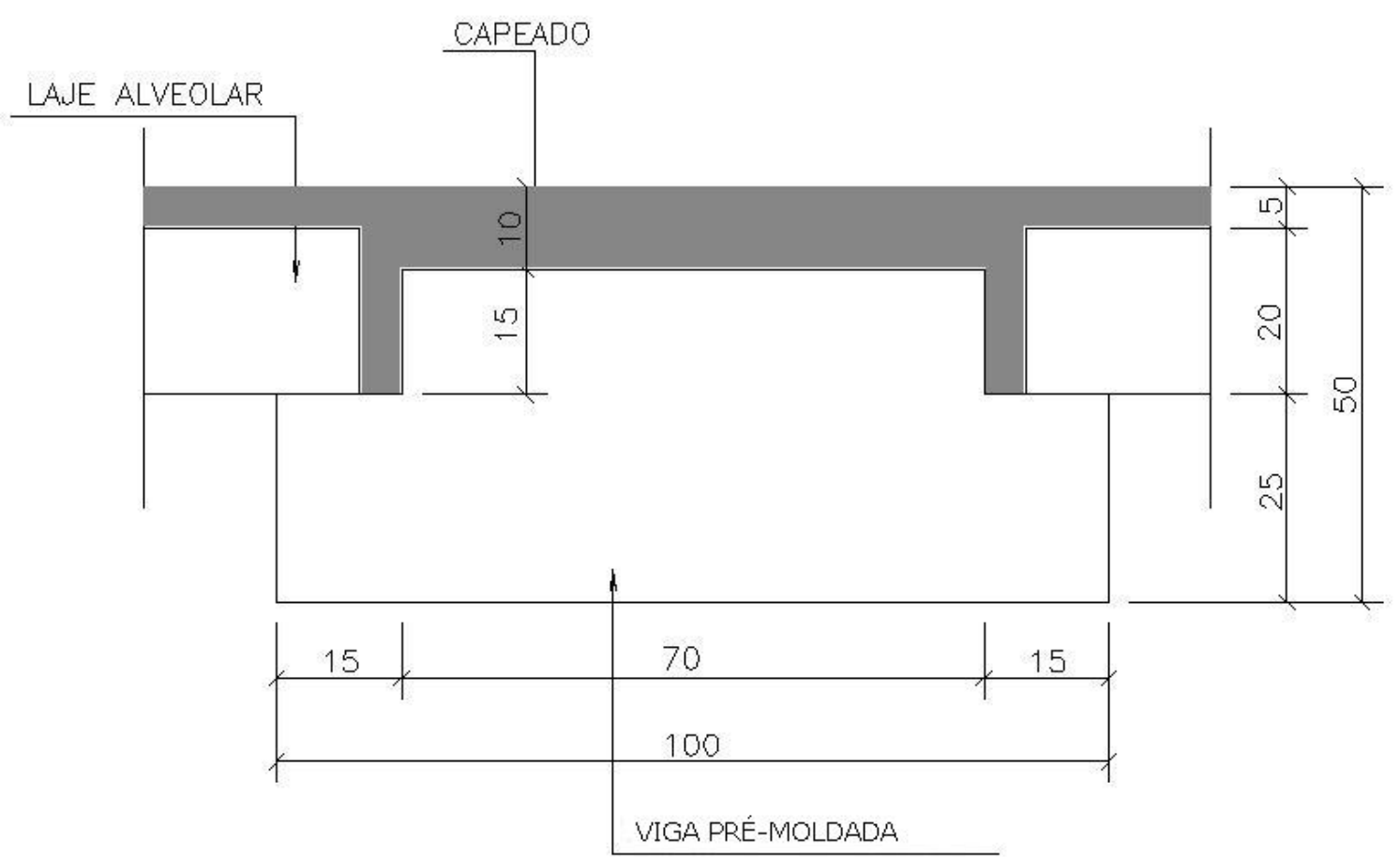

Figura 5-10 - Seção de viga da alternativa 3 (medidas em "cm") 
Desses resultados, constata-se ainda que os custos são consistentes, porque, segundo informações do fabricante T\&A, os custos dos edifícios prémoldados variam entre $R \$ 200,00 / \mathrm{m}^{2}$ e $R \$ 300,00 / \mathrm{m}^{2}$, e que a participação das etapas fabricação, transporte e montagem, na composição de custos, também confere com os dados médios do fabricante (Tabela 5-7).

Tabela 5-7 - Participação das etapas nos resultados do SATD

\begin{tabular}{|c|c|c|c|c|c|}
\hline Etapas & $\begin{array}{c}\text { Valores } \\
\text { médios T\&A } \\
(\%)\end{array}$ & SATD 1 & SATD 2 & SATD 3 & SATD 4 \\
\hline Fabricação & 81,6 & 83,0 & 83,0 & 83,0 & 83,0 \\
\hline Transporte & 11,0 & 10,0 & 10,0 & 9,8 & 9,7 \\
\hline Montagem $^{\prime, 0}$ & 7,4 & 6,2 & 6,2 & 6,2 & 6,3 \\
\hline Total $^{*}$ & 100,0 & 99,2 & 99,2 & 99,0 & 99,0 \\
\hline
\end{tabular}

*As diferenças nos valores apresentados são devidas aos arredondamentos

\subsubsection{Edifício Comercial Carvalho}

O Comercial Carvalho é um edifício comercial com 3 pavimentos, projetado pela Hepta (figura 5-11), e construído em Teresina/PI pela T\&A. É um edifício cuja arquitetura já previa uma modulação livre de $8,0 \mathrm{~m}$, com dimensão do pavimento, em planta, de $\ell_{x}=96,0 \mathrm{~m}$ e $\ell_{y}=56,0 \mathrm{~m}$, e exigia que o pavimento tivesse uma altura máxima de $45 \mathrm{~cm}$. Esses dados alimentaram o SATD juntamente com o carregamento de $7,5 \mathrm{kN} / \mathrm{m}^{2}$.

Apresentam-se, na tabela 5-8, 3 alternativas fornecidas pelo SATD, com praticamente o mesmo custo entre si, tendo uma variação máxima de 2,2\%, e com uma pequena variação em relação ao custo calculado do projeto original com a mesma função-custo implementada no SATD, que foi de $-0,06$ a $1,60 \%$. Foram realizados 6 processamentos.

Dentre as respostas apresentadas, observam-se duas configurações estruturais distintas, tem-se a primeira com as vigas orientadas na menor 
direção do pavimento (1 e 3, figura 5-12), e a segunda igual à adotada no projeto original (2).

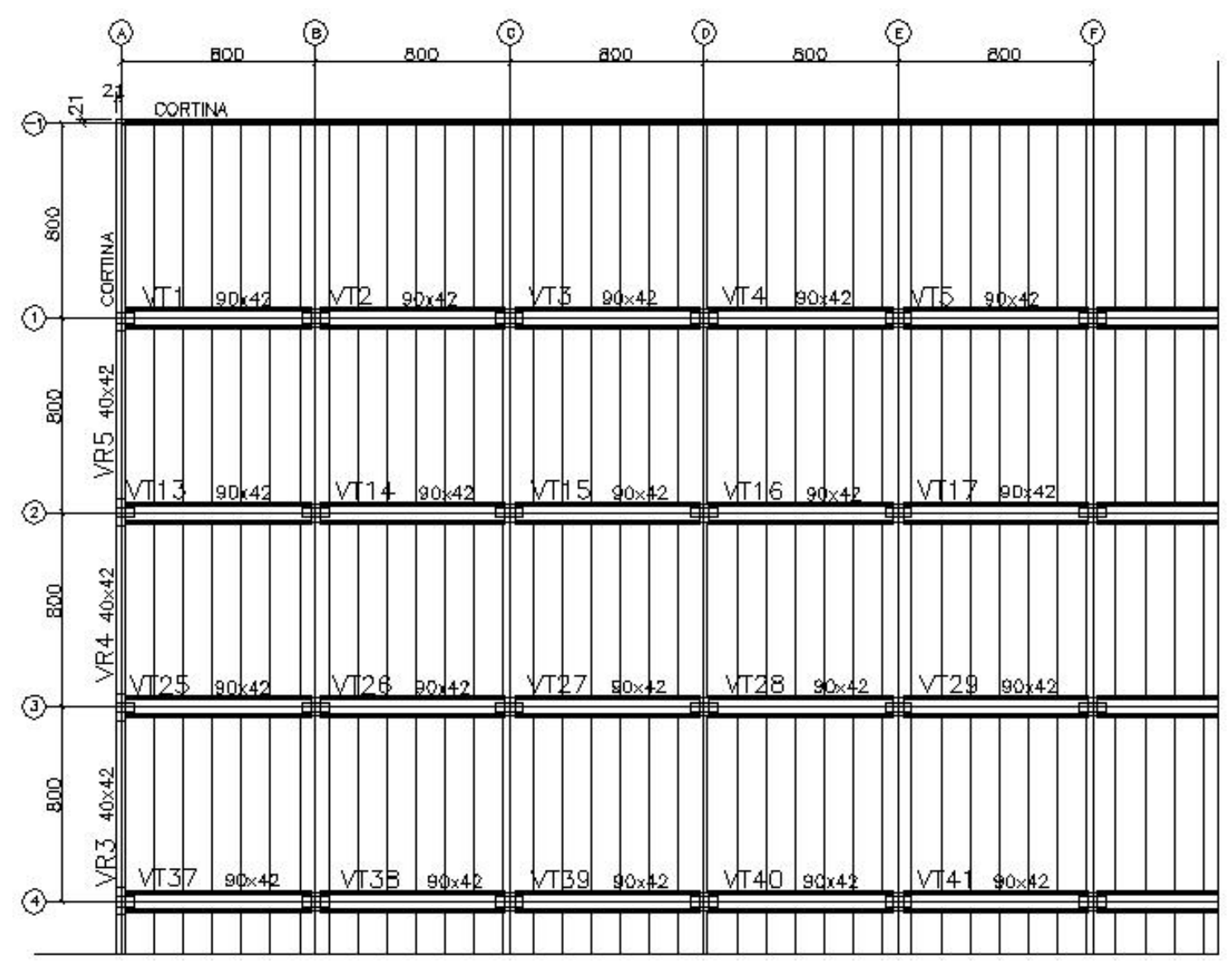

Figura 5-11 - Forma parcial do edifício Comercial Carvalho (medidas em $\mathrm{cm}$ )

Tabela 5-8 - Resultados do SATD para o Comercial Carvalho

\begin{tabular}{|c|c|c|c|c|}
\hline Dados & (1) & (2) & (3) & Projeto \\
\hline $\begin{array}{l}\text { Configuração } \\
\left(N_{X} / N_{Y} / D L\right)\end{array}$ & $12 / 7 / 0$ & $12 / 7 / 1$ & \begin{tabular}{|l}
$12 / 7 / 0$ \\
\end{tabular} & $12 / 7 / 1$ \\
\hline$f_{c k m l}$ & 20 & 35 & 25 & 25 \\
\hline$f_{\text {ckpm }}$ & 40 & 40 & 45 & 40 \\
\hline$h_{1}$ & 20 & 20 & 17 & 17 \\
\hline $\mathrm{h}_{\mathrm{v}}$ & 20 & 20 & 20 & 20 \\
\hline$b_{w}$ & 90 & 80 & 80 & 60 \\
\hline $\begin{array}{l}\text { Custo } \\
\left(\mathrm{R} \$ / \mathrm{m}^{2}\right)\end{array}$ & 208,7 & 208,3 & 204,2 & $205,4^{*}$ \\
\hline$\Delta "(\%)$ & $(+1,6 \%)$ & $(+1,4 \%)$ & $(-0,06 \%)$ & (1) \\
\hline
\end{tabular}


${ }^{(*)}$ Esse custo foi calculado utilizando a mesma função custo que foi implementada no SATD;

$\left.{ }^{* *}\right)$ Variação percentual do custo em relação ao custo do projeto original.

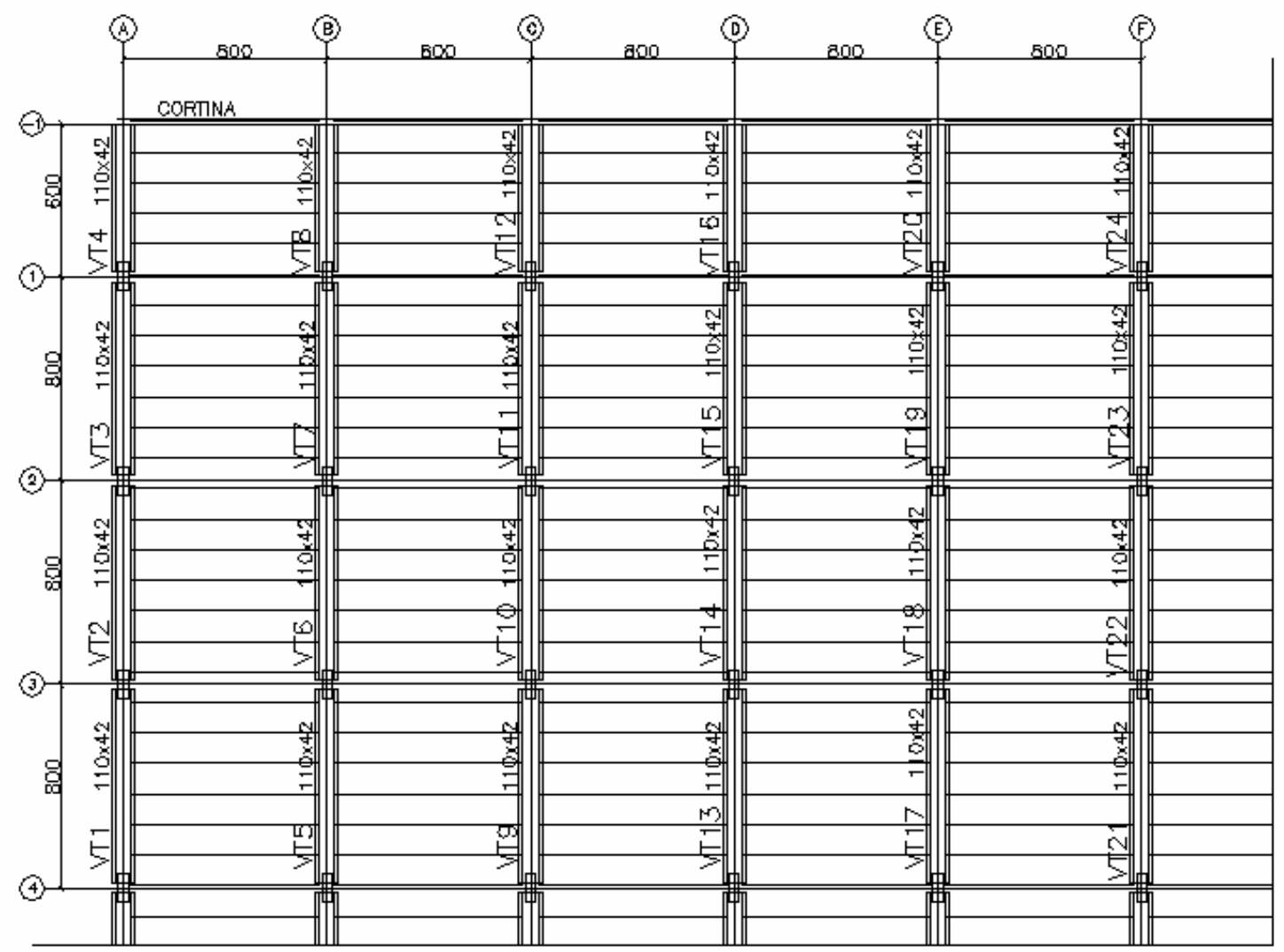

Figura 5-12 - Configuração estrutural, parcial, das alternativas 1 e 3 (medidas em "cm")

Observa-se que a alternativa (3), embora tenha orientação contrária à adotada no projeto original, indicou a mesma laje $h_{L}=17 \mathrm{~cm}$ e uma viga similar (figura 5-13) à escolhida pelo projeto (figura 5-14). Essa solução mostrou-se mais econômica que à adotada no projeto. Percebe-se que a solução que adota as vigas, na mesma direção do menor lado do pavimento, apresenta a vantagem de possuir menos vigas, que são elementos mais caros, além de diminuir os custos de montagem. No exemplo em questão, a quantidade de vigas baixou de 96 para 91 unidades, enquanto o número de lajes e pilares permaneceu constante.

Ressalta-se, ainda, que os resultados do SATD foram extraídos de processamentos completamente automáticos e otimizados, enquanto o projeto passou por um longo processo de amadurecimento para definição da 
configuração estrutural adequada e, posteriormente, para o dimensionamento e detalhamento dos elementos.

Essa etapa de análise de pré-projetos é muito dispendiosa, e demanda tempo e experiência e às vezes requer, para que as comparações sejam fidedignas, que as opções estudadas sejam detalhadas quase que completamente. Essa fase pode chegar a utilizar toda uma semana de trabalho do engenheiro.

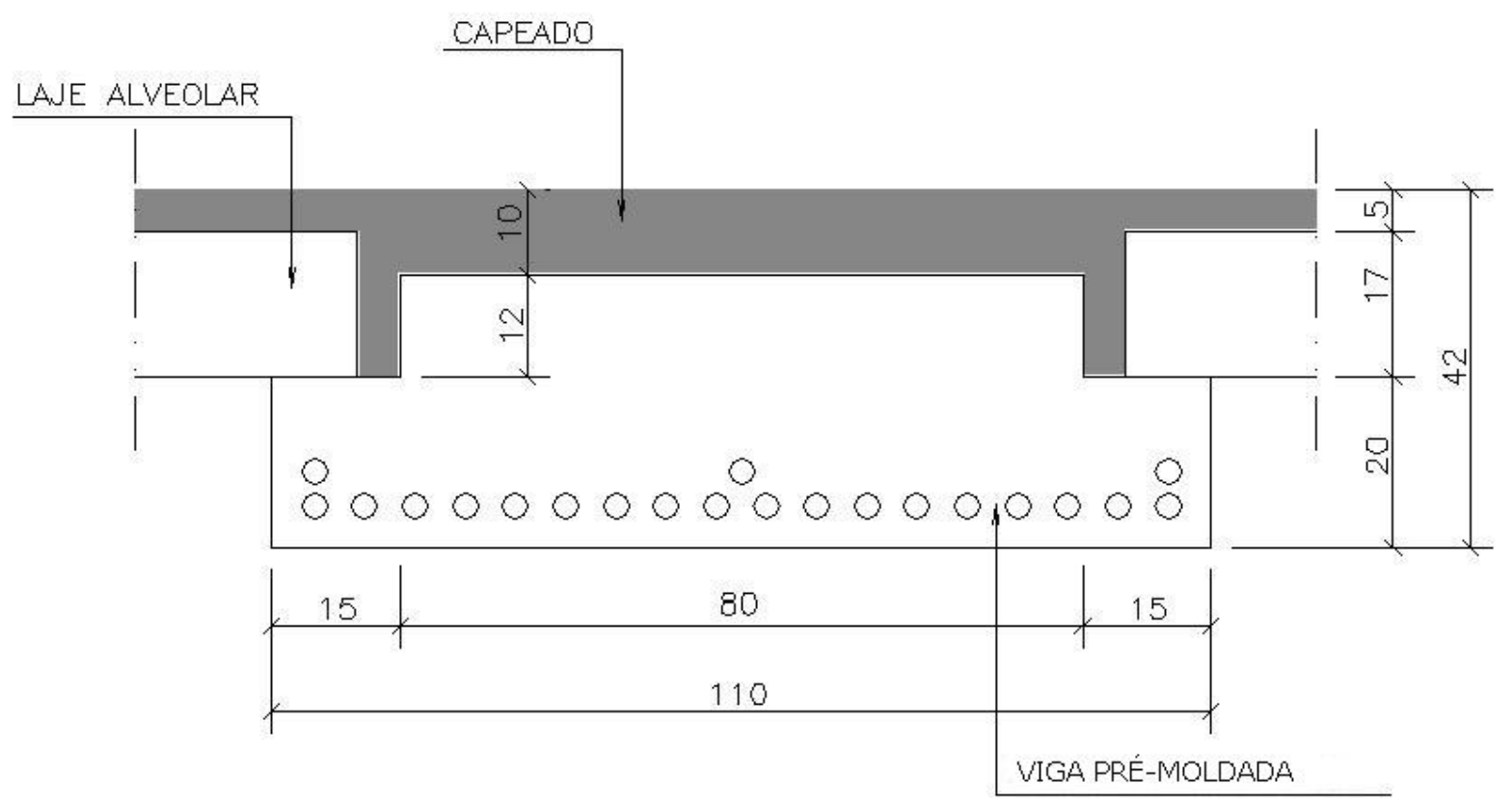

Figura 5-13 - Viga adotada pelo SATD (alternativa 3)

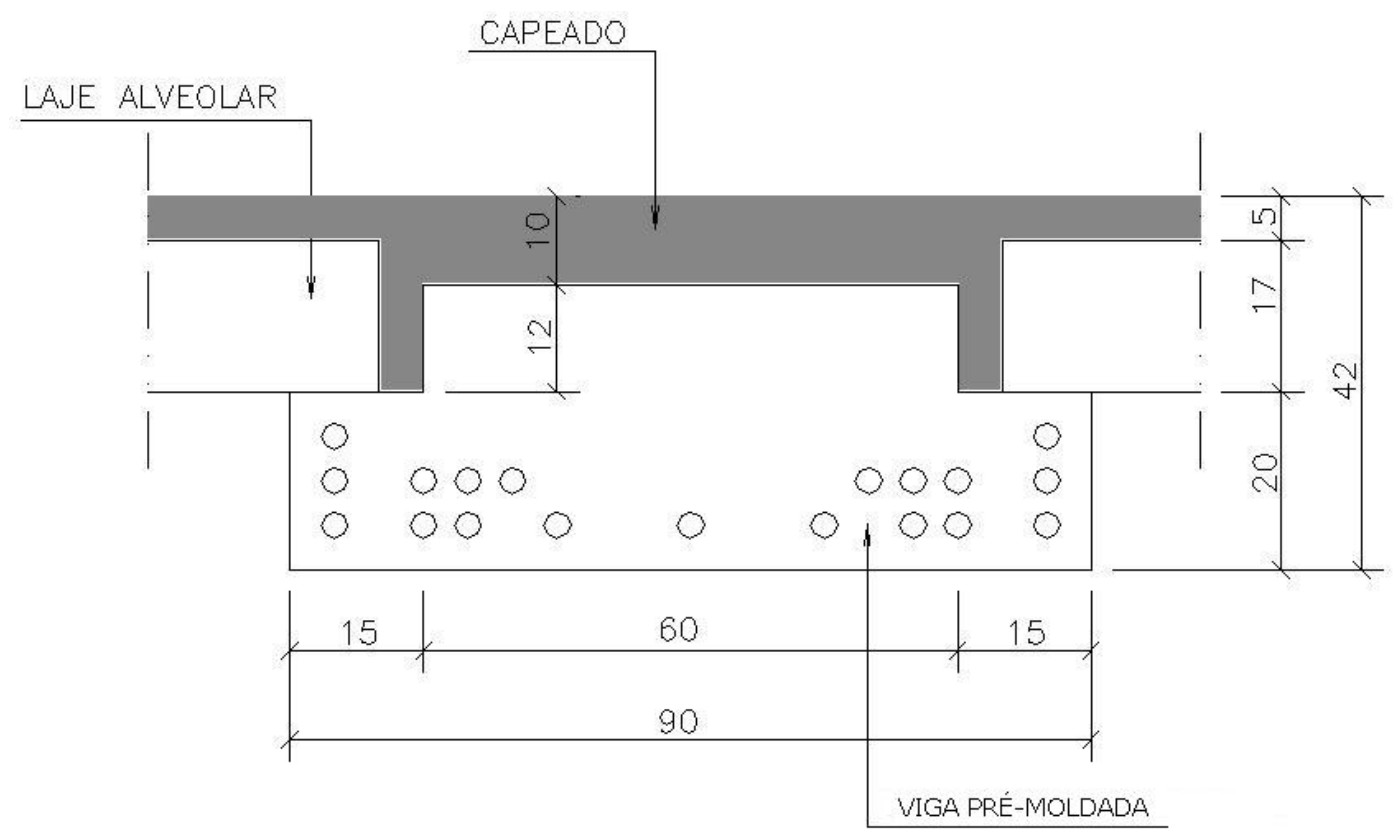

Figura 5-14 - Viga adotada pelo projeto 
As variáveis envolvidas na concepção estrutural são muito dependentes entre si, de forma que toda escolha tem uma série de impactos, que devem ser analisadas pelo engenheiro. Enquanto no SATD todas as dependências são consideradas de maneira integrada. Citam-se, por exemplo, algumas dúvidas que surgem aos engenheiros nesse momento:

a) A altura da laje tem influência direta na altura da viga. Logo, aumentar a altura da laje, diminuindo a protensão dela, e aumentando a altura da viga talvez seja mais econômico;

b) Ao aumentar a largura da viga, embora seja menos eficiente que aumentar a altura, diminui-se o vão da laje;

c) Ao usar os vãos mínimos permitidos, as peças têm um menor consumo de material, embora aumentem o número de peças a serem transportadas e montadas;

d) Qual seria o vão ideal para as lajes e as vigas? Usar lajes com vãos maiores e vigas com vãos menores ou, o contrário, ou ainda usar vãos da mesma ordem?

e) Sobre a orientação, as vigas devem ficar na mesma direção ou na direção perpendicular à maior dimensão do pavimento?

Para dirimir todas essas dúvidas, várias alternativas devem ser concebidas e comparadas. Após terminada a análise dos pré-projetos e escolhido o mais econômico dentre eles, inicia-se a etapa de refinamento do projeto, tentando melhorar, ao máximo, o detalhamento dos elementos do ponto de vista construtivo e de rendimento. Nessa etapa, o engenheiro utiliza a sua experiência para identificar características particulares que podem ser adotadas. Citam-se, por exemplo, a consideração de um maior grau de engastamento da viga, a consideração de continuidade das lajes, a utilização de enchimento dos alvéolos próximos às vigas para aumentar a região de compressão das vigas (figura 5-15) etc. 


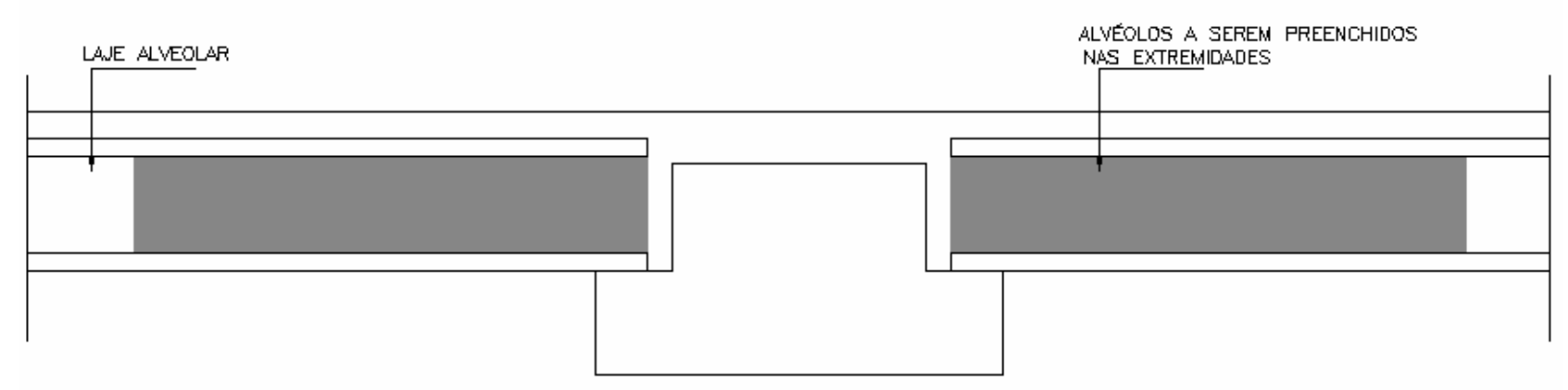

Figura 5-15 - Alvéolos preenchidos

Para melhor ilustrar a diferença entre um elemento idealizado na fase preliminar e o elemento detalhado no projeto, solicitou-se a um engenheiro da HEPTA Engenharia que pré-dimensionasse uma viga. Forneceu-se-lhe a configuração estrutural e o carregamento do edifício Comercial Carvalho. Apresenta-se na figura 5-16 o pré-dimensionamento da viga, salienta-se que esta viga foi verificada apenas para o estado limite último e provavelmente necessitaria de ajustes para que atendesse a todas as outras verificações.

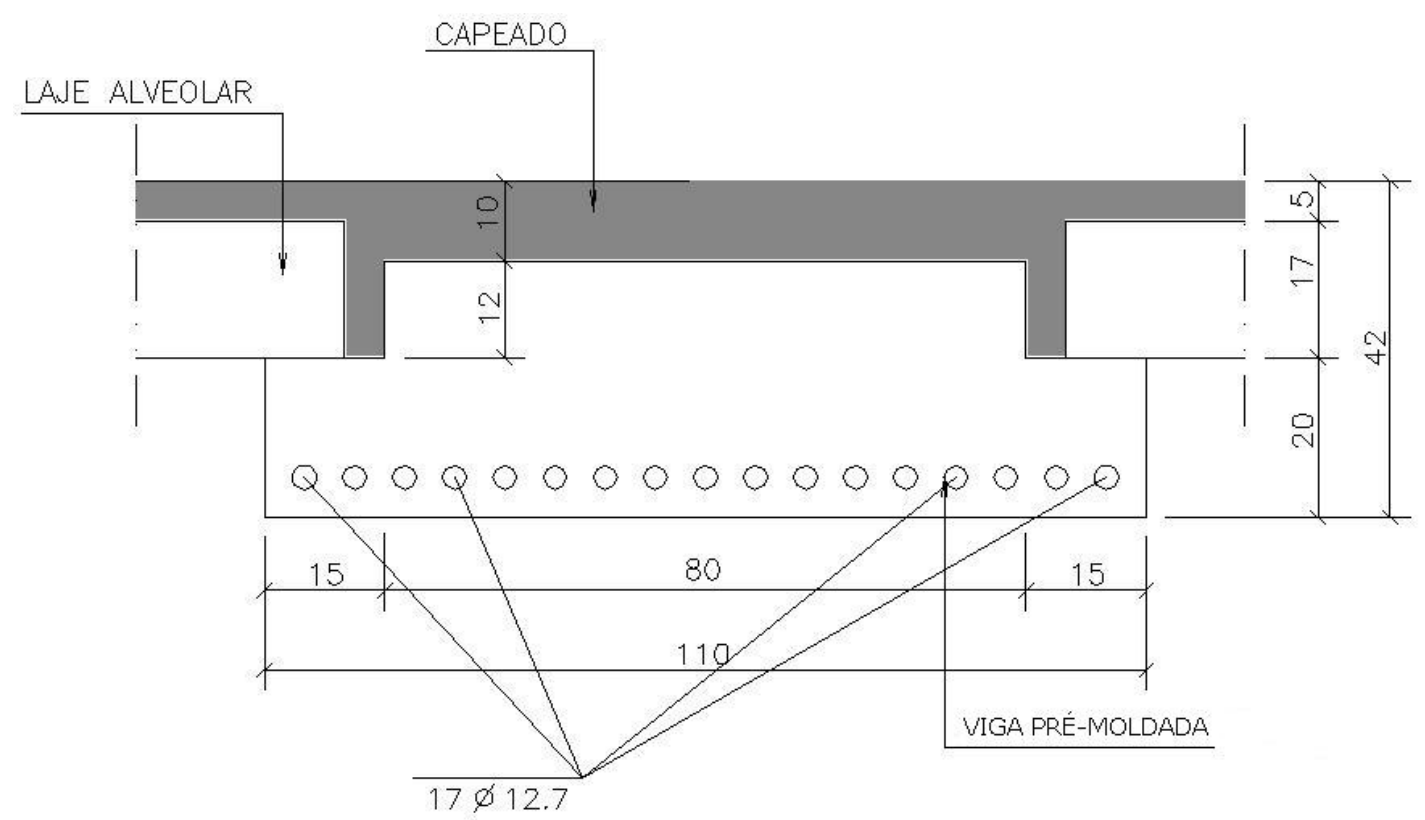

Figura 5-16 - Viga adotada pelo pré-projeto (verificada apenas para estado limite último)

Percebe-se que a viga obtida através do pré-dimensionamento da HEPTA é muito parecida com a viga fornecida pelo SATD (figura 5-13). 
Conclui-se, com o exemplo apresentado, que o SATD pode ser uma excelente ferramenta no auxílio ao engenheiro no desenvolvimento do projeto, já que tem condição de realizar toda a fase de pré-projeto, deixando para o engenheiro os arremates finais, em que o conhecimento e a experiência ficam intangíveis e as particularidades adquirem maior importância. Vale salientar que o tempo, que seria gasto no estágio inicial, pode ser empregado em atividades mais nobres como o detalhamento final, verificações adicionais, revisões e compatibilizações.

Para se analisar o comportamento dos resultados, foram feitas algumas variações nos custos e nas restrições:

\section{a) Resultados para o custo do concreto alterado}

Com o desenvolvimento da tecnologia dos materiais e com o aumento da utilização de concretos de resistência mais elevada, o preço do concreto de alta resistência tem diminuído com 0 tempo. Então para testar 0 comportamento das alternativas com essa hipotética situação diminuiu-se a diferença entre os custos do concreto pré-moldado, que inicialmente era de $8 \%$ e adotou-se nesse exemplo apenas 4\%, ou seja, o concreto de 45MPa é suposto $4 \%$ mais caro do que o concreto de $40 \mathrm{MPa}$ e assim sucessivamente. Processaram-se 5 exemplos e verificou-se que, mesmo com a diferença entre os custos dos concretos reduzida, o SATD continuou indicando soluções similares às apresentadas na tabela 5-8.

Conclui-se então que, para esse exemplo, com as restrições que foram apresentadas, a utilização de um concreto melhor, tal qual $50 \mathrm{MPa}$, não proporcionaria vantagens econômicas.

\section{b) Resultados para a restrição de altura máxima do pavimento aumentada}

Aumentou-se o limite da restrição de altura máxima do pavimento para $\mathrm{h}_{\text {máxima }}=47 \mathrm{~cm}$ e $\mathrm{h}_{\text {máxima }}=60 \mathrm{~cm}$, de forma que o sistema pudesse adotar um pavimento mais alto. Após vários processamentos percebe-se que o custo continua na mesma faixa de variação da tabela 5-8 e as melhores alternativas encontradas são apresentadas na tabela 5-9. 
Tabela 5-9 - Resultados do SATD com altura máxima aumentada (Comercial Carvalho)

\begin{tabular}{|l|l|l|}
\hline Dados & $\begin{array}{l}\text { Melhor } \\
\text { resultado } \\
\mathrm{h}_{\text {máxima }}=47 \mathrm{~cm}\end{array}$ & $\begin{array}{l}\text { Melhor } \\
\text { resultado } \\
\mathrm{h}_{\text {máxima }}=60 \mathrm{~cm}\end{array}$ \\
\hline $\begin{array}{l}\text { Configuração } \\
\left(\mathrm{N}_{\mathrm{X}} / \mathrm{N}_{\mathrm{Y}} / \mathrm{DL}\right)\end{array}$ & $12 / 7 / 0$ & $12 / 7 / 0$ \\
\hline $\mathrm{f}_{\mathrm{ckml}}$ & 25 & 25 \\
\hline $\mathrm{f}_{\mathrm{ckpm}}$ & 40 & 40 \\
\hline $\mathrm{h}_{\mathrm{l}}$ & 17 & 17 \\
\hline $\mathrm{h}_{\mathrm{v}}$ & 25 & 30 \\
\hline $\mathrm{b}_{\mathrm{w}}$ & 70 & 60 \\
\hline $\begin{array}{l}\text { Custo } \\
\left(\mathrm{R} \$ / \mathrm{m}^{2}\right)\end{array}$ & 204,9 & 202,4 \\
\hline
\end{tabular}

\section{c) Resultados para o custo do transporte alterado}

Como a obra, em questão, se localizava em Teresina, e foi fabricada pela unidade de Fortaleza, que é a mais próxima, pois a T\&A tem fábricas em Fortaleza, no Recife e em Salvador, o custo do transporte foi alterado e foram feitos novos processamentos. Segundo informações coletadas, o custo do transporte teria de ser o triplo em relação ao preço normal, isto é, o custo por viagem foi multiplicado por 3 . Esses novos processamentos conduziram a uma nova alternativa (alternativa 5 , da tabela 5-10) além de uma alternativa (alternativa 4, da tabela 5-10) com a mesma configuração das alternativas (1 e 3) dos processamentos com o custo do transporte sem alteração.

O surgimento de uma nova opção ainda não contemplada, se dá por ter passado o item transporte a ter uma maior participação na composição do custo total, alterou-se, em média, para 22,5\%. Enquanto nos outros processamentos era, em média, de 11\%. Essa nova alternativa optou por lajes com vãos maiores $\ell_{\text {laje }}=8,72 \mathrm{~m}$ (figura 5-17), que reduzem o número de elementos. 
Tabela 5-10 - Resultados do SATD para o Comercial Carvalho com o custo do transporte alterado

\begin{tabular}{|l|l|l|l|}
\hline Dados & Projeto & $(4)$ & $(5)$ \\
\hline $\mathrm{N}_{\mathrm{X}} / \mathrm{N}_{\mathrm{Y}} / \mathrm{DL}$ & $12 / 7 / 1$ & $12 / 7 / 0$ & $11 / 7 / 0$ \\
\hline $\mathrm{f}_{\mathrm{ckml}}$ & 25 & 25 & 20 \\
\hline $\mathrm{f}_{\mathrm{ckpm}}$ & 40 & 45 & 50 \\
\hline $\mathrm{h}_{\mathrm{l}}$ & 17 & 17 & 17 \\
\hline $\mathrm{h}_{\mathrm{v}}$ & 20 & 20 & 20 \\
\hline $\mathrm{b}_{\mathrm{w}}$ & 60 & 90 & 80 \\
\hline $\begin{array}{l}\text { Custo } \\
\left(\mathrm{R} \$ \mathrm{~m}^{2}\right)\end{array}$ & $240,7^{\left({ }^{*}\right)}$ & 246,4 & 249,9 \\
\hline Fabricação & - & & \\
\hline Transporte & - & 71,0 & 73,0 \\
\hline Montagem & - & 23,0 & 22,0 \\
\hline
\end{tabular}

${ }^{(*)}$ Esse custo foi calculado utilizando-se a mesma função custo que foi implementada no SATD.

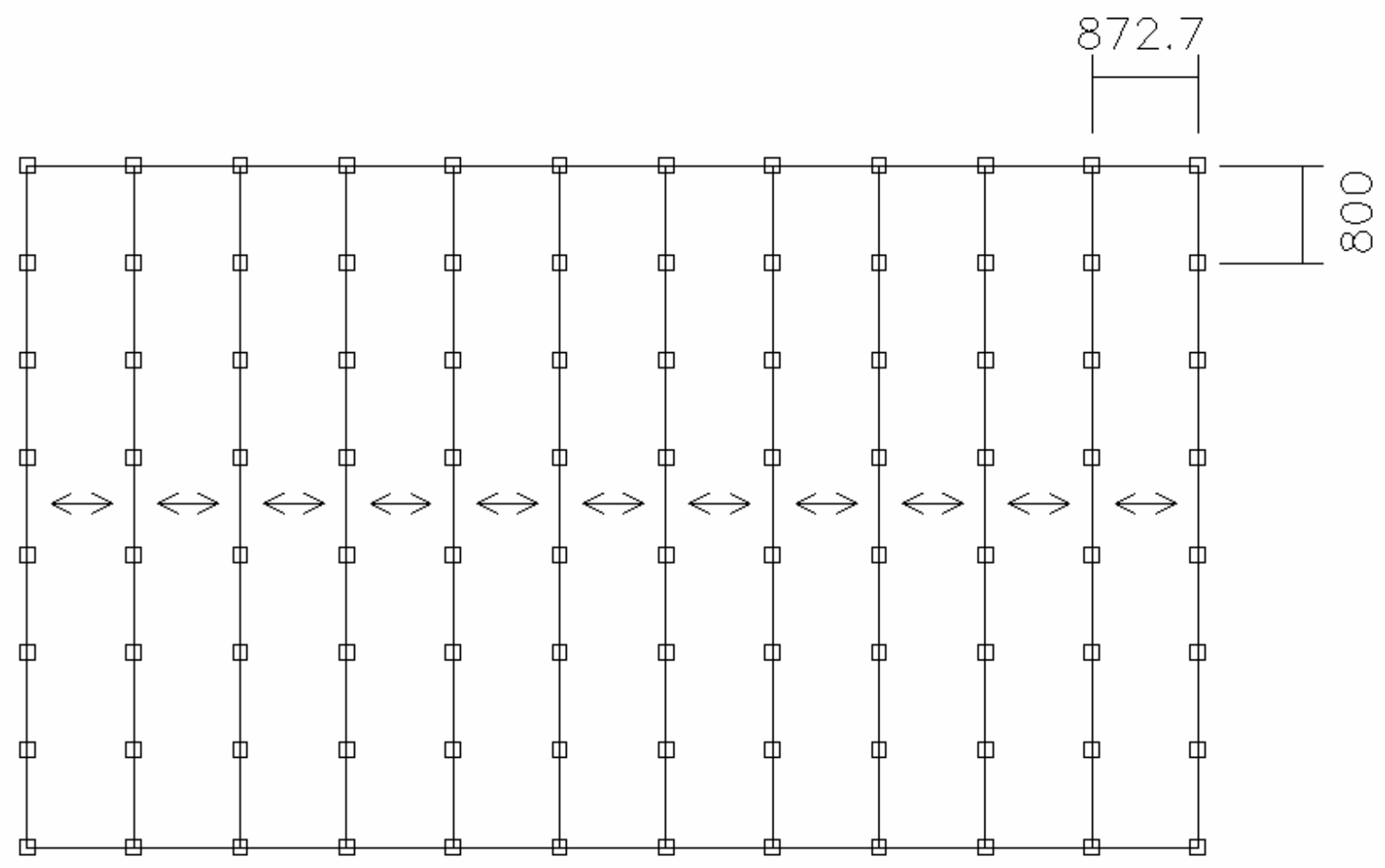

Figura 5-17 - Configuração estrutural da alternativa 5 (medidas em cm) 
d) Resultados para vão mínimo reduzido ( $\mathrm{d}_{\text {mínimo }}=5,0 \mathrm{~m}$ )

Com o intuito de se testar a alteração das respostas, em função da permissão de utilização de vãos menores, fizeram-se novos processamentos (tabela 5-11) considerando a restrição de vão mínimo de 5,0 m. Salienta-se que o custo do transporte voltou a ser o valor original.

Tabela 5-11 - Resultados do SATD para o Comercial Carvalho com vão mínimo 5,0 m

\begin{tabular}{|l|l|l|l|l|l|l|}
\hline Dados & $(6)$ & $(7)$ & $(8)$ & $(9)$ & $(10)$ & $(11)$ \\
\hline $\mathrm{N}_{\times} / \mathrm{N}_{\mathrm{Y}} / \mathrm{DL}$ & $15 / 7 / 0$ & $14 / 8 / 0$ & $15 / 8 / 0$ & $15 / 10 / 1$ & $16 / 9 / 0$ & $16 / 8 / 1$ \\
\hline $\mathrm{f}_{\mathrm{ckml}}$ & 30 & 30 & 30 & 20 & 20 & 25 \\
\hline $\mathrm{f}_{\text {ckpm }}$ & 40 & 40 & 40 & 40 & 40 & 40 \\
\hline $\mathrm{h}_{\mathrm{L}}$ & 13 & 13 & 13 & 13 & 13 & 13 \\
\hline $\mathrm{h}_{\mathrm{v}}$ & 30 & 20 & 20 & 25 & 25 & 30 \\
\hline $\mathrm{b}_{\mathrm{w}}$ & 40 & 70 & 80 & 40 & 50 & 50 \\
\hline$\ell_{\text {viga }}$ & 6,4 & 6,85 & 6,4 & 6,4 & 6,0 & 6,0 \\
\hline$\ell_{\text {laje }}$ & 8,0 & 7,0 & 7,0 & 5,6 & 6,22 & 7,0 \\
\hline $\begin{array}{l}\text { Custo } \\
\left(\mathrm{R} \$ / \mathrm{m}^{2}\right.\end{array}$ & 188,0 & 189,9 & 192,5 & 191,5 & 192,0 & 191,6 \\
\hline
\end{tabular}

Observa-se que a diminuição do vão mínimo proporcionou uma maior variabilidade de alternativas, com 6 configurações estruturais diferentes e com um custo médio mais baixo. A variação entre o maior e o menor custo das alternativas apresentadas foi de apenas 1,9\%.

Observa-se, ainda, que a direção $X$ poderia ser dividida em até 19 partes $(\ell=5,05 \mathrm{~m})$, e a direção $Y$, em até 11 partes $(\ell=5,09 \mathrm{~m})$, mas em nenhuma alternativa se atingiu o vão mínimo pois a função-custo leva em consideração todos os aspectos e, não apenas, o consumo de materiais. De maneira geral, quando se compara apenas consumo de materiais, há uma tendência para escolha da configuração de menores vãos possíveis.

Por fim, ressalta-se a predominância de alternativas em que as vigas estão dispostas na menor direção do pavimento e que, na maioria das opções, os vãos das lajes são maiores que os das vigas. 
e) Resultados para vão mínimo aumentado ( $\mathrm{d}_{\text {mínima }}=10,0 \mathrm{~m}$ )

Como última análise de sensibilidade, processaram-se exemplos utilizando como restrição de distância mínima entre pilares de $d_{\text {minima }}=10,0 \mathrm{~m}$. Para que se encontrassem indivíduos factíveis foi necessário aumentar a restrição de altura máxima do pavimento para $h_{\text {máxima }}=66 \mathrm{~cm}$. Alguns resultados são apresentados na tabela 5-12.

Tabela 5-12 - Resultados do SATD para o Comercial Carvalho com vão mínimo 10,0 $\mathrm{m}$ e altura máxima do pavimento $66 \mathrm{~cm}$

\begin{tabular}{|l|l|l|l|}
\hline Dados & $(1)$ & $(2)$ & $(3)$ \\
\hline $\mathrm{N}_{\mathrm{X}} / \mathrm{N}_{\mathrm{Y}} / \mathrm{DL}$ & $9 / 5 / 0$ & $9 / 5 / 1$ & $9 / 5 / 1$ \\
\hline $\mathrm{f}_{\text {ckml }}$ & 20 & 30 & 25 \\
\hline $\mathrm{f}_{\text {ckpm }}$ & 45 & 40 & 40 \\
\hline $\mathrm{h}_{\mathrm{L}}$ & 21 & 21 & 21 \\
\hline $\mathrm{h}_{\mathrm{v}}$ & 40 & 40 & 40 \\
\hline $\mathrm{b}_{\mathrm{w}}$ & 90 & 90 & 90 \\
\hline$\ell_{\text {viga }}$ & 11,2 & 10,67 & 10,67 \\
\hline$\ell_{\text {laje }}$ & 10,67 & 11,2 & 11,2 \\
\hline $\begin{array}{l}\text { Custo } \\
\left(\mathrm{R} \$ / \mathrm{m}^{2}\right)\end{array}$ & 261,6 & 261,3 & 263,0 \\
\hline
\end{tabular}

Observa-se que uma eventual exigência de vãos mínimos para 10,0 m, nesse exemplo, ocasionaria um acréscimo no custo médio da estrutura de $26,5 \%$ em relação ao custo médio da tabela $5-8$, que adotava a restrição mínima de $8,0 \mathrm{~m}$ original do projeto.

\subsection{EXEMPLOS DE UTILIZAÇÃO DO SATD}

Vários exemplos foram processados para testar a potencialidade do SATD, bem como tentar extrair alguns indicativos para ajudar na concepção da estrutura. 


\subsubsection{EXEMPLO APRESENTADO NO RELATÓRIO DA UNIVERSIDADE DE LEHIGH (ATLSS REPORT - PRIOR, 1993)}

Repetiu-se inicialmente o primeiro exemplo utilizado para a calibração, que fora executado ainda com a função-custo simplificada. Esse exemplo foi executado 10 vezes e os resultados dos melhores indivíduos são apresentados na Tabela 5-13. Utilizou-se como distância mínima entre pilares $d_{\text {minima }}=7,5 \mathrm{~m}$.

Tabela 5-13 - Resultados do exemplo ATLSS $\left(\mathrm{d}_{\text {minimo }}=7,5 \mathrm{~m}\right)$

\begin{tabular}{|c|c|c|c|c|c|}
\hline Dados & $\begin{array}{c}\text { SATD } \\
(1)\end{array}$ & $\begin{array}{c}\text { SATD } \\
(2)\end{array}$ & $\begin{array}{c}\text { SATD } \\
(3)\end{array}$ & $\begin{array}{c}\text { SATD } \\
(4)\end{array}$ & $\begin{array}{c}\text { SATD } \\
(5)\end{array}$ \\
\hline $\begin{array}{c}\text { Configuração } \\
\mathrm{N}_{\mathrm{X}} / \mathrm{N}_{\mathrm{Y}} / \mathrm{DL}\end{array}$ & $8 / 4 / 0$ & $8 / 4 / 0$ & $7 / 4 / 0$ & $8 / 4 / 0$ & $8 / 4 / 0$ \\
\hline $\mathrm{f}_{\mathrm{ckml}}$ & 20 & 30 & 25 & 30 & 30 \\
\hline $\mathrm{f}_{\mathrm{ckPM}}$ & 40 & 40 & 40 & 40 & 40 \\
\hline $\mathrm{h}_{\mathrm{L}}$ & 21 & 17 & 17 & 20 & 17 \\
\hline $\mathrm{h}_{\mathrm{V}}$ & 35 & 40 & 40 & 35 & 35 \\
\hline $\mathrm{b}_{\mathrm{w}}$ & 40 & 40 & 50 & 40 & 40 \\
\hline$\ell_{\text {viga }}(\mathrm{m})$ & 7,62 & 7,62 & 7,62 & 7,62 & 7,62 \\
\hline$\ell_{\text {laje }}(\mathrm{m})$ & 7,62 & 7,62 & 8,70 & 7,62 & 7,62 \\
\hline Custo $\left(\mathrm{R} \$ / \mathrm{m}^{2}\right)$ & 212,4 & 208,8 & 212,0 & 208,7 & 206,8 \\
\hline Fabricação & 82,0 & 82,0 & 83,0 & 82,0 & 83,0 \\
\hline$(\%)$ & & & & & \\
\hline Transporte $(\%)$ & 11,0 & 10,0 & 10,0 & 11,0 & 10,0 \\
\hline Montagem (\%) & 6,4 & 6,5 & 5,9 & 6,5 & 6,6 \\
\hline
\end{tabular}

\begin{tabular}{|c|c|c|c|c|c|}
\hline Dados & $\begin{array}{c}\text { SATD } \\
(6)\end{array}$ & $\begin{array}{c}\text { SATD } \\
(7)\end{array}$ & $\begin{array}{c}\text { SATD } \\
(8)\end{array}$ & $\begin{array}{c}\text { SATD } \\
(9)\end{array}$ & $\begin{array}{c}\text { SATD } \\
(10)\end{array}$ \\
\hline $\begin{array}{c}\text { Configuração } \\
\mathrm{N}_{\mathrm{X} / \mathrm{N}_{\mathrm{Y}} / \mathrm{DL}}\end{array}$ & $8 / 4 / 0$ & $8 / 4 / 0$ & $8 / 4 / 0$ & $8 / 4 / 0$ & $8 / 4 / 0$ \\
\hline $\mathrm{f}_{\mathrm{ckml}}$ & 20 & 20 & 30 & 20 & 20 \\
\hline $\mathrm{f}_{\mathrm{ckPM}}$ & 40 & 40 & 40 & 40 & 40 \\
\hline
\end{tabular}




\begin{tabular}{|c|c|c|c|c|c|}
\hline $\mathrm{h}_{\mathrm{L}}$ & 17 & 17 & 20 & 17 & 20 \\
\hline $\mathrm{h}_{\mathrm{V}}$ & 30 & 40 & 40 & 40 & 30 \\
\hline $\mathrm{b}_{\mathrm{w}}$ & 60 & 40 & 40 & 40 & 60 \\
\hline$\ell_{\text {viga }}(\mathrm{m})$ & 7,62 & 7,62 & 7,62 & 7,62 & 7,62 \\
\hline$\ell_{\text {laje }}(\mathrm{m})$ & 7,62 & 7,62 & 7,62 & 7,62 & 7,62 \\
\hline Custo $\left(\mathrm{R} \$ / \mathrm{m}^{2}\right)$ & 213,0 & 207,3 & 209,2 & 208,1 & 211,9 \\
\hline $\begin{array}{c}\text { Fabricação } \\
(\%)\end{array}$ & 83,0 & 82,0 & 82,0 & 82,0 & 82,0 \\
\hline Transporte (\%) & 10,0 & 10,0 & 11,0 & 10,0 & 11,0 \\
\hline Montagem (\%) & 6,4 & 6,6 & 6,5 & 6,5 & 6,4 \\
\hline
\end{tabular}

Constatou-se entre as varias execuções desse exemplo:

a) Existiam várias soluções eficientes com os custos muito próximos e a maior variação foi de 3,3 \%;

b) $90 \%$ das soluções indicaram a configuração estrutural adotada na figura 5-1, e apenas uma (3) indicou uma configuração diferente cujos vãos das lajes são maiores, já que a direção $X$ foi dividida apenas em 7 partes. Como a distância mínima é definida a partir de $\mathrm{N}_{\mathrm{x}}$, pode-se dizer também que em $90 \%$ dos casos esta restrição está ativa $\left(\mathrm{N}_{\mathrm{x}}=8\right)$, pois para $N_{x}=9$ tem-se $l_{\text {laje }}=6,77 \mathrm{~m}$ que viola o mínimo de $7,5 \mathrm{~m}$;

c) Todas as soluções indicaram as vigas orientadas na menor direção do pavimento;

d) Apareceram soluções com o formato das vigas, mais achatado, priorizando a largura (6 e 10). Esse fato é interessante, pois o mais natural seria optar por vigas mais altas, mas percebe-se que as vigas achatadas podem ser competitivas e ainda agregam economias indiretas como redução da distância de piso a piso. Essa redução tem impacto nos revestimentos, nas instalações, nas divisórias, na climatização e em outras áreas;

e) Todas as opções adotaram um $\mathrm{f}_{\mathrm{ckPM}}=40 \mathrm{MPa}$, que é o mesmo adotado pelo fabricante T\&A, e também por $55 \%$ das obras cadastradas no levantamento brasileiro (capítulo 3). Pode-se citar, como novidade, o 
fato de $40 \%$ das alternativas apresentarem um $\mathrm{f}_{\mathrm{ckml}}=20 \mathrm{MPa}$, valor que praticamente não foi encontrado no levantamento. Esse aspecto sugere que talvez tenham sido utilizados, na prática, valores mais altos por questões de durabilidade e não por desempenho;

f) Observa-se uma uniformidade absoluta na participação percentual das etapas fabricação, transporte e montagem, e os valores apresentados são coerentes com os valores históricos da T\&A;

g) O valor do custo da estrutura também é coerente com a informação do fabricante de que o custo variaria entre $R \$ 200,00$ e $R \$ 300,00 / \mathrm{m}^{2}$.

Novas execuções do mesmo exemplo (tabela 5-14) foram feitas, diminuindo-se a distância mínima para $\mathrm{d}_{\text {minima }}=5,0 \mathrm{~m}$, com intuito de observar a variação dos resultados com a restrição de vão mínimo mais branda.

Tabela 5-14 - Resultados do exemplo ATLSS $\left(\mathrm{d}_{\text {mínimo }}=5,0 \mathrm{~m}\right.$ )

\begin{tabular}{|c|c|c|c|c|c|}
\hline Dados & $\begin{array}{c}\text { SATD } \\
(1)\end{array}$ & $\begin{array}{c}\text { SATD } \\
(2)\end{array}$ & $\begin{array}{c}\text { SATD } \\
(3)\end{array}$ & $\begin{array}{c}\text { SATD } \\
(4)\end{array}$ & $\begin{array}{c}\text { SATD } \\
(5)\end{array}$ \\
\hline $\begin{array}{c}\text { Configuração } \\
\mathrm{N}_{\times} / \mathrm{N}_{\mathrm{Y}} / \mathrm{DL}\end{array}$ & $10 / 5 / 0$ & $10 / 6 / 0$ & $9 / 5 / 0$ & $10 / 5 / 0$ & $8 / 6 / 0$ \\
\hline $\mathrm{f}_{\mathrm{ckml}}$ & 20 & 25 & 35 & 20 & 20 \\
\hline $\mathrm{f}_{\mathrm{ckPM}}$ & 40 & 40 & 40 & 40 & 40 \\
\hline $\mathrm{h}_{\mathrm{L}}$ & 13 & 13 & 13 & 13 & 17 \\
\hline $\mathrm{h}_{\vee}$ & 35 & 20 & 20 & 20 & 20 \\
\hline $\mathrm{b}_{\mathrm{w}}$ & 40 & 50 & 60 & 60 & 50 \\
\hline$\ell_{\text {viga }}(\mathrm{m})$ & 6,09 & 5,08 & 6,09 & 6,09 & 5,08 \\
\hline$\ell_{\text {laje }}(\mathrm{m})$ & 6,09 & 6,09 & 6,77 & 6,09 & 7,62 \\
\hline Custo $\left(\mathrm{R} \$ / \mathrm{m}^{2}\right)$ & 199,9 & 196,3 & 194,6 & 202,1 & 199,8 \\
\hline Fabricação & 80,0 & 79,0 & 81,0 & 81,0 & 81,0 \\
$(\%)$ & & & & & \\
\hline Transporte $(\%)$ & 10,0 & 10,0 & 9,5 & 9,6 & 10,0 \\
\hline Montagem (\%) & 8,9 & 9,7 & 8,4 & 8,8 & 7,6 \\
\hline
\end{tabular}


Das novas execuções constatou-se que:

a) Com a diminuição do limite da restrição, as alternativas ficaram mais variadas, ainda, principalmente as configurações estruturais;

b) Observa-se uma tendência de a viga procurar o vão mínimo mais do que a laje, isso se dá por ser a viga mais cara;

c) Observa-se um pequeno acréscimo na participação do item montagem nos custos, devido ao aumento do número de peças com a diminuição do vão mínimo permitido;

d) Novamente todos os $\mathrm{f}_{\mathrm{ckPM}}=40 \mathrm{MPa}$;

e) Houve uma redução média nos custos de 5,3\%.

\subsubsection{HOTEL HOLLIDAY INN (OMAHA / NE)}

Repetiu-se também o segundo exemplo utilizado para a calibração, além de se utilizar a função-objetivo completa, adotou-se como distância mínima entre pilares $d_{\text {mínima }}=7,5 \mathrm{~m}$ nas duas direções. Foram feitos 10 processamentos e os resultados dos melhores indivíduos são apresentados na Tabela 5-15.

Tabela 5-15 - Resultados do exemplo do hotel $\left(\mathrm{d}_{\text {minimo }}=7,5 \mathrm{~m}\right)$

\begin{tabular}{|c|c|c|c|c|c|}
\hline Dados & $\begin{array}{c}\text { SATD } \\
(1)\end{array}$ & $\begin{array}{c}\text { SATD } \\
(2)\end{array}$ & $\begin{array}{c}\text { SATD } \\
(3)\end{array}$ & $\begin{array}{c}\text { SATD } \\
(4)\end{array}$ & $\begin{array}{c}\text { SATD } \\
(5)\end{array}$ \\
\hline $\begin{array}{c}\text { Configuração } \\
\mathrm{N}_{\mathrm{X}} / \mathrm{N}_{\mathrm{Y}} / \mathrm{DL}\end{array}$ & $9 / 3 / 0$ & $9 / 3 / 0$ & $9 / 3 / 0$ & $9 / 3 / 0$ & $9 / 3 / 0$ \\
\hline $\mathrm{f}_{\mathrm{ckml}}$ & 20 & 20 & 25 & 20 & 25 \\
\hline $\mathrm{f}_{\mathrm{ckPM}}$ & 40 & 40 & 40 & 40 & 40 \\
\hline $\mathrm{h}_{\mathrm{L}}$ & 20 & 17 & 20 & 21 & 17 \\
\hline $\mathrm{h}_{\mathrm{V}}$ & 50 & 40 & 40 & 35 & 40 \\
\hline $\mathrm{b}_{\mathrm{w}}$ & 40 & 50 & 50 & 50 & 50 \\
\hline Custo (R\$ $\left./ \mathrm{m}^{2}\right)$ & 206,5 & 212,3 & 205,1 & 211,0 & 212,7 \\
\hline $\begin{array}{c}\text { Fabricação } \\
(\%)\end{array}$ & 82,0 & 83,0 & 82,0 & 82,0 & 83,0 \\
\hline
\end{tabular}




\begin{tabular}{|c|c|c|c|c|c|}
\hline Transporte (\%) & 11,0 & 10,0 & 11,0 & 11,0 & 10,0 \\
\hline Montagem (\%) & 6,0 & 5,8 & 6,0 & 6,0 & 5,8 \\
\hline
\end{tabular}

\begin{tabular}{|c|c|c|c|c|c|}
\hline Dados & $\begin{array}{c}\text { SATD } \\
(6)\end{array}$ & $\begin{array}{c}\text { SATD } \\
(7)\end{array}$ & $\begin{array}{c}\text { SATD } \\
(8)\end{array}$ & $\begin{array}{c}\text { SATD } \\
(9)\end{array}$ & $\begin{array}{c}\text { SATD } \\
(10)\end{array}$ \\
\hline $\begin{array}{c}\text { Configuração } \\
\mathrm{N}_{\times} / \mathrm{N}_{Y} / \mathrm{DL}\end{array}$ & $9 / 3 / 0$ & $9 / 3 / 0$ & $9 / 3 / 0$ & $9 / 3 / 0$ & $9 / 3 / 0$ \\
\hline $\mathrm{f}_{\mathrm{ckml}}$ & 20 & 20 & 20 & 20 & 30 \\
\hline $\mathrm{f}_{\mathrm{ckPM}}$ & 40 & 40 & 40 & 40 & 40 \\
\hline $\mathrm{h}_{\mathrm{L}}$ & 17 & 17 & 20 & 17 & 20 \\
\hline $\mathrm{h}_{\mathrm{V}}$ & 40 & 40 & 40 & 30 & 35 \\
\hline $\mathrm{b}_{\mathrm{w}}$ & 50 & 40 & 50 & 60 & 50 \\
\hline Custo (R\$ /m $\left.{ }^{2}\right)$ & 207,4 & 201,8 & 212,3 & 205,5 & 210,2 \\
\hline Fabricação & 83,0 & 83,0 & 83,0 & 83,0 & 83,0 \\
$(\%)$ & 10,0 & 10,0 & 11,0 & 10,0 & 11,0 \\
\hline Transporte (\%) & 6,0 & 6,0 & 5,8 & 6,0 & 6,0 \\
\hline Montagem (\%) & & & & & \\
\hline
\end{tabular}

A partir dos resultados observa-se que:

a) Todas as melhores alternativas foram por dividir a direção $X$ em 9 partes, de forma que o vão da laje passou a ser $\ell_{\text {laje }}=8,22 \mathrm{~m}$;

b) Todas mantiveram a orientação do projeto original, com vigas na menor direção e as lajes na direção do maior lado do pavimento;

c) A maior diferença entre as aptidões foi de apenas 3\%, em relação à menor aptidão encontrada;

d) Tanto aparecem soluções que priorizaram a altura da viga (1), como as que privilegiam largura (9);

e) Novamente todas as alternativas utilizaram um $\mathrm{f}_{\mathrm{ckPM}}=40 \mathrm{MPa}$ e, em $70 \%$ das melhores alternativas, o $f_{\text {ckml }}=20 \mathrm{MPa}$;

f) Permaneceram coerentes os custos da estrutura e os valores relativos dos itens fabricação, transporte e montagem. 
Da mesma forma que foi feito, no exemplo 5.3.1, refizeram-se alguns exemplos considerando uma distância mínima entre pilares $d_{\text {minima }}=5,0 \mathrm{~m}$ e todas as constatações, verificadas logo após a tabela 5-14, voltaram a ocorrer.

\subsubsection{ESTACIONAMENTO DO SUPERMERCADO NORDESTÃO}

Trata-se de um edifício comercial com dois andares de estacionamento e 1 andar de loja, com uma área de cada pavimento de $4950 \mathrm{~m}^{2}$ ( $\ell_{x}=82,5 \mathrm{~m} \mathrm{e}$ $\left.l_{Y}=60,0 \mathrm{~m}\right)$. Fez-se uma série de processamentos para os andares de estacionamento utilizando, como premissa fundamental, o respeito à

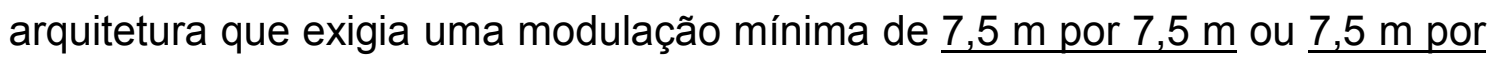
$10,0 \mathrm{~m}$, em função da passagem dos carros e do tamanho das vagas (figura 5 18). Adotou-se um carregamento de $1 \mathrm{kN} / \mathrm{m}^{2}$ para as cargas de pavimentação e revestimento e uma carga acidental de $3 \mathrm{kN} / \mathrm{m}^{2}$.

Inicialmente, adotou-se, como restrições, uma distância mínima entre pilares nas duas direções $d_{\min } \mathrm{X}, \mathrm{y}=7,5 \mathrm{~m}$ e uma altura máxima de pavimento de $75 \mathrm{~cm}$. Os resultados dessa série de processamentos encontram-se na tabela $5-16$.

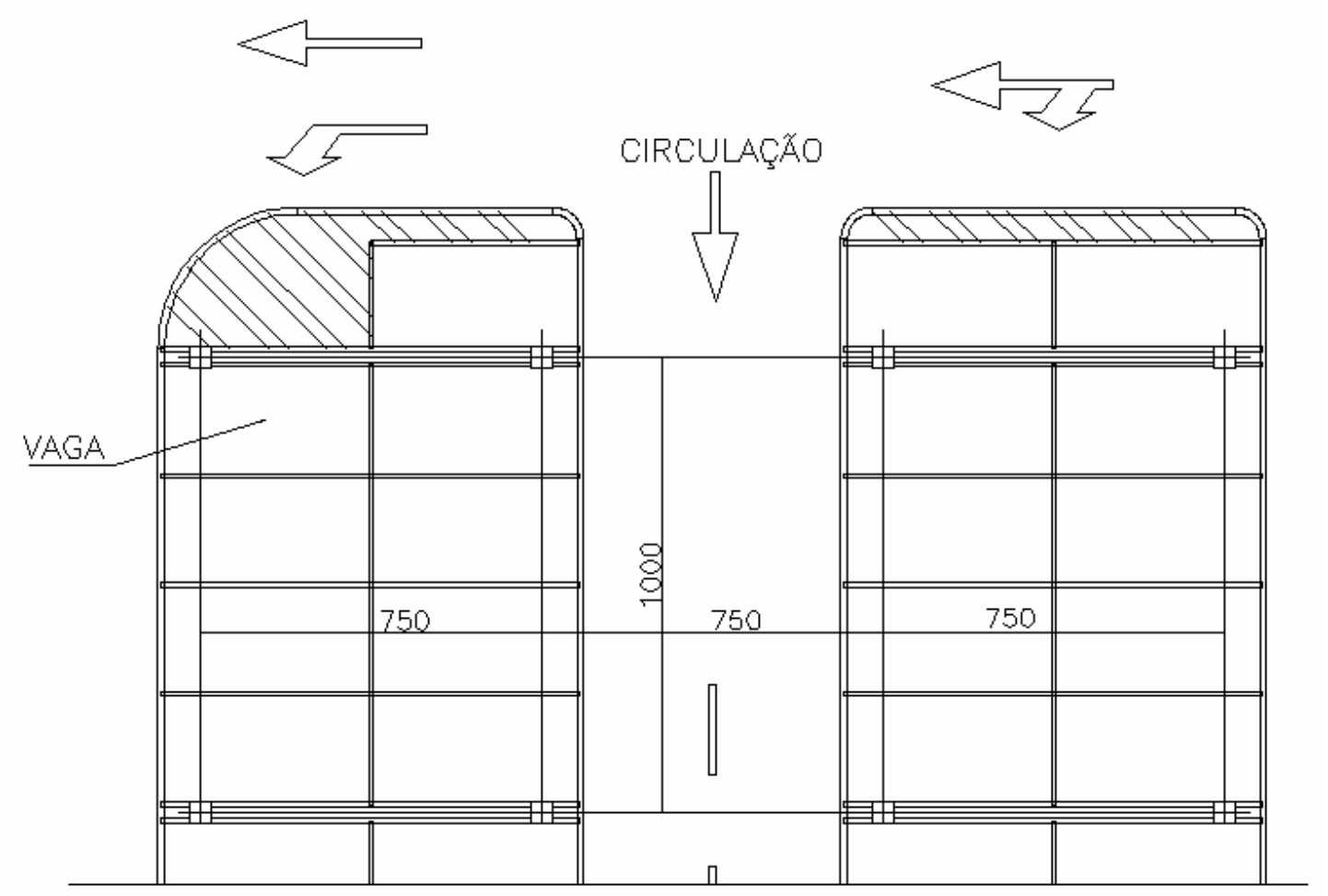

Figura 5-18 - Arquitetura do estacionamento do supermercado Nordestão 
Tabela 5-16 - Resultados do exemplo do Nordestão $\left(d_{\text {mínimoX,Y }}=7,5\right.$ m)

\begin{tabular}{|c|c|c|c|c|c|}
\hline Dados & $\begin{array}{c}\text { SATD } \\
(1)\end{array}$ & $\begin{array}{c}\text { SATD } \\
(2)\end{array}$ & $\begin{array}{c}\text { SATD } \\
(3)\end{array}$ & $\begin{array}{c}\text { SATD } \\
(4)\end{array}$ & $\begin{array}{c}\text { SATD } \\
(5)\end{array}$ \\
\hline $\begin{array}{c}\text { Configuração } \\
\mathrm{N}_{\mathrm{X}} / \mathrm{N}_{\mathrm{Y}} / \mathrm{DL}\end{array}$ & $11 / 7 / 0$ & $11 / 8 / 1$ & $10 / 8 / 0$ & $11 / 7 / 1$ & $11 / 8 / 0$ \\
\hline $\mathrm{f}_{\mathrm{ckml}}$ & 25 & 30 & 20 & 25 & 25 \\
\hline $\mathrm{f}_{\mathrm{ckPM}}$ & 40 & 40 & 40 & 40 & 40 \\
\hline $\mathrm{h}_{\mathrm{L}}$ & 13 & 13 & 20 & 21 & 13 \\
\hline $\mathrm{h}_{\mathrm{V}}$ & 35 & 25 & 40 & 35 & 40 \\
\hline $\mathrm{b}_{\mathrm{w}}$ & 40 & 60 & 40 & 40 & 40 \\
\hline Custo $\left(\mathrm{R} \$ / \mathrm{m}^{2}\right)$ & 191,3 & 190,9 & 195,7 & 196,1 & 191,1 \\
\hline$\Delta(\%)$ & $(+0,2 \%)$ & $(1)$ & $(+2,5 \%)$ & $(+2,7 \%)$ & $(+0,1 \%)$ \\
\hline$\ell_{\text {viga }}$ & 8,57 & 7,5 & 7,5 & 7,5 & 7,5 \\
\hline$\ell_{\text {laje }}$ & 7,5 & 7,5 & 8,25 & 8,57 & 7,5 \\
\hline
\end{tabular}

Dos resultados observa-se que:

a) Apresentam-se 5 configurações estruturais distintas e economicamente viáveis (figura 5-19). A maioria delas tem a direção das vigas na mesma direção do menor lado do pavimento e a maior diferença de custos foi de $2,7 \%$;

b) Todas as respostas indicaram um $\mathrm{f}_{\mathrm{ckpm}}=40 \mathrm{MPa}$ e a maioria das respostas indicaram $\mathrm{um}_{\mathrm{ckml}}=25 \mathrm{MPa}$;

c) As alternativas 1, 3 e 4 não se aplicariam na prática, por não atenderem à modulação do estacionamento, porquanto o vão na direção $X$ deveria ser múltiplo de 2,5 m (largura da vaga);

d) A alternativa mais econômica (2) apresenta uma seção de viga que prioriza a largura, ao invés da altura;

e) O custo médio das alternativas foi de $\mathrm{R} \$ 193,02 / \mathrm{m}^{2}$. 

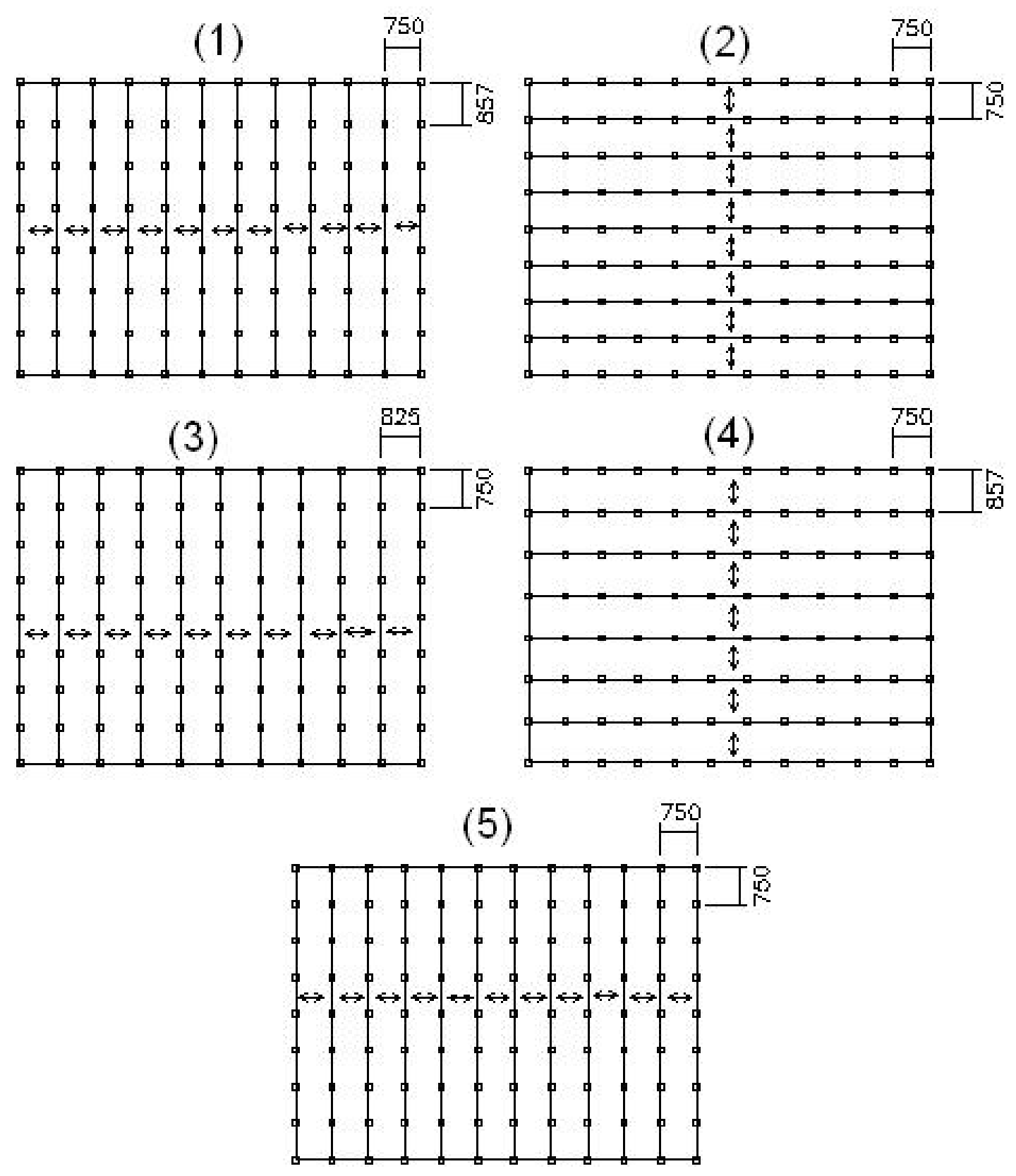

Figura 5-19 - Configurações estruturais da primeira série de processamentos (medidas em "cm")

Outros processamentos foram feitos, e são apresentados na tabela 5-17, considerando agora que a distância mínima entre pilares, na direção " $Y$ ", seria de $d_{\min Y}=10,0 \mathrm{~m}$ em função de uma melhor modulação para as vagas de garagem (figura 5-18). Isso porque, ao se modular em 7,5 m, e considerandose pilares de $40 \mathrm{~cm}$, haveria 3 vagas de $236,6 \mathrm{~cm}$, enquanto, para 10,0 m, haveria 4 vagas de $240 \mathrm{~cm}$. 
Tabela 5-17 - Resultados do exemplo do Nordestão $\left(d_{\text {minimox }}=7,5 \mathrm{~m} \mathrm{e}_{\mathrm{m}_{\text {minimoY }}}=10,0 \mathrm{~m}\right.$ )

\begin{tabular}{|c|c|c|c|c|c|}
\hline Dados & $\begin{array}{c}\text { SATD } \\
(1)\end{array}$ & $\begin{array}{c}\text { SATD } \\
(2)\end{array}$ & $\begin{array}{c}\text { SATD } \\
(3)\end{array}$ & $\begin{array}{c}\text { SATD } \\
(4)\end{array}$ & $\begin{array}{c}\text { SATD } \\
(5)\end{array}$ \\
\hline $\begin{array}{c}\text { Configuração } \\
\mathrm{N}_{\mathrm{X}} / \mathrm{N}_{\mathrm{Y}} / \mathrm{DL}\end{array}$ & $11 / 6 / 0$ & $11 / 6 / 1$ & $11 / 6 / 0$ & $11 / 6 / 0$ & $10 / 6 / 0$ \\
\hline $\mathrm{f}_{\mathrm{ckml}}$ & 25 & 20 & 20 & 30 & 20 \\
\hline $\mathrm{f}_{\mathrm{ckPM}}$ & 40 & 35 & 40 & 40 & 45 \\
\hline $\mathrm{h}_{\mathrm{L}}$ & 17 & 20 & 17 & 13 & 20 \\
\hline $\mathrm{h}_{\mathrm{V}}$ & 40 & 30 & 35 & 35 & 40 \\
\hline $\mathrm{b}_{\mathrm{w}}$ & 40 & 60 & 60 & 60 & 40 \\
\hline Custo $\left(\mathrm{R} \$ / \mathrm{m}^{2}\right)$ & 201,9 & 205,9 & 205,6 & 199,1 & 206,5 \\
\hline$\Delta(\%)$ & $(+1,4)$ & $(+3,4)$ & $(+3,2)$ & $(1)$ & $(+3,7)$ \\
\hline$\ell_{\text {viga }}$ & 10,0 & 7,5 & 10,0 & 10,0 & 10,0 \\
\hline$\ell_{\text {laje }}$ & 7,5 & 10 & 7,5 & 7,5 & 8,25 \\
\hline
\end{tabular}

Conclui-se dos resultados que:

a) Dos resultados apresentados, observam-se 3 configurações estruturais distintas e economicamente viáveis (figura 5-20). Com o aumento da distância mínima, para $10,0 \mathrm{~m}$, a variabilidade diminui;

b) Duas delas têm a direção das vigas na mesma direção do menor lado do pavimento e a maior diferença de custos foi de 3,7\%;

c) A maioria das respostas indicou um $f_{\text {ckpm }}=40 \mathrm{MPa}$ e um $\mathrm{f}_{\mathrm{ckml}}=20$ MPa;

d) O custo médio das alternativas foi de $\mathrm{R} \$ 203,8 / \mathrm{m}^{2}$, que representa um acréscimo de $5,6 \%$ em relação à série anterior. Essa tendência de acréscimo justifica-se pela diminuição do espaço factível de projeto, já que, ao aumentar o vão mínimo, diminuem as alternativas de vigas e lajes que atendem às novas solicitações; 
e) Considerando que o pavimento tem uma área de $4950 \mathrm{~m}^{2}$ e que o edifício tem 2 pavimentos, o aumento de 5,6\% corresponde a um aumento absoluto de aproximadamente $\mathrm{R} \$ 106.000,00$;

f) A configuração estrutural da alternativa 2 foi a mesma adotada no projeto.

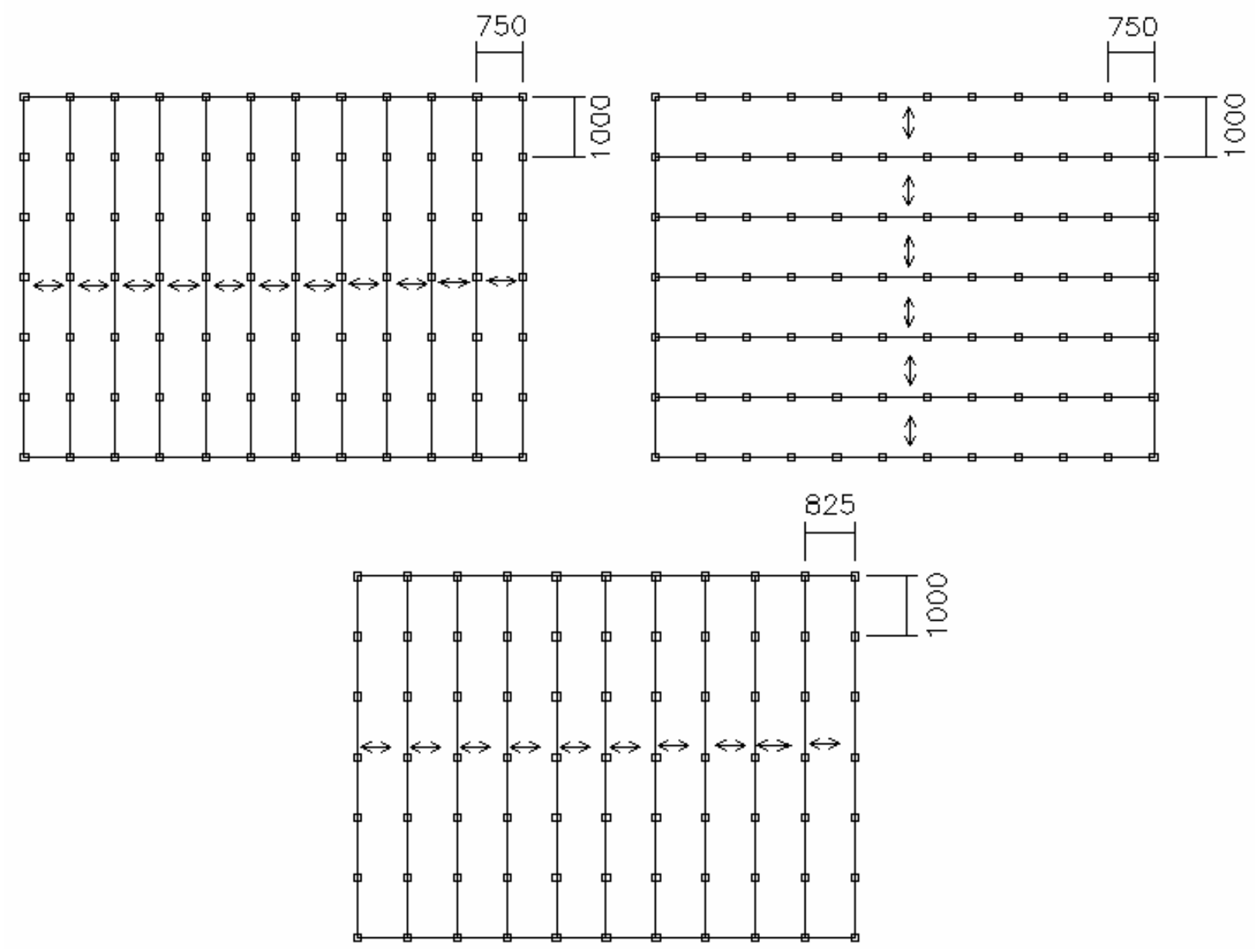

Figura 5-20 - Configurações estruturais da segunda série de processamentos (medidas em "cm")

Muitas vezes, em função da distância entre os pavimentos principalmente em áreas de garagens, a altura máxima do pavimento tem de ser mais restritiva, uma vez que os carros estão cada vez mais altos. Por isso, fizeram-se novos processamentos considerando-se uma altura máxima de 60 cm e $d_{\min } x, y=7,5 m$ (tabela $5-18$ ). 
Tabela 5-18 - Resultados do exemplo do Nordestão para altura máxima de $60 \mathrm{~cm}$ $\left(d_{\text {mínimoX,Y }}=7,5 \mathrm{~m}\right)$

\begin{tabular}{|c|c|c|c|c|c|}
\hline Dados & $\begin{array}{c}\text { SATD } \\
(1)\end{array}$ & $\begin{array}{c}\text { SATD } \\
(2)\end{array}$ & $\begin{array}{c}\text { SATD } \\
(3)\end{array}$ & $\begin{array}{c}\text { SATD } \\
(4)\end{array}$ & $\begin{array}{c}\text { SATD } \\
(5)\end{array}$ \\
\hline $\begin{array}{c}\text { Configuração } \\
\mathrm{N}_{\mathrm{X}} / \mathrm{N}_{\mathrm{Y}} / \mathrm{DL}\end{array}$ & $11 / 8 / 0$ & $11 / 8 / 1$ & $11 / 8 / 0$ & $11 / 8 / 0$ & $11 / 8 / 1$ \\
\hline $\mathrm{f}_{\mathrm{ckml}}$ & 20 & 20 & 25 & 35 & 35 \\
\hline $\mathrm{f}_{\mathrm{ckPM}}$ & 40 & 40 & 40 & 40 & 40 \\
\hline $\mathrm{h}_{\mathrm{L}}$ & 13 & 20 & 13 & 13 & 13 \\
\hline $\mathrm{h}_{\mathrm{V}}$ & 25 & 25 & 40 & 30 & 25 \\
\hline $\mathrm{b}_{\mathrm{w}}$ & 80 & 50 & 40 & 60 & 60 \\
\hline Custo (R\$ /m $\left.{ }^{2}\right)$ & 193,1 & 195,2 & 191,5 & 188,8 & 190,1 \\
\hline$\ell_{\text {viga }}$ & 7,5 & 7,5 & 7,5 & 7,5 & 7,5 \\
\hline$\ell_{\text {laje }}$ & 7,5 & 7,5 & 7,5 & 7,5 & 7,5 \\
\hline Fabricação(\%) & 82 & 81 & 82 & 82 & 82 \\
\hline Transporte (\%) & 8,9 & 10 & 9 & 9 & 9 \\
\hline Montagem (\%) & 7,4 & 7,5 & 7,5 & 7,6 & 7,5 \\
\hline
\end{tabular}

A partir das alternativas apresentadas, considera-se que:

a) Observam-se apenas 2 configurações estruturais distintas e economicamente viáveis (figura 5-21). O espaço de busca ficou menor, porém proporcionou um custo médio de $\mathrm{R} \$ 191,74 / \mathrm{m}^{2}$ que é um pouco mais baixo do que o apresentado na série em que a altura máxima permitida era $75 \mathrm{~cm}\left(\mathrm{R} \$ 193,02 / \mathrm{m}^{2}\right)$. Isso acontece devido à restrição de altura máxima não está ativa conforme apresentado na tabela 5-16. A tendência de aumento só se verificaria se a solução anterior fosse a ótima global. Percebese que a alternativa 3 da tabela 5-18 é praticamente igual à alternativa 5 da tabela $5-16$, inclusive;

b) Observa-se também que, embora algumas alternativas tenham as aptidões muito próximas, não possuem as variáveis coincidentes. 
Essa é uma característica do modelo, já que a aleatoriedade das combinações faz com que as respostas estejam espalhadas por todo o domínio e não concentradas em uma mesma região;

c) Todas as respostas indicaram um $\mathrm{f}_{\mathrm{ckpm}}=40 \mathrm{MPa}$ e, na maioria, um $\mathrm{f}_{\mathrm{ckml}}=20 \mathrm{MPa}$ ou $25 \mathrm{MPa}$.
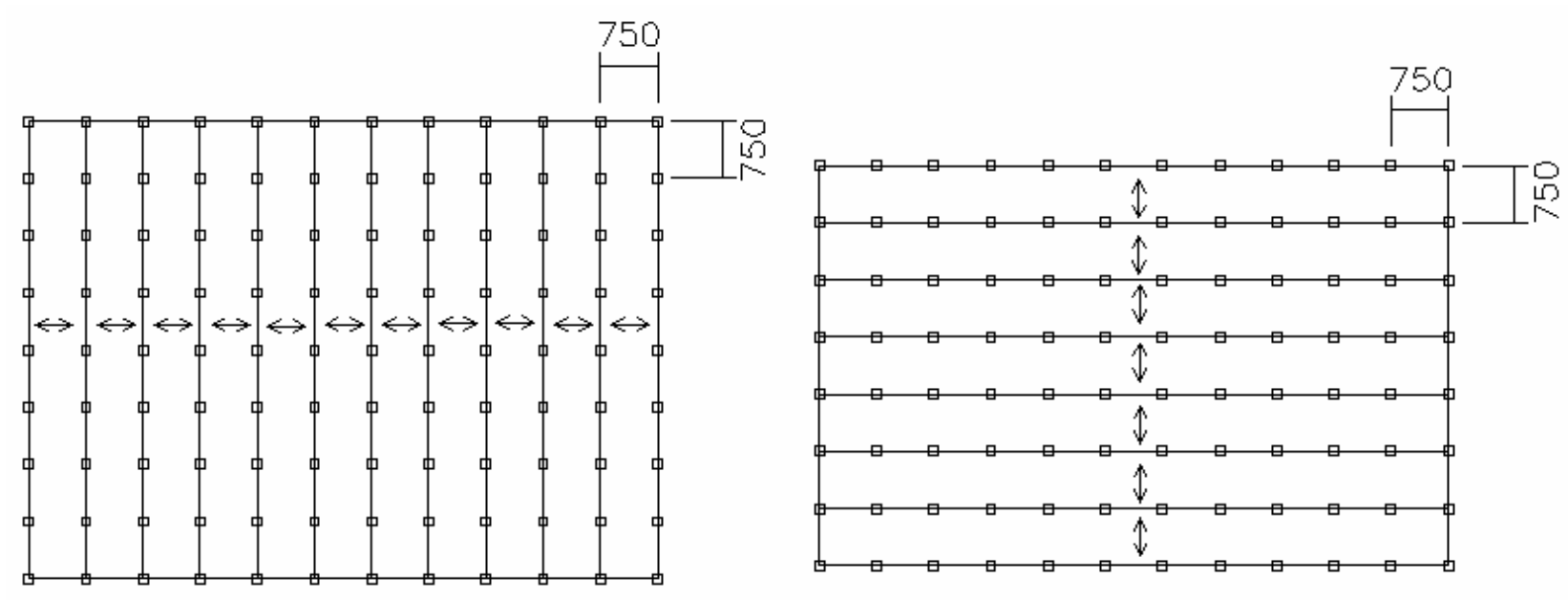

Figura 5-21 - Configurações estruturais da terceira série de processamentos (medidas em "cm")

\section{Análise de Sensibilidade}

Aproveitou-se esse exemplo para se fazer uma análise de sensibilidade, variando inicialmente o custo do aço (tabela 5-19), e, posteriormente, o custo do concreto (tabela 5-20), considerando-se uma variação de $25 \%$ para ambos os casos. Adotou-se novamente uma altura máxima do pavimento de $60 \mathrm{~cm}$ e uma distância mínima entre pilares nas duas direções de $d_{\text {minima }}=7,5 \mathrm{~m}$. 
Tabela 5-19 - Resultados com custo do aço $25 \%$ maior

\begin{tabular}{|c|c|c|c|c|c|}
\hline Dados & $\begin{array}{c}\text { SATD } \\
(1)\end{array}$ & $\begin{array}{c}\text { SATD } \\
(2)\end{array}$ & $\begin{array}{c}\text { SATD } \\
(3)\end{array}$ & $\begin{array}{c}\text { SATD } \\
(4)\end{array}$ & $\begin{array}{c}\text { SATD } \\
\left(^{*}\right)\end{array}$ \\
\hline $\begin{array}{c}\text { Configuração } \\
\mathrm{N}_{\times} / \mathrm{N}_{\mathrm{Y}} / \mathrm{DL}\end{array}$ & $11 / 8 / 1$ & $10 / 8 / 1$ & $11 / 8 / 1$ & $10 / 8 / 1$ & $\mathbf{1 1 / 8 / 1}$ \\
\hline $\mathrm{f}_{\mathrm{ckml}}$ & $25 \uparrow$ & 35 & 20 & 20 & $\mathbf{2 0}$ \\
\hline $\mathrm{f}_{\mathrm{ckPM}}$ & 40 & 40 & 40 & 40 & $\mathbf{4 0}$ \\
\hline $\mathrm{h}_{\mathrm{L}}$ & $13 \downarrow$ & 20 & 13 & 17 & $\mathbf{2 0}$ \\
\hline $\mathrm{h}_{\mathrm{V}}$ & $35 \uparrow$ & 30 & 30 & 30 & $\mathbf{2 5}$ \\
\hline $\mathrm{b}_{\mathrm{w}}$ & $40 \uparrow$ & 40 & 50 & 60 & $\mathbf{5 0}$ \\
\hline Custo (R\$ /m $\left.{ }^{2}\right)$ & 206,2 & 210,0 & 211,5 & 211,6 & $\mathbf{1 9 5 , 2}$ \\
\hline Fabricação(\%) & 83,0 & 82,0 & 84,0 & 83,0 & $\mathbf{8 1 , 0}$ \\
\hline Transporte (\%) & 8,1 & 9,6 & 7,9 & 9,4 & $\mathbf{1 0 , 0}$ \\
\hline Montagem (\%) & 7,1 & 6,7 & 7 & 6,7 & $\mathbf{7 , 5}$ \\
\hline
\end{tabular}

(*) Alternativa 2 da tabela 5-18

Conclui-se que, com o aumento do preço do aço:

a) O custo médio $\left(\mathrm{R} \$ 209,83 / \mathrm{m}^{2}\right)$ subiu $8,6 \%$ em relação ao custo médio da tabela 5-16 ( $\left.\mathrm{R} \$ 193,26 / \mathrm{m}^{2}\right)$;

b) Ao se comparar a alternativa 1 da tabela 5-19 com a alternativa 2 da tabela 5-18 $\left({ }^{*}\right)$, ambas com a mesma configuração, observa-se que houve um aumento do $f_{c k m l}$, que diminui a armadura da laje, e houve uma modificação na geometria da viga aumentando a altura, para que tivesse ela melhor desempenho com menos armadura;

c) Houve, em média, um pequeno acréscimo no percentual da etapa de fabricação, que é a etapa que sofre influência dos custos dos materiais;

d) As configurações estruturais passaram a apresentar as vigas orientadas na maior direção do pavimento (figura 5-22). 


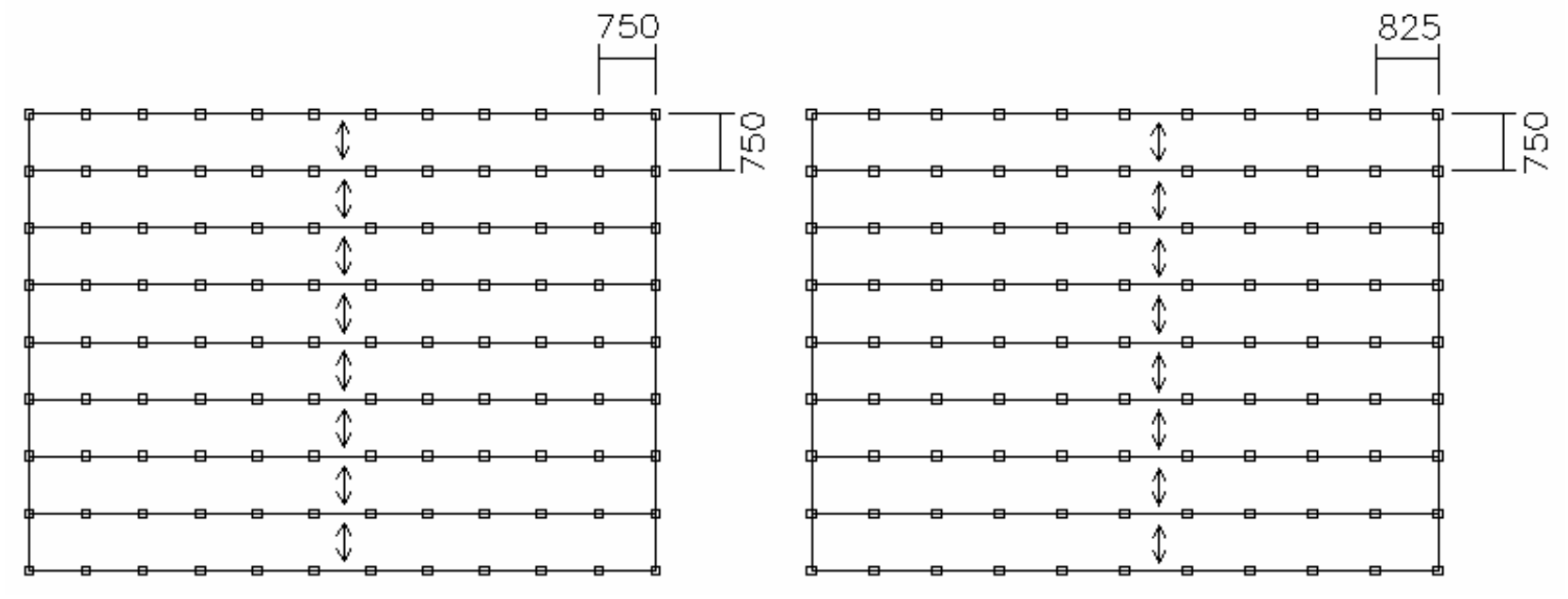

Figura 5-22 - Configurações para o caso em que o aço é $25 \%$ mais caro (medidas em "cm")

Tabela 5-20 - Resultados com o custo do concreto $25 \%$ maior

\begin{tabular}{|c|c|c|c|c|c|}
\hline Dados & $\begin{array}{c}\text { SATD } \\
(1)\end{array}$ & $\begin{array}{c}\text { SATD } \\
(2)\end{array}$ & $\begin{array}{c}\text { SATD } \\
(3)\end{array}$ & $\begin{array}{c}\text { SATD } \\
(4)\end{array}$ & $\begin{array}{c}\text { SATD } \\
\left(^{*}\right)\end{array}$ \\
\hline $\begin{array}{c}\text { Configuração } \\
\mathrm{N}_{\mathrm{X}} / \mathrm{N}_{\mathrm{Y}} / \mathrm{DL}\end{array}$ & $11 / 7 / 0$ & $10 / 8 / 1$ & $11 / 8 / 0$ & $11 / 8 / 1$ & $\mathbf{1 1 / 8 / 1}$ \\
\hline $\mathrm{f}_{\mathrm{ckml}}$ & 20 & 35 & 25 & 20 & $\mathbf{2 0}$ \\
\hline $\mathrm{f}_{\mathrm{ckPM}}$ & 40 & 40 & 40 & 40 & $\mathbf{4 0}$ \\
\hline $\mathrm{h}_{\mathrm{L}}$ & 13 & 13 & 13 & $13 \downarrow$ & $\mathbf{2 0}$ \\
\hline $\mathrm{h}_{\mathrm{V}}$ & 40 & 35 & 25 & 25 & $\mathbf{2 5}$ \\
\hline $\mathrm{b}_{\mathrm{w}}$ & 40 & 40 & 60 & $40 \downarrow$ & $\mathbf{5 0}$ \\
\hline Custo (R\$ /m $\left.{ }^{2}\right)$ & 208,5 & 204,5 & 200,8 & 205,7 & $\mathbf{1 9 5 , 2}$ \\
\hline Fabricação(\%) & 84,0 & 84,0 & 83,0 & 83,0 & $\mathbf{8 1 , 0}$ \\
\hline Transporte (\%) & 8,2 & 8,1 & 8,1 & 8,2 & $\mathbf{1 0 , 0}$ \\
\hline Montagem (\%) & 6,8 & 6,9 & 7,1 & 7,2 & $\mathbf{7 , 5}$ \\
\hline
\end{tabular}

(*) Alternativa 2 da tabela 5-18 
Conclui-se que, com o aumento do preço do concreto:

a) O custo médio $\left(R \$ 204,9 / \mathrm{m}^{2}\right)$ subiu $6,1 \%$ em relação ao custo médio da tabela 5-18 (R\$ 193,26/m²);

b) Assim como no exemplo anterior, houve um pequeno acréscimo percentual na etapa de fabricação;

c) Ao se comparar a alternativa 4 da tabela 5-20 com a alternativa 2 da tabela $5-18$, observa-se que houve uma diminuição $(\downarrow)$ da altura da laje e da altura da viga, que reduz o consumo de concreto e aumenta o consumo de armadura. A quantidade de cabos nas vigas aumentou em $15,4 \%$ e nas lajes aumentou em $21,4 \%$.

(1)

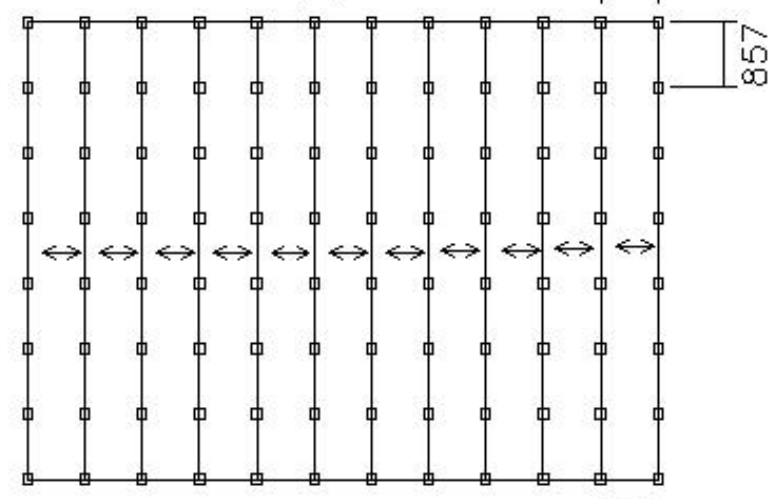

(3)

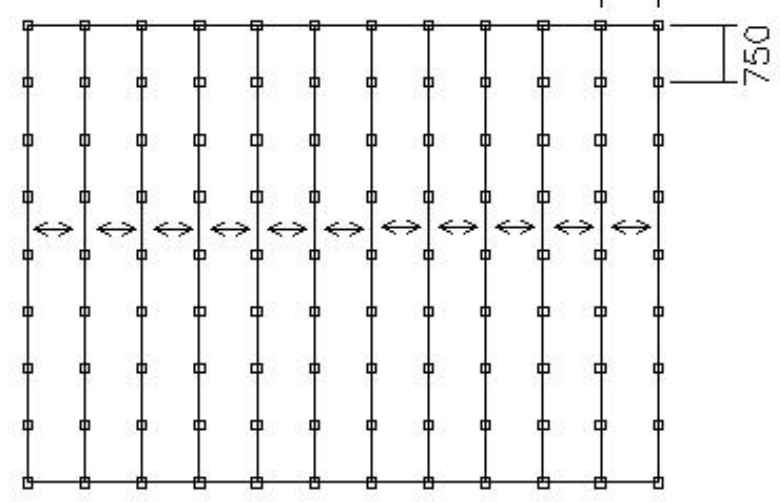

(2)

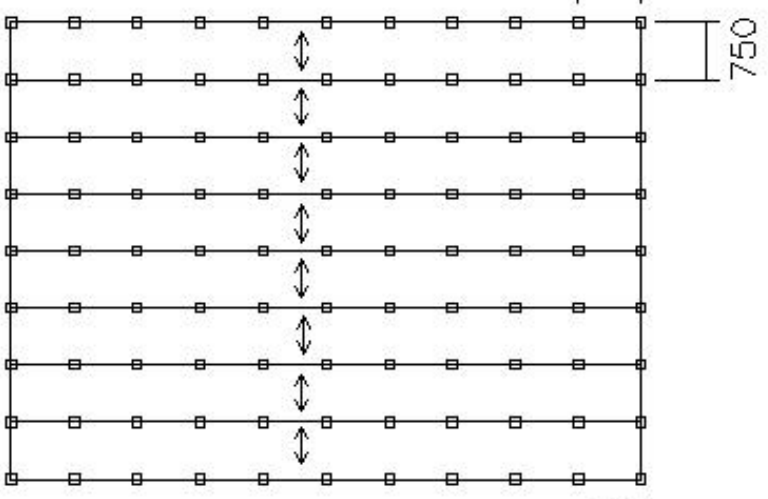

(4)

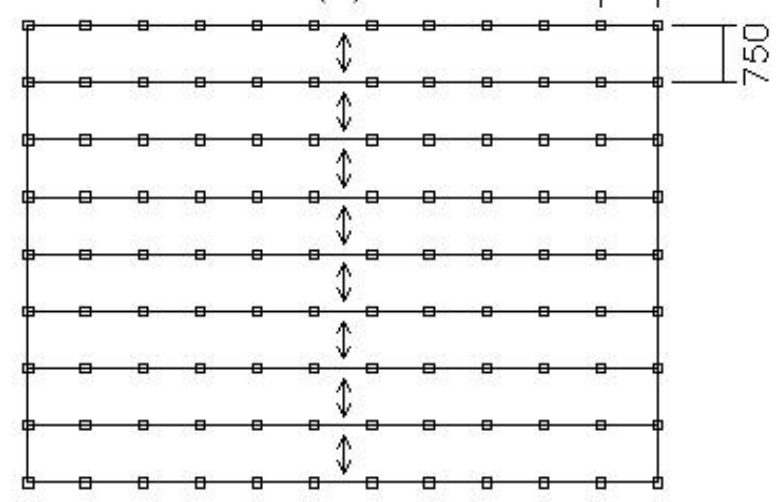

Figura 5-23 - Configurações para o caso em que o concreto é $25 \%$ mais caro (medidas em "cm") 
Observa-se que o aumento em $25 \%$ no custo do aço ou no custo do concreto representou, em média, um acréscimo de apenas $8,6 \%$ e 6,1\% respectivamente no custo total. Isso se deve ao fato da composição do custo não levar em consideração somente o consumo de materiais e também pelo fato de o SATD ter a capacidade de procurar as soluções que melhor se adaptam ao meio ambiente, no caso, o custo. Conforme apresentado nas tabelas 5-19 e 5-20, quando o custo de um insumo aumenta, o sistema diminui seu consumo automaticamente, procurando sempre a alternativa com o menor custo. Esse comportamento das soluções diante, das perturbações, demonstra a validade do sistema, e corrobora a importância de uma otimização integrada, que considera todas as etapas em uma mesma rotina.

Com o intuito de analisar o comportamento dos resultados com um incremento gradual nos custos do aço e do concreto, foram processados vários novos exemplos aumentando-se os custos do aço e do concreto em 15\%, 35\% e $45 \%$, e encontraram-se as curvas da figura 5-24 e o gráfico da figura 5-25, em que a partir do preço original (1) se aumenta o custo em 15\% (2), $25 \%$ (3), $35 \%$ (4) e $45 \%$ (5).

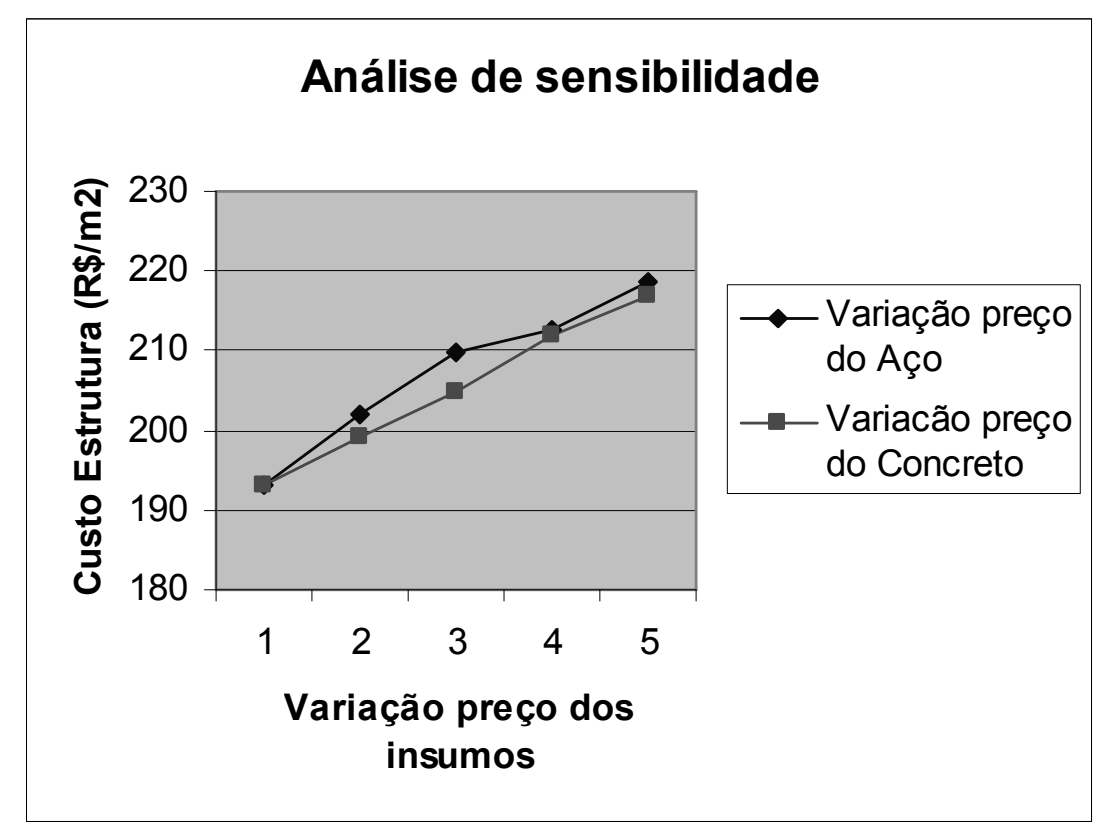

Figura 5-24 - Custo da estrutura para acréscimos incrementais dos insumos 


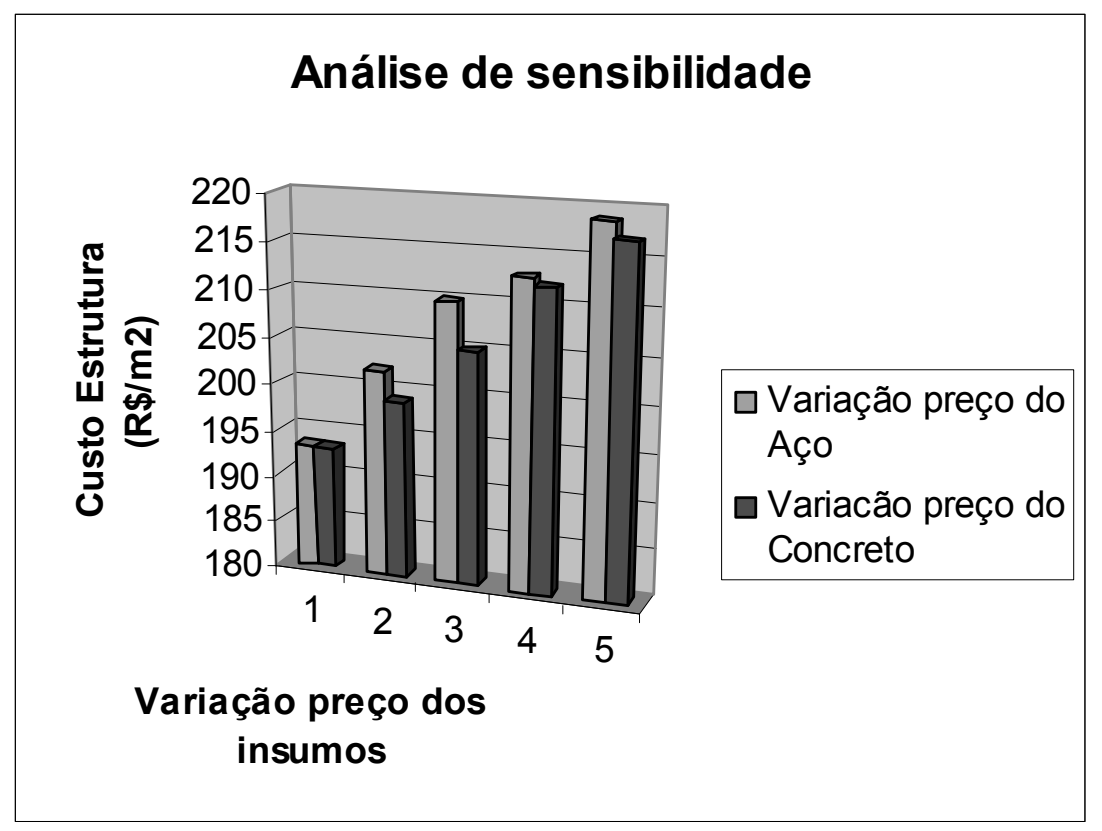

Figura 5-25 - Custo da estrutura para acréscimos incrementais dos insumos

Observou-se uma variação quase linear para os dois insumos, principalmente o concreto (os valores apresentados são médios de 6 processamentos cada). Observou-se, ainda, que o aumento do aço tem um maior impacto no custo da estrutura e que a variação máxima no custo foi de $13,2 \%$ para um aumento de $45 \%$ no custo do aço. Fez-se, então, uma última análise, considerando um acréscimo simultâneo no custo do aço e do concreto, também em 25\%. Alguns desses resultados são apresentados na tabela 5-21. Lembra-se que existem outros custos na função-objetivo que foram mantidos constantes.

Analisando-se os resultados, encontra-se uma predominância de soluções em que se divide a maior dimensão em menos partes, de forma que os vãos ficam maiores. Isso se justifica pelo fato de a fabricação ter ficado mais cara e as únicas etapas que não foram afetadas serem o transporte e a montagem, que se beneficiam com uma menor quantidade de peças. Observase ainda que o aumento do custo foi de $16 \%$ em relação ao custo médio da tabela 5-18. 
Tabela 5-21 - Resultados com o custo do concreto e do aço $25 \%$ maior

\begin{tabular}{|c|c|c|c|c|c|c|}
\hline Dados & $\begin{array}{c}\text { SATD } \\
(1)\end{array}$ & $\begin{array}{c}\text { SATD } \\
(2)\end{array}$ & $\begin{array}{c}\text { SATD } \\
(3)\end{array}$ & $\begin{array}{c}\text { SATD } \\
(4)\end{array}$ & $\begin{array}{c}\text { SATD } \\
(5)\end{array}$ & $\begin{array}{c}\text { SATD } \\
(6)\end{array}$ \\
\hline $\begin{array}{c}\text { Configuração } \\
\mathrm{N}_{\mathrm{X}} / \mathrm{N}_{\mathrm{Y}} / \mathrm{DL}\end{array}$ & $10 / 8 / 1$ & $11 / 8 / 0$ & $10 / 8 / 1$ & $10 / 8 / 1$ & $10 / 8 / 1$ & $10 / 8 / 0$ \\
\hline $\mathrm{f}_{\mathrm{ckml}}$ & 20 & 30 & 25 & 20 & 25 & 30 \\
\hline $\mathrm{f}_{\mathrm{ckPM}}$ & 40 & 40 & 45 & 40 & 40 & 40 \\
\hline $\mathrm{h}_{\mathrm{L}}$ & 13 & 13 & 13 & 13 & 13 & 17 \\
\hline $\mathrm{h}_{\mathrm{V}}$ & 35 & 40 & 25 & 30 & 30 & 25 \\
\hline $\mathrm{b}_{\mathrm{w}}$ & 40 & 60 & 60 & 50 & 60 & 60 \\
\hline Custo (R $\left.\$ \mathrm{~m}^{2}\right)$ & 224,7 & 224,1 & 226,7 & 223,2 & 222,3 & 222,3 \\
\hline Fabricação(\%) & 85 & 84 & 85 & 85 & 85 & 84 \\
\hline Transporte (\%) & 7,4 & 8,3 & 7,2 & 7,4 & 7,7 & 8,3 \\
\hline Montagem (\%) & 6,3 & 6,4 & 6,2 & 6,3 & 6,3 & 6,0 \\
\hline
\end{tabular}

Composição relativa do item fabricação

Apresenta-se na tabela 5-22 e nas figuras 5-26 e 5-27 a composição percentual, discriminada, do item fabricação para a alternativa 1 e para a alternativa 3 da tabela 5-16. Para a fabricação das vigas, lajes e pilares consideram-se os custos do concreto, do aço de protensão, do aço para armadura passiva e das despesas operacionais.

Tabela 5-22 - Composição relativa do item fabricação

\begin{tabular}{|c|c|c|c|}
\hline Fabricação & $\begin{array}{c}\text { Custos (\%) } \\
(1)\end{array}$ & $\begin{array}{c}\text { Custos (\%) } \\
(3)\end{array}$ & $\begin{array}{c}\text { Custos (\%) } \\
\text { Média }\end{array}$ \\
\hline Concreto* $^{*}$ & 28,5 & 34,5 & 31,5 \\
\hline Armadura ativa & 33,3 & 25,7 & 29,5 \\
\hline Armadura passiva & 7,3 & 6,2 & 6,8 \\
\hline $\begin{array}{c}\text { Despesas } \\
\text { operacionais }\end{array}$ & 31,0 & 33,5 & 32,3 \\
\hline
\end{tabular}

* Concreto pré-moldado e moldado no local 


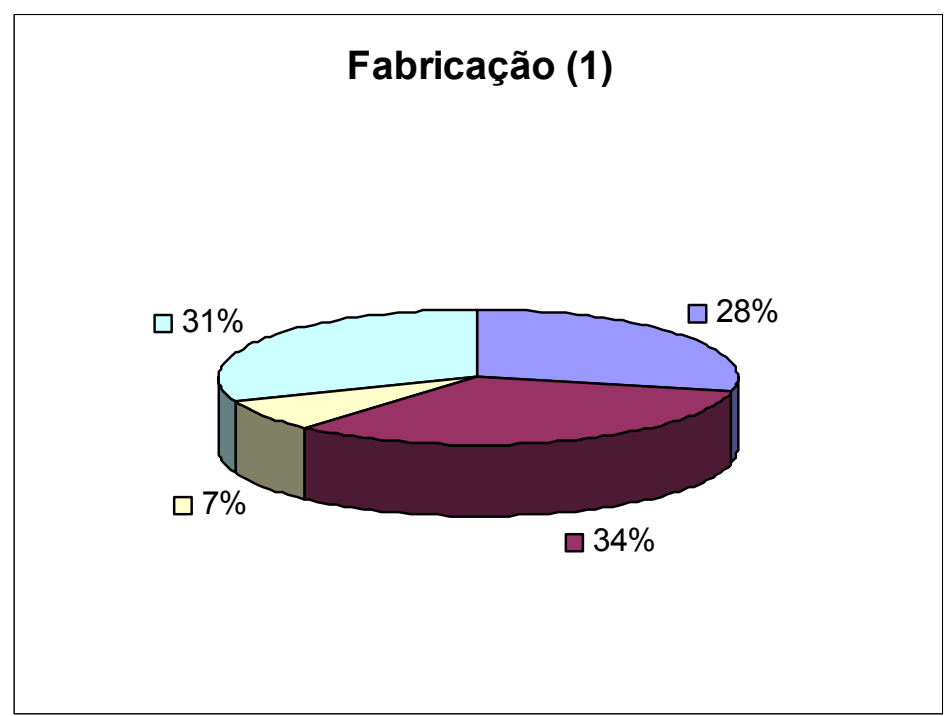

Figura 5-26 - Fabricação para a alternativa 1 da tabela 5-16

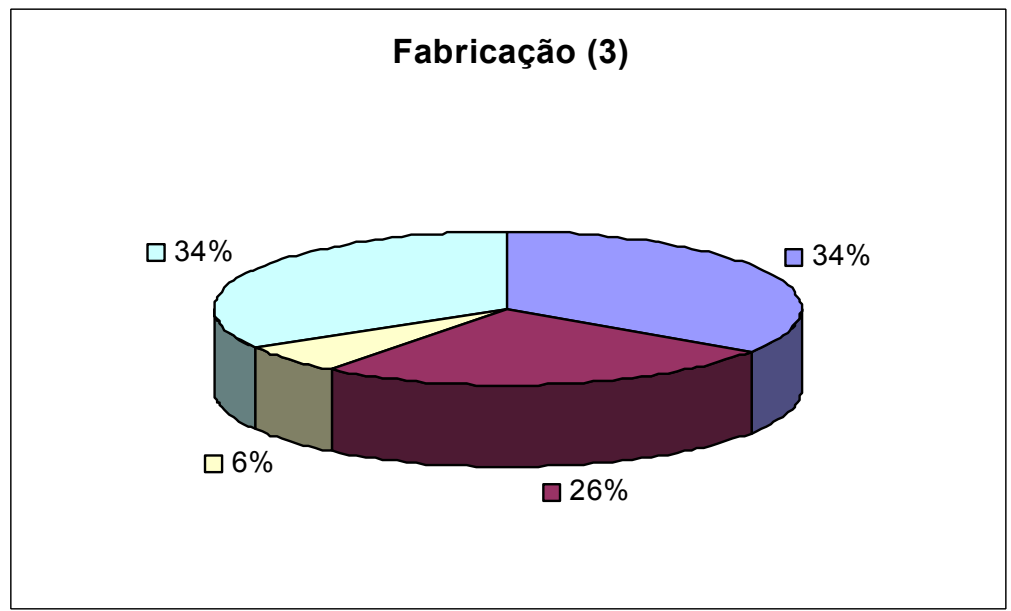

Figura 5-27 - Fabricação para a alternativa 3 da tabela 5-16

Observa-se que as participações do custo do aço passivo e das despesas operacionais permanecem próximas, enquanto as do concreto e do aço de protensão se invertem devido à mudança das relações entre os vãos. $\mathrm{Na}$ alternativa 1 o vão da laje é menor que o vão da viga e na alternativa 3 é o oposto.

Para efeito de comparação apresenta-se a tabela 5-23, fornecida pela HEPTA, com os custos relativos de estruturas em concreto moldado no local para um edifício com vãos da ordem de $7,0 \mathrm{~m}$. 
Tabela 5-23 - Custos relativos de estruturas em concreto moldado no local

\begin{tabular}{|c|c|c|c|}
\hline Fabricação & $\begin{array}{c}\text { Custos }^{*} \\
(\%)\end{array}$ & $\begin{array}{c}\text { Custos }^{* *} \\
(\%)\end{array}$ & $\begin{array}{c}\text { Custos (\%) - } \\
\text { Média }\end{array}$ \\
\hline Concreto & 24,7 & 24,0 & 24,4 \\
\hline $\begin{array}{c}\text { Forma+Corte e } \\
\text { dobra+Protensão }\end{array}$ & 33,8 & 39,7 & 36,8 \\
\hline Armadura passiva & 41,4 & 28,4 & 38,9 \\
\hline Armadura ativa & - & 7,9 & \\
\hline
\end{tabular}

* Lajes maciças e vigas em concreto armado

** Lajes nervuradas com faixas protendidas

Percebe-se que, em média, a influência do concreto, nos custos, é maior nas estruturas de concreto pré-moldado $(31,5 \%)$ em relação às estruturas em concreto moldado no local $(24,4 \%)$. Isso acontece devido às peças prémoldadas possuírem um menor grau de engastamento.

\subsection{CONSIDERAÇÕES ADICIONAIS SOBRE O SATD}

O tempo médio de processamento dos exemplos foi de 7 minutos, que é um valor compatível com os processamentos extensos de análise estrutural. Utilizou-se um computador HP pavilion ze5700, com processador Celeron 2.8 $\mathrm{GHz}$ e $256 \mathrm{MB}$ de memória ram. Observa-se que o equipamento utilizado possui uma configuração simples, de forma que o custo computacional poderia ser bem menor em uma máquina de melhor desempenho. Observa-se, ainda, a constante evolução do hardware e também a possibilidade da utilização de processamento paralelo nos algoritmos genéticos, que diminuem o tempo de processamento.

Os resultados apresentam bastante consistência e coerência, já que a grande maioria dos processamentos indicaram a mesma resistência para o concreto pré-moldado adotada pela $T \& A\left(\mathrm{f}_{\mathrm{ckPM}}=40 \mathrm{MPa}\right)$, bem como as 
resistências mais usuais para o concreto moldado no local. Esses valores também coincidem com a maioria das obras catalogadas no banco de dados.

A diversidade de alternativas apresentadas comprova um dos aspectos ressaltados nos algoritmos genéticos, que é a obtenção de uma população de resultados e, não, de apenas um resultado para cada processamento. Outro aspecto importante é o fato de apresentar resultados com aptidões muito próximas, mas com variáveis de projeto bem distintas. Fato justificável por se tratar de um problema de otimização combinatória em que não se evidencia uma vizinhança para os resultados.

Observou-se a mesma participação no custo total das atividades de fabricação, transporte e montagem nos resultados do SATD e nos valores informados pelo fabricante.

Salienta-se, ainda, que os custos finais encontrados conferem com a faixa de valores praticados e fornecidos também pela T\&A, que é de $R \$ 200,00$ a $R \$ 300,00 / \mathrm{m}^{2}$. Isso reflete a representatividade da função-objetivo, que foi adotada de acordo com as informações do fabricante.

O SATD indica que pode ser uma boa ferramenta de apoio ao desenvolvimento de projetos, realizando as comparações entre estudos preliminares, e deixando para o Engenheiro a tarefa de refinar e determinar particularidades para cada obra, baseado em um pré-projeto já dimensionado e otimizado. Verificou-se uma grande coincidência entre os projetos adotados na prática e os resultados fornecidos pelo SATD.

A adequação das alternativas, em função da análise de sensibilidade do último exemplo, é bastante importante, pois passou a ser automática e imediata com a utilização do SATD. Observa-se que, na rotina dos escritórios, as variações de custo de alguns insumos vão sendo absorvidas aos poucos na concepção dos projetos. Cita-se, como exemplo, o aumento de $47 \%$ do preço do aço em 2004, que, aos poucos, fez com que os projetistas mudassem o enfoque do dimensionamento deixando as seções maiores para diminuir o consumo de aço.

Após a calibração do modelo, em que adotou-se o tamanho da população de 700 e 3000 gerações, na solução de um problema são gerados 2.100.000 indivíduos ao longo das gerações e, para um cromossomo com 34 
bits tem-se $2^{34}$ possibilidades de solução. Logo, o espaço explorado pelo SATD foi de:

$$
\text { espaço_explorado }=\frac{\text { população } \cdot \text { gerações }}{2^{\text {comprimento_cromossomo }}}=\frac{700 \cdot 3000}{2^{34}}=1,22 \cdot 10^{-4}
$$

Em função dessa percepção calculou-se o mesmo índice, percentual de espaço explorado, para alguns trabalhos da literatura pesquisada e apresentase na tabela 5-24. Verifica-se que muitos deles têm a mesma ordem de grandeza do índice utilizado no SATD e que o espaço explorado pelo SATD está ente os maiores.

Tabela 5-24 - Índice de espaço explorado

\begin{tabular}{|c|c|}
\hline Trabalho & Índice \\
\hline $\begin{array}{c}\text { Lemonge } \\
(1999)\end{array}$ & $1,24.10^{-20}$ \\
\hline $\begin{array}{c}\text { Nanakorn } \\
(2001)\end{array}$ & $2,7.10^{-16}$ \\
\hline $\begin{array}{c}\text { Castro (2005) } \\
\text { Leu (2001) }\end{array}$ & $\mathbf{9 , 5 3 . 1 0 ^ { - 4 }}$ \\
\hline $\begin{array}{c}\text { SAHAB } \\
(2005 \mathrm{~b})\end{array}$ & $\mathbf{2 , 7 9 . 1 0 ^ { - 6 }}$ \\
\hline $\begin{array}{c}\text { Rajeev (1992) } \\
\text { CASTILHO } \\
(2003)\end{array}$ & $\mathbf{1 , 9 6 . 1 0 ^ { - 6 }}$ \\
\hline $\begin{array}{c}\text { CASTILHO } \\
(2003)\end{array}$ & $\mathbf{2 , 3 2 . 1 0 ^ { - 2 2 }}$ \\
\hline Camp (2003) & $\mathbf{7 , 1 4 . 1 0 ^ { - 1 7 }}$ \\
\hline
\end{tabular}




\section{VARIANTES DO SATD}

O trabalho de MILLES (2001) ao ser avaliado por projetistas recebeu sugestões de ser mais flexível quanto à participação dos usuários, assim como vários outros trabalhos, sobre inteligência artificial, comentaram a importância da interação humana com o computador. Segundo RAFIQ et al. (2003) um sistema de apoio à tomada de decisão deve efetivamente ser uma ferramenta de suporte e, não, uma tentativa de substituição do engenheiro.

Diante disso, foram implementadas duas variantes do SATD: a primeira tem como dado adicional de entrada a definição do layout da estrutura, e a segunda permite que o usuário estabeleça, em quantos vãos, uma determinada dimensão do pavimento deve ser dividida, e ainda especifique os valores desses vãos.

Avalia-se que as variantes do SATD permitem essa maior participação do usuário, além de permitirem uma exploração dos resultados do SATD.

\subsection{OTIMIZAÇÃO LOCAL (SATDL)}

A partir dos resultados obtidos com o SATD, observou-se que, na maioria dos processamentos de um mesmo exemplo, o melhor indivíduo possuía a mesma configuração estrutural, mas que, algumas outras variáveis de projeto apresentavam pequenas diferenças. Verificou-se, ainda, que os segundos e terceiros indivíduos apresentavam configurações bastante interessantes e que poderiam ser bastante competitivos se fossem refinados.

Desenvolveu-se então uma variante do SATD, denominada SATDL, em que a configuração estrutural passou a ser um dado de entrada também, ou seja, as variáveis de projeto $\mathrm{N}_{X}, \mathrm{~N}_{Y}$ e DL passaram a ser definidas pelo usuário. 
Com isso, diminuíram-se as variáveis de projeto, e o cromossomo passou de um comprimento máximo de 34 bits para 25 bits (tabela 6-1), de forma que a busca se torna mais eficiente porque se dá num espaço reduzido. Salienta-se que no SATDL a otimização deixa de ser completa e passa a ser apenas dos elementos.

Tabela 6-1 - Comprimento máximo do cromossomo (quantidade máxima de bits)

\begin{tabular}{|c|c|c|}
\hline Variável de projeto & Descrição & $\begin{array}{c}\text { Tamanho do } \\
\text { cromossomo (bits) }\end{array}$ \\
\hline $\mathrm{pm}$ & $\mathrm{f}_{\mathrm{ck}}$ pré-moldado & 2 \\
\hline $\mathrm{cml}$ & $\mathrm{f}_{\mathrm{ck}}$ moldado no local & 2 \\
\hline $\mathrm{VL}$ & Tipo de laje & 5 \\
\hline $\mathrm{VV}$ & Tipo de viga & 4 \\
\hline $\mathrm{na}$ & Quantidade cordoalhas primeira camada & 3 \\
\hline $\mathrm{nb}$ & Quantidade cordoalhas segunda camada & 2 \\
\hline $\mathrm{npt}$ & Quantidade de barras passivas & 2 \\
\hline $\mathrm{bp}$ & Bitola barras passivas & $\mathbf{2 5}$ \\
\hline Comprimento Total & & \\
\hline
\end{tabular}

Com a busca localizada, em um espaço reduzido, conseguiu-se refinar um pouco os melhores indivíduos dos processamentos e tornaram-se competitivos os segundos e terceiros melhores indivíduos. Além desses aspectos, o SATDL é bastante útil para os casos em que, por algum motivo arquitetônico, a modulação da estrutura já está definida. Esse conceito foi baseado em PULLMANN et al. (2003), onde o usuário especifica as regiões viáveis onde podem ser locados os pilares e as vigas.

Assim, pode-se aplicar o SATDL, após os processamentos no SATD para extrair a melhor alternativa de cada configuração ou para os casos em que a posição dos pilares seja obrigatoriamente pré-estabelecida pela arquitetura. 


\subsubsection{Validação do SATDL}

Para validar o SATDL, utilizou-se como bench-mark o projeto preliminar do Wal Mart - Bonocó, de autoria da Hepta Engenharia Estrutural. Trata-se de uma grande loja cujo pavimento é parcialmente modulado. Adotou-se, como dado de entrada, o trecho modulado que é composto de 6 vãos de viga $\ell=7,75$ $\mathrm{m}$ e 6 vãos de laje $\ell=8,0 \mathrm{~m}$. A arquitetura exigia um restrição de altura máxima do pavimento de $55 \mathrm{~cm}$, e a carga adotada foi de $8 \mathrm{kN} / \mathrm{m}^{2}$. O comparativo dos resultados é apresentado na tabela 6-2. Salienta-se que os comparativos de armadura não são apresentados porque o projeto original era preliminar e não estava detalhado.

Tabela 6-2 - Comparações de validação do SATDL

\begin{tabular}{|c|c|c|c|c|c|}
\hline & Projeto & SATDL (1) & SATDL (2) & SATDL (3) & SATD \\
\hline $\mathrm{f}_{\mathrm{ckml}}(\mathrm{MPa})$ & $\mathbf{2 5}$ & 30 & 30 & 20 & 25 \\
\hline $\mathrm{f}_{\mathrm{ckPM}}(\mathrm{MPa})$ & $\mathbf{4 0}$ & 40 & 40 & 40 & 40 \\
\hline $\mathrm{h}_{\mathrm{l}}(\mathrm{cm})$ & $\mathbf{2 0}$ & 20 & 20 & 20 & 20 \\
\hline $\mathrm{h}_{\mathrm{V}}(\mathrm{cm})$ & $\mathbf{3 0}$ & 30 & 30 & 30 & 30 \\
\hline $\mathrm{b}_{\mathrm{w}}(\mathrm{cm})$ & $\mathbf{6 0}$ & 60 & 60 & 70 & 70 \\
\hline $\begin{array}{c}\text { Custo } \\
\text { Estrutura } \\
\left(\mathrm{R} \$ / \mathrm{m}^{2}\right)\end{array}$ & - & 218,4 & 218,4 & 222,3 & 221,1 \\
\hline
\end{tabular}

Observa-se que os resultados do SATDL se mostraram bastante consistentes e, similares ao pré-projeto. Aproveitou-se também para realizar mais um teste com o SATD, considerando como distância mínima entre os pilares, nas duas direções, 7,0 m. O SATD indicou a mesma configuração estrutural do pré-projeto original e as seções também foram muito similares. 


\subsubsection{Exemplos de utilização do SATDL}

Como exemplos de utilização, processaram-se inicialmente vários melhores indivíduos extraídos de processamentos no SATD (capítulo 5) para se observar a existência de melhoria na solução (Tabela 6-3).

Tabela 6-3 - Comparações da aptidão nos melhores indivíduos

\begin{tabular}{|c|c|c|c|}
\hline & SATD & $\begin{array}{c}\text { SATDL } \\
(5\end{array}$ & $\Delta(\%)$ \\
processamentos) & 2,979 & $-0,23$ \\
\hline $\begin{array}{c}\text { Aptidão do melhor } \\
\text { indivíduo }\left(\mathrm{R} \$ / 10^{5}\right)- \\
\text { ATLSS }\end{array}$ & 2,986 & 218,4 & $-1,2$ \\
\hline $\begin{array}{c}\text { Custo da estrutura } \\
\left(\mathrm{R} \$ / \mathrm{m}^{2}\right)\end{array}$ & 221,1 & 198,0 & $-4,0$ \\
Wal-Mart (Bonoco) & & 205,9 & \\
\hline $\begin{array}{c}\text { Custo da estrutura } \\
\left(\mathrm{R} \$ / \mathrm{m}^{2}\right) \\
\text { Nordestão }\end{array}$ & & & \\
\hline
\end{tabular}

Observou-se que a melhoria dos resultados, com o SATDL, para os melhores indivíduos extraídos do processamento do SATD, não foi tão significativa.

Posteriormente, processaram-se alguns indivíduos que apareciam com configuração estrutural diferente da indicada pelos melhores indivíduos apresentados pelo SATD, também para avaliar a melhoria na solução (Tabela 6-4).

Tabela 6-4 - Variação da aptidão de indivíduos com configurações diferentes da do melhor indivíduo

\begin{tabular}{|c|c|c|c|}
\hline & SATD & $\begin{array}{c}\text { SATDL } \\
(5\end{array}$ & $\Delta(\%)$ \\
& & processamentos $)$ & \\
\hline Aptidão $\left(\mathrm{R} \$ / 10^{5}\right)-$ Hotel & 3,128 & 3,055 & $-2,3$ \\
\hline $\begin{array}{c}\text { Aptidão }\left(\mathrm{R} \$ / 10^{5}\right)-\text { Bom } \\
\text { Preço }\end{array}$ & 3,018 & 2,775 & $-8,0$ \\
\hline
\end{tabular}


Os resultados apresentados indicaram que a rotina local é eficiente para refinar as soluções que apareciam, não como melhor indivíduo do processamento no SATD, já que a melhoria para o melhor indivíduo foi muito discreta, mas, sim, para os indivíduos com colocação próxima aos melhores. A rotina mostrou-se eficiente, principalmente nos casos em que há uma alta variabilidade das respostas, ou seja, quando o espaço factível é relativamente grande.

Logo, a maior utilização do SATDL seria para tornar mais competitivos alguns indivíduos que não fossem os melhores indivíduos dos processamentos no SATD, ou mesmo para os casos em que o usuário desejasse fazer alguns testes com alternativas que não tenham aparecido, também no SATD. Seria ainda útil, quando a modulação já estivesse definida por razões arquitetônicas.

\subsection{VARIANTE RESTRITA DO SATD (SATDR)}

Conforme RAFIQ et al. (2003), é fundamental que o sistema seja flexível e, que interaja com o usuário. Ao usuário deve ser permitido que faça modificações ou que imponha algumas restrições na concepção estrutural. Baseada nessa idéia, foi criada uma variação do SATD, chamada de SATDR, que permite ao usuário a indicação de alinhamentos pré-determinados em que serão inseridos os pilares e as vigas.

Nesses alinhamentos, a quantidade de pilares será otimizada juntamente com os vãos das vigas, os quais continuam sendo modulados, mas os das lajes, os quais estão na outra direção, já foram informados e, podem ser distintos entre si (figura 6-1).

Tanto as vigas, como as lajes, serão detalhadas considerando a pior situação. Logo, será detalhada a viga que receber a maior contribuição de cargas das lajes, e será detalhada a que tiver maior vão. Geralmente, na indústria, por questões econômicas, a pista de laje é fabricada por completo e, com isso, nas obras que têm lajes de vãos distintos, utiliza-se a mesma solução adotada para o maior vão e para os vãos menores.

Dessa forma, o número de divisões do pavimento na direção " $X$ " (Nx) e a direção da laje (DL) deixam de ser variáveis de projeto, e passam a ser 
informações fornecidas pelo usuário. Com isso, o cromossomo fica definido conforme apresentado na tabela 6-5.

Tabela 6-5 - Comprimento máximo do cromossomo (quantidade máxima de bits)

\begin{tabular}{|c|c|}
\hline Variável de projeto & $\begin{array}{c}\text { Tamanho do cromossomo } \\
\text { (bits) }\end{array}$ \\
\hline $\mathrm{N}_{\mathrm{Y}}$ & 5 \\
\hline $\mathrm{pm}$ & 2 \\
\hline $\mathrm{cml}$ & 2 \\
\hline $\mathrm{VL}$ & 5 \\
\hline $\mathrm{VV}$ & 5 \\
\hline $\mathrm{na}$ & 4 \\
\hline $\mathrm{nb}$ & 3 \\
\hline $\mathrm{npt}$ & 2 \\
\hline $\mathrm{bp}$ & 2 \\
\hline Comprimento Total & $\mathbf{3 0}$ \\
\hline
\end{tabular}
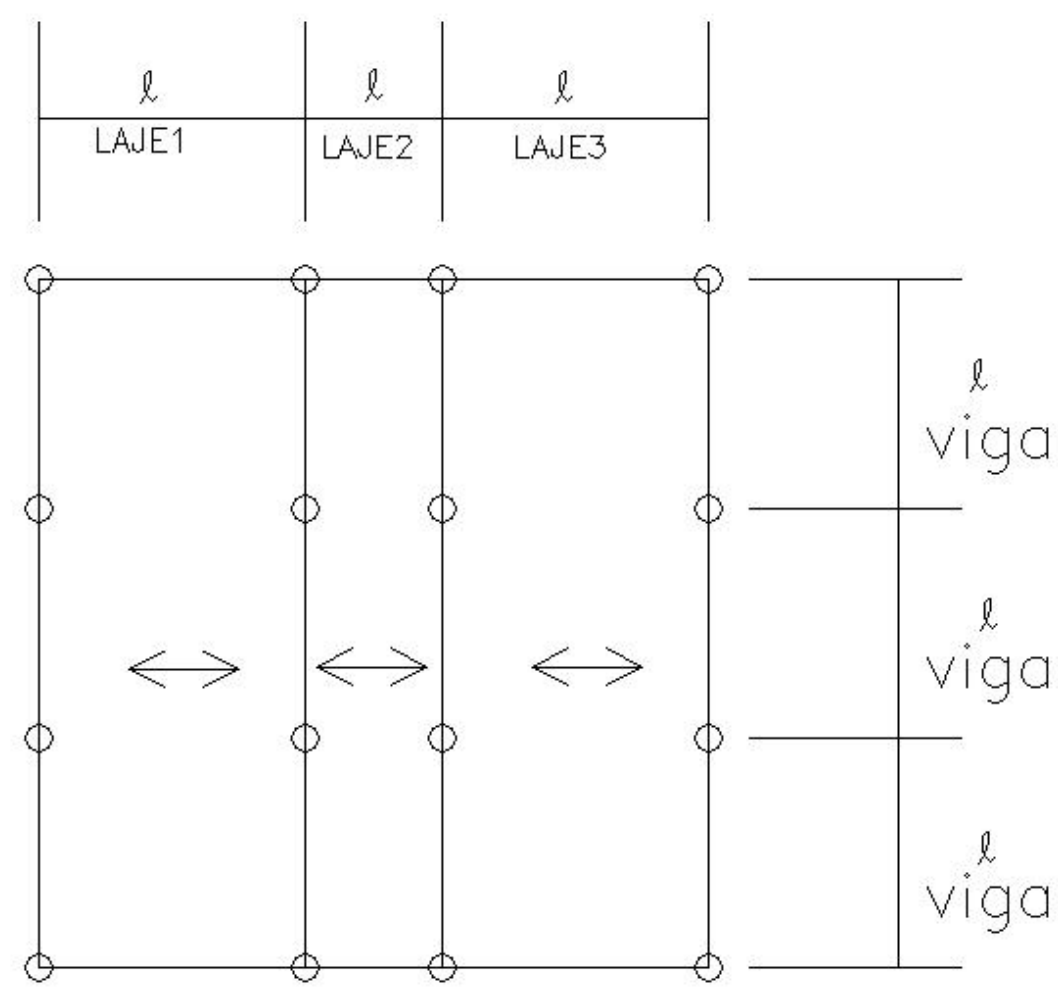

Figura 6-1 - Alinhamentos pré-determinados do SATDR 
Essa variante é importante para os casos em que o projeto estrutural completamente modulado não é possível. Como exemplo, pode-se citar o projeto arquitetônico de um colégio ou de uma faculdade que possui grandes vãos para as salas e um pequeno vão central para o corredor. Nesse caso, fica praticamente imposto que o alinhamento dos pilares e das vigas fique na divisão entre as salas e o corredor.

Conforme SACKS et al. (2000), quando uma das dimensões do pavimento é três vezes menor que a outra dimensão, muito provavelmente será necessária a utilização de um corredor. Esta afirmação coincide com a indicação da necessidade do SATDR.

A idéia do SATDR é que o usuário possa indicar qual seria este alinhamento obrigatório para o posicionamento das vigas e dos pilares, em uma direção, e o sistema otimizaria o restante do projeto. Entende-se, como restante do projeto, o comprimento dos vãos das vigas, bem como a seção das vigas e das lajes, suas armaduras e as resistências dos concretos.

\subsubsection{Validação do SATDR}

Para validar o SATDR, utilizou-se como bench-mark o projeto da Escola Jurista Tobias Barreto (figura 6-2), de autoria da HEPTA Engenharia Estrutural, que foi fabricado e montado pela T\&A em Recife/PE. Trata-se de um edifício de 5 pavimentos destinado a cursos jurídicos, com 4 pavimentos-tipo e um pavimento de coberta. Esse projeto tem como características lajes com vãos diferentes e vãos modulados para as vigas, que são características ideais para a utilização do SATD restrito, já que, a partir da informação dos vãos da laje, o SATDR busca a modulação ideal para as vigas. 


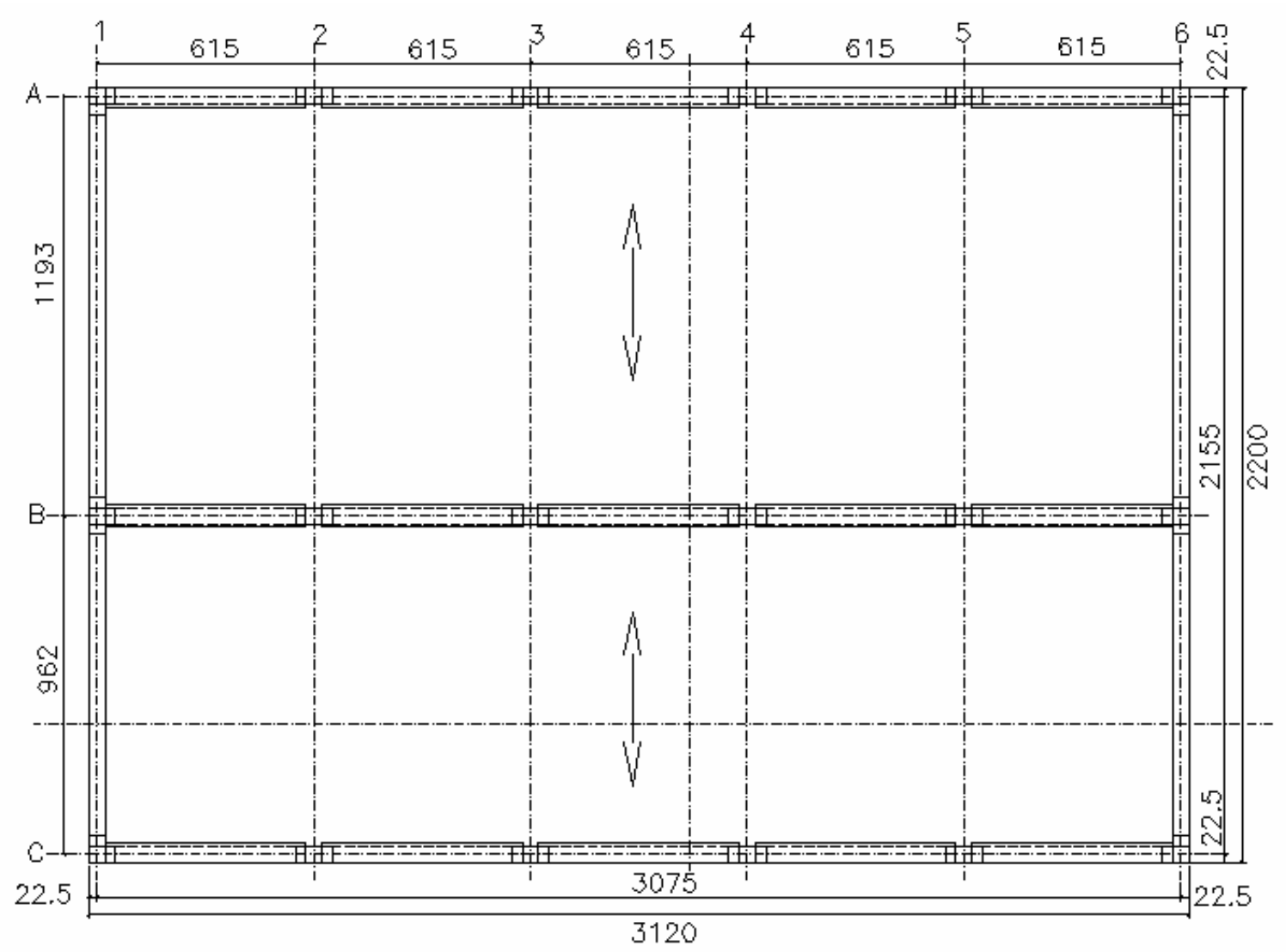

Figura 6-2 - Forma do pavimento tipo (medidas em $\mathrm{cm}$ )

Inicialmente, processou-se o exemplo admitindo uma distância mínima entre pilares na direção $X$ de $6,0 \mathrm{~m}$, e uma altura máxima de pavimento de 50 $\mathrm{cm}$, e observou-se que a solução encontrada foi praticamente a mesma adotada no projeto. O SATDR indicou a mesma modulação das vigas $\ell_{\text {viga }}=6,15$ $\mathrm{m}$, a mesma resistência do concreto moldado no local ( $\left.\mathrm{f}_{\mathrm{ckml}}=25 \mathrm{MPa}\right)$ e do prémoldado $\left(f_{\mathrm{ckPM}}=40 \mathrm{MPa}\right)$, e indicou um custo estimado em $R \$ 237,0 / \mathrm{m}^{2}$. Sobre as lajes, o SATDR indicou uma laje de $h_{\ell}=21 \mathrm{~cm}$ com $8 \Phi 12.7 \mathrm{~mm}$, enquanto o projeto original indicou uma laje de $h_{\ell}=20 \mathrm{~cm}$ com $9 \Phi 12.7 \mathrm{~mm}$. Observam-se com isso soluções bastante similares. Sobre as vigas, também se vê que a alternativa indicada pelo SATDR (figura 6-3) é similar, principalmente em geometria, à viga detalhada no projeto original (figura 6-4). 


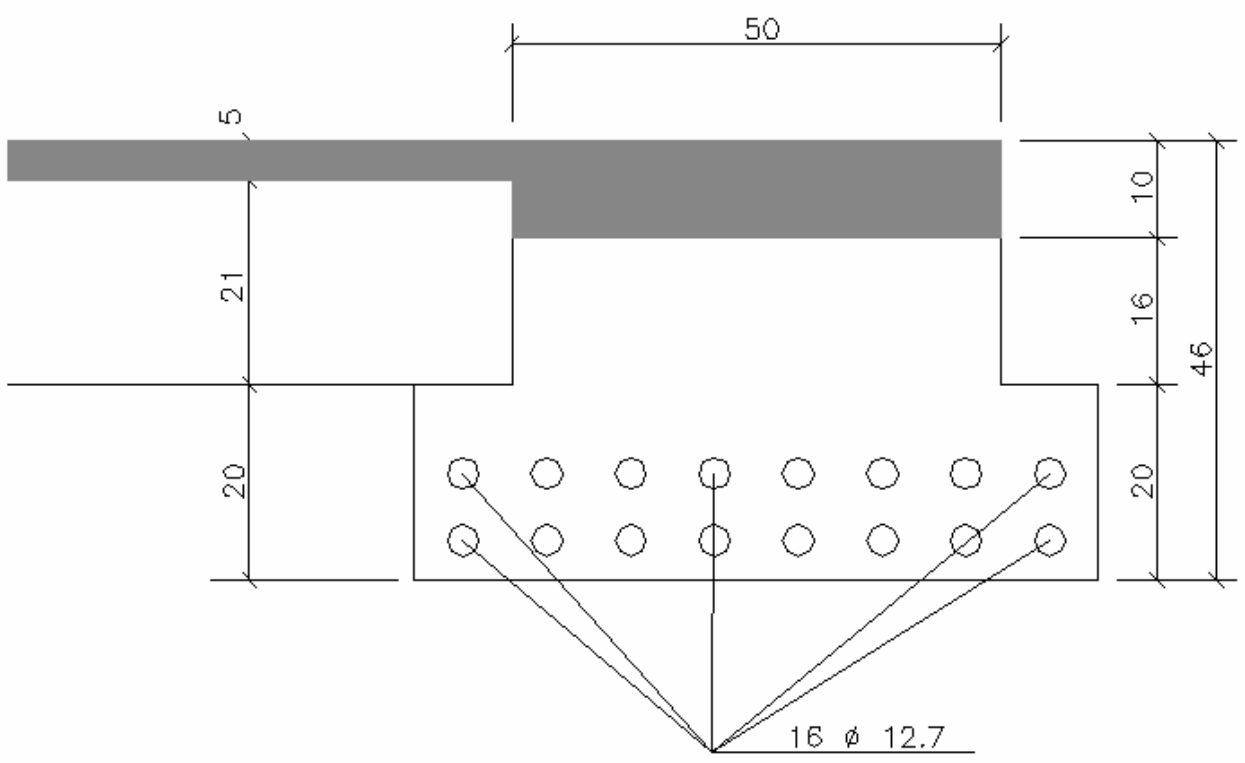

Figura 6-3 - Seção de viga apresentada pelo SATDR (medidas em cm)

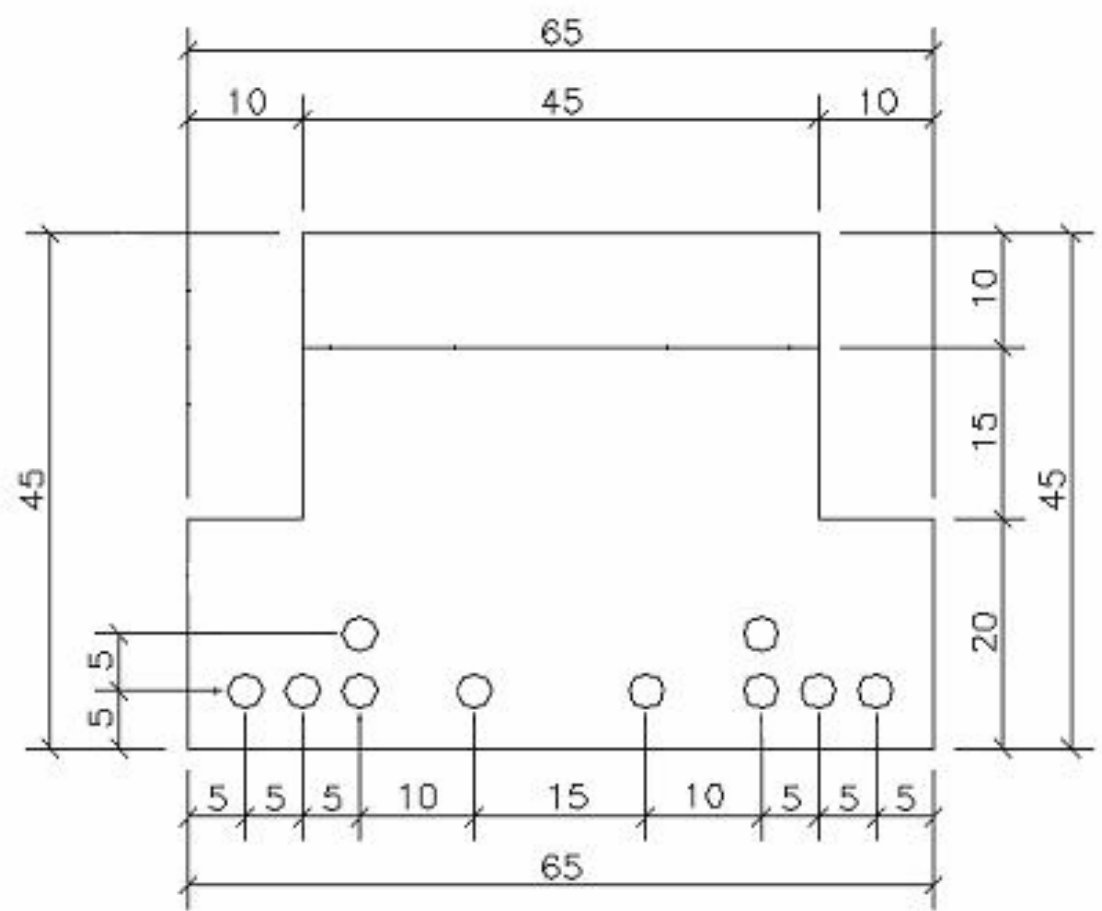

Figura 6-4 - Seção de viga apresentada no projeto (medidas em cm) 
Salienta-se, ainda, que algumas diferenças, na viga, podem ser justificadas devido aos valores adotados para o momento fletor, após a solidarização, considerados pelo SATD e os valores adotados em projeto, conforme apresentado no apêndice $C$.

Conclui-se então que o SATDR apresentou resultados bastante coerentes e significativos.

Refez-se o exemplo, considerando que o pavimento poderia ter uma altura total de até $55 \mathrm{~cm}$, e obteve-se, como melhor resposta a seção detalhada na figura 6-5 que apresenta um custo de $R \$ 234,3 / \mathrm{m}^{2}$. Nota-se que, embora tenha sido permitida uma viga mais alta, a economia não foi significativa.

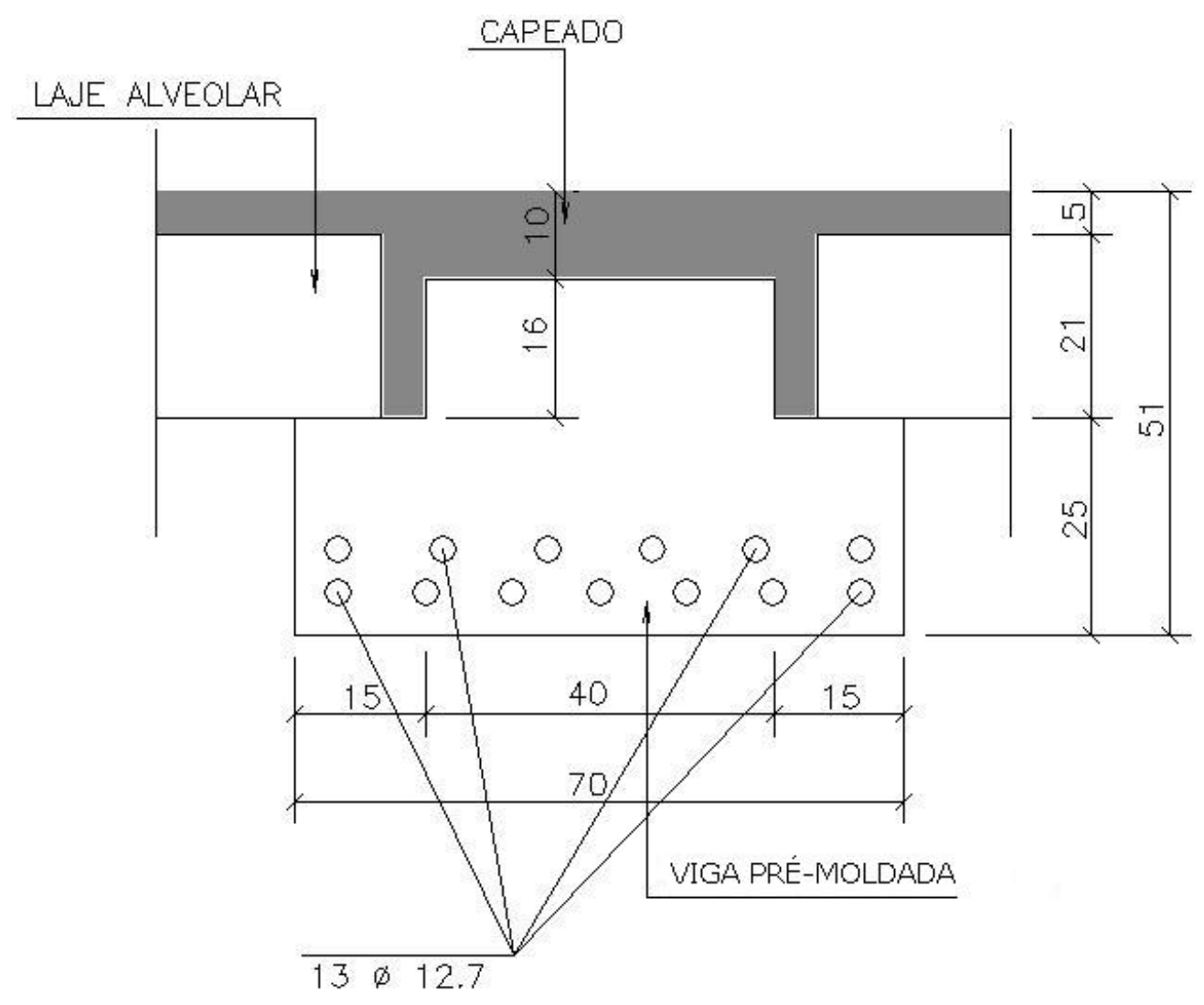

Figura 6-5 - Seção de viga apresentada pelo SATDR para uma altura de pavimento máxima de $55 \mathrm{~cm}$ 


\subsubsection{Exemplos de utilização do SATDR}

\section{a) Variação da Escola Jurista Tobias Barreto}

A partir do exemplo anterior, foi feita uma tentativa para melhorar o projeto original. Refez-se, então, o processamento considerando a seguinte hipótese: como o pavimento térreo também seria de salas de aula, de forma que não havia impedimento para a distância entre pilares ao longo da direção $X$, adotou-se uma distância mínima de apenas $2,0 \mathrm{~m}$. Nesse processamento o vão da viga foi conduzido a $\ell_{\text {viga }}=4,39 \mathrm{~m}$, e o custo da estrutura foi de $R \$ 230,00$ $/ \mathrm{m}^{2}$.

Conclui-se que a redução no custo da estrutura, aproximadamente $3 \%$, foi muito baixa e, que, talvez não fosse interessante reduzir os vãos da viga devido ao acréscimo de pilares marcando a arquitetura. Verifica-se, ainda, que embora tivesse liberdade para reduzir o vão da viga até 2,0 m o SATDR não o fez em função do cálculo do custo de maneira mais completa, o qual levou em consideração todos os aspectos e não apenas os consumos de material. É comum na prática adotar os vãos mínimos permitidos pela arquitetura, já que muitas vezes os projetistas não têm a percepção sistêmica da composição dos custos e visam somente à redução do consumo de materiais.

\section{b) Edifício da FAELCE}

O edifício da FAELCE é um centro administrativo da Companhia Energética do Ceará. Consta de 10 pavimentos, sendo 4 de garagens e 6 de escritórios.

Utilizou-se o SATDR, na HEPTA Engenharia, para ajudar na concepção estrutural do pavimento de escritórios, já que por uma imposição da arquitetura só seriam possíveis pilares nas extremidades e na linha central, de forma que o prédio ficava dividido, na menor direção, em dois vãos de 13,0 m que seriam vencidos pelas lajes (figura 6-6). Os pilares de extremidade já estavam definidos pelas vagas de garagem, mas os pilares centrais tinham liberdade de modulação. 


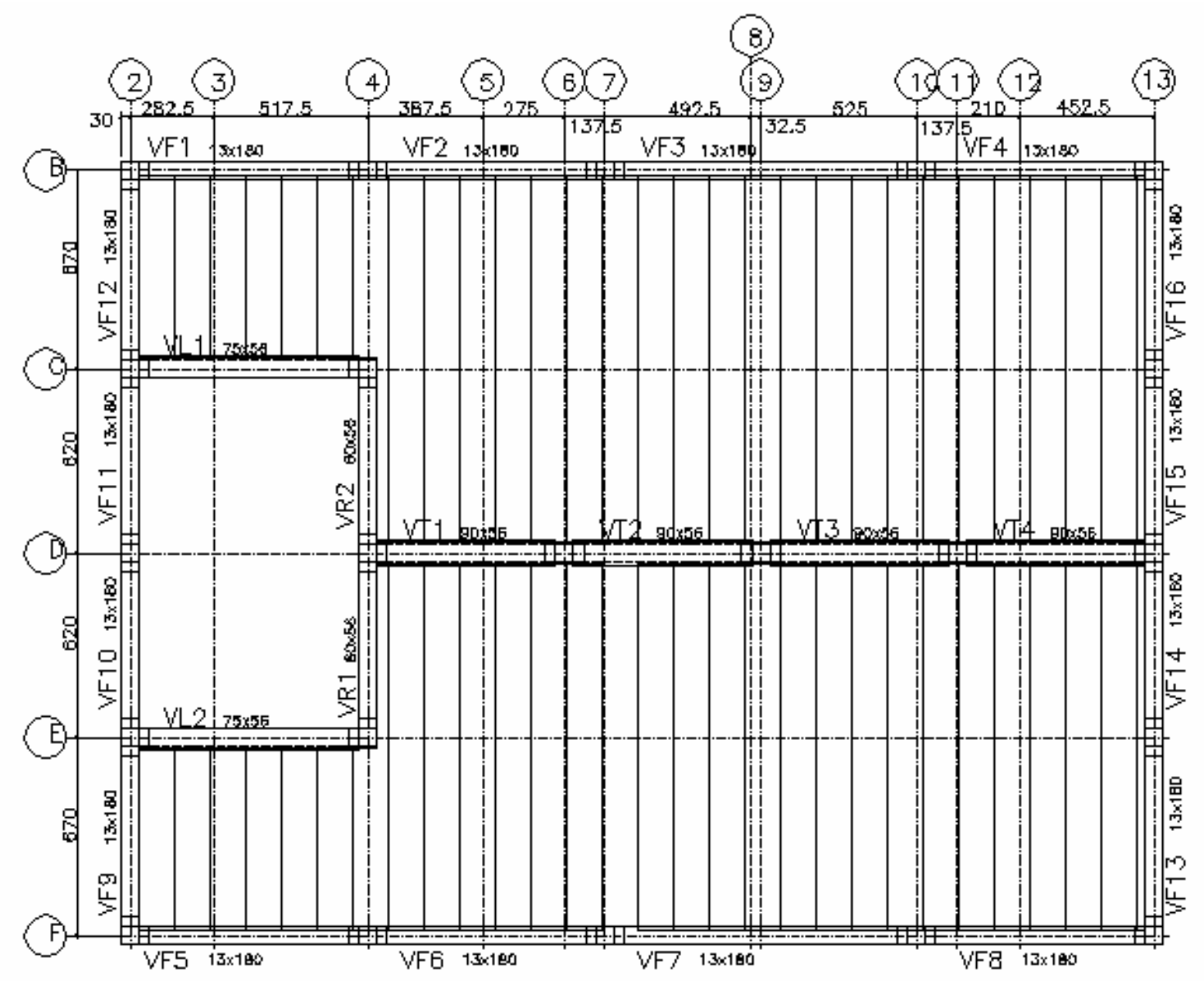

Figura 6-6 - Planta de forma do pavimento de escritórios do Edifício da FAELCE

A idéia inicial era de que o vão da viga central fosse da mesma ordem do vão da laje, mas o SATDR não encontrou uma viga que atendesse todas as restrições. Passou-se, então, a considerar que o vão da viga poderia ser até de $6,0 \mathrm{~m}$ (limite mínimo) e então surgiram duas boas alternativas que são apresentadas nas figuras 6-7 e 6-8. 


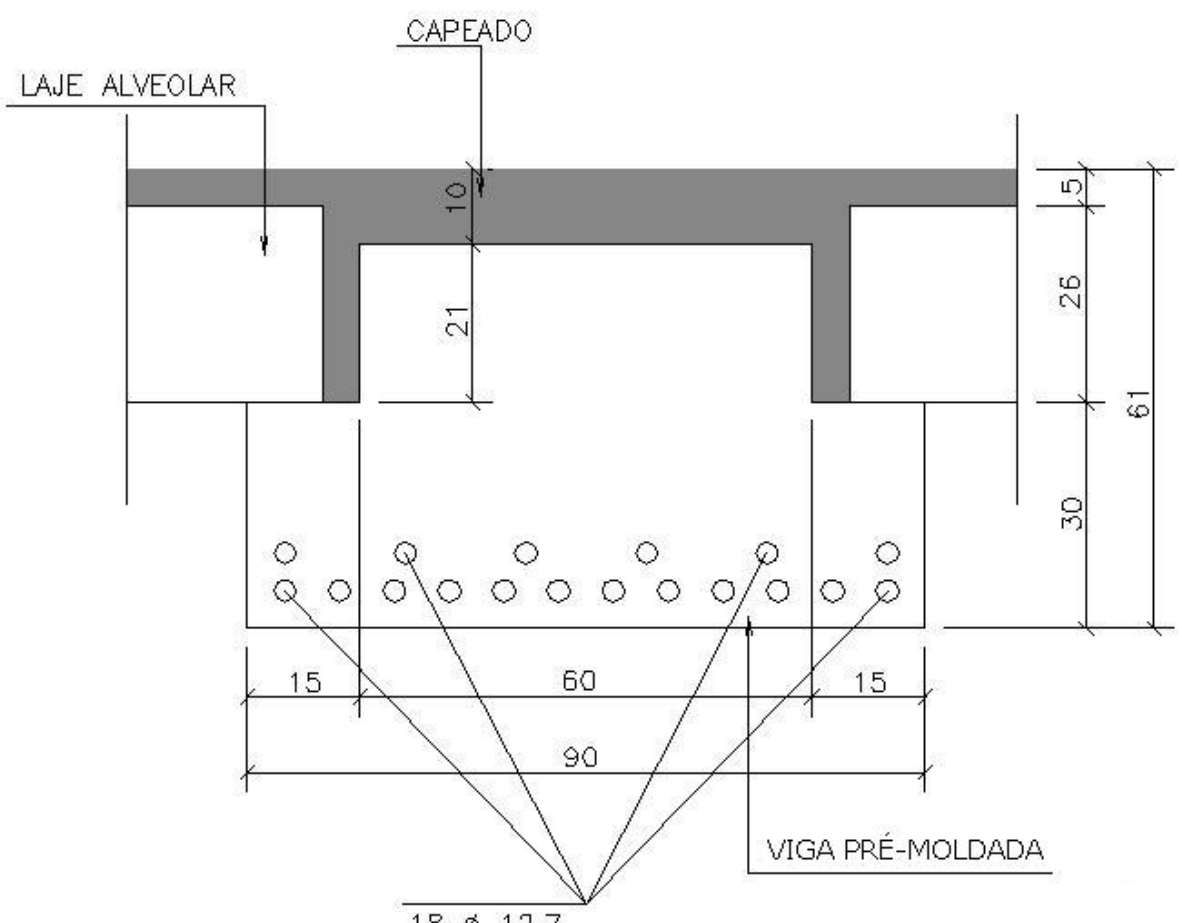

Figura 6-7 - Seção de viga apresentada pelo SATDR para uma altura de pavimento máxima de $65 \mathrm{~cm}$

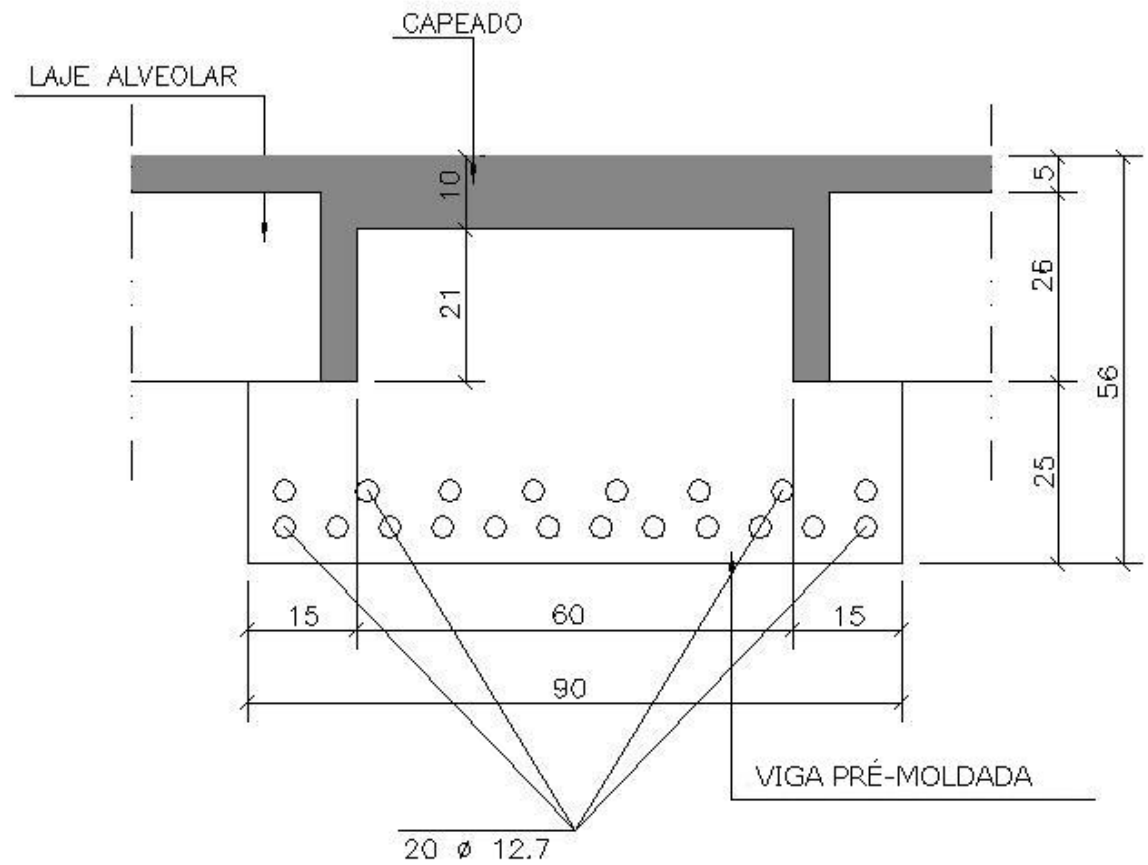

Figura 6-8 - Seção de viga apresentada pelo SATDR para uma altura máxima de pavimento de $60 \mathrm{~cm}$ 
A primeira alternativa (figura 6-7) resultou em uma resistência de concreto de $\mathrm{f}_{\mathrm{ckPM}}=40 \mathrm{MPa}$ e $\mathrm{f}_{\mathrm{ckml}}=30 \mathrm{MPa}$, e o custo da estrutura foi de $\mathrm{R} \$$ $302,00 / \mathrm{m}^{2}$. A segunda alternativa (figura 6-8) adotou uma resistência de concreto de $\mathrm{f}_{\mathrm{ckPM}}=50 \mathrm{MPa}$ e $\mathrm{f}_{\mathrm{ckml}}=30 \mathrm{MPa}$ e o custo da estrutura foi de $\mathrm{R} \$$ $306,20 / \mathrm{m}^{2}$.

As duas alternativas indicaram a mesma opção para a laje, tanto a geometria como a protensão. Também indicaram o vão mínimo possível para a viga, já que a dimensão era de 26,5 m ( $\ell_{\text {viga }}=6,625 \mathrm{~m}$ ). Como era de se esperar, a configuração com grandes vãos ( $\ell_{\text {laje }}=13,0 \mathrm{~m}$ ) tem um custo maior, próximo a $\mathrm{R} \$ 300,00 / \mathrm{m}^{2}$.

Como a variação no custo foi desprezível, optou-se por adotar a segunda alternativa de viga que proporciona uma altura total do pavimento menor. Fez-se, então, um novo dimensionamento para a viga, de maneira mais refinada, considerando toda a mesa colaborante e com um maior grau de engastamento nas ligações. Com isso diminuiu-se a resistência do concreto para $\mathrm{f}_{\mathrm{ckPM}}=45 \mathrm{MPa}$ e $\mathrm{f}_{\mathrm{ckml}}=25 \mathrm{MPa}$, mantendo a mesma geometria e a mesma protensão apresentada na figura 6-8.

Observa-se que o SATDR foi utilizado como uma ferramenta de apoio, eliminando uma série de comparações e testes que seriam feitos pelo engenheiro. O dimensionamento indicado para a laje foi aproveitado e a viga sofreu apenas ajustes mediante consideração de algumas particularidades.

\subsection{CONSIDERAÇÕES ADICIONAIS SOBRE AS VARIANTES DO SATD}

Conclui-se que as variantes do SATD apresentaram resultados coerentes que demonstraram serem úteis para aplicações específicas, nas quais o usuário precisa de uma maior participação no processo da concepção estrutural. Observa-se ainda que as variantes são importantes para exploração de resultados originalmente obtidos com o SATD.

Novas variantes poderiam ser desenvolvidas, como o caso em que o tipo de laje seria fornecido e a otimização se daria em função desse elemento. Esse caso seria válido quando a fábrica tivesse determinada laje em estoque e desejasse utilizá-la. 
Novamente os exemplos indicaram a possibilidade da utilização de vigas um pouco mais baixas e mais largas, com custo muito similar às mais altas $\mathrm{e}$ esbeltas.

O exemplo do Edifício da FAELCE demonstra a viabilidade da utilização dessa ferramenta no desenvolvimento de projetos no dia-a-dia dos escritórios. 


\section{CONSIDERAÇÕES FINAIS E CONCLUSÕES}

Os vários exemplos apresentados mostraram a robustez e a aplicabilidade do SATD. Em quase todos eles, a mesma escolha feita pelo engenheiro foi adotada automaticamente pelo SATD. Desta forma os resultados do SATD estão atingindo seu objetivo de fornecer subsídios para facilitar o processo de decisão do usuário, pois que realiza vários estudos comparativos, automaticamente, para o engenheiro. Cumpre, assim, um dos objetivos básicos do planejamento que é possibilitar a comparação de alternativas para facilitar a tomada de decisão. Dessa forma, o SATD elimina uma etapa que demanda bastante tempo, no dia-a-dia dos escritórios, que é a etapa inicial da concepção estrutural. Pode-se dizer que o processo tradicional de desenvolvimento de projeto é automatizado e a proposta do SATD é transformá-lo em um processo otimizado.

A partir dos resultados do SATD e de suas variantes, o usuário pode iniciar o trabalho de refinar a solução escolhida, por meio de alguns artifícios por vezes utilizados, pelos projetistas, tais como: consideração de um maior grau de engastamento das vigas, consideração da mesa colaborante da capa, utilização de continuidade parcial entre lajes, grauteamento de trechos dos alvéolos para aumentar a capacidade resistente da viga etc.

Além de uma ferramenta de apoio à tomada de decisão para os engenheiros de estruturas o SATD, pode auxiliar arquitetos e fabricantes.

Os arquitetos poderiam utilizá-lo para contemplar em seus projetos as dimensões viáveis das peças, e, também, a melhor modulação dos vãos, de forma que seus projetos fiquem mais compatíveis com a estrutura pré-moldada. De posse do SATD, o arquiteto teria noção do impacto financeiro que a exigência de um determinado vão livre proporcionaria ao empreendimento. Cita-se, como exemplo, o caso do Edifício Comercial Carvalho, apresentado no 
capítulo 5, que teve um aumento de custo de $26 \%$ quando se alterou a restrição de distância mínima de $8,0 \mathrm{~m}$ para $10,0 \mathrm{~m}$.

Os fabricantes poderiam utilizá-lo para confecção dos orçamentos e dos estudos preliminares, porque muitas vezes, na etapa de contratação, só existem os projetos arquitetônicos. Um pré-dimensionamento inicial pode demandar bastante tempo e caso não seja bem feito pode comprometer a proposta, seja inviabilizando economicamente a solução pré-moldada ou levando a um orçamento aquém da realidade. É importante, ainda, para quando o fabricante esteja competindo com um sistema estrutural moldado no local, que geralmente não está otimizado nas etapas iniciais.

Algumas recomendações de projeto podem ser obtidas a partir dos resultados do SATD e variantes:

a) Observa-se que, em quase todos os exemplos apresentados e em vários outros, que foram executados, está sendo indicada como melhor alternativa aquela na qual as vigas são dispostas na menor direção do pavimento. Esta solução, embora não seja a mais usual citada por ELLIOTT (1996), está de acordo com grande parte das soluções encontradas no banco de obras do levantamento Brasil (ALBUQUERQUE \& EL DEBS, (2005)) e, também conta, com a opinião do engenheiro Haroldo Gadelha ${ }^{14}$, diretor técnico da fábrica T\&A. Sobre essa configuração ainda se observa que possui um número menor de vigas, em relação à opção que as posiciona na maior direção do pavimento e que tem um melhor comportamento aos esforços horizontais, na direção principal;

b) O fato de o SATD sempre indicar, como uma das melhores soluções uma alternativa com vigas de seção transversal de forma achatada reforça a vantagem de um sistema como o MOS (Midwest Office System), apresentado no Anexo 1. Esse indicativo é bastante importante, pois há uma preferência por se explorarem as vigas mais altas, enquanto observou-se que sempre há uma alternativa com viga de forma achatada, com praticamente o mesmo custo. A vantagem

\footnotetext{
${ }^{14}$ Conversa particular em outubro de 2006.
} 
disso é que os pavimentos de menor altura propiciam uma série de economias indiretas tais como os apresentados no Anexo 1;

c) A utilização dos vãos mínimos permitidos leva, às vezes, a um menor consumo de materiais, mas nem sempre é a melhor solução, pois aumenta o número de peças e, conseqüentemente, onera o transporte e a montagem, conforme apresentado na tabela 5-11;

d) Outra recomendação, que se pode inferir dos resultados, é a confirmação da eficiência da utilização do C40 para os elementos prémoldados e do C25 para o concreto moldado no local. Como os prémoldados poderiam adotar ainda as classes C45 e C50 conclui-se que, hoje em dia, aumentar a resistência do concreto não proporcionaria economia;

e) De modo geral, os vãos das lajes são maiores que os das vigas, fato justificável por terem as lajes um custo mais baixo de fabricação e montagem. Esse tipo de solução, embora não seja utilizada em estruturas em concreto armado, é bastante comum em estruturas em concreto protendido, onde as lajes vencem os vãos maiores se apoiando em vigas com vãos menores.

O SATD poderia ser utilizado também para pavimentos compostos por retângulos, pavimentos em "L" por exemplo, em que o SATD seria aplicado em partes, retângulo por retângulo. Caso fossem necessários alguns ajustes poder-se-ia utilizar alguma das variantes.

Em função das análises de sensibilidade apresentadas no capítulo 5 recomenda-se que as indústrias revejam suas metodologias para calcular os custos, principalmente os fatores que consideram as médias históricas por onerarem às vezes apenas um dos insumos, como o caso do concreto nas despesas operacionais das vigas e dos pilares. Cita-se, ainda, o fato de se produzir um aumento em cadeia, já que, se o concreto sobe de preço, não necessariamente os custos fixos crescem na mesma proporção, fato este que ocorre com a função considerada.

Ressalta-se que o modelo adotado atingiu seus objetivos de representar o problema da maneira mais realista possível. A função-objetivo contemplou não só o consumo de materiais, mas também os aspectos relativos à 
fabricação, transporte e montagem. As restrições consideraram além das verificações estruturais algumas restrições arquitetônicas. As variáveis de projeto foram trabalhadas de maneira integrada considerando todas as relações existentes entre elas. Atesta-se a eficiência da representação do problema pelo modelo em função dos resultados que foram muito coerentes com a prática dos projetos.

Também a partir dos resultados, conclui-se que a utilização dos algoritmos genéticos para o desenvolvimento do SATD, foi muito apropriada. Os fundamentos dos algoritmos genéticos permitiram uma perfeita adaptação ao problema, e confirmaram suas potencialidades de produzir excelentes resultados com consistência e diversidade. Essa diversidade permite aos projetistas que façam escolhas entre soluções distintas, mas com uma variação de custo muito baixa.

Ressalta-se ainda que, embora a redução percentual na aptidão do melhor indivíduo tenha sido pequena, a implementação das rotinas dos transgênicos e dos gêmeos proporcionou uma convergência mais rápida e uma maior diversidade dos indivíduos.

Sugere-se como continuação do presente trabalho:

a) Uma rotina de otimização em que o usuário informe as posições possíveis para os pilares, defina o contorno do pavimento, dos vazios e das regiões de escada e dos elevadores e o programa faça a concepção das vigas, lajes e do posicionamento dos pilares;

b) Implementar a verificação da estabilidade global;

c) Implementar na função-objetivo além do custo de fabricação, transporte e montagem o planejamento da produção;

d) Implementar uma programação orientada ao objeto e fazer a hibridação do algoritmo genético com outra técnica;

e) Utilizar o processamento paralelo para redução no tempo computacional;

f) Exportar os dados de saída para um sistema que produzisse os desenhos das peças, completando assim o ciclo da tecnologia da informação. Além dos desenhos das peças, poder-se-ia se produzir o 
desenho da estrutura montada em 3D para se identificarem incompatibilidades;

g) Melhorar a interface com o usuário, utilizando programação orientada a objeto;

h) Desenvolver uma expressão para a definição do tamanho da população e do número de gerações em função do índice de espaço explorado apresentado no capítulo 5 . 


\section{REFERÊNCIAS BIBLIOGRÁFICAS}

AMERICAN CONCRETE INSTITUTE. (1995). Building code requirements for structural concrete (ACl-318M). Farmington Hills.

ALBUQUERQUE, A. T. (1998). Análise de alternativas estruturais para edifícios em concreto armado. Dissertação (Mestrado) - Escola de Engenharia de São Carlos, Universidade de São Paulo.

ALBUQUERQUE, A. T. \& EL DEBS, M. K. (2005). Levantamento dos sistemas estruturais em concreto pré-moldado para edifícios no Brasil. $1^{\circ}$. Encontro nacional de produção, projeto e pesquisa em concreto pré-moldado, São Carlos, São Paulo.

ARAÚJO, B.D. et al. (2003). Gestão integrada de inovações tecnológicas: um empreendimento de shopping center em Natal/RN. Anais do III SIBRAGEC - Simpósio Brasileiro de Gestão e Economia da Construção, Universidade Federal de São Carlos.

ASSOCIAÇÃO BRASILEIRA DA CONSTRUÇÃO INDUSTRIALIZADA (1986).

Manual técnico de pré-fabricados de concreto. São Paulo: Projeto.

ASSOCIAÇÃO BRASILEIRA DE NORMAS TÉCNICAS - ABNT (1985). NBR 9062 - Projeto e execução de estruturas de concreto pré-moldado. Rio de Janeiro.

ASSOCIAÇÃO BRASILEIRA DE NORMAS TÉCNICAS - ABNT (2003). NBR 6118 - Projeto de estruturas de concreto - Procedimento. Rio de Janeiro.

BALLING, R. J. \& YAO, X. (1997). Optimization of reinforced concrete frames. Journal of Structural Engineering, V. 123, N. 2, February.

BENJAORAN, V. e DAWOOD, N. (2006). Intelligence approach to production planning system for bespoke precast concrete products. Automation in Construction, 15, 737-745.

BRADSHAW, J. e MILES, J. C. (1997). Using Standard fitnesses with genetic algorithms. Advances in Engineering Software, 28, 425-435.

CARROLL, D. L. (1999). Fortran GA driver. Manual of program. CU aerospace, Champaign, Illinois.

CASTILHO, V. C. (2003). Otimização de componentes de concreto prémoldado protendidos mediante algorítmos genéticos. Tese (Doutorado) Escola de Engenharia de São Carlos, Universidade de São Paulo. 
CHAN, W. and HU, H. (2001). An application of genetic algorithms to precast production scheduling. Computer \& Structures, 79, pg. 1605-1616.

CORRÊA, M.R.S. (1991). Aperfeiçoamento de modelos usualmente empregados no projeto de edifícios. Tese (Doutorado) - Escola de Engenharia de São Carlos, Universidade de São Paulo.

DAWOOD, N. N. (1995). Scheduling in the precast concrete industry using the simulation modelling approach. Building and Enviroment, V. 30, N. 2, pg. 197-207.

EL DEBS, M. K. (2000). Concreto Pré-Moldado: Fundamentos e aplicações. São Carlos, Publicação EESC - USP.

ELLIOTT, K. S. (1996). Multi-storey precast concrete framed structures. Blackwell Science Ltd.

FÉDÉRATION INTERNATIONALE DE LA PRÉCONTRAINE. (1994). Precast prestressed hollow core floors. London, Thomas Telford.

GRIERSON, D. E. et al. (2002). Method for conceptual design applied to office buildings. Journal of Computing in Civil Engineering, Vol. 16, N.2, april.

GOLDBERG, D. E. (1989). Genetic Algorithms in search, optimization and machine learning. U.S.A., Addison-Wesley Publishing Company.

GOVINDARAJ, V. and RAMASAMY, J. V. (2005). Optimum detailed design of reinforced concrete continuous beams using Genetic Algorithms. Computers \& Structures, 84, 34-48.

HANAI, J. B. (2003). Fundamentos do Concreto Protendido. Notas de aula para o curso de Engenharia Civil. Escola de Engenharia de São Carlos, Universidade de São Paulo.

KHAJEHPOUR, S. (2001). Optimal conceptual design of high-rise office buildings. Tese (Doutorado) - University of Waterloo.

KICINGER, R. et al. (2005). Evolutionary computation and structural design: A survey of the state of art. Computers \& Strucutres, 83, 1943-1978.

KICINGER, R. and ARCISZEWSKI, T. (2004). Multiobjective Evolutionary Design of Steel Structures in Tall Buildings. Proceedings in: $1^{\text {st }}$ Intelligent Systems Technical Conference Chicago, IL, September, 20-23. 
LEMONGE, A. C. C. (1999). Aplicação de algotimos genéticos em otimização estrutural. Tese (doutorado) - Universidade Federal do Rio de Janeiro, Rio de Janeiro.

LEU, S. and HWANG, S. (2001). GA-based resource-constrained flow-shop scheduling model for mixed production. Automation in construction. 11, 439-452.

LOUNIS, Z.; COHN, M. Z. (1993). Optimization of precast prestressed concrete bridge girder systems. PCI Journal. v.123, n.3, p.60-77, July-August.

MELO, C. E. E. et al (2004). Manual Munte de projetos pré-fabricados de concreto. São Paulo, PINI.

MICHALEWICZ, Z. (1996). Genetic Algorithms + data structures = evolution programs. Berlim, Springer-Verlag.

MILES, J.C. et al. (2001). The conceptual design of commercial buildings using a genetic algorithm. Computers \& Structures, 79, p. 1583-1592.

PCI. (2004). Design Handbook. $6^{\text {th }}$ edition, Chicago, Illinois.

PRAKASH, A.; AGARWALA, S. K.; SINGER, K. K. (1988). Optimum design of reinforced concrete sections. Computers \& Structures. v.30, n.4, p.10091011.

PRIOR, R.; PESSIKI, S.; SAUSE, R.; SLAUGHTER, S.; van ZYVERDEN, W. (1993). Identification and preliminary assessment of existing precast concrete floor framing systems. Bethlehem, Lehigh University. (ATLSS Report 93-07).

PRIOR, R.; PESSIKI, S.; SAUSE, R.; SLAUGHTER, S.; van ZYVERDEN, W. (1997). Proposed concepts for floor framing systems for orecast/prestressed concrete office buildings. PCI Journal, v.42, n.4, p.6676.

PULLMANN, T. et al. (2003). Structural design of reinforced concrete tall buildings: Evolutionary computation aproach using fuzzy sets. Proceedings in: $10^{\text {th }}$ International Workshop of the European group for intelligent computing engineering, Delft, Netherlands, p. 53-61.

RAFIQ, M. Y. et al. (2003). Conceptual Building Design - Evolutionary Aproach. Journal of Computing in Civil Engineering, Vol. 17, N. 3, july. 
RAJEV, S.; KRISHNAMOORTHY, C. S. (1992). Discrete optimization of structures using Genetic Algorithm. Journal of Structural Engineeing, ASCE, v.118, n.5,p.1233-1250.

RAJEV, S.; KRISHNAMOORTHY, C. S. (1997). Genetic Algorithms-based methodologies for design optimization of trusses. Journal of Structural Engineeing, ASCE, v.123, n.3.

SACKS, R. et al. (2000). Structural design in an automated building system. Automation in construction, 10, 181-197.

SACKS et al. (2004). Process model perspectives on management and engineering procedures in the precast/prestressed concrete industry. Journal of construction engineering and management, Vol. 130, No. 2, March/April, pp. 206-215.

SAHAB, M. G. et al. (2005a). A hybrid genetic algorithm for reinforced concrete flat slab buildings. Computers \& Structures, 83, p. 551-559.

SAHAB, M. G. et al. (2005b). Cost optimization of reinforced concrete flat slab buildings. Engineering Structures, 27, p. 313-322.

SARMA, K. C.; ADEL, H. (1998). Cost optimization of concrete structures. Journal of Structural Engineeing, ASCE, v.124, n.5, p.570-578, May.

SARMA, K. C.; ADELI, H. (2005). Comparative study of optimum designs of steel high rise building structures using allowable stress design and load and resistance factor design codes. Practice Periodical on Structural Design and Construction, ASCE, vol. 10, n. 1, february.

SILVA, E. E. da. (2001). Otimização de estruturas de concreto armado utilizando algoritmos genéticos. Tese (Doutorado) - Escola Politécnica da Universidade de São Paulo.

SOARES, R.C. (1999). Otimização de seções transversais de concreto armado sujeita à flexão: aplicação a pavimentos. Dissertação (Mestrado), Escola de Engenharia de São Carlos - Universidade de São Paulo.

ZHENG D. X. M. et al. (2004). Applying a genetic algorithm-based multiobjective approach for time-cost optimization. Journal of construction and management, v. 130, n. 2, April. 


\section{BIBLIOGRAFIA COMPLEMENTAR}

ALI, N. et al. (2003). Applicability and viability of a GA based finite element analysis architectrue for structural design optimization. Computers \& Structures, 81, p. 2259-2271.

ARORA, J. S. (1989). Introduction to Optimum Design. New York: McGraw-Hill.

BRADSHAW, J. e MILES, J. C. (1997). Using Standard fitnesses with genetic algorithms. Advances in Engineering Software, 28, 425-435.

CARROLL, D. L. (1999). Fortran GA driver. Manual of program. CU aerospace, Champaign, Illinois.

C. LEE P. E. (2003). Flexural design of reinforced concrete frames by genetic algorithm. Journal of structural engineering, v. 129, n. 6, june.

CAMP C. V. et al. (2003). Flexural design of reinforced concrete frames using a genetic algorithm. Journal of structural engineering, ASCE, v.129, n.1, Jan.

CASTRO, L. C. L. B. e LOPES, A. P. (2005). Aplicação de algoritmo genético na otimização do dimensionamento de seções transversais de vigas de concreto armado. Anais do $47^{\circ}$ Congresso Brasileiro do Concreto, Olinda, Pernambuco, Brasil.

CASTRO, L. C. L. B. et al. (2006). The influence of penalty functions in structural optimization using GA. Proceedings of the XXVII CILAMCE, Belém, Pará, Brazil.

CHEN, T.-Y.; CHEN, C.-J. (1997). Improvements of simple Genetic Algorithm in structural design. International Journal for Numerical Methods in Engineering. v.40, p.1323-1334, April.

CHENG, F. Y.; LI, D. (1998). Genetic Algorithm for multiobjective optimization of structures. AIAA Journal. v.36, n.6, p.1105-1112, June.

COELLO, C. C.; HERNÁNDEZ, F. S.; FARRERA, F. A. (1997). Optimal design of reinforced concrete beams using Genetic Algorithm. Expert Systems with Applications. v.12, n.1, p.101-108.

FONSECA, L. G. \& BARBOSA, H. J. C. (2006). A genetic algorithm with similarity-based fitness approximation for structural optimization. Proceedings of the XXVII CILAMCE, Belém, Pará, Brazil. 
HRSTA O. et al. (2003). A competitive comparison of different types of evolutionary algorithms. Computers \& Structures, v.81, p.1979-1990.

JENKIS, W. M. (1997). On the application of natural algorithms to structural design optimization. Engineering Structures. v.19, n.4, p.302-308, April.

KALLASSY, A.; MARCELIN, J.-L. (1997). Optimization of stiffened plates by genetic search. Structural Optimization. v.13, p.134-141.

KOSKISTO, O. J.; ELLINGWOOD, B. R. (1997). Reliability-based optimization of plant precast concrete structures. Journal of Structural Engineeing, ASCE, v.123, n.3, p.298-304, March.

KOUMOUSIS, V. K.; ARSENIS, S. J. (1998). Genetic Algorithm in optimal detailed design of reinforced concrete members. Computer-Aided Civil and Infrastructure Engineering. v.13, p.43-52.

KWAN, A. S. (1998). An evolutionary approach for layout-optimization of truss structures. International Journal of Space Structures. v.13, n.3, p.145-155.

LAGAROS, N. D. et al. (2002). Structural optimization using evolutinary algorithms. Computers \& Structures, 80 , p. 571-589.

LEITE, J. P. B.; TOPPING, B. H. V. (1998). Improved genetic operators for structural engineering optimization. Advances in Engineering Software. v.29, n.7-9, p.529-562, Aug-Nov..

LOVE, P.; LI, H. (1997). Using improved Genetic Algorithms to facilitate timecost optimization. Journal of Construction Engineering and Management. v.123, n.3, p.233-237, Sep.

LOW, S. G.; TADROS, M. K.; NIJHAWAN, J.C. (1991). Minimization of floor thickness in precast prestressed concrete multistory buildings. $\mathrm{PCl}$ Journal, v.36, n.4, p.74-92.

MANOHARAM, S. e SHANMUGANATHAN, S. (1999). A comparison of search mechanisms for structural optimization. Computers \& Structures, 73, p. 363-372.

NANAKORN, P.; MEESOMKLIN, K. (2001). An adaptive penalty function in genetic algorithms for structural design optimization, 79, p. 2527-2539.

RAFIQ, M. Y.; SOUTHCOMBE, C. (1998). Genetic Algorithm in optimal design and detailing of reinforced concrete biaxial columns supported by a declarative approach for capacity checking. Computers \& Structures. v.69, p.443-457. 


\section{ANEXO 1}

Novo sistema estrutural da universidade do Nebraska

(Midwest Office System - MOS) 


\section{AN-1. INTRODUÇÃO}

O sistema estrutural da Universidade do Nebraska apresentado no capítulo 3 (University of Nebraska System, figura 3-16) foi desenvolvido em 1991, procurando minimizar a espessura do pavimento para reduzir o custo total da construção. Conforme LOW et al. (1991), a idéia principal era que o custo direto da estrutura é apenas um item do custo total da construção e que às vezes uma estrutura mais cara pode levar a um custo total mais baixo.

Essa consideração era baseada no conhecimento de que os elementos mais esbeltos são mais caros, mas proporcionam economia se considerarmos a redução nos custos dos sistemas de serviços e nos de arquitetura, tais como revestimentos e divisórias.

É importante observar que nos Estados Unidos, segundo o Professor Tadros $^{1}$, se estima que os custos com os sistemas de serviços e de arquitetura correspondem, em média, a 75\% do custo total da construção de um edifício.

Atualmente os projetistas de estruturas continuam procurando por pavimentos com espessuras menores, que são reconhecidos como uma melhor solução para os sistemas de serviço e para proporcionar uma maior flexibilidade ao layout arquitetônico. Inspirado nesse conceito e utilizando as tendências do concreto pré-moldado, tais como concreto de alto desempenho, confinamento do concreto e seções compostas, a Universidade do Nebraska, em 2006, propõe um novo sistema estrutural para edifícios com estrutura de concreto pré-moldado.

\section{AN-2. NOVO SISTEMA ESTRUTURAL DA UNIVERSIDADE DO NEBRASKA}

Antes de iniciar o desenvolvimento do novo sistema foi feita uma análise crítica, sobre o sistema desenvolvido anteriormente, para identificar porque não tinha sido utilizado pelos fabricantes desde sua criação. O único ponto negativo apresentado pelos fabricantes foi a quantidade de trabalho nas fases de montagem. Essa mesma avaliação foi feita pelo relatório da ATLSS (PRIOR, 1993), que classificava o sistema como muito eficiente, mas que requeria um significativo esforço de construção.

\footnotetext{
${ }^{1}$ Professor Maher Tadros, reunião na Universidade do Nebraska em maio de 2006.
} 
Após essa constatação, decidiu-se manter uma interação com fabricantes e montadores para incorporar suas sugestões e expectativas sobre as características que um sistema estrutural deveria ter para ser viável tecnicamente, economicamente e construtivamente.

\subsection{Reuniões com fabricantes e montadores}

Para descobrir as necessidades dos fabricantes houve várias reuniões e alguns requerimentos foram apontados.

a) Deve-se utilizar o mínimo de formas e o mínimo de trabalho manual na fase de montagem. A montagem deve ser rápida e não deve esperar pela solidarização do pavimento com a capa de concreto;

b) Os pilares devem ser contínuos (múltiplos pavimentos);

c) As lajes alveolares devem ser montadas antes das ligações das vigas serem executadas. As lajes são os elementos que aparecem em maior número e devem ser montadas, rapidamente, para não atrasarem a montagem;

d) As equipes de montagem devem ser independentes, não deveriam esperar pela completa execução das ligações das vigas e pela concretagem da capa;

e) Seria um grande avanço se as vigas fossem contínuas para o peso próprio das lajes, da capa e para as cargas acidentais;

f) Seria interessante se as ligações das vigas suportassem os momentos positivos e negativos devido aos efeitos de terremotos e ações do vento;

g) O sistema deveria ser dividido em dois, um para edifícios comerciais e outro para edifícios residenciais. Essa divisão é baseada na diferença de vãos e de requisitos de altura do forro entre os dois. Diante disso o novo sistema do Nebraska foi dividido em Midwest office system (MOS) e Residential system (RS).

Após essas reuniões, houve encontros com os montadores para descobrir particularidades da seqüência de montagem e a capacidade dos 
montadores fazerem algumas ligações. As conclusões desses encontros são apresentadas abaixo.

a) Os montadores poderiam fazer ligações com solda facilmente durante a montagem;

b) Eles poderiam colocar algumas barras de aço e preencher com grout aberturas nas vigas sem diminuir a produtividade do serviço;

c) Eles gostariam de eliminar quaisquer serviços que requisitassem forma de madeira na sua atividade.

Durante essas reuniões muitas alternativas foram sugeridas e muitas mudanças foram sendo feitas para alcançar todas as expectativas. Depois disso, apresenta-se o Midwest Office System (MOS), que foi desenvolvido pelo candidato no período que passou na Universidade do Nebraska, sob orientação dos professores Maher K. Tadros e Amgad Girgis.

\section{AN-3. SISTEMA ESTRUTURAL PARA EDIFÍCIOS COMERCIAIS (MIDWEST OFFICE SYSTEM - MOS)}

\subsection{Descrição do sistema}

Em geral, as necessidades arquitetônicas para edifícios comerciais requerem áreas livres de 9,0 m por 9,0 m e nessas edificações existe sempre um forro falso para passagem das instalações. Os edifícios comerciais com estrutura de concreto pré-moldado têm, em geral, um pavimento com altura total em torno de $58 \mathrm{~cm}$ e têm vigas com largura de $100 \mathrm{~cm}$, que suportam lajes alveolares de $20 \mathrm{~cm}$.

O sistema proposto tem uma altura total de pavimento de $41 \mathrm{~cm}$ com vigas com largura de $120 \mathrm{~cm}$ para compensar a redução de altura. Obteve-se uma redução de $17 \mathrm{~cm}$ na altura do pavimento. Apresenta-se na figura AN-1 a seção da viga no meio do vão e na figura AN-2 a seção na extremidade. $O$ aumento da largura das vigas ainda propicia a diminuição dos vãos das lajes e facilita a utilização das laterais dos pilares para a colocação de armadura negativa da viga. 
Para conseguir essa redução de altura foi necessário estabelecer a continuidade da viga para o peso próprio das lajes, para o peso próprio da capa de concreto e para as cargas acidentais, de forma que a continuidade só não é estabelecida para o peso próprio das vigas. Para isso a fase de montagem foi dividida em duas etapas que são a etapa anterior à montagem das lajes e a etapa anterior à concretagem da capa.

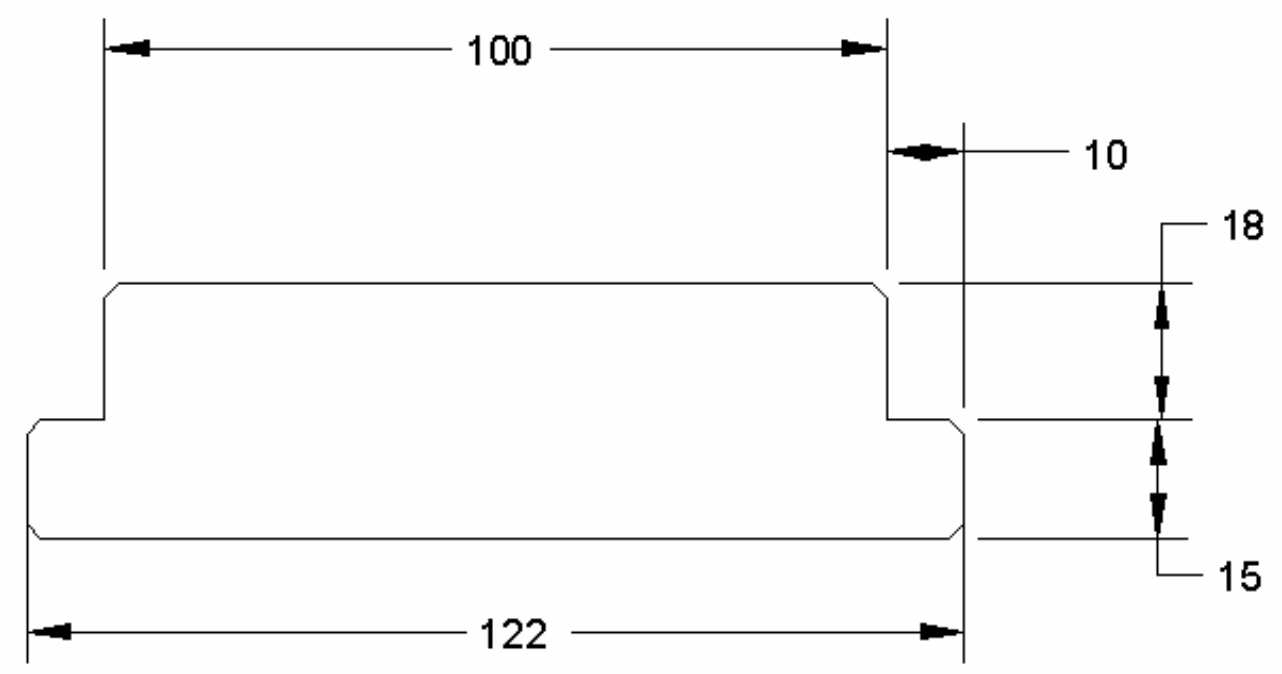

Figura AN-1 - Seção transversal no meio do vão (medidas em "cm")

Conforme apresentada na figura AN-2, as extremidades das vigas têm um detalhe por um dos lados do pilar para eliminar a necessidade de formas, para preencher a lacuna entre duas vigas adjacentes na região do pilar. Observa-se também, nas extremidades das vigas, uma reentrância (pocket) de aproximadamente $1,5 \mathrm{~m}$ de comprimento. Observam-se ainda placas metálicas na parte superior das vigas devidamente ancoradas e luvas metálicas cruzando a viga na direção transversal.

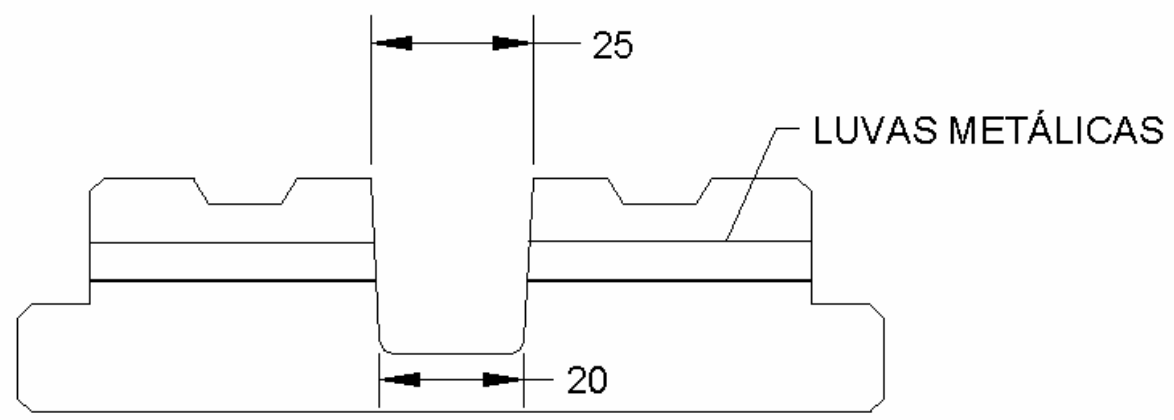

(a) Corte (medidas em “cm”) 


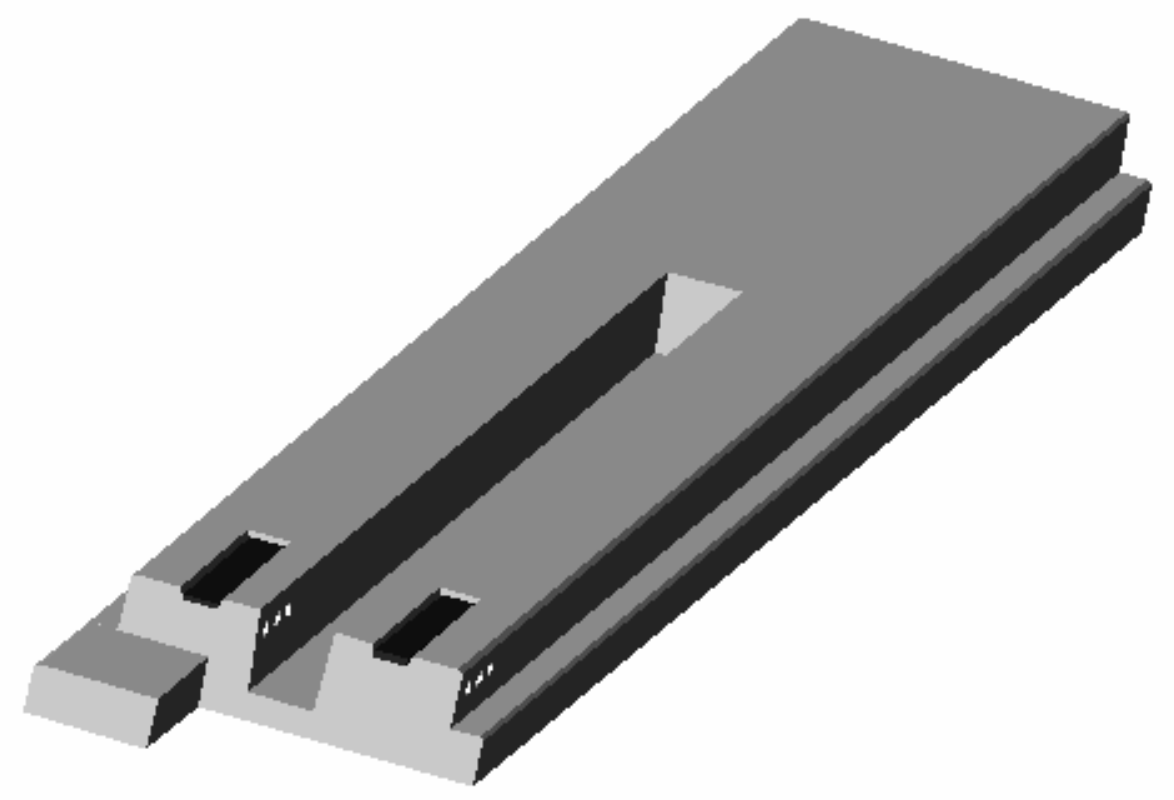

(b) Perspectiva

Figura AN-2 - Seção transversal na extremidade das vigas

As vigas são montadas em dois consoles metálicos separados, constituídos por tubos metálicos, que estão soldados em placas embutidas nos pilares. Existe ainda um tubo metálico dentro do pilar para permitir a passagem de armaduras por dentro do pilar para efetivar a ligação entre as vigas e os pilares. O tubo metálico é necessário para que o pilar vazado tenha resistência suficiente para suportar as ações das fases transitórias, já que as lajes serão montadas antes do preenchimento do pilar. Todos esses detalhes são apresentados na figura AN-3. 

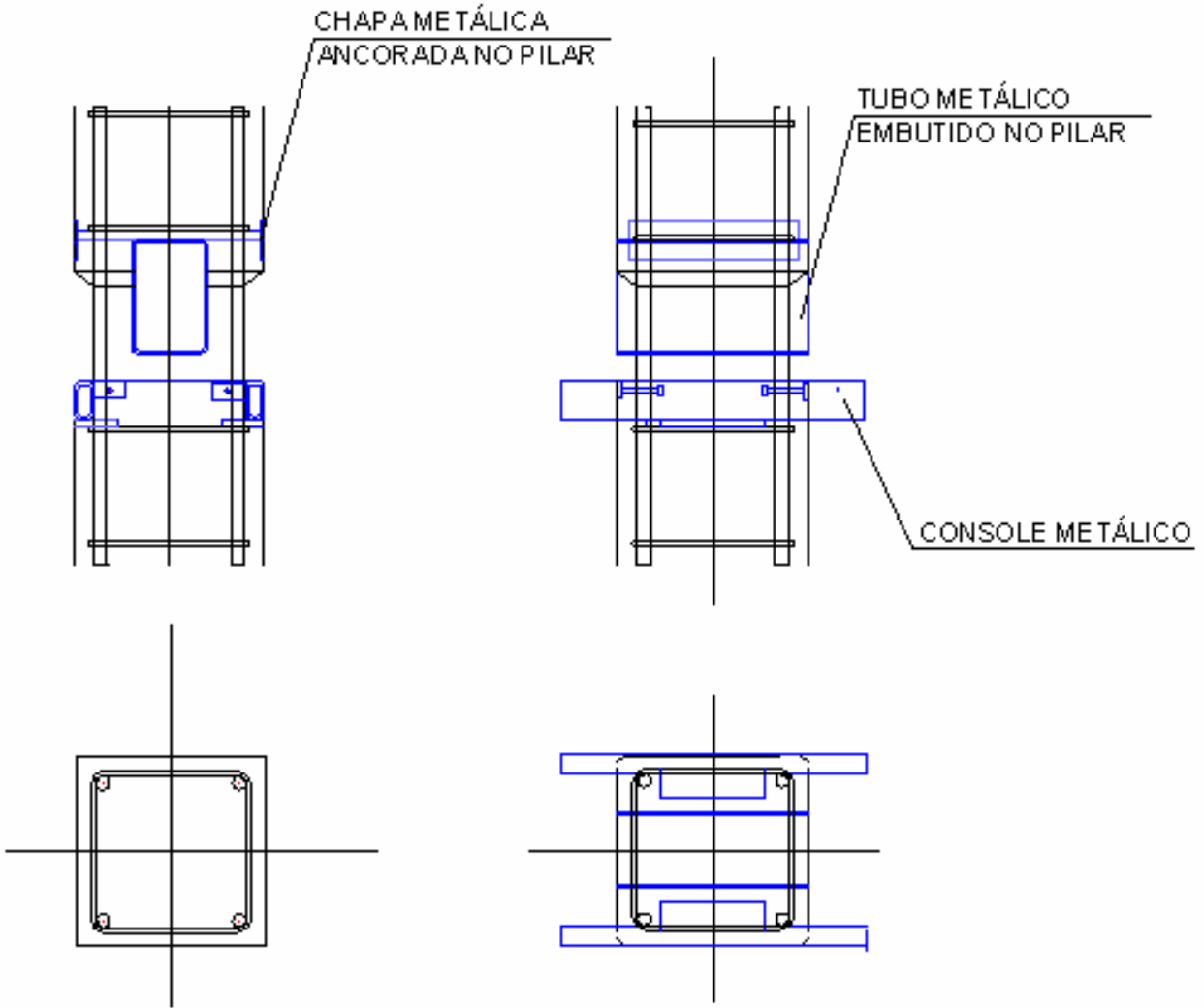

(a) Cortes

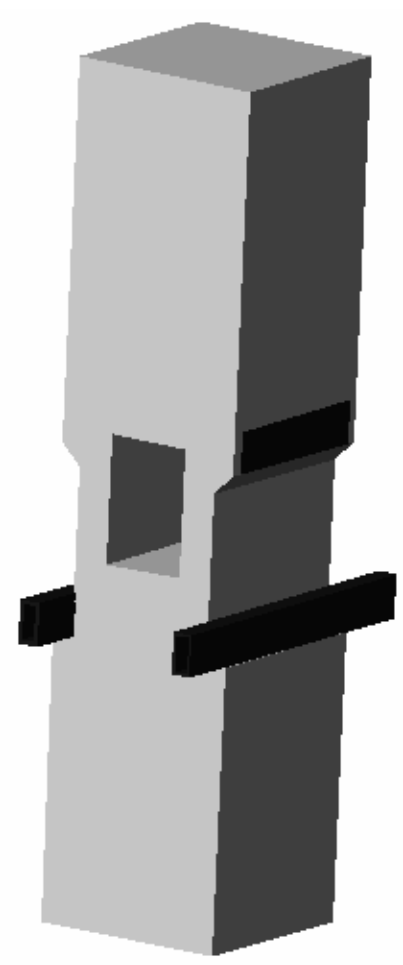

(b) Perspectiva

Figura AN-3 - Detalhes do pilar 


\subsection{Primeira etapa da montagem}

Antes da montagem das lajes, as vigas devem ser ligadas aos pilares usando um perfil metálico em "L" soldado nas placas metálicas que estão embutidas nas laterais dos pilares e no topo das vigas. Para completar a primeira etapa devem ser instaladas placas de alta resistência (shimpack) entre a zona inferior das vigas e os pilares.

Essa primeira conexão, apresentada na figura AN-4, possibilita que o perfil metálico absorva os esforços de tração e as placas absorvam os esforços de compressão, formando um binário resistente às ações produzidas pelo peso próprio das lajes, que serão montadas na seqüência. Além da capacidade resistente essa conexão garante a estabilidade do sistema durante a montagem.

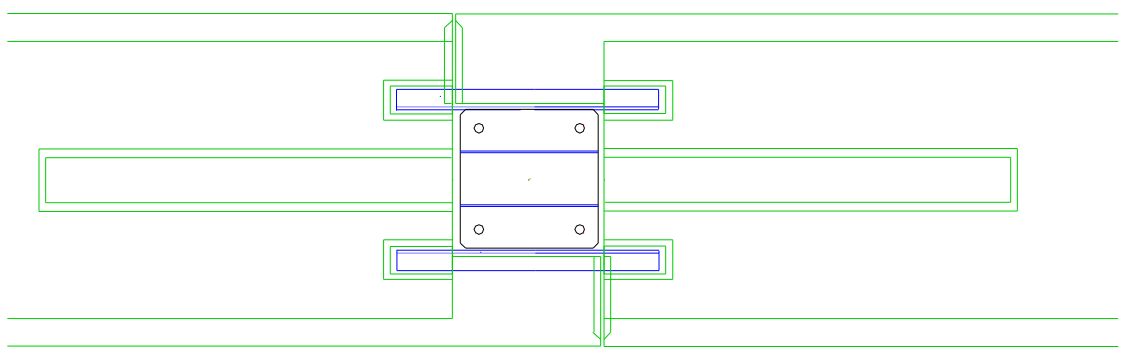

(a) Vista superior do perfil metálico

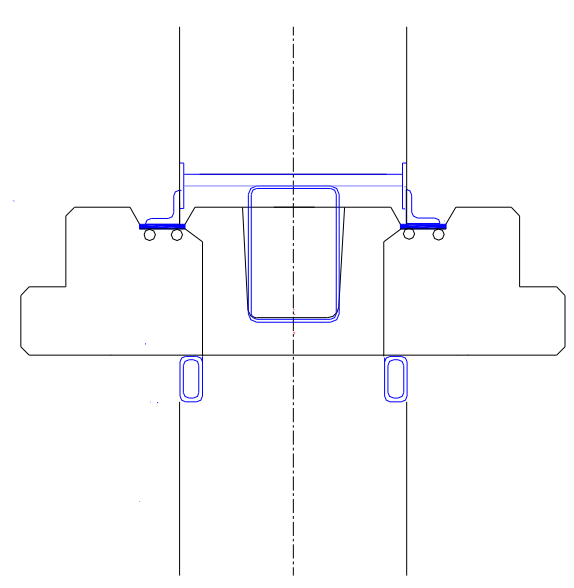

(b) Corte 


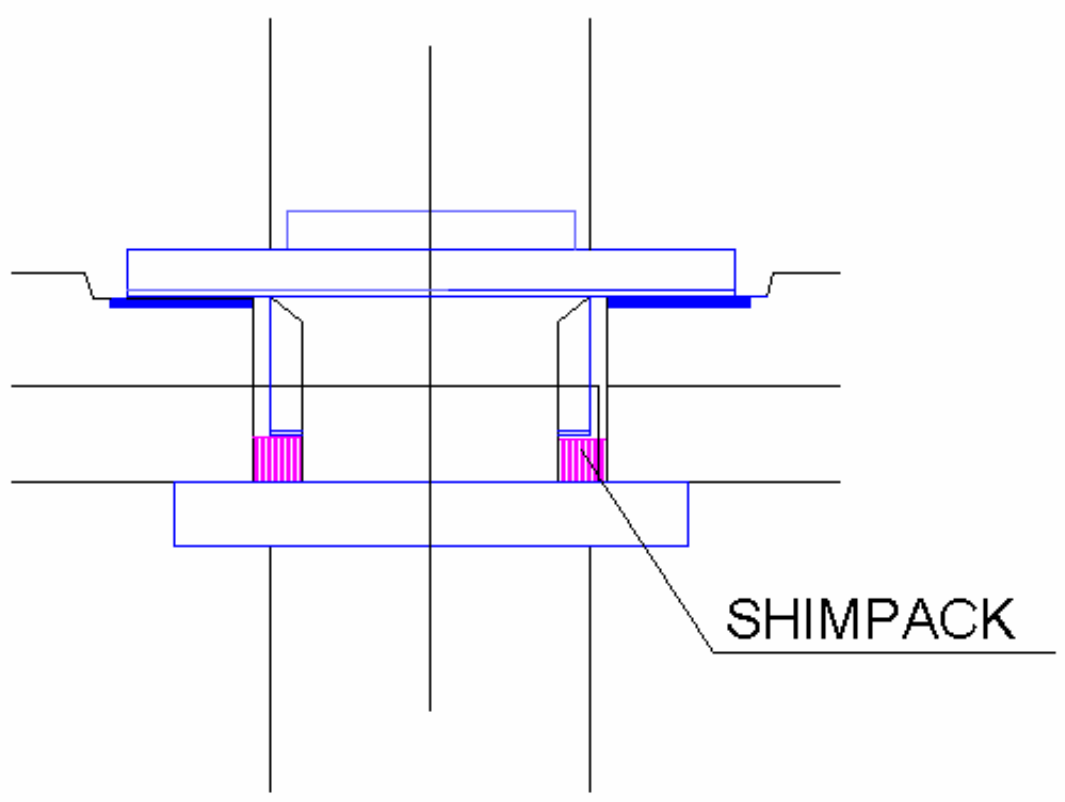

(c) Vista lateral

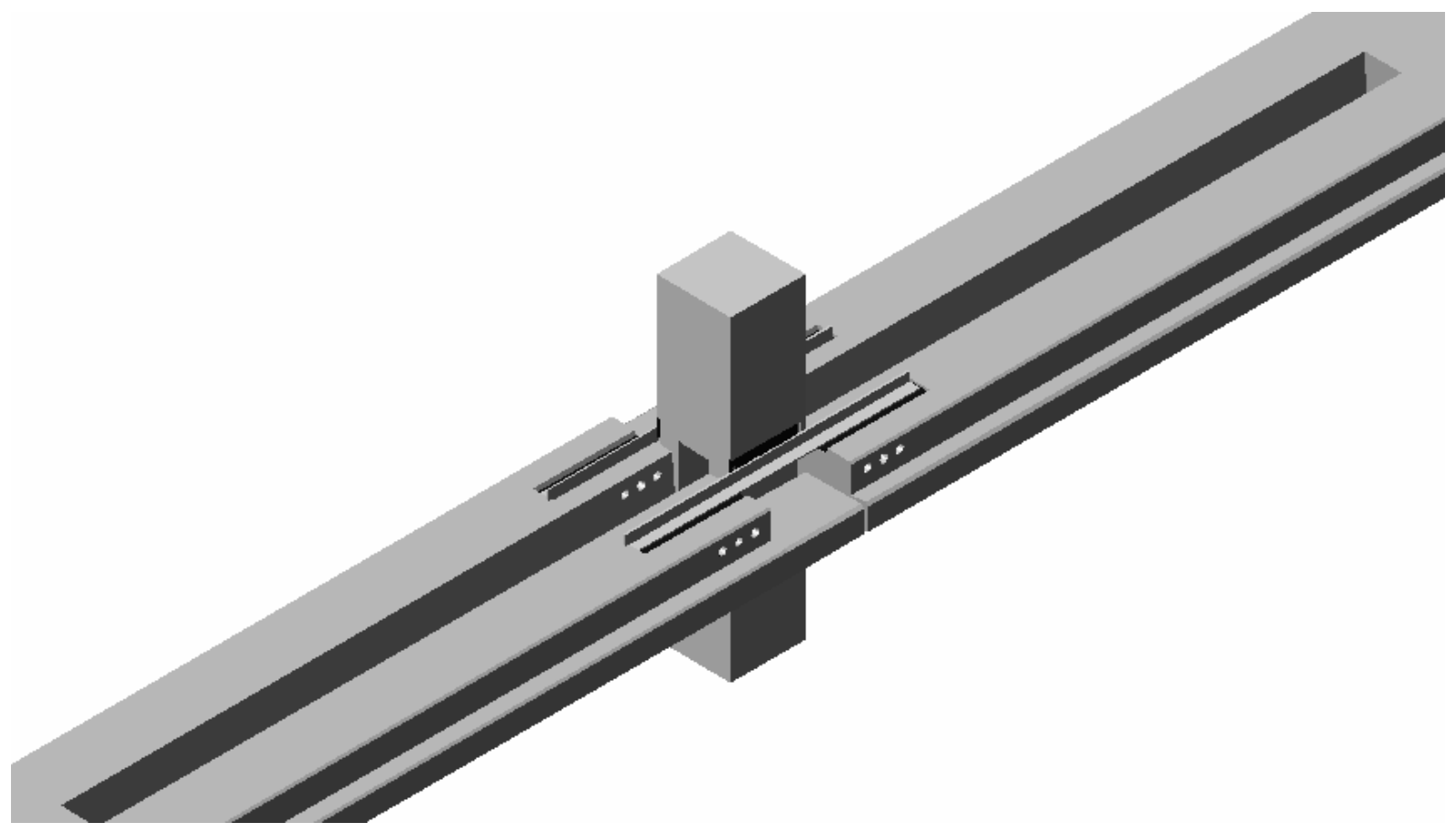

(d) Perspectiva superior

Após a conclusão da primeira etapa, as lajes alveolares podem ser montadas (figura AN-5). 


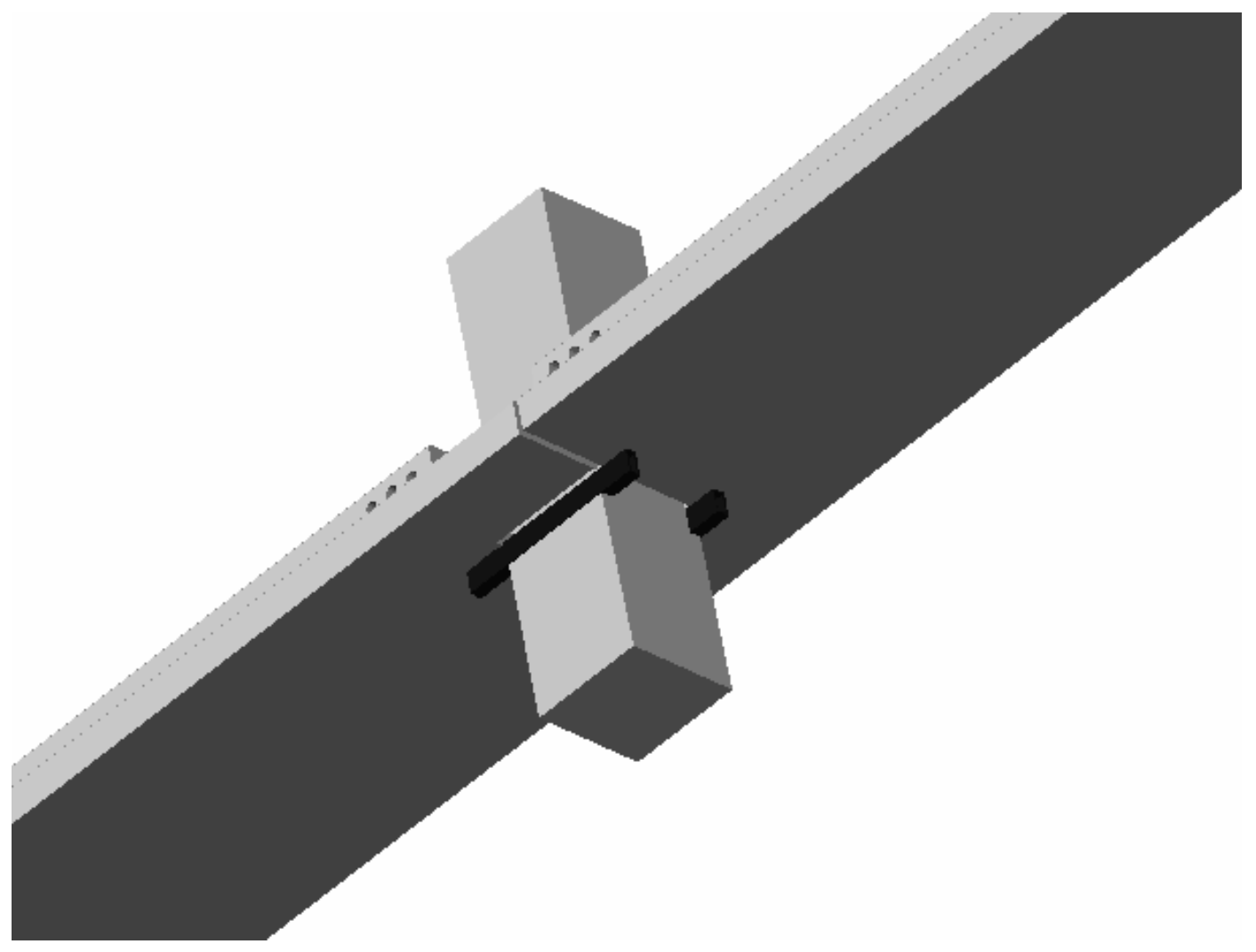

(e) Perspectiva inferior

Figura AN-4 - Ligações realizadas antes da montagem das lajes

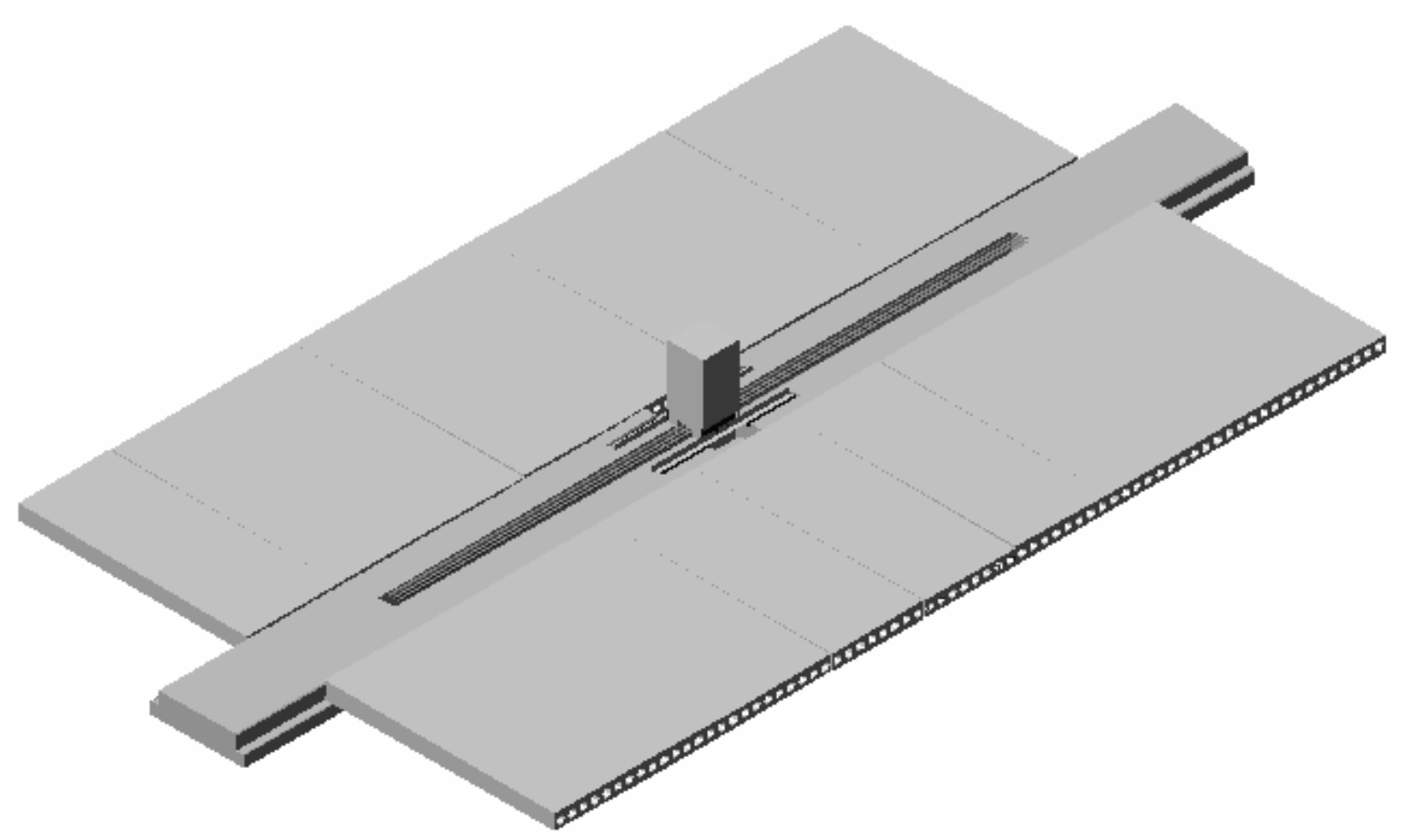

Figura AN-5 - Montagem das lajes alveolares 


\subsection{Segunda etapa de montagem}

Antes da concretagem da capa é necessário realizar-se a ligação através da reentrância. Colocam-se barras de armadura na região vazada nas extremidades das vigas passando pelo tubo metálico embutido no pilar e posteriormente preenche-se toda a reentrância da viga e o vazado do pilar com concreto (figuras AN-6 e 7). Essas barras conferem à ligação a resistência necessária para resistir ao peso próprio da capa e por isso deve-se esperar que o concreto da região adquira a resistência necessária antes da concretagem da capa. Observa-se ainda que dentro dessa reentrância também se colocam barras na posição inferior para que seja efetivada a ligação do pórtico para as ações do vento e terremoto.

Algumas barras devem ser instaladas passando pelas luvas, deixadas transversalmente às extremidades das vigas, para prover a ligação na direção transversal, através das lajes alveolares (figura AN-6).

Ainda antes da concretagem da capa, são posicionadas barras de armadura pelas laterais e através do pilar, dentro da capa, na mesma direção das vigas para prover a ligação de resistência para as ações das cargas acidentais (figura AN-8).

Alguns alvéolos próximos ao pilar, por onde passaram as barras transversais às vigas, devem ser preenchidos juntamente com a capa para prover a ligação na direção transversal, através das lajes alveolares (figura AN9). Colocam-se, também, barras na direção transversal pelas laterais do pilar na região da capa. 


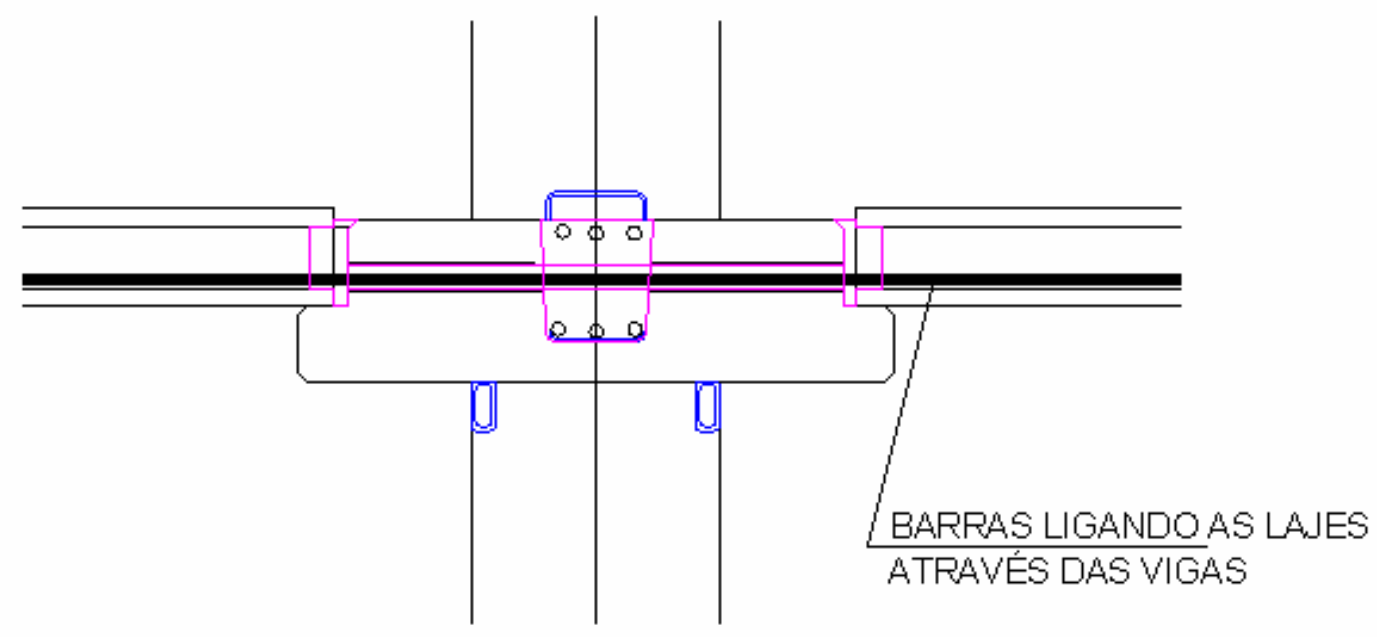

(a) Corte

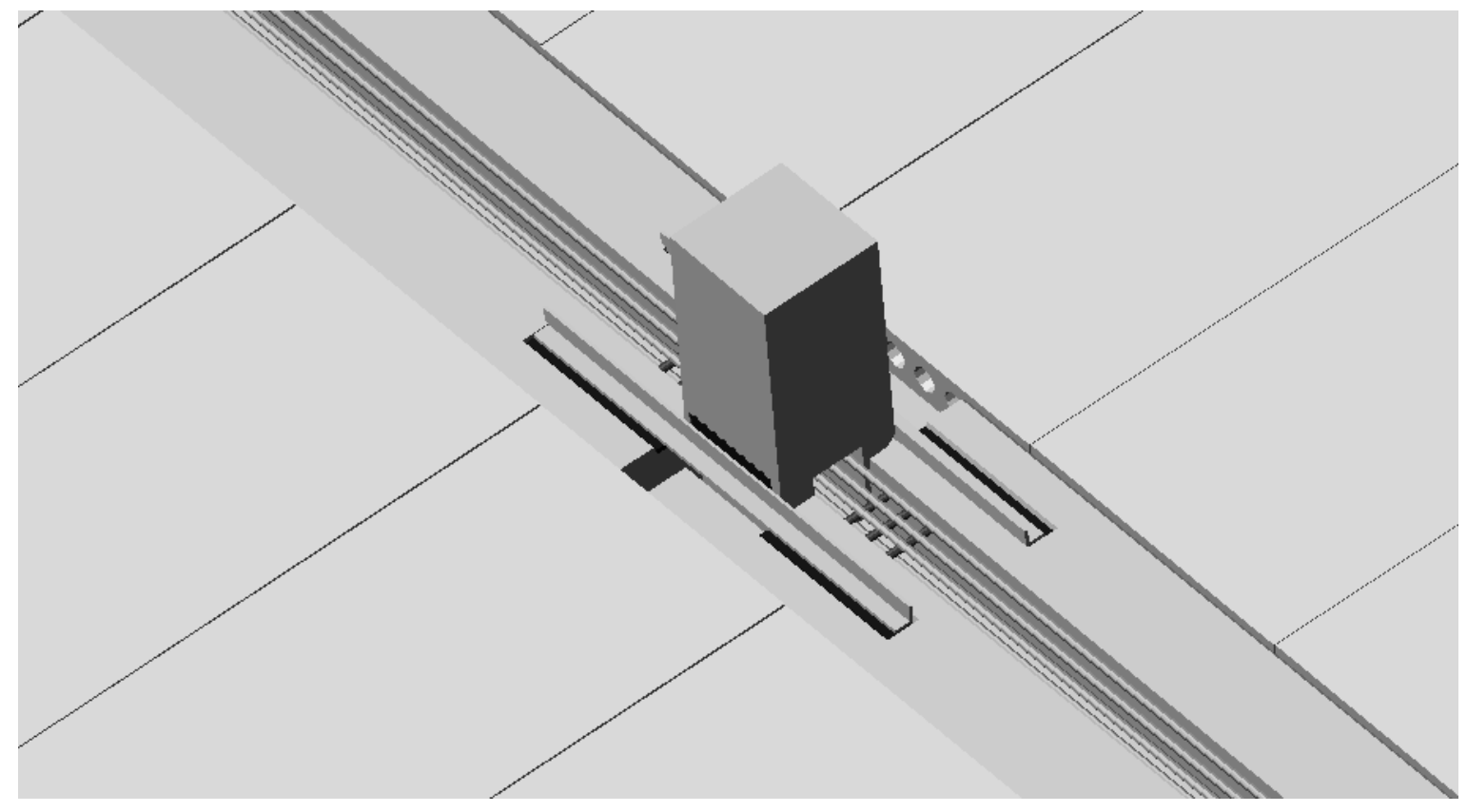

(b) Perspectiva

Figura AN-6 - Ligações antes da concretagem da capa 


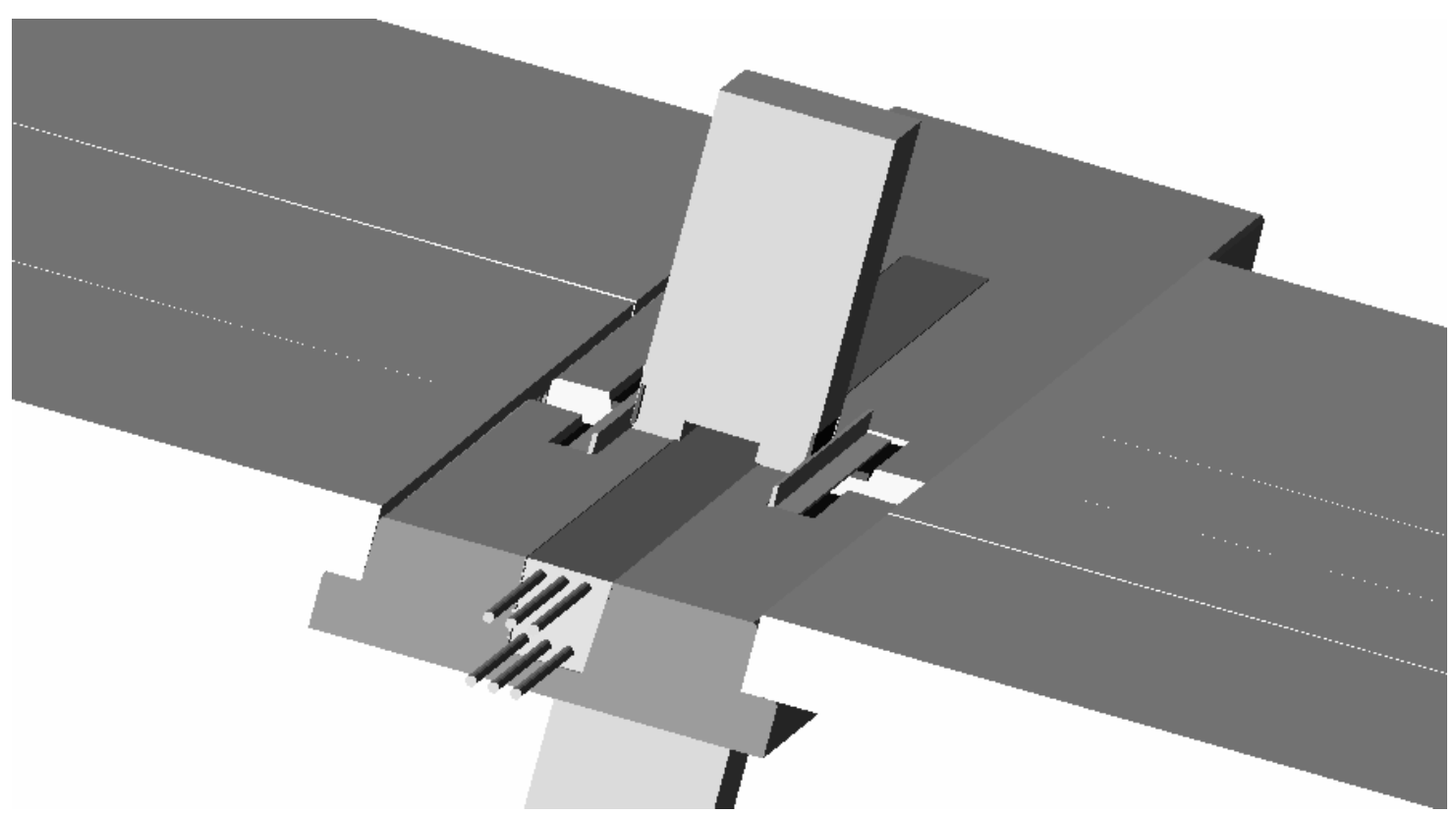

(a) Perspectiva 1

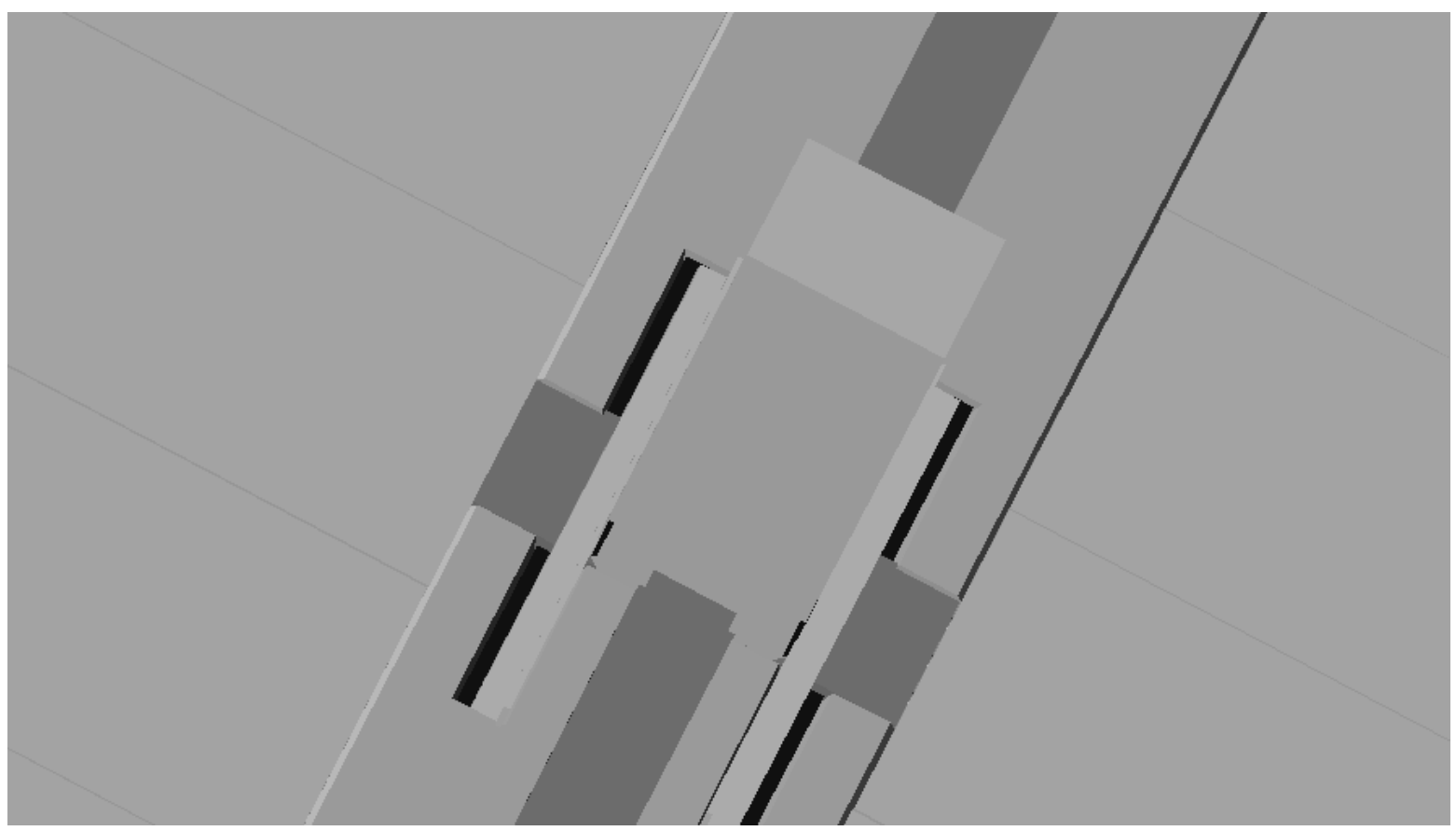

(b) Perspectiva 2

Figura AN-7 - Concretagem da reentrância da viga e do vazado do pilar 


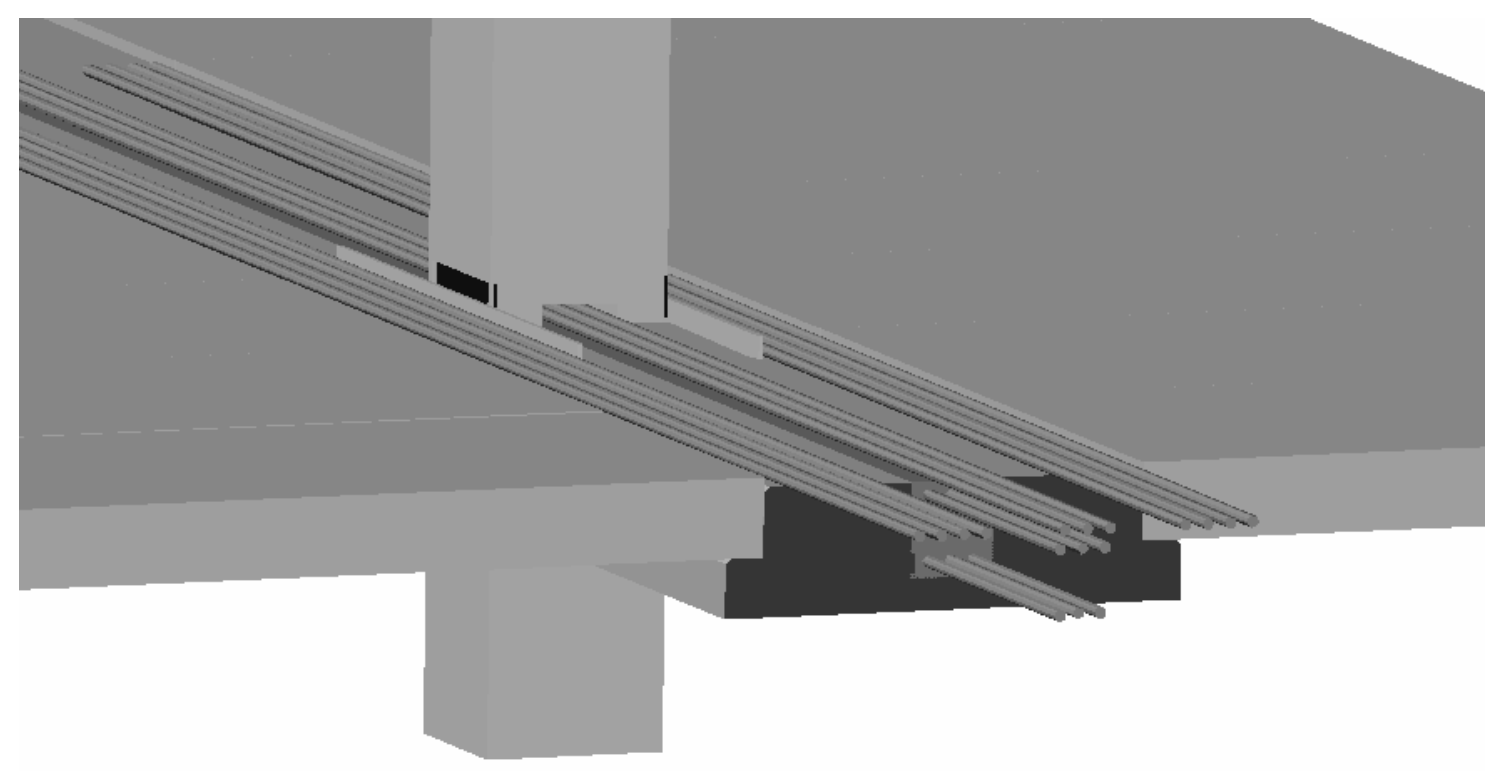

Figura AN-8 - Posicionamento de barras na região da capa

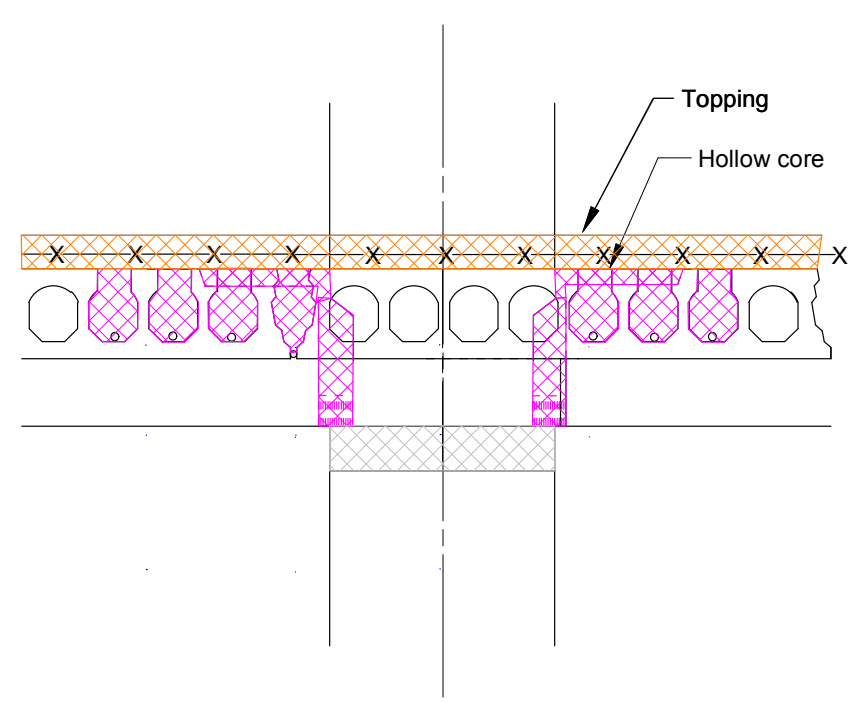

Figura AN-9 - Alvéolos preenchidos

A idéia é reduzir ou eliminar por completo a dependência de paredes e núcleos estruturais para absorverem as ações laterais, necessários em geral nas estruturas pré-moldadas. Isso é possível devido ao efeito de pórtico conferido pela ligação tanto na direção das vigas como na direção das lajes.

Foi feita uma simulação numérica considerando a efetividade dessa ligação entre as lajes alveolares, a extremidade das vigas e o pilar para um 
prédio de 5 pavimentos com 3 vãos, $\ell_{\text {vigas }}=10,0 \mathrm{~m}$, na direção das vigas e 6 vãos, $\ell_{\text {lajes }}=10,0 \mathrm{~m}$, na direção das lajes. Os resultados indicaram que somente essas ligações seriam suficientes para resistir aos esforços laterais, desprezando a existência de pilares-parede, núcleos estruturais e pórticos de periferia.

\section{AN-4. PARTICULARIDADES DO SISTEMA}

As vigas possuem estribos que saem da seção pré-moldada de forma que criam o confinamento do concreto no meio do vão, para aumentar a resistência à compressão do concreto da capa, e nas extremidades para diminuir os comprimentos de ancoragem das barras longitudinais, já que é uma região tracionada (figuras $\mathrm{AN}-10$ e 11).

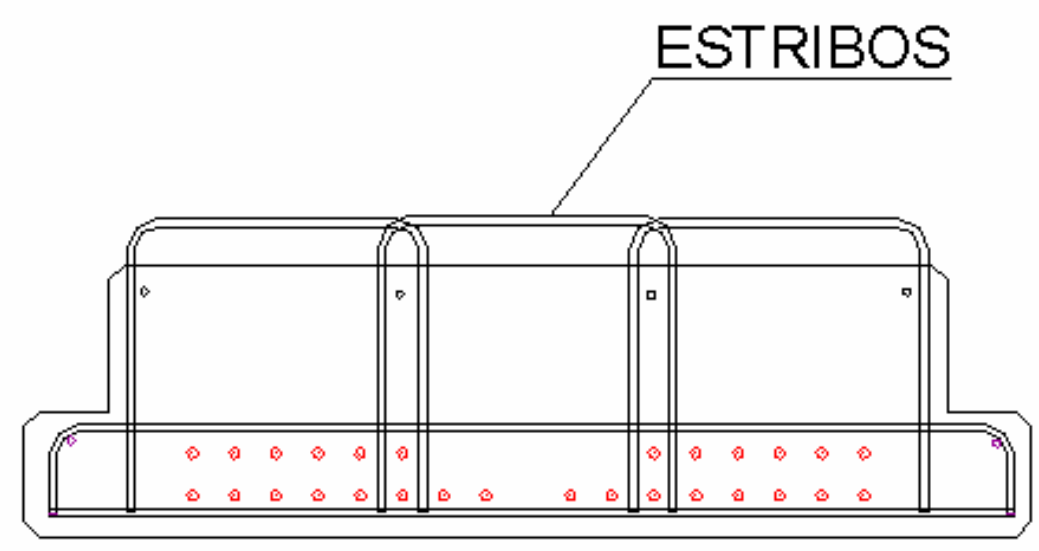

Figura AN-10 - Detalhe dos estribos no meio do vão

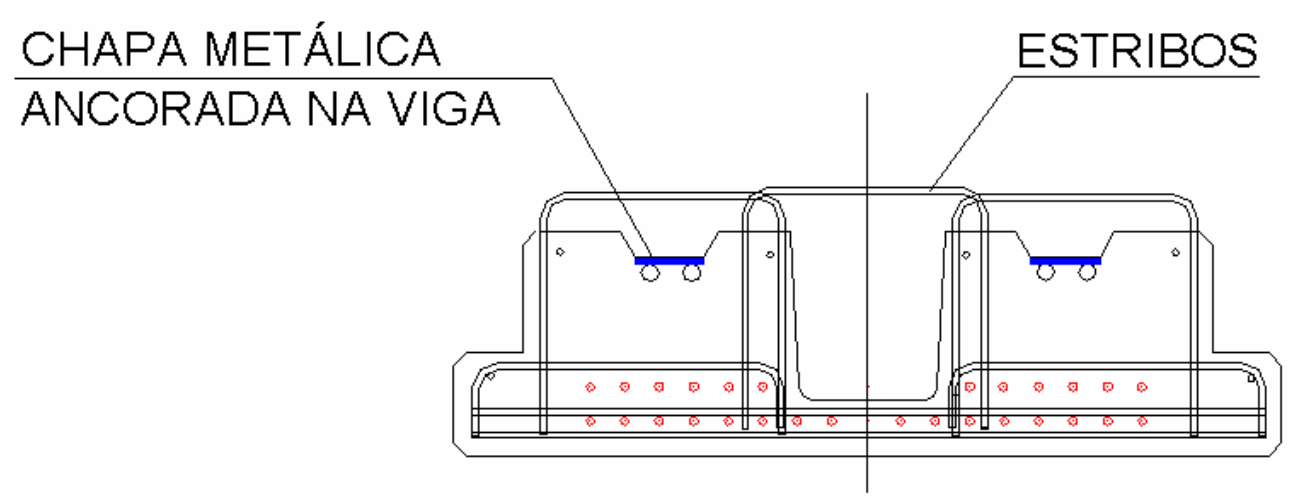

Figura AN-11 - Detalhe dos estribos nas extremidades 
Após o término da montagem quando o concreto da capa já tiver atingido a resistência necessária, os consoles metálicos podem ser removidos e a região do pilar, que eles ocupavam, pode ser preenchida com grout por questões estéticas e por questões de segurança contra incêndio. Os consoles podem ser desprezados devido à quantidade de armadura ligando às vigas passando por dentro do pilar.

Caso não haja empecilhos, quanto à norma de proteção a incêndios, os consoles poderiam também ser deixados no local, pois são pequenos e poderiam ficar escondidos no forro falso.

As simulações para o MOS foram feitas considerando uma carga acidental de $5 \mathrm{kN} / \mathrm{m}^{2}$, um concreto de resistência $42 \mathrm{MPa}$ e uma redistribuição de cargas de $18 \%$ para as cargas acidentais. Utilizou-se o software RISA.

\section{AN-5. CONSIDERAÇÕES FINAIS}

Com as duas etapas descritas o sistema permite a montagem da estrutura sem a necessidade da concretagem da capa e sem um grande acréscimo de trabalho. Dessa forma a montagem fica mais rápida e independente. Nos sistemas estruturais existentes, de concreto pré-moldado, em geral, recomenda-se que não sejam montados mais do que 3 pavimentos sem a concretagem da capa em pelo menos 1 pavimento.

As ligações efetuadas na direção das vigas possibilitam o surgimento de pórticos e a redução da altura do pavimento, fazendo que o sistema seja bastante semelhante a um sistema estrutural moldado no local.

Essas ligações permitem que as vigas sejam mais eficientes devido à sua maior continuidade e que os pilares sejam considerados travados em todos os pavimentos durante a montagem. A verificação da montagem para os pilares em estruturas pré-moldadas é, em geral, a que predomina no dimensionamento porque ficam até 3 lances livres. Com isso há uma economia significativa nos pilares que são um dos elementos mais caros.

As ligações efetuadas transversalmente às vigas são bastante promissoras, já que podem conferir rigidez às ações laterais considerando as lajes. 
De acordo com o relatório apresentado em PRIOR et al. (1993) as melhorias nos sistemas estruturais pré-moldados deveriam ser alcançadas através de algumas premissas:

a) Reduzir o número de peças diferentes;

b) Facilitar o alinhamento das ligações para reduzir a mão de obra;

c) Aumentar a resistência dos elementos e das ligações;

d) Desenvolver pavimentos mais esbeltos.

Observa-se que todas essas características foram contempladas no MOS.

Salienta-se ainda que os resultados do SATD sempre apontam como uma das melhores soluções uma alternativa com vigas priorizando a largura. Constata-se então que, além das economias nos sistemas de serviço e de arquitetura, o MOS pode ser mais econômico, também, na comparação direta entre as estruturas com um sistema pré-moldado tradicional.

O MOS já possui um plano de ensaios, que contempla as etapas de ligação entre as vigas e as ligações das lajes e será testado no laboratório da University of Nebraska at Omaha. 


\section{APÊNDICE A}

Questionários sobre utilização dos pré-moldados 


\section{Questionário distribuído para os arquitetos}

a) Existem modulações em função dos tipos de ocupação? Por exemplo, edifícios garagens são modulados em múltiplos do tamanho estabelecido para as vagas. Residenciais? Comerciais? Hospitais? Hotéis? Faculdades?

b) Quais os tipos de prédios (residenciais, comerciais, hospitais, hotéis, faculdades e etc.) que mais se adaptam as estruturas pré-moldadas?

c) Qual a seqüência de desenvolvimento de um projeto arquitetônico para uma edificação pré-moldada?

d) Existem restrições impostas pelas instalações (elétricas, sanitárias, telefone e etc.)? Quais seriam?

e) Quais as particularidades de um projeto arquitetônico concebido para uma estrutura pré-moldada? O que se procura para tornar o projeto mais racional?

f) Quais os pedidos mais freqüentes dos fabricantes? dos engenheiros de estruturas? dos engenheiros de instalação?

g) Quais as vantagens que o projeto arquitetônico tenta tirar do sistema?

h) Quais as limitações que o sistema impõe ao projeto arquitetônico?

i) Seria possível fazer um quadro resumo dos edifícios projetados pelo seu escritório?

j) Poderia fornecer as plantas baixas de algumas obras que julgue mais relevantes e preencher o formulário fichamento arquitetura?

k) Após a entrega da obra qual a receptividade dos usuários em relação à edificação, quais as críticas e elogios?

\section{Questionário distribuído para os projetistas de estrutura}

a) Quais os sistemas estruturais utilizados? Geometria das seções (lajes, vigas e pilares), nível de pré-moldagem (utilização de concreto moldado no local), ligações utilizadas?

b) Qual a seqüência de construção destes sistemas?

c) Qual a resistência do concreto, pré-moldado e moldado no local?

d) Quando se utiliza uma capa de concreto moldado no local: Como é feita a verificação das seções compostas no estado limite último? Como é dimensionado o capeamento para garantir o efeito do diafragma rígido? 
e) Qual a seqüência de desenvolvimento de um projeto estrutural para edifícios pré-moldados?

f) Como estes sistemas têm acomodado as instalações (embutidas ou independentes)?

g) Quais as restrições impostas pela arquitetura em função do tipo de edificação?

h) O que se procura fazer para tornar o projeto estrutural mais racional? Quais os pedidos mais freqüentes dos fabricantes? arquitetos? Instaladores?

i) Quais os impactos que a produção, armazenamento, transporte e montagem têm no projeto estrutural?

j) Seria possível fazer um quadro resumo dos edifícios projetados pelo seu escritório?

k) Poderia fornecer as plantas de forma de algumas obras que julgue mais relevantes?

1) Quais as condições ideais para o desenvolvimento de um projeto racional?

m) Na sua avaliação qual é a tendência da pré-fabricação para os edifícios de múltiplos pavimentos?

\section{Questionário distribuído para os fabricantes}

a) Qual percentual de obras em que o projeto não foi originalmente concebido para estruturas pré-moldadas e sim adaptado?

b) Na sua avaliação quais os maiores empecilhos para o desenvolvimento e/ou expansão do setor no ramo das edificações?

c) Na sua avaliação qual é a tendência da pré-fabricação para os edifícios de múltiplos pavimentos?

d) Quais as características que um projeto arquitetônico, estrutural e de instalação devem ter para que o sistema pré-moldado atinja sua maior eficiência?

e) Na sua opinião o que poderia ser melhorado na relação entre projeto, indústria e obra?

f) Como conduz a compatibilização e a coordenação dos projetos (arquitetura, cálculo estrutural e instalação) juntamente com o proprietário da obra?

g) Utiliza algum software de otimização para alocação de equipamentos e funcionários, produção, transporte e montagem das peças? 
h) Quais os tipos de prédios (residenciais, comerciais, hospitais, hotéis, faculdades e etc.) que mais se adaptam as estruturas pré-moldadas?

i) Quais os sistemas estruturais utilizados? Geometria das seções (lajes, vigas e pilares), nível de pré-moldagem (utilização de concreto moldado no local), ligações utilizadas?

j) Qual a seqüência de construção destes sistemas?

k) Fazer uma breve descrição dos equipamentos disponíveis em seu parque industrial:

n) Seria possível fazer um quadro resumo dos edifícios fabricados? 


\section{APÊNDICE B}

Otimização viga "T" invertida

(Método do gradiente reduzido generalizado) 


\section{AP-B-1. INTRODUÇÃO}

Com o objetivo de verificar algumas características citadas como desvantagens da otimização convencional, por CASTILHO (2003) $)^{2}$, desenvolveu-se uma rotina de otimização, por técnica convencional, para uma viga de seção "T" invertida que sirva de apoio para lajes. Utilizou-se o método do gradiente reduzido generalizado disponível na planilha EXCELL, por ser de fácil implementação. Esse método foi desenvolvido por Leon Lasdon (Universidade do Texas, Austin) e por Allan Waren (Universidade de Cleveland).

\section{AP-B-2. OTIMIZAÇÃO}

Os métodos de otimização têm como objetivo tornar qualquer atividade mais eficiente através de métodos científicos, por isso a indústria tradicional foi pioneira na utilização dessas ferramentas matemáticas. Na indústria da construção civil os pré-moldados têm uma fácil adaptação devido à forma de produção e às tipologias estruturais.

Para que o processo de otimização tenha resultados efetivos é necessária uma grande quantidade de informações por parte de todos os envolvidos e também garantir que a busca pelo custo mínimo não diminua a qualidade do produto.

Diante disso a função custo (função objetivo) deve ser a mais representativa possível e levar em consideração todas as variáveis envolvidas. Deve-se considerar além do consumo de materiais todas as etapas de produção, transporte e montagem. Utilizou-se a função custo ${ }^{3}$ apresentada em CASTILHO (2003) com o acréscimo da armadura passiva. Custos considerados:

- Custo pré-moldado (material, mão de obra e equipamento);

- Custo protensão (material, mão de obra e equipamento);

\footnotetext{
${ }^{2}$ Referência no texto principal

${ }^{3}$ Utilizou-se a função de CASTILHO (2003) pois esse exemplo foi realizado no início da pesquisa e ainda não se tinha a função do SATD
} 
- Custo armaduras passivas;

- Custo adicional;

- Custo indireto administrativo;

- Custo tributário;

- Custo transporte externo;

- Custo montagem;

- Custo indireto administrativo;

- Custo capa de concreto.

\section{AP-B-3. VIGA “T” INVERTIDA}

Considerou-se que a viga receberia uma laje alveolar de $20 \mathrm{~cm}$ de altura (figura AP-B-1), por isso adotou-se que a viga teria abas de $10 \mathrm{~cm}$ de largura (recomendável para apoiar laje de $20 \mathrm{~cm}$ de altura) e teria uma altura acima das abas de $20 \mathrm{~cm}$ (para ficar nivelada com o topo da laje). A viga "T" invertida é uma das seções mais utilizadas para apoio de lajes alveolares e considerouse a existência de um capeamento de $5 \mathrm{~cm}$.

Para essa consideração foram analisadas situações transitórias onde o capeamento entra nas solicitações, mas não acrescenta capacidade resistente (fase em que o concreto está amadurecendo), e em uma situação definitiva onde o capeamento está solidarizado à seção e amplia a capacidade resistente da peça.
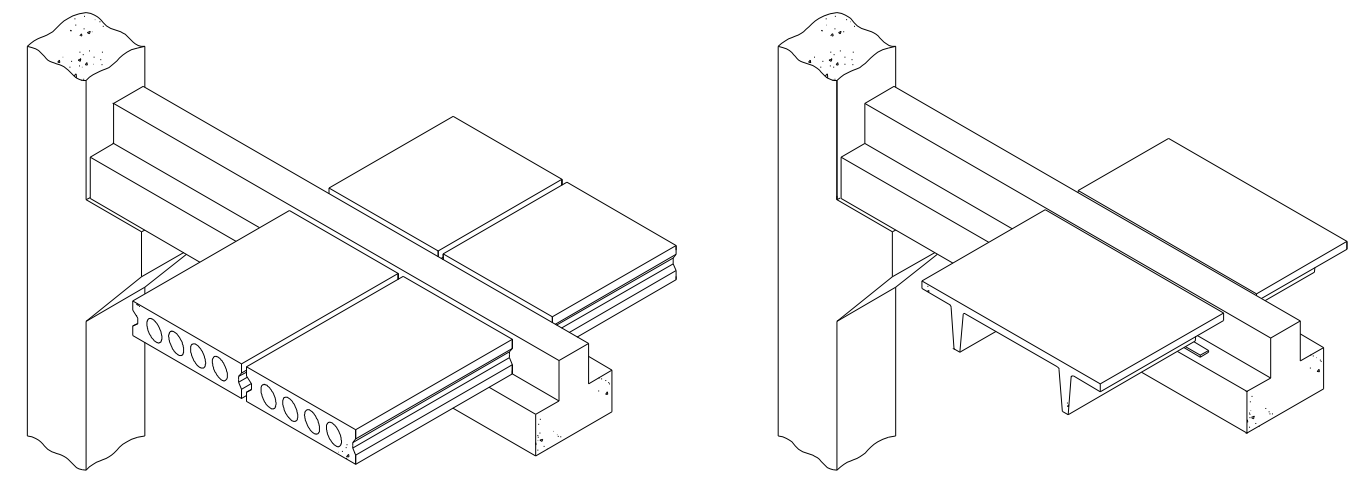

Figura AP-B-1 - Viga "T" invertida 
Adotou-se como variáveis de projeto:

- X1: altura da base;

- X2: largura alma;

- X3: Área de protensão;

- X4: Área de armadura passiva;

- X5: $f_{c k}$ do concreto pré-moldado;

- X6: $f_{c k}$ da capa de concreto;

- X7: $\beta_{\mathrm{x}}$;

- X8: Armadura de cisalhamento.

Adotou-se como dados de entrada:

- $g_{2}, g_{3}, q$ : carregamentos da laje;

- a: vão da viga;

- h: altura máxima;

- b: largura máxima;

- c: cobrimento.

Os carregamentos são separados devido às verificações transitórias e os valores de altura e largura máximas serão restrições do problema.

\section{AP-B-4. PROBLEMAS ENCONTRADOS NO DESENVOLVIMENTO}

Alguns problemas foram encontrados no desenvolvimento da rotina e serão apresentados abaixo:

a) Havia uma restrição de armadura mínima de protensão muito alta que estava indicando uma geometria distorcida que priorizava largura, isso foi corrigido diminuindo esta restrição e os resultados ficaram mais coerentes;

b) O solver não encontrava solução para muitos exemplos e a restrição violada era sempre a tensão de tração no transporte, por isso colocou-se 
uma armadura passiva para controlar a fissuração nesta fase. Sabe-se que após a concretagem da capa essas fissuras são fechadas. Para ilustrar melhor serão apresentados resultados (tabela 1) de um mesmo exemplo para o caso em que se limitava a tensão de tração a $1,5 \mathrm{f}_{\mathrm{ct}} \mathrm{e}$ para o caso em que se limita a tensão de tração a $3 \mathrm{f}_{\mathrm{ct}}$, observou-se uma economia de 40 \% com esta alteração para o exemplo abaixo:

Tabela AP-B-1 - Diferença entre custos para novo limite de tensão de tração no concreto

\begin{tabular}{lll}
\hline Variável & $\mathbf{1 , 5} \mathbf{f c t}$ & $\mathbf{3}$ fct \\
\hline $\mathrm{X} 1$ & 0,65 & 0,65 \\
$\mathrm{X} 2$ & 0,38 & 0,15 \\
$\mathrm{X} 3$ & 0,00071 & 0,0006 \\
$\mathrm{R} \$$ & 807,00 & 482,00 \\
& & $\Delta=-\mathbf{4 0 \%}$ \\
\hline
\end{tabular}

c) Para a consideração do modelo de cálculo de cisalhamento, fizeram-se vários testes considerando os modelos de cálculo I e II da NBR 6118 (2003) e constatou-se que para vigas usuais de edifício a economia proporcionada, com o modelo II, não é significativa.

\section{AP-B-5. EXEMPLOS}

Várias simulações foram feitas e alguns exemplos serão apresentados:

- Exemplo 1: analisou-se a sensibilidade do algoritmo em relação ao ponto de partida, no caso particular, o $f_{c k}$ refletiu a maior diferença nos resultados, ou seja de acordo com o valor inicial da célula correspondente ao $f_{c k}$ havia diferença nos resultados;

- Exemplo 2: Otimizaram-se 4 seções pela rotina geral, com os dados obtidos (geometria e resistência) e depois otimizou-se a armadura de cisalhamento na rotina específica de cisalhamento. 


\subsection{Exemplo 1}

Repetiu-se, várias vezes, um mesmo exemplo alterando apenas o valor do $f_{c k}$ inicial e a convergência da função custo apresentou diferenças entre os processamentos, que serão apresentadas na tabela 2.

Tabela AP-B-2 - Diferenças máximas encontradas no custo

\begin{tabular}{ccccc}
\hline $\mathrm{h}_{\text {máx }}(\mathrm{m})$ & $\mathrm{b}_{\text {máx }}(\mathrm{m})$ & $\mathrm{R} \$$ máx & $\mathrm{R} \$$ min & $\Delta(-\%)$ \\
\hline 0,65 & 0,60 & 567 & 543 & 4,2 \\
0,75 & 0,60 & 525 & 479 & 8,7 \\
0,80 & 0,60 & 628 & 568 & 9,6 \\
0,85 & 0,60 & 501 & 449 & 10,3 \\
1,00 & 0,60 & 490 & 414 & 15,5 \\
0,60 & 1,00 & 680 & 664 & 2,3 \\
\hline
\end{tabular}

Observou-se que surgiram variações elevadas, sendo a maior diferença encontrada de $15,5 \%$.

\subsection{Exemplo 2}

A partir de 4 seções já otimizadas em relação à flexão, fez-se uma rotina de otimização da armadura de cisalhamento, utilizando os dois modelos permitidos pela NBR-6118 (2003), modelo I e modelo II (Tabela 3).

Tabela AP-B-3 - Otimização armadura de cisalhamento

$\begin{array}{lcccc}\text { Vão }(\mathrm{m}) & 6 & 7 & 8 & 9 \\ \mathrm{~h}(\mathrm{~cm}) & 75 & 75 & 75 & 75 \\ \mathrm{~b}_{\mathrm{w}}(\mathrm{cm}) & 20 & 22 & 30 & 39 \\ \mathrm{~A}_{\mathrm{sl}}(\mathrm{cm} 2 / \mathrm{m}) & 3,26 & 3,96 & 4,89 & 6,34 \\ \mathrm{~A}_{\text {sII }}(\mathrm{cm} 2 / \mathrm{m}) & 3,26 & 3,53 & 4,89 & 6,34\end{array}$

As vigas pré-fabricadas, na maioria das vezes, sempre atuam carregamentos distribuídos e nesses casos o dimensionamento é geralmente 
comandado pelo momento fletor, já que não existem grandes forças cortantes e as seções são geralmente largas. Diante disso observa-se que na tabela 3 quase todas as armaduras de cisalhamento são mínimas.

\section{AP-B-6. CONCLUSÕES}

Baseado nos resultados obtidos algumas conclusões serão apresentadas abaixo:

a) Em todos os casos a etapa transitória de transporte atingiu o limite (restrição ativa) e para tentar melhorar o resultado será feita uma implementação de protensão em níveis diferentes para se observar à variação das soluções;

b) Conforme citado em CASTILHO (2003), os métodos de otimização convencionais apresentam sensibilidade aos valores iniciais das variáveis de projeto (exemplo 1). Pode-se, ainda, citar que esses métodos não trabalham bem quando se misturam variáveis contínuas e discretas ou ainda quando as variáveis têm ordens de grandeza muito diferentes;

c) Nas situações usuais o momento fletor comanda o dimensionamento da geometria, que geralmente conduz a resultados de armadura mínima para o cisalhamento. 


\section{APÊNDICE C}

Rotina para dimensionamento viga "T" invertida 


\section{AP-C-1. INTRODUÇÃO}

O SATD adota para a otimização a viga central que recebe lajes pelos dois lados e considera, para efeito de cálculo, que a mesma está bi-apoiada para o carregamento aplicado antes da solidarização da capa e considera uma continuidade para todo carregamento aplicado após a capa. Para uma consideração simplificada da continuidade utilizou-se a indicação 8.3 do ACl318 (1995) que recomenda $M_{\text {Positivo }}=\frac{q \cdot \ell^{2}}{16}$ e $M_{\text {Negativo }}=\frac{q \ell^{2}}{10}$. Essa recomendação se aplica para vãos aproximadamente iguais, com cargas distribuídas e onde a carga acidental não exceda em três vezes a carga permanente. Observa-se que essa mesma recomendação foi utilizada no desenvolvimento do Midwest Office System.

Algumas diferenças de detalhamento das vigas, entre o SATD e os projetos, podem ser justificadas pelo fato de nos projetos da HEPTA se utilizar para a continuidade das vigas valores de momento até $M_{\text {Positivo }}=\frac{q \cdot \ell^{2}}{24} \mathrm{e}$ $M_{\text {Negativo }}=\frac{q \ell^{2}}{12}$. Observa-se que $\circ$ momento positivo, para $\circ$ carregamento atuante após a solidarização, nos projetos, chega a ser da ordem de 2/3 do utilizado pelo SATD.

\section{AP-C-2. Características geométricas da seção isolada (pré-moldada)}

Momento de Inércia da seção pré-moldada:

$$
I_{v}=I+A \cdot y_{g v}{ }^{2}
$$

Cálculo do momento estático e da linha neutra: 


$$
\begin{aligned}
& A_{v}=\left[\left(b_{w}(V V)+0,3\right) \cdot h_{v}(V V)\right]+\left[\left(h_{l}(V L)-0,05\right) \cdot b_{w}(V V)\right] \\
& p p_{v}=A_{v} \cdot \rho_{c} \\
& m e=\left[\frac{\left(b_{w}(V V)+0,3\right) \cdot h_{v}(V V)^{2}}{2}\right]+\left[b_{w}(V V) \cdot\left(h_{l}(V L)-0,05\right) \cdot\left(h_{v}(V V)+\frac{\left(h_{l}(V L)-0,05\right)}{2}\right)\right] \\
& y_{g v}=\frac{m e}{A_{v}} \\
& I_{v}=\left[\frac{\left(b_{w}(V V)+0,3\right) \times h_{v}(V V)^{3}}{12}\right]+\left[\left(b_{w}(V V)+0,3\right) \times h_{v}(V V) \times\left(\frac{h_{v}(V V)}{2}-y_{g v}\right)^{2}\right]+ \\
& \frac{b_{w}(V V) \times\left(h_{l}(V L)-0,05\right)^{3}}{12}+b_{w}(V V) \times\left(h_{l}(V L)-0,05\right) \times\left(h_{v}(V V)+\left(\frac{\left(h_{l}(V L)-0,05\right)}{2}-y_{g v}\right)\right)^{2}
\end{aligned}
$$

\section{AP-C-3. Características geométricas Seção Composta (pré-moldado} solidarizado com o capeamento)

Momento de Inércia de uma seção composta em relação ao centro de gravidade:

Cálculo da linha neutra:

$$
\begin{aligned}
& A_{v c}=A_{v}+b_{w}(V V) \cdot 0,10 \\
& p p_{v c}=A_{v c} \cdot \rho_{c} \\
& m e c=\left[\frac{\left(b_{w}(V V)+0,3\right) \cdot h_{v}(V V)^{2}}{2}\right]+\left[b_{w}(V V) \cdot\left(h_{l}(V L)-0,05\right) \cdot\left(h_{v}(V V)+\frac{\left(h_{l}(V L)-0,05\right)}{2}\right)\right]+
\end{aligned}
$$


$b_{w}(V V) \cdot 0,10 \cdot\left(h_{v}(V V)+h_{l}(V L)+0,05\right)$

$y_{g v c}=\frac{m e c}{A_{v c}}$

$I_{v c}=\left[\frac{\left(b_{w}(V V)+0,3\right) \cdot h_{v}(V V)^{3}}{12}\right]+\left[\left(b_{w}(V V)+0,3\right) \cdot h_{v}(V V) \cdot\left(\frac{h_{v}(V V)}{2}-y_{g v c}\right)^{2}\right]+$

$\left[\frac{b_{w}(V V) \cdot\left(h_{l}(V L)-0,05\right)^{3}}{12}+b_{w}(V V) \cdot\left(h_{l}(V L)-0,05\right) \cdot\left(h_{v}(V V)+\frac{\left(h_{l}(V L)-0,05\right)}{2}-y_{g v c}\right)^{2}\right]+$

$\left[\frac{b_{w}(V V) \cdot 0,10^{3}}{12}+b_{w}(V V) \cdot 0,10 \cdot\left(h_{v}(V V)+h_{l}(V L)+0,05-y_{g v c}\right)^{2}\right]$

AP-C-4. Excentricidade das camadas A e B em relação ao centro de gravidade da viga pré-moldada:

$e_{p a}=y_{g v}-0,05$

$e_{p b}=y_{g v}-0,10$

\section{AP-C-5. Módulos Resistentes}

Cálculo da seção isolada

$W_{v i}=\frac{I_{v}}{y_{g v}}$

$W_{v s}=\frac{I_{v}}{y_{g v}-\left(h_{v}(V V)+h_{l}(V L)-0,05\right)}$

Cálculo da seção composta

$W_{c v i}=\frac{I_{v c}}{y_{g c v}}$

$W_{c v s}=\frac{I_{v c}}{y_{g c v}-\left(h_{v}(V V)+h_{l}(V L)-0,05\right)}$ 


\section{AP-C-6. Momentos atuantes e tensões devidas ao carregamento nas fases transitórias e em serviço}

Os carregamentos atuantes considerados são:

(1) Peso próprio da laje que se apóia sobre a viga;

(2) Peso próprio do capeamento é considerado apenas como um carregamento extra, na fase transitória;

(3) Pavimentação + Revestimento;

(4) Paredes sobre a laje;

(5) Carga Acidental;

(6) Carga de trabalho sobre a laje (equipamentos e operários na fase de construção);

(7) Peso próprio da viga Isolada;

(8) Peso próprio da viga seção composta;

Faz-se a verificação transitória devido à fase de montagem, quando as lajes já estão apoiadas sobre as vigas e se concreta a capa, além dessas cargas se tem o peso próprio da viga. Para as verificações de desmoldagem e transporte só serão consideradas as tensões devido ao peso próprio da viga. Para o transporte o peso próprio da viga é multiplicado por 0,8 e 1,2 (duas verificações distintas) para considerar o efeito dinâmico:

$$
\begin{aligned}
& M_{v t}=\frac{((R L(1)+R L(2)) \cdot 2+P P V) \cdot \ell_{v i g a}{ }^{2}}{8} \\
& \sigma_{v i}=\frac{M_{v t}}{W_{v i}} \\
& \sigma_{v s}=\frac{M_{v t}}{W_{v s}} \\
& M_{v p p}=\frac{p p_{v} \cdot \ell_{v i g a}^{2}}{8}
\end{aligned}
$$




$$
\begin{gathered}
\sigma_{v p p i}=\frac{M_{v p p}}{W_{v i}} \\
\sigma_{v p p s}=\frac{M_{v p p}}{W_{v s}}
\end{gathered}
$$

Calculam-se os momentos durante a vida útil da estrutura, que produzem tensões utilizadas para as verificações do estado limite de serviço (ELS). Adotou-se uma protensão limitada, logo se verificou a descompressão para uma combinação quase permanente de ações $\left(\Psi_{2}=0,3\right.$ para as cargas acidentais) e se verificou a formação de fissura para uma combinação freqüente ( $\psi_{1}=0,4$ para as cargas acidentais principais). Estes valores estão de acordo com a NBR-6118 (2003).

$$
\begin{aligned}
& M_{v g}=\frac{\left(((R L(3)+R L(4)) \cdot 2) \cdot \ell_{v i g a}^{2}\right.}{8} \\
& M_{v q}=\frac{R L(5) \cdot 2 \cdot \ell_{v i g a}^{2}}{8} \\
& \sigma_{v g i}=\frac{M_{v g}}{W_{c v i}} \\
& \sigma_{v q}=\frac{M_{v q}}{W_{c v i}}
\end{aligned}
$$

Observou-se que muitas vezes a fase crítica na verificação eram as verificações transitórias, principalmente a fase de transporte quando o peso próprio é minorado por $y=0,8$. Nessa situação muitas vezes o limite admissível de tração era ultrapassado. Diante disso adotou-se uma protensão na zona superior $\left(\mathrm{N}_{\mathrm{C}}\right)$ da viga pré-moldada (figura 4.3), que já serve de porta estribo. Para a indústria de pré-moldados, a utilização de cabos de protensão como porta estribos é bastante comum, pois embora sejam mais caros que a armadura passiva dispensam a mão de obra de corte e montagem. 
Lembra-se que as tensões provocadas pelas cargas acidentais e pelas cargas permanentes após a execução do capeamento, tais como pavimentação, revestimento e divisórias, são calculadas em relação à seção composta enquanto as demais são calculadas em relação apenas à seção prémoldada.

$\sigma_{v i}+\sigma_{v p p i}+\sigma_{v g i}+0,3 \cdot \sigma_{v q}+\sigma_{T I N P I} \leq 0 \rightarrow$ Descompressão

$\sigma_{v i}+\sigma_{v p p i}+\sigma_{v g i}+0,4 \cdot \sigma_{v q}+\sigma_{\text {TINPI }} \leq 1,5 \cdot f_{\text {ctkinf erior }} \rightarrow$ Formação_Fissura

Segundo a NBR-6118 (2003) as tensões limites para a compressão e tração do concreto são:

$f_{c} \leq 0,7 \cdot f_{c k P M}$

$f_{c t} \leq 1,5 \cdot 0,7 \cdot 0,3 \cdot f_{c k P M}^{2 / 3} \rightarrow$ seção_retan gular

Para as verificações transitórias adotou-se um $\mathrm{f}_{\mathrm{ckj}}$ da ordem de $70 \%$ do $\mathrm{f}_{\text {ckPM}}$. Como a seção não é uma seção "T" o valor do limite para a formação de fissura deve ser multiplicado por 1,5 e não por 1,2.

Para o cálculo do valor do momento solicitante de cálculo, considerou-se a contribuição da laje sobre a viga multiplicada por dois para contemplar a existência das lajes nos dois lados das vigas. Os carregamentos relativos a peso próprio dos elementos pré-moldados são majorados por $\mu=1,3$, conforme permitido pela norma NBR-6118 (2203) :

$M_{V D}=\left(\frac{(1,3 R L(1)+1,4 R L(2)+1,4 R L(3)+1,4 R L(4)+1,4 R L(5)) \cdot 2+1,3 P P V}{8}\right) \cdot \ell_{v i g a}{ }^{2}$

\section{AP-C-7. Protensão em vigas (CP-190 RB)}

Resistência do aço:

$f_{p t k}=1900 M P a$

$f_{p y k}=1710 \mathrm{MPa}$ 
$E_{p}=195000 \mathrm{MPa}$

$\sigma_{P i} \leq\left\{\begin{array}{l}0,77 f_{p t k}=1463 M P a \\ 0,85 f_{p y k}=1453 M P a\end{array} \rightarrow \sigma_{P i}=1453 M P a\right.$

Tensão de protensão:

$\sigma_{p i}=1453 M P a$

$\phi 12.7 \mathrm{~mm} \rightarrow A_{\phi}=101,4 \cdot 10^{-6} \mathrm{~m}^{2}$

Força inicial de protensão considerando-se uma perda inicial de 3\%:

$P_{a v}=0,97 \cdot\left(n_{A}+n_{B}\right) \cdot A_{\phi} \cdot \sigma_{P i}$

Cálculo de $P_{0}$ após a transferência:

$\sigma_{P 0}=\sigma_{P a}+\frac{E_{P}}{E_{C}} \sigma_{C P}$

$\frac{E_{P}}{E_{C}}=\frac{195000}{0,85 \cdot 5600 \cdot \sqrt{f_{c k P M}(P M)}}=\frac{40,9664}{\sqrt{f_{c k P M}(P M)}}$

$S O M A=\left(n_{A} \cdot e_{p a}+n_{B} \cdot e_{p b}\right) \cdot 0,142914$

SOMA2 $=\left(n_{A} \cdot e_{p a}{ }^{2}+n_{B} \cdot e_{p b}{ }^{2}\right) \cdot 0,142914$

$\sigma_{P o}=S P T V=\left[\frac{P_{a v}}{A V}+\frac{S O M A}{W V I}\right]-\left(\frac{40,966}{\sqrt{f_{c k P M}(P M)}}\right) \cdot\left[\frac{P_{a v}}{A_{v}}+\frac{S O M A 2}{I V}\right]$

$P_{0}=P_{a t}=P_{a v}-\left(n_{A}+n_{B}\right) \cdot A_{\phi} \cdot S P T V$

Tensões na seção pré-moldada após a transferência da protensão: 


$$
\begin{aligned}
& S O M A 3=P_{a t}\left(\frac{n_{A}}{n_{A}+n_{B}} \cdot e_{p a}+\frac{n_{B}}{n_{A}+n_{B}} \cdot e_{p b}\right) \\
& \sigma_{a t}^{\text {inf erior }}=\frac{P_{a t}}{A_{v}}+\frac{S O M A 3}{W_{v i}} \\
& \sigma_{a t}^{\text {sup erior }}=\frac{P_{a t}}{A_{v}}+\frac{S O M A 3}{W_{v s}}
\end{aligned}
$$

Estimativa da força de protensão em um tempo infinito, e as tensões na seção pré-moldada em um tempo infinito. Admitindo-se, simplificadamente, uma perda de protensão de $20 \%$ :

$$
\begin{aligned}
& P_{\infty}=0,8 \cdot P_{a v} \\
& \sigma_{\infty}^{\text {inf erior }}=\frac{P_{\infty}}{A_{v}}+\frac{0,8 \cdot S O M A}{W_{v i}} \\
& \sigma_{\infty}^{\text {sup erior }}=\frac{P_{\infty}}{A_{v}}+\frac{0,8 \cdot S O M A}{W_{v s}}
\end{aligned}
$$

\section{AP-C-8. Verificações das tensões atuantes nas fases transitórias}

Desmoldagem:

$\sigma_{\text {desmoldagem }}^{\text {inf erior } \text { sup erior }}=\sigma_{\infty}^{\text {inf erior }, \text { sup erior }}+\sigma_{p p}^{\text {inf erior } \text {, sup erior }}$

Transporte $\beta=0,8$ e $\beta=1,3$ :

$\sigma_{\text {transporte }}^{\text {inf erior } \text { sup erior }}=\sigma_{\infty}^{\inf \text { erior, sup erior }}+0,8 \cdot \sigma_{p p}^{\text {inf erior }, \text { sup erior }}$

$\sigma_{\text {transporte }}^{\inf \text { erior } \text { sup erior }}=\sigma_{\infty}^{\inf \text { erior, sup erior }}+1,3 \cdot \sigma_{p p}^{\text {inf erior } \text {, sup erior }}$

Montagem:

$\sigma_{\text {montagem }}^{\text {inf erior } \text { sup erior }}=\sigma_{\infty}^{\text {inf erior }, \text { sup erior }}+\sigma_{v}^{\text {inf erior }, \text { sup erior }}$ 


\section{AP-C-9. Estado Limite Último (Solicitações Normais)}

Cálculo da altura total do pavimento, já considerando o capeamento, e dos braços de alavanca dos dois níveis de camadas de protensão A e B:

$h_{T}=h_{V}(V V)+h_{L}(V L)+0,05$

$d_{A}=h_{T}-0,05$

$d_{b}=h_{T}-0,10$

Admite-se a seção trabalhando no domínio 3, logo:

$0,259 \leq \frac{x}{d} \leq 0,625$

$\beta_{\text {xmax }}=0,6 \rightarrow \varepsilon_{s} \min =0,0023$

$f_{y}=210000 \cdot 0,0023=483 \mathrm{MPa}$

$f_{y}=f_{y d}=434,8 M P a$

Adotando um $\beta_{x}$ no máximo de 0,6 a armadura passiva vai sempre está trabalhando com a tensão máxima, $\mathrm{f}_{\mathrm{yd}}$. Da mesma forma o aço de protensão vai sempre trabalhar com uma tensão máxima $\left(f_{\text {pyd }}\right)$ :

$$
\begin{aligned}
& \frac{F_{P \infty}}{A_{P}}=0,8 \cdot \frac{F_{P i}}{A_{P}}=0,8 \cdot \sigma_{P i} \\
& \varepsilon_{p r e}=0,9 \frac{F_{P \infty}}{E_{P} \cdot A_{P}}=0,9 \cdot \frac{0,8}{195000} \cdot 1453=0,0054
\end{aligned}
$$

$\Delta \varepsilon=\varepsilon_{p r e}+\varepsilon_{s}=0,0077$

$f_{P y}=195000 \cdot 0,0077=1501 \mathrm{MPa}$

$$
f_{P y}=f_{P y d}=0,9 \cdot \frac{f_{p t k}}{1,15}=1486,9 M P a
$$


Adotando-se como valores para os módulos de elasticidade:

$E_{p}=195000 \mathrm{MPa}$

$E_{s}=210000 \mathrm{MPa}$

Com os valores das tensões nos aços de protensão e passivo se tem as componentes de tração e com isso calcula-se a posição da linha neutra, a partir da igualdade dos esforços de tração e compressão na seção. Por último calcula-se o momento resistente da seção:

$$
\begin{aligned}
& x_{V}=\left(\frac{1486,9 \cdot\left(A_{P A}+A_{P B}\right)+434,8 \cdot A s}{0,4857 \cdot f_{c k P M} \cdot b_{v}}\right) \\
& Z A=h_{T}-0,05-0,4 \cdot x_{V} \\
& Z B=Z A-0,05 \\
& M_{\text {resviga }}=1486,9 \cdot\left(A_{P A} \cdot Z A+A_{P B} \cdot Z B\right) \\
& M_{\text {resviga }} \geq M d
\end{aligned}
$$

\section{AP-C-10. Estimativa da flecha}

Para a estimativa da flecha adotou-se uma simplificação do $\mathrm{ACl}$ para considerar a deformação total no tempo infinito como um produto da deformação inicial do carregamento e da contra flecha da protensão pelos majoradores 2,5 e 2,2 respectivamente.

$$
\begin{aligned}
& c f=\frac{P_{i} \cdot e \cdot \ell}{8 \cdot E \cdot I} \rightarrow c f_{\infty}=c f \cdot 2,2 \\
& f=\frac{3 \cdot w \cdot \ell^{4}}{384 \cdot E \cdot I} \rightarrow f_{\infty}=f \cdot 2,5 \\
& f_{\text {Total }}=f+c f
\end{aligned}
$$


Como as vigas vão ter uma continuidade parcial através de armaduras posicionadas no capeamento considerou-se para o cálculo das flechas uma situação intermediária entre simplesmente apoiadas e engastadas. Por isso a equação do cálculo da flecha apresenta o multiplicador 3, que é uma média entre as equações da flecha para vigas bi-apoiadas e bi-engastadas.

Adotou-se como limite a verificação visual, que considera que quando atuando todo o carregamento a flecha não pode ser superior à relação l/250. 
APÊNDICE D

Lajes Alveolares 


\section{AP-D-1. INTRODUÇÃO}

A Laje alveolar é Original da Alemanha e segundo EL DEBS (2000) os painéis alveolares são os elementos pré-moldados mais populares empregados no mundo, em especial na América do Norte e Europa Ocidental. As lajes alveolares são utilizadas em $60 \%$ das obras na Escandinávia e em $39 \%$ das obras na Bélgica e Holanda. Segundo o PCl (1998) são os elementos mais utilizados, por serem econômicos e eficientes. A economia vem da quantidade de lajes que podem ser produzidas em um determinado período com um mínimo trabalho requerido. Para simplificar e aumentar a produtividade se recomenda o máximo de repetição possível, de vãos e de número de fios de protensão.

Segundo o engenheiro Mark Lafferty ${ }^{4}$, as lajes alveolares são os elementos mais utilizados para hospitais, hotéis, edifícios residenciais e comerciais, quando é adotada uma solução pré-fabricada.

\section{AP-D-2. FUNÇÃO}

A função das lajes alveolares é receber as cargas verticais e transmitilas aos apoios (vigas ou painéis) e desempenhar o papel de diafragma rígido (distribuição das cargas horizontais). As unidades são montadas juntas e conectadas para formar o pavimento.

O efeito diafragma trata da transferência de forças horizontais, que atuam na edificação, para os elementos de contraventamento, que é feita através das lajes mediante esforços no plano do pavimento, com um comportamento de chapa. O efeito do diafragma é obtido através de um capeamento ou de ligações apropriadas entre as lajes, entre as lajes e vigas e entre as lajes e os painéis. Segundo o $\mathrm{PCl}$ (1998), para uma capa de $5 \mathrm{~cm}$ de concreto pode-se desprezar a participação das lajes alveolares e deixar todo o efeito diafragma para o capeamento, caso a sua resistência e rigidez sejam suficientes.

\footnotetext{
${ }^{4}$ Visita à Concrete Industries em maio de 2006 (Lincoln, Nebraska, USA)
} 
Segundo indicações da FIP, pesquisas recentes têm mostrado que determinadas ligações sem a capa entre as unidades de lajes alveolares são suficientemente monolíticas para a distribuição das cargas verticais e horizontais.

Salienta ainda o PCl (1998), a excelente resistência ao fogo da laje alveolar e sua característica como isolante acústico.

\section{AP-D-3. OUTROS DADOS RELEVANTES}

A faixa de vãos que esses elementos são usados vai de $5 \mathrm{~m}$ a $15 \mathrm{~m}$, e as alturas variam, em média, de $10 \mathrm{~cm}$ a $30 \mathrm{~cm}$. O PCl (1998) recomenda que se adote uma relação de vão / altura do pavimento de 40 para pisos, embora comente que na prática tem-se adotado 45 . Este valor de 45 foi implementado no sistema como uma restrição de limite máximo da relação vão / altura do pavimento, inclusive.

São apontadas como vantagens deste elemento: a dispensa de escoramento e formas, economia de tempo, mão-de-obra e material. As lajes alveolares são compatíveis com estruturas convencionais de concreto, metálicas, pré-moldadas e alvenaria. Devido aos alvéolos permitem redução de peso e economia nas fundações.

No sistema em questão adotou-se que a zona de compressão das lajes alveolares estaria acima dos furos, de forma que estaria sempre trabalhando como uma seção maciça.

Outras particularidades das lajes alveolares:

a) Armadura constituída apenas de armadura ativa na parte inferior e às vezes na mesa superior também, quando são concebidas para absorverem momentos negativos ou por questões executivas;

b) Não utilizam armaduras transversais de forma que o concreto resiste às tensões de tração;

c) Colocação de armaduras adicionais é praticamente inviável devido ao processo de execução. 


\section{AP-D-4. DESCRIÇÃO DO PROCESSO DE FABRICAÇÃO E MONTAGEM}

O produto é totalmente industrializado e envolve um baixo número de horas / homem na sua produção. Por isso as intervenções manuais devem ser evitadas ao máximo (recorte ou reforço) para que seu custo continue sendo prioritariamente devido ao processo mecanizado.

\section{$\underline{4.1 \text { Sistema de protensão }}$}

Pré-tração com aderência inicial (figura AP-D-1).

\subsection{Pista de fabricação e formas}

As pistas têm em geral entre $100 \mathrm{~m}$ e $200 \mathrm{~m}$ com fundo metálico (figura AP-D-2). As lajes são produzidas utilizando todo o comprimento e, posteriormente, são cortadas no comprimento desejado. Geralmente são produzidas por extrusão ou formas deslizantes.

\subsection{Posicionamento da armadura e pré-tração}

Apenas armadura ativa (pré-tracionada) na zona inferior.

\subsection{Lançamento e adensamento do concreto}

Concreto lançado pela moldadora e admiti-se adensado pelo movimento das palhetas (figura AP-D-3).

\section{$\underline{4.5 \text { Cura do concreto }}$}

Cura a vapor (figura AP-D-5). A Concrete Industries, em Lincoln, Nebraska, USA, utiliza um sistema de aquecimento em que tubulações correm por baixo das pistas mantendo a temperatura controlada (figura AP-D-18). 


\subsection{Transporte interno à fábrica}

Através de pórticos rolantes (figura AP-D-7 e 9), as lajes são içadas através de braçadeiras com vigas metálicas. Desta forma não é necessário a colocação de insertos metálicos para o içamento, e são levantas pelas extremidades de forma que produzem apenas momentos positivos.

\section{$\underline{4.7 \text { Estocagem }}$}

As lajes são posicionadas em dois pontos de apoio simulando a situação após a montagem. Podem ser empilhadas (figura AP-D-10).

\section{$\underline{4.8 \text { Transporte externo à fábrica }}$}

Através de grua (figura AP-D-9), as lajes são içadas através de braçadeiras com vigas metálicas (transporte vertical). No trajeto rodoviário uma série de solicitações são introduzidas como o efeito dinâmico e torção na peça devido aos buracos nas estradas (transporte horizontal).

\subsection{Montagem e fixação dos elementos}

As lajes se apóiam diretamente sobre as vigas ou sobre consolos, nas vigas elas podem ser colocadas sobre a parte superior (vigas retangulares) ou na parte inferior (vigas em "L" ou "T" invertido). A vantagem de serem montadas em viga "T" invertido ou "L" é que não se perde altura no pavimento.

\subsection{Principais equipamentos}

Para efetuar a protensão tem-se os macacos hidráulicos (figura AP-D14) e tem uma máquina de corte para cortar as lajes nos tamanhos especificados em projeto. 


\section{$\underline{4.11 \text { Outros dados relevantes }}$}

Quando se faz necessário propiciar capacidade de resistir momentos negativos nas lajes alveolares (balanços ou continuidade) pode-se deixar alguns alvéolos preenchidos e com armadura.

Segundo a FIP, algumas disposições construtivas devem ser obedecidas:

a) $h f \geq 1,6 \sqrt{h} \quad$ (espessura mínima da mesa)

b) $c \geq \frac{0,056 \phi \sqrt{\sigma_{p 0} f_{c k j}}}{f_{t k j}}$ (além das verificações do cobrimento à corrosão e ao fogo deve ser verificado a capacidade de transferência de esforços da armadura para o concreto)

c) espaçamento $\leq\left\langle\begin{array}{l}400 \mathrm{~mm} \\ 2 \mathrm{~h}\end{array}\right.$ (espaçamento máximo dos cabos de protensão)

\section{AP-D-5. MATERIAIS EMPREGADOS}

\section{$\underline{5.1 \text { Concreto }}$}

a) Cobrimento: segundo a NBR-6118 (2003), se considerássemos uma zona de fraca agressividade teríamos que adotar um cobrimento de 20 $\mathrm{mm}$ para peças protendidas, considerando tolerância $=0,0$. O texto base da norma de concreto pré-moldado indica um cobrimento de no mínimo $20 \mathrm{~mm}$ para as lajes alveolares;

b) Relação a/c: para peças protendidas em zona de fraca agressividade $\mathrm{a} / \mathrm{c} \leq 0,60$;

c) Aditivos: não é permitido o uso de aditivos que contenham cloreto;

d) Ainda em função da classe de agressividade tem-se que adotar um $f_{c k} \geq 25 \mathrm{MPa}$, no caso o SATD tem opção de adotar resistências entre 35 MPa e 50 MPa;

e) Admitiu-se que na data da protensão a resistência do concreto $\left(f_{c k j}\right)$ seja de $70 \%$ do valor do $f_{c k}$; 
f) Resistência à tração: $f_{c t k \text {,inf }}=0,7\left(0,3 f_{c k j}{ }^{2 / 3}\right)$, que é calculado para 28 dias $\left(f_{c k}\right)$ e na data da protensão $\left(0,7 f_{c k}=f_{c k j}\right)$;

g) Módulo de elasticidade: $E=0,85.5600 \sqrt{f_{c k}}$ (valor secante);

h) Controle de qualidade: feito na fábrica com ensaios de compressão (figura 15) em várias datas. A Concrete Industries, Lincoln, NE, US, utiliza um sistema bastante interessante que reproduz, automaticamente, no corpo de prova exatamente as mesmas condições de cura da pista (figura AP-D-17).

\section{$\underline{5.2 \text { Aço de protensão }}$}

a) Adotado aço CP-190 RB: resistência à ruptura $f_{p t k}=1900 \mathrm{MPa}$ e ao escoamento $f_{\text {pyk }}=1580 \mathrm{MPa}\left(0,9 \mathrm{f}_{\mathrm{ptk}}\right)$, módulo de elasticidade 195000 $\mathrm{MPa}$, baixa relaxação (RB);

\section{AP-D-6. CARACTERÍSTICAS GEOMÉTRICAS E MECÂNICAS DA SEÇÃO TRANSVERSAL}

a) Área: $A_{C}=A-n A_{f}$ (n=número furos e $\mathrm{A}_{\mathrm{f}}=$ =área furo);

b) Momento de Inércia: $I=\frac{b h^{3}}{12}-\frac{\pi d^{2}}{4}$

c) Centróide: $y_{C G}=\frac{h}{2}=y 1=-y 2$

d) Módulos de resitência: $w_{i}=\frac{I}{y_{i}}$

Em função dos seis tipos de lajes adotados, todas as características geométricas foram inseridas no sistema, para o cálculo das características da seção composta (laje e capa) se utilizou: 
$b=1,2 \cdot m$

$y_{g c}=\frac{A \cdot y_{g}+A_{C}\left(h_{l}+0,025\right)}{A+A_{C}}$

$I C=I+A\left(y_{g c}-y_{g}\right)^{2}+\frac{b \cdot 0,05^{3}}{12}+A_{C}\left(h_{l}+0,025-y_{g c}\right)^{2}$

$m=\sqrt{\frac{f_{c k m l}}{f_{c k p m}}}$

○ b : largura do capeado transformada;

- $y_{g}$ e $y_{g c}$ : centro de gravidade das seções isoladas e compostas;

- $\quad$ e $I_{\mathrm{C}}$ : Momento de inércia das seções isoladas e compostas;

○ $\mathrm{m}$ : relação entre os módulos de elasticidade.

$e_{p}=y_{g}-c l-0,06$

- $e_{p}$ : excentricidade dos cabos

$$
\begin{aligned}
& W_{\text {inf }}=\frac{I}{y_{g}} \\
& W_{\text {sup }}=\frac{I}{y_{g}-h_{l}} \\
& W_{c \text { inf }}=\frac{I_{C}}{y_{g c}} \\
& W_{c \text { sup }}=\frac{I_{C}}{y_{g c}-h_{l}-0,05}
\end{aligned}
$$

○ W : Módulos resistentes das seções 


\section{AP-D-7. CÁLCULO DE ESFORÇOS E TENSÕES DE REFERÊNCIA}

$$
\begin{array}{ll}
M_{g 1}=\frac{(A c .25) \ell^{2}}{8} & \text { (peso próprio) } \\
M_{g 2}=\frac{\left(g_{2} \cdot b\right) \ell^{2}}{8} & \text { (capeamento) } \\
M_{g 3}=\frac{\left(g_{3} \cdot b\right) \ell^{2}}{8} & \text { (pavimento + revestimento) } \\
M_{g 4}=\frac{\left(g_{4} \cdot b\right) \ell^{2}}{8} & \text { (paredes sobre lajes) } \\
M q=\frac{(q . b) \ell^{2}}{8} & \text { (acidentais) }
\end{array}
$$

As tensões são calculadas em função das fases. Por exemplo, na fase transitória (calculadas em relação à seção isolada) atuam peso-próprio, capa e carga de trabalho nas zonas inferior e superior (j), já em serviço atuam cargas permanentes assentadas após o capeamento e a carga acidental (estas são calculadas em relação à seção composta, pois a capa já está solidarizada ao pré-moldado).

$$
\begin{gathered}
\sigma_{i, j}=\frac{M_{i}}{W_{j}} \\
\sigma_{c}=\frac{M_{i}}{W_{C_{j}}}
\end{gathered}
$$

- $\sigma$ : Tensões em relação as seções isoladas e compostas 


\section{AP-D-8. CÁLCULO DA FORÇA DE PROTENSÃO}

Aplicação da força de protensão $\sigma_{P i} \leq\left\{\begin{array}{l}0,77 \cdot f_{p t k} \\ 0,85 f_{p y k}\end{array}\right.$ para o CP-190RB tem-

se que: $\left\{\begin{array}{l}f_{p t k}=1900 M P a \\ f_{p y k}=1710 M P a \\ \sigma_{P i}=1453 M P a\end{array}\right.$

Logo a força inicial de protensão, descontando as perdas iniciais da pista:

$$
F_{P i}=n_{c} \cdot A_{\phi} \cdot \sigma_{P i} \cdot 0,97 \Rightarrow P_{a}
$$

Após a deformação do concreto se tem $\mathrm{P}_{0}$, que é calculado a partir de:

$$
\begin{aligned}
& S_{c p}=\frac{P a}{A}+\frac{P a \cdot e_{p}^{2}}{I} \rightarrow \text { Tensão_no_concreto } \\
& S_{P t}=\left[\frac{P a}{A}+\frac{P a \cdot e_{p}}{W 1}\right]+\frac{E p}{E c} \cdot S_{c p} \rightarrow \text { Tensão_na_armadura } \\
& P_{0}=P a-n_{c} \cdot A_{\phi} \cdot S_{P t}
\end{aligned}
$$

Verificações ao término da protensão $\sigma_{P 0} \leq\left\{\begin{array}{l}0,74 f_{p t k}=1406 M P a \\ 0,82 f_{p y k}=1402 M P a\end{array}\right.$

\section{AP-D-9. Tensões devidas à protensão}

$$
\begin{aligned}
& \sigma_{P o}^{\text {inf erior }}=\frac{P_{0}}{A}+\frac{P_{0} \cdot e_{p}}{W_{\text {inf }}} \\
& \sigma_{P o}^{\text {sup erior }}=\frac{P_{0}}{A}+\frac{P_{0} \cdot e_{p}}{W_{\text {sup }}}
\end{aligned}
$$


Repete-se estas expressões, substituindo a força após a deformação do concreto $\left(\mathrm{P}_{0}\right)$ para se calcular as tensões devido à protensão no tempo infinito. As tensões devido à protensão são sempre em relação à seção isolada.

\section{AP-D-10. Verificações em vazio}

Os limites para as verificações em vazio são para compressão $0.7 \cdot 0.7 \cdot f_{c k P M}$ e para a tração $0,7 \cdot 0.3 \cdot\left(0,7 \cdot f_{c k P M}\right)^{2 / 3} \cdot 1,2=f_{c t k \text { inf }}$, usou-se o valor de 1,2 pelo fato de se ter uma seção "T". Considerou-se ainda que na época da fase transitória o $f_{c k j}=0,7 \cdot f_{c k P M}$.

$$
\begin{aligned}
& f_{c t m}=0,3 \cdot f_{c k}^{2 / 3} \\
& f_{c t k \text { inf }}=0,7 \cdot f_{c t m}
\end{aligned}
$$

\section{AP-D-11. Estado limite de Serviço (ELS)}

Assim como para as vigas adotou-se uma protensão limitada, para a combinação quase-permanente admiti-se estado de descompressão e para combinação freqüente estado de formação de fissura.

\section{AP-D-12. Estado limite último (ELU)}

Para o estado limite último se adotou a mesma consideração das vigas, ou seja, que a peça estaria trabalhando no domínio 3 (três). Com isso utilizouse a tensão nas armaduras de protensão de $f_{\text {pyd. Adotou-se ainda que }}$ existiriam duas situações possíveis: toda a compressão na capa de concreto ou considerando a contribuição de parte do pré-fabricado, de forma que a linha neutra não ficasse abaixo do início dos alvéolos.

A partir dessas considerações se calcula a posição da linha neutra $\left(x_{\ell}\right)$ e na seqüência o momento resistente da seção ( $\left.M_{\text {res }}\right)$. 
$x_{\ell}=\frac{2551.05 \cdot A_{p l}(v l)}{f_{c k M L}(\mathrm{cml})}$

$\mathrm{Se}{ }_{-} x_{\ell} \leq 0.05 \rightarrow \mathrm{Ok}$

$S e_{-} x_{\ell}>0.05 \rightarrow x_{\ell}=\frac{1486.9 \cdot A_{p l}(v l) \cdot-0.0291 \cdot f_{c k M L}(\mathrm{cml})}{0.58285 \cdot f_{c k P M}(P M)}+0.05$

$M_{r e s}=A_{p l}(v l) \cdot 1486.9 \cdot Z_{\ell}$

$M_{r e s}=0.0291 \cdot f_{c k M L}(m l) \cdot Z_{\ell b}+0.58285 \cdot f_{c k P M}(P M) \cdot\left(\left(x_{\ell}-0.05\right) \cdot Z_{\ell a}\right)$

AP-D-13. Estimativa da flechas

Adotou-se, para as lajes, exatamente as mesmas considerações adotadas para as vigas em relação ao modo de cálculo da estimativa das flechas. 


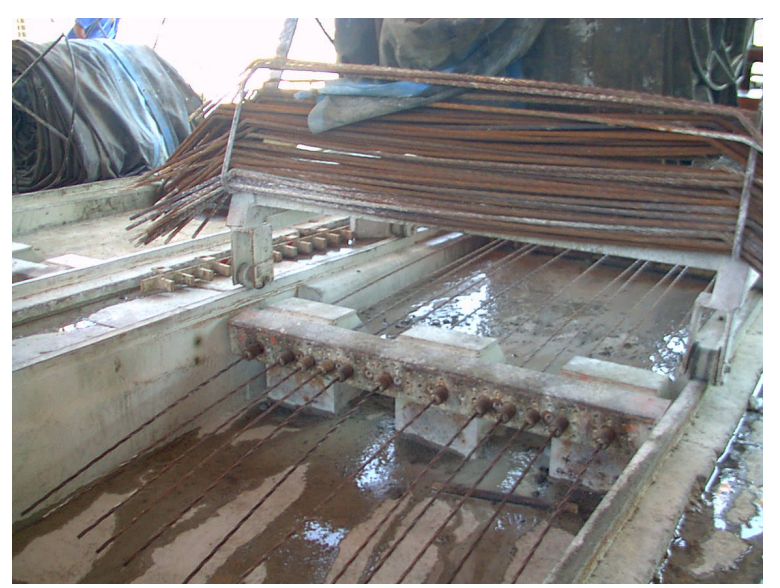

Figura AP-D-1 - Cabos ancorados

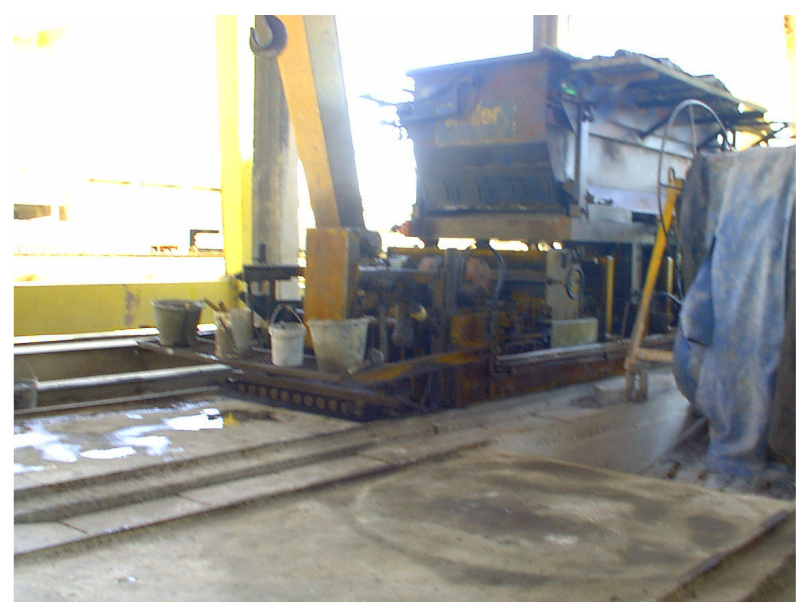

Figura AP-D-3 - Moldadora

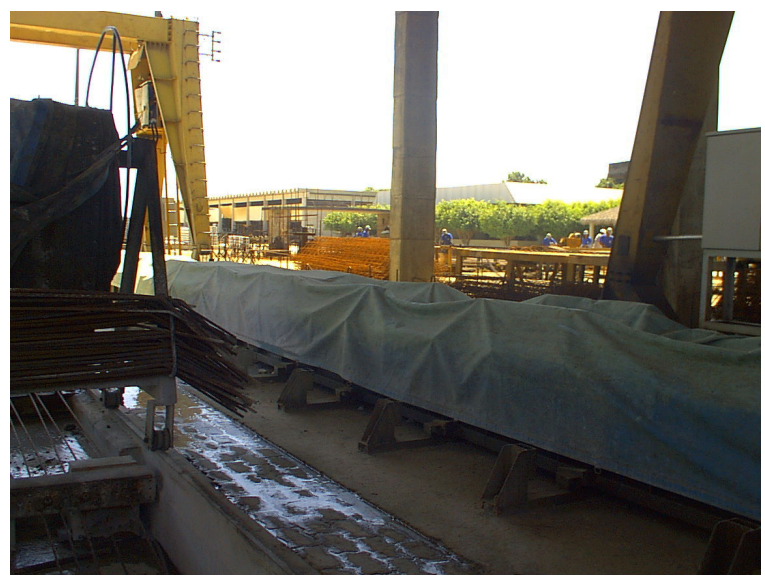

Figura AP-D-5 - Peça sendo curada

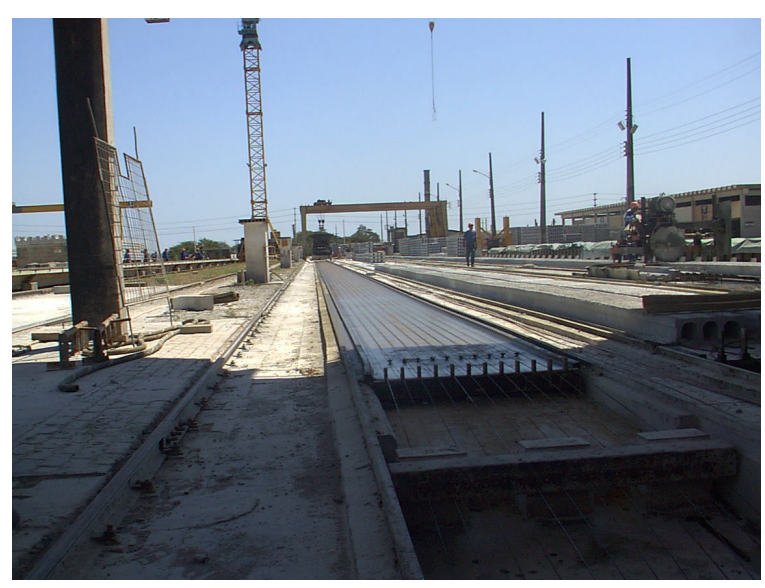

Figura AP-D-2 - Pista de protensão

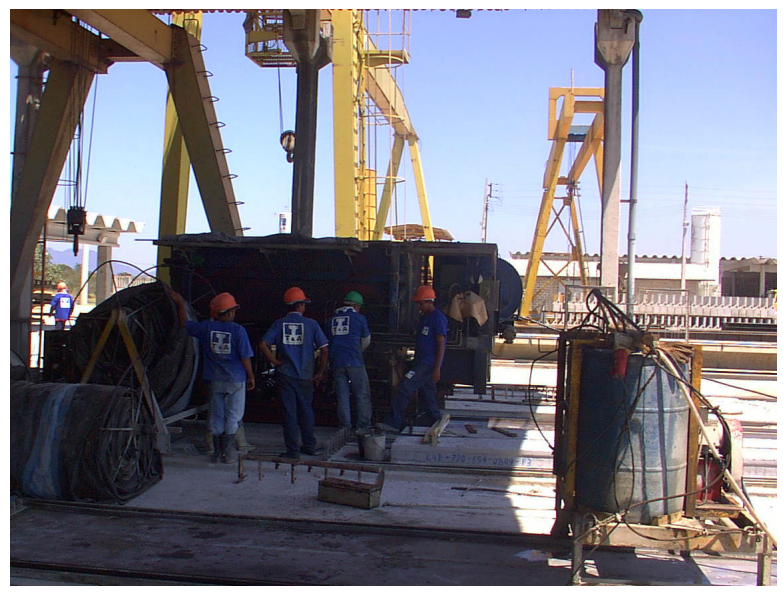

Figura AP-D-4 - Moldadora

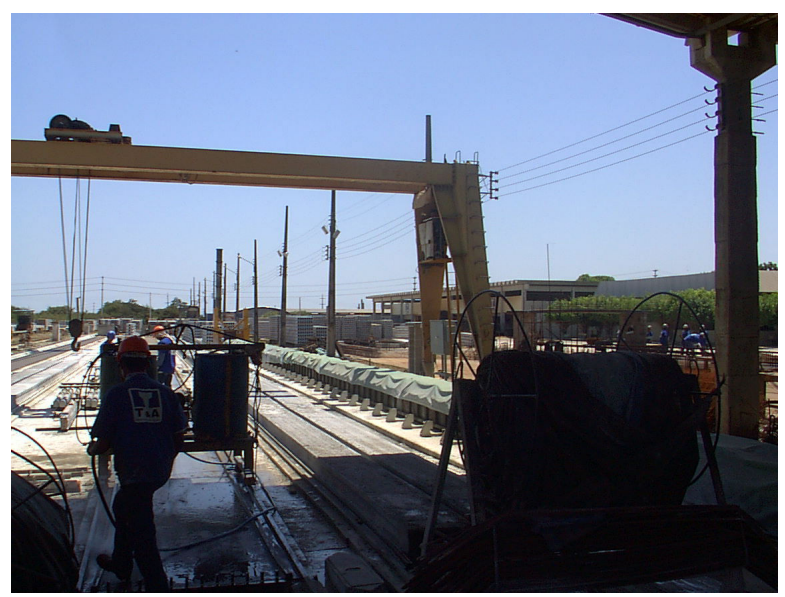

Figura AP-D-6 - Pista de protensão 


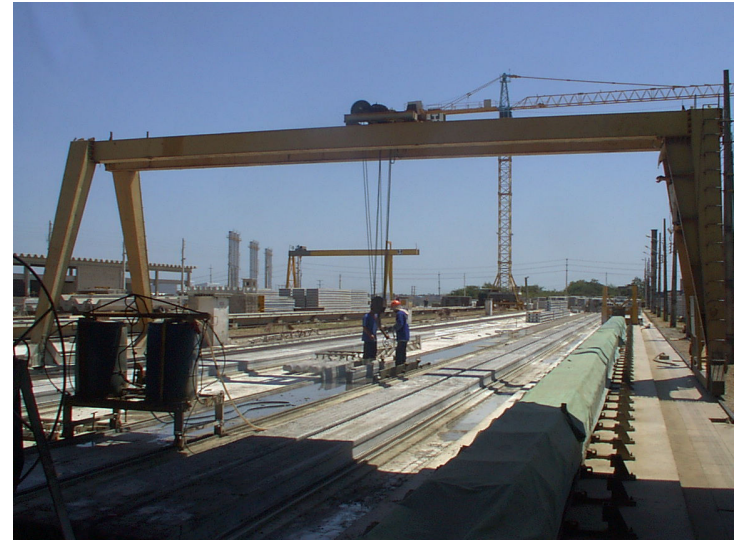

Figura AP-D-7 - Pórticos Rolantes

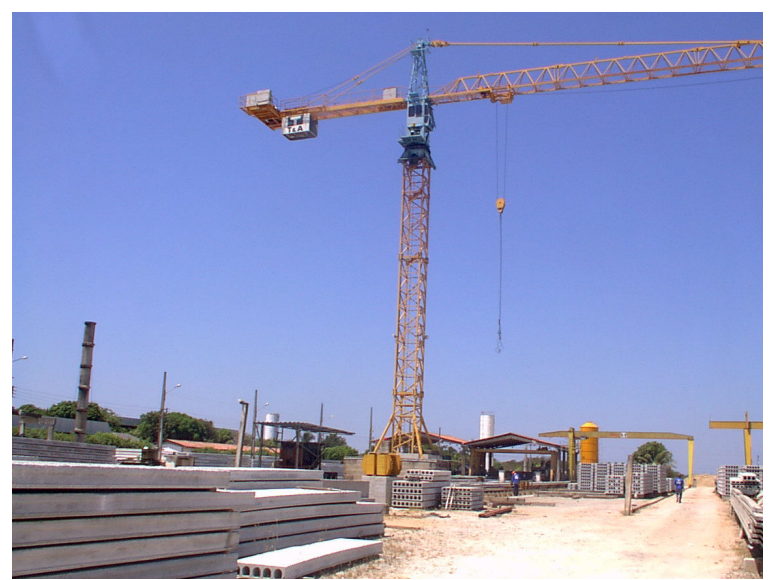

Figura AP-D-9 - Grua

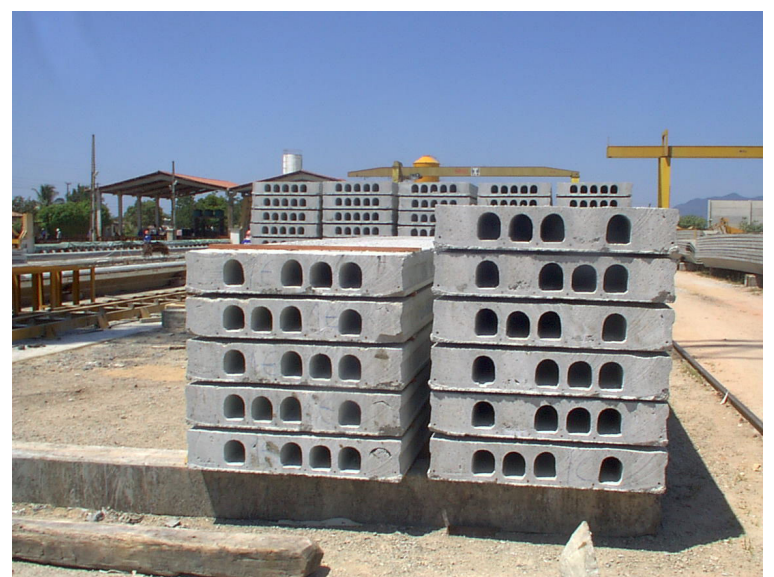

Figura AP-D-11 - Alvéolos preenchidos

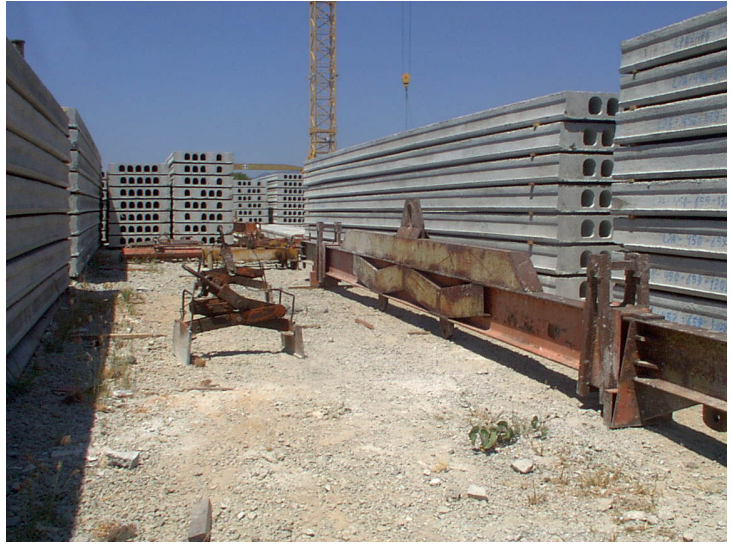

Figura AP-D-8 - Viga metálica e prensas

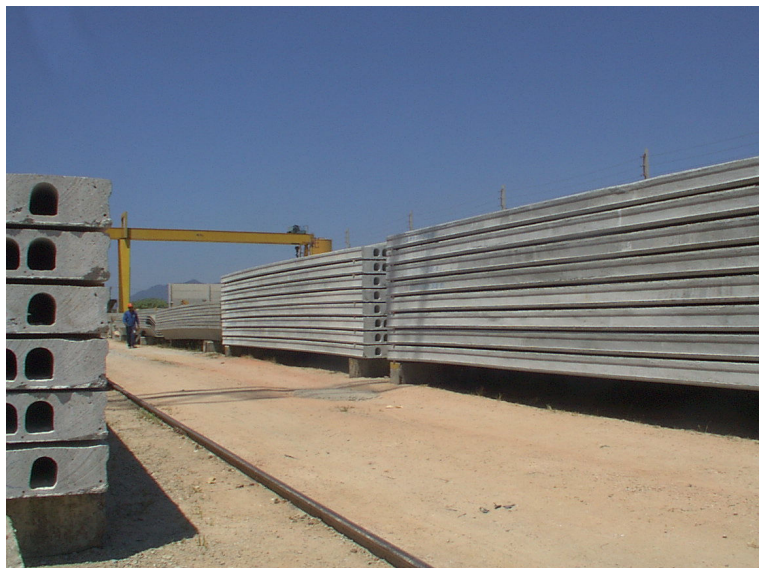

Figura AP-D-10 - Armazenamento

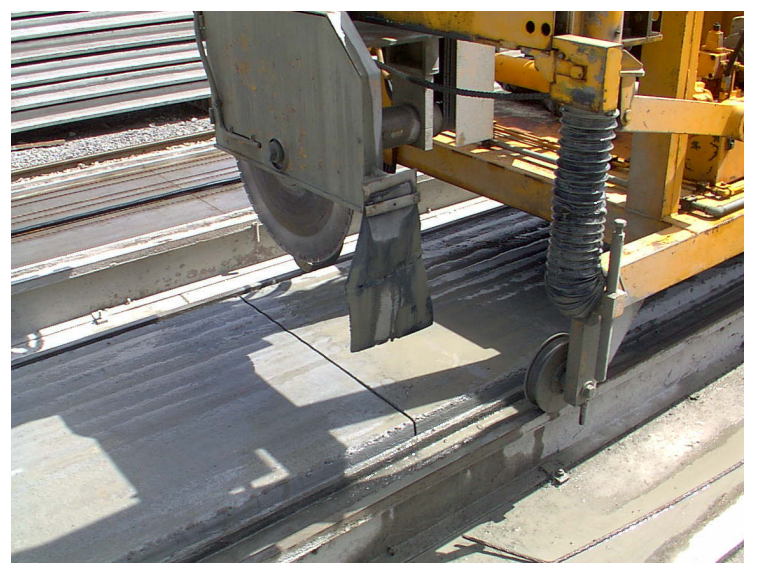

Figura AP-D-12 - Corte de laje 


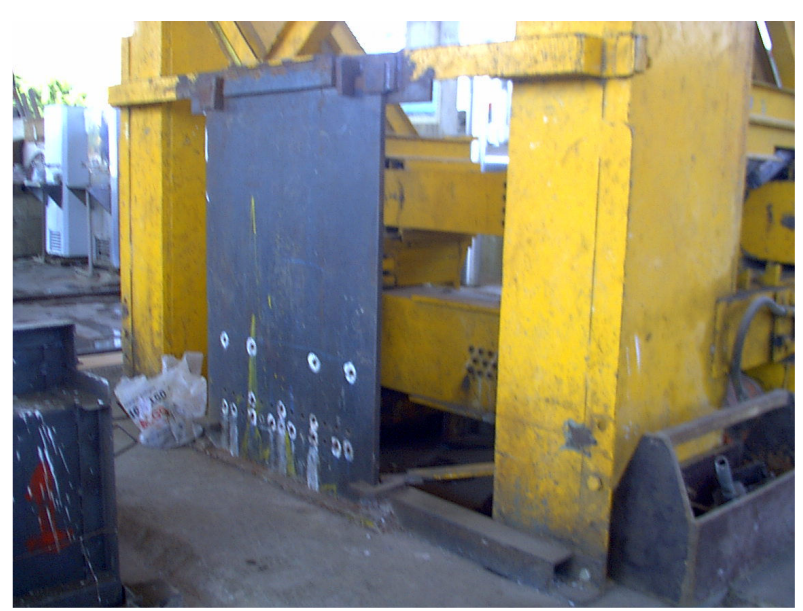

Figura AP-D-13 - Cabeceira da Pista

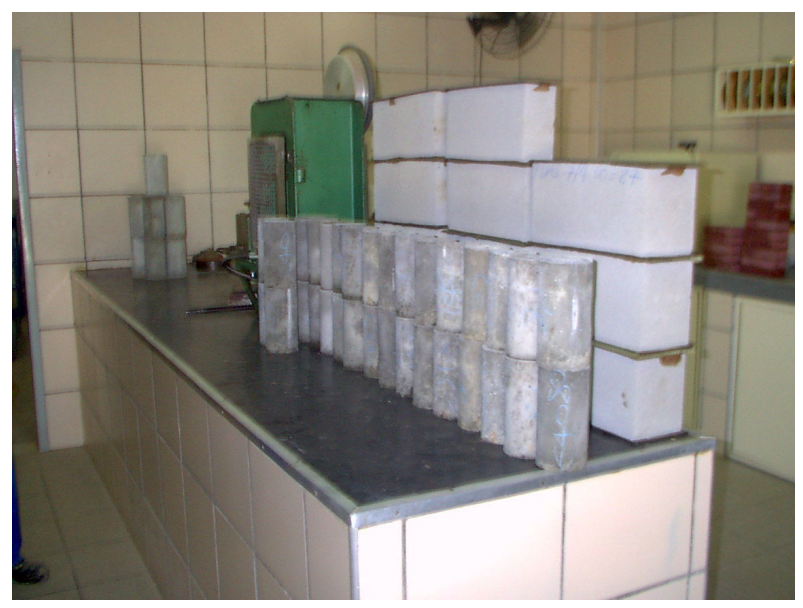

Figura AP-D-15 - Laboratório

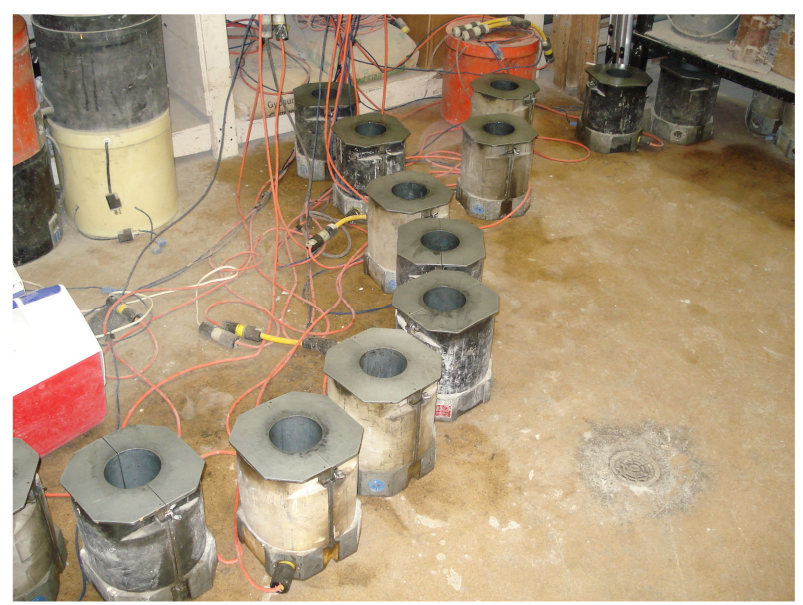

Figura AP-D-17 - Laboratório Concrete Ind.

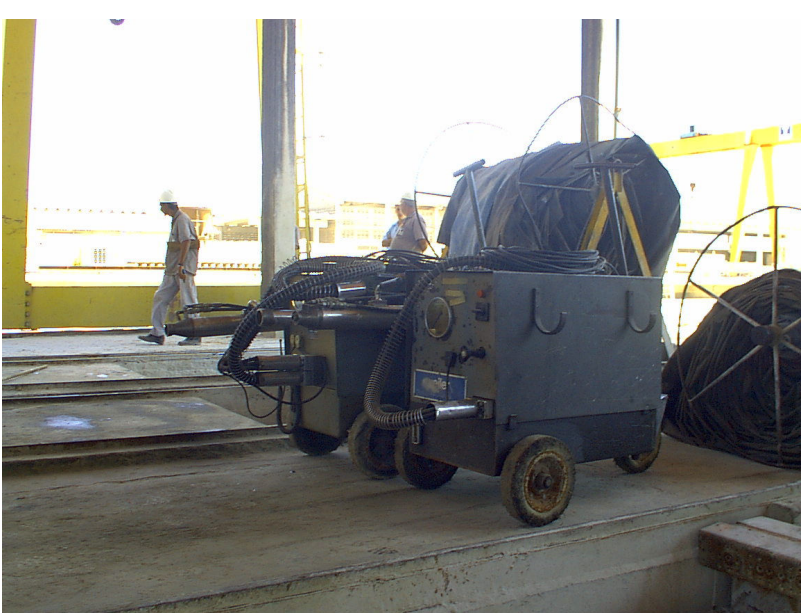

Figura AP-D-14 - Macaco hidráulico

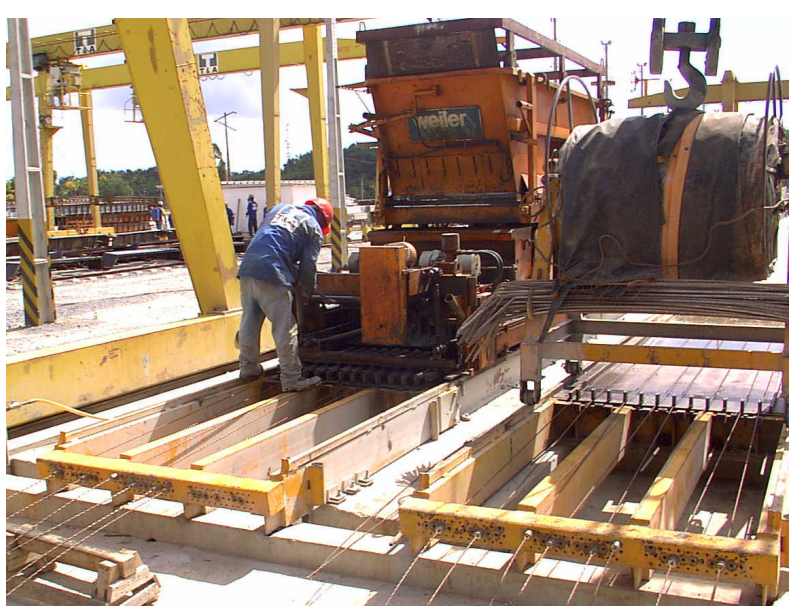

Figura AP-D-16 - Início concretagem

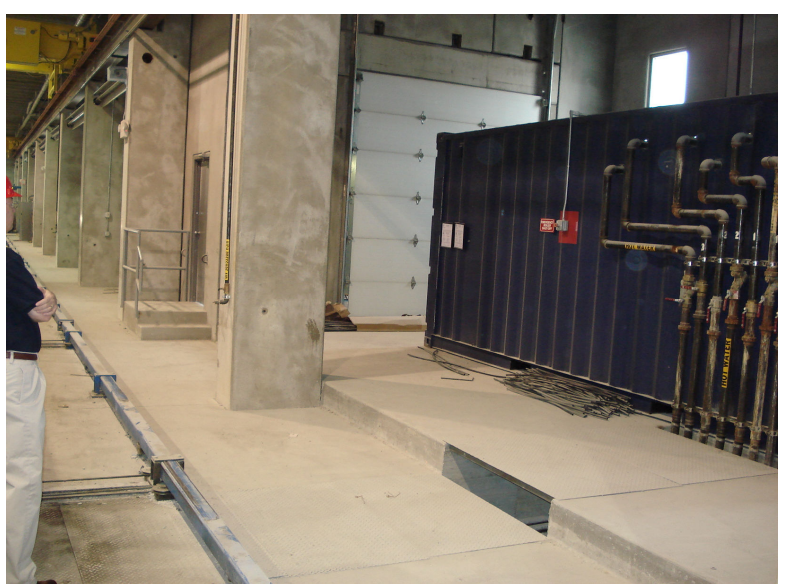

Figura AP-D-18 - Painel de controle temperatura pista 


\section{APÊNDICE E}

Fundamentos dos Algoritmos Genéticos 


\section{AP-E-1. HISTÓRICO DOS ALGORITMOS GENÉTICOS}

Os Algoritmos genéticos são baseados na teoria da evolução através da seleção natural de Charles Darwin (1837) e na genética. Foram apresentados por John Holland com a publicação do livro "Adaptation in Natural and Artificial Systems" em 1975. A partir de 1980 a utilização dos Algoritmos genéticos ganhou impulso e hoje vêm sendo aplicados com sucesso nos mais diversos problemas de otimização (GOLDBERG (1983) e CASTILHO (2003)).

\section{AP-E-2. FUNDAMENTOS TEÓRICOS}

\subsection{Funcionamento}

Os Algoritmos genéticos simulam os processos naturais para a resolução de problemas reais e pertencem à classe de algoritmos que simulam a evolução natural (algoritmos evolutivos). Na natureza os indivíduos menos aptos à sobrevivência têm menor probabilidade de gerarem descendentes, conseqüentemente menor probabilidade de propagar suas características genéticas. Ao contrário, os indivíduos mais aptos propagam suas características genéticas com maior freqüência, de forma que se possibilita o surgimento de descendentes ainda mais aptos em função das trocas genéticas entre bons indivíduos. O meio ambiente e a competição exercem pressão sobre o sistema para que a evolução se desenvolva.

Os Algoritmos genéticos utilizam uma analogia direta desse fenômeno em que os indivíduos são compostos por possíveis soluções do problema e são classificados através de uma função avaliação. Aos indivíduos que têm uma melhor avaliação é dada uma maior possibilidade de se reproduzirem, produzindo descendentes possivelmente ainda melhores.

Tem-se como característica fundamental do AG essa busca a partir de um conjunto de soluções, e não de uma única solução, que vão sendo melhoradas a cada geração. Com isso os algoritmos genéticos conseguem fazer uma extensa varredura no espaço de soluções.

Cada nova geração passará pelo mesmo processo de seus pais até que gerem uma nova população. Esse processo se repete até que se atinja um critério de parada, que pode ser uma quantidade pré-fixada de gerações ou algum critério de convergência. 


\subsection{Algumas definições da genética}

Cromossomo: Conjunto de códigos que representam uma possível solução para o problema. É formado por uma seqüência de genes;

Gene: Parte do cromossomo. Cada gene codifica uma característica, no caso uma variável de projeto. As informações contidas nos genes são chamadas de genótipo;

Fenótipo: Cromossomo decodificado, manifestação do genótipo;

População: Conjunto de cromossomos (indivíduos);

Geração: Cada etapa em que uma população é substituída por uma nova.

\subsection{Representação}

Após a definição das variáveis de projeto tem se que criar uma representação para as mesmas, essa representação é quem vai determinar o tamanho do cromossomo e é feita através de códigos.

Os algoritmos genéticos trabalham com uma representação das variáveis de projeto (genótipo) ao invés dos valores das mesmas (fenótipo). Essa representação pode ser binária ou real e a sua escolha depende do tipo de variável, por exemplo, a representação binária é mais adequada para variáveis discretas.

A partir da decodificação da representação é que se encontram os valores das variáveis de projeto.

\subsection{População inicial}

A população inicial pode ser gerada aleatoriamente ou pode ser previamente selecionada entre indivíduos já conhecidos, a partir dela é que se inicia o processo de evolução. O tamanho da população inicial pode se manter constante ao longo das gerações ou pode ser alterado à medida que vão sendo produzidas novas gerações.

A escolha do tamanho da população é uma das escolhas mais importantes para o algoritmo. Se a população é pequena demais pode haver uma convergência prematura e se a população é muito grande pode haver uma perda de tempo computacional proporcional. 


\subsection{Função Aptidão}

A função aptidão avaliará os indivíduos a cada ciclo do processo evolutivo e exerce no AG o mesmo papel do meio ambiente no processo de evolução, fazendo pressão sobre os indivíduos para que eles se tornem melhores. É a responsável por mensurar a qualidade do indivíduo e deve ter a capacidade de separar as boas soluções das más, ou seja, identifica o grau de adaptabilidade do indivíduo ao ambiente.

A função aptidão pode ser a própria função objetivo ou uma função objetivo modificada. A função objetivo modificada é geralmente a função objetivo acrescida de termos de penalidade.

\subsection{Função Penalidade}

Os algoritmos genéticos só tratam problemas sem restrições, logo para que eles sejam implementados em problemas com restrições se faz necessária a adoção de algumas estratégias.

a) Rejeição: todos os indivíduos gerados na região inviável são descartados;

b) Reparo: todos os indivíduos gerados na região inviável são reparados até se tornarem viáveis;

c) Penalidade: penaliza a aptidão dos indivíduos gerados na região inviável.

As duas primeiras têm a vantagem de não produzirem soluções inviáveis, mas têm a desvantagem de não considerarem nenhum ponto da região inviável. Sabe-se que para problemas com muitas restrições a região inviável pode ser bastante considerável, logo fica difícil de encontrar um ótimo global em uma pequena e confinada região viável. Por isso talvez a estratégia mais utilizada seja a atribuição de penalidades.

A função penalidade transforma problemas com restrições em problemas sem restrições, já que as restrições passam a serem tratadas como penalizações, sempre quando violadas. Dessa forma é permitido ao algoritmo explorar a região inviável também. Essa estratégia é muito utilizada nos 
Algoritmos genéticos devido à sua impossibilidade de tratar problemas com restrições.

Muitas maneiras de tratar as penalidades têm sido sugeridas na literatura e de modo geral elas podem se dividir em: constantes e variáveis. As penalidades constantes não levam em consideração a intensidade da violação ao contrário das variáveis. Utilizou-se neste trabalho penalidades variáveis.

\subsection{Seleção}

O mecanismo de seleção é responsável pela escolha dos indivíduos, em função de sua aptidão, que irão participar da reprodução para produzirem indivíduos da nova geração. Os métodos de seleção mais utilizados são: roleta, torneio e rank.

\section{Roleta}

Quantifica-se uma probabilidade de escolha para a reprodução de todos os indivíduos em função de sua aptidão.

$$
\begin{aligned}
p_{i} & =\frac{f_{i}}{\sum_{j=1}^{N} f_{j}} \\
& \circ \quad \mathrm{f}_{\mathrm{i}}: \text { aptidão de cada indivíduo; } \\
& \circ \quad \mathrm{p}_{\mathrm{i}}: \text { probabilidade de seleção. }
\end{aligned}
$$

Atribui-se aos indivíduos uma área proporcional à sua probabilidade de escolha, simulando uma roleta. Assim os indivíduos mais aptos têm uma maior probabilidade de serem escolhidos. Então se roda a roleta tantas vezes quantas forem o tamanho da população e escolhe-se para a fase de reprodução os indivíduos sorteados.

\section{$\underline{\text { Torneio }}$}

Promove-se um torneio entre um grupo de indivíduos escolhidos aleatoriamente da população, assim o indivíduo com maior aptidão dentro do grupo é selecionado enquanto os demais são descartados. 


\section{$\underline{\text { Rank }}$}

Os indivíduos são ordenados em função de suas aptidões e depois é atribuída para cada indivíduo uma probabilidade de seleção a partir de uma determinada distribuição.

A seleção tipo RANK apresenta como vantagem o não surgimento do super indivíduo. O superindivíduo seria aquele que tem uma aptidão muito melhor do que os demais e que, por isso, pode aparecer várias vezes na mesma população, quando se adota uma seleção por roleta ou por torneio, por exemplo. O surgimento do super indivíduo muitas vezes leva a uma convergência prematura já que diminui a diversidade da população.

\subsection{Operadores genéticos}

Os operadores genéticos buscam melhorias na população através das gerações e os mais utilizados são a reprodução e a mutação. Os operadores são fundamentais para que as populações se diversifiquem (variabilidade das espécies) e ampliem o espaço de busca.

\subsubsection{Reprodução}

A reprodução é o principal operador genético e é a responsável pela mistura dos genes dos pais para a formação dos filhos, permitindo que as novas gerações tenham uma maior variabilidade. A reprodução pode ser feita de 3 formas:

a) Um-ponto: é escolhido aleatoriamente um ponto para o cromossomo ser dividido e assim serem trocados (figura AP-E-1);

\begin{tabular}{|c|c|c|c|c|c|c|c|c|c|c|c|c|}
\hline Pai & \begin{tabular}{|l|}
1 \\
\end{tabular} & 1 & 0 & 0 & 0 & 1 & 0 & 1 & 1 & 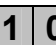 & & 1 \\
\hline$\tilde{a} \mathrm{e}$ & \begin{tabular}{|l|}
0 \\
\end{tabular} & 1 & 1 & 0 & 1 & 0 & 0 & 0 & 1 & \begin{tabular}{l|l}
0 & 1
\end{tabular} & & \begin{tabular}{|l|}
1 \\
\end{tabular} \\
\hline ho & 1 & 1 & 0 & 0 & 1 & 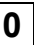 & 0 & 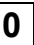 & 1 & 0 & & 1 \\
\hline ho & & & & & & & & & & & & \\
\hline
\end{tabular}

Figura AP-E-1 - Reprodução um-ponto 
b) Multi-ponto: mais de um ponto é escolhido aleatoriamente para que haja a troca de cromossomos (figura AP-E-2);

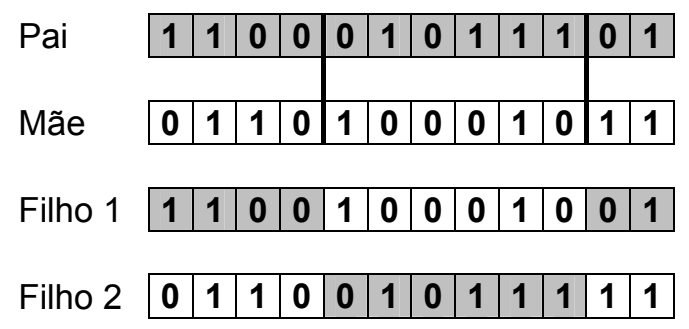

Figura AP-E-2 - Reprodução multi-ponto

c) Uniforme: utiliza uma máscara aleatória que determina qual bit do pai e da mãe vai formar o descendente (figura AP-E3).

\begin{tabular}{|c|c|c|c|c|c|c|c|c|c|c|c|}
\hline Máscar & & & & $\begin{array}{ll}0 & 1\end{array}$ & 18 & & & 1 & & & 1 \\
\hline Pai & 1 & 1 & 0 & 0 & 0. & 1 & & 1 & 1 & & 1 \\
\hline Mãe & 0 & 1 & 1 & 0 & 1 & & 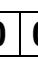 & 1 & & & 1 \\
\hline Filho 1 & 1 & 1 & 0 & \begin{tabular}{l|l}
0 & 1 \\
\end{tabular} & 0 & & & 1 & & & 1 \\
\hline Ilho 2 & 0 & 1 & 1 & 0 & 1 & & ) & 1 & 1 & & I \\
\hline
\end{tabular}

Figura AP-E-3 - Reprodução uniforme

\subsubsection{Mutação}

A mutação é uma mudança do bit em qualquer gene do indivíduo, que caracteriza uma mudança de genótipo, independente das características biológicas dos pais. Este fenômeno ocorre com baixa probabilidade, mas proporciona uma interessante diversidade na população.

A mutação possibilita que a probabilidade de se chegar a qualquer ponto do espaço de busca nunca seja zero.

\subsection{Elitismo}

Com a utilização dos operadores genéticos, corre-se o risco de perder indivíduos com alta aptidão, podendo este não ser criado nas próximas 
gerações. A fim de evitar este problema, aplica-se o elitismo que tem como objetivo copiar os melhores indivíduos de uma geração para outra, conservando todas as suas características genéticas. Comenta CASTILHO (2003) que o elitismo deve ser uma pequena porcentagem para não correr o risco de estacionar em um ótimo local, opinião esta também compartilhada por MILES (2001).

MICHALEWICZ (1996) comenta que o AG básico nunca converge para o ótimo global, mas o AG modificado com o elitismo converge.

\subsection{Parâmetros}

A determinação dos parâmetros de um AG é uma das etapas mais importantes para garantir um bom desempenho do método. Não se tem muita literatura sobre como adotar esses valores já que, na realidade, esses parâmetros dependem muito das particularidades do problema. Os parâmetros básicos são descritos abaixo:

a) Tamanho da população: número de indivíduos que irão existir em cada geração, usualmente é constante.

b) Probabilidade de cruzamento: indica a quantidade de indivíduos da população que irão participar do cruzamento.

c) Probabilidade de mutação: probabilidade de um cromossomo qualquer ser alterado.

\subsection{Critério de parada}

São implementados, geralmente, como critério de parada a convergência da aptidão média das últimas gerações ou a quantidade máxima de gerações.

A aptidão média das últimas gerações verifica se está havendo variações significativas na população.

A quantidade máxima de gerações simplesmente indica quantas gerações são consideradas suficientes para se atingir um resultado satisfatório. 


\subsection{Transgênico}

Atualmente muito se tem falado nos transgênicos. Os transgênicos são indivíduos que tiveram algum gene inserido artificialmente com o intuito de melhorar sua performance em uma determinada característica. Logo é uma modificação pontual, ao contrário da genética clássica onde o material genético dos pais é trocado para produzir os descendentes. Por exemplo, se introduz no algodão alguns genes para aumentar sua resistência a uma determinada praga.

Esse conceito pode ser eficientemente aplicado nos algoritmos genéticos para introdução de características, que baseadas na experiência profissional são reconhecidamente boas para o problema. 